\title{
The Eleven Nocturnes for Solo Piano of Lowell Liebermann: A Field-Chopin-Faure Lineage
}

\author{
Martin Harvey \\ West Virginia University
}

Follow this and additional works at: https://researchrepository.wvu.edu/etd

\section{Recommended Citation}

Harvey, Martin, "The Eleven Nocturnes for Solo Piano of Lowell Liebermann: A Field-Chopin-Faure Lineage" (2013). Graduate Theses, Dissertations, and Problem Reports. 3680.

https://researchrepository.wvu.edu/etd/3680

This Dissertation is protected by copyright and/or related rights. It has been brought to you by the The Research Repository @ WVU with permission from the rights-holder(s). You are free to use this Dissertation in any way that is permitted by the copyright and related rights legislation that applies to your use. For other uses you must obtain permission from the rights-holder(s) directly, unless additional rights are indicated by a Creative Commons license in the record and/ or on the work itself. This Dissertation has been accepted for inclusion in WVU Graduate Theses, Dissertations, and Problem Reports collection by an authorized administrator of The Research Repository @ WVU.

For more information, please contact researchrepository@mail.wvu.edu. 


\title{
The Eleven Nocturnes for Solo Piano of Lowell Liebermann:
}

\section{A Field-Chopin-Fauré Lineage}

\author{
Martin Harvey \\ Research Document submitted to the \\ School of Music \\ at West Virginia University \\ in partial fulfillment of the requirements \\ for the degree of \\ Doctor of Musical Arts \\ in \\ Piano Performance and Literature \\ Peter Amstutz, D.M.A., chair \\ Andrew Kohn, Ph.D., research advisor \\ James Miltenberger, D.M.A. \\ Mikylah Myers McTeer, D.M.A. \\ Thomas Sloane, Ph.D. \\ Morgantown, West Virginia \\ 2013
}

Keywords: Lowell Liebermann; Nocturnes; Field; Chopin; Fauré;

Copyright 2013 Martin Harvey 


\section{ABSTRACT \\ The Eleven Nocturnes for Solo Piano of Lowell Liebermann: A Field-Chopin-Fauré Lineage}

\section{Martin Harvey}

Since 1987, Lowell Liebermann (b. 1961) has composed eleven piano Nocturnes, making him the most significant recent contributor to the genre. This research analyzes these Nocturnes, six of which have no previously published analysis. This paper also considers Liebermann's Nocturnes as a continuation of the tradition of nocturne-writing, initiated in the nineteenth century by composers like John Field and continued by Fryderyck Chopin and Gabriel Fauré. Numerous composers have written Nocturnes since Fauré's opus 119 in 1921; however no one did so with an interest as marked as Liebermann's. Moreover, Liebermann shares with Fauré many stylistic features. Liebermann is therefore the true and sole successor to this great dynasty of nocturne-composers thus far.

Liebermann's Nocturnes, while maintaining a clear singable melody, a "simple" accompaniment, and suggesting the atmosphere of the night, also include new aspects of ornamentation, multi-layering and form. New features also include use of canon and greater virtuosity.

Keywords: Lowell Liebermann, Nocturne, Field, Chopin, Fauré. 


\section{ACKNOWLEDGMENTS}

This research project would have been impossible without the help of many individuals to whom I would like to express my deepest gratitude. I sincerely would like to say thank you to:

Dr. Peter Amstutz, my piano teacher who, for some twenty years, encouraged me on countless occasions, inspired me to be a better pianist-musician-artist and probably human being, and who kindly served on my doctoral committee;

Dr. Andrew Kohn, who supervised this project with an immense patience, infallible eyes and invaluable insights, and who diligently served on my doctoral committee;

Dr. James Miltenberger, Dr. Mikylah Myers McTeer and Dr. Thomas Sloane who also generously served on my committee;

The very efficient library staff at WVU, particularly Mrs. Beth Royall, who helped me gain access to scholarly resources and also suggested paths I did not suspect existed;

Mrs. Molly Dolan, Digital Initiatives and Scholarly Communications Librarian, who played a crucial role in obtaining the rights to use the music from the composer's publisher;

Ms. Kathy Fletcher, Manager of IT Training, who helped me finalize the last electronic version of this research document;

All the fellow music researchers who have published papers on Liebermann, particularly those who graciously have sent those documents to me when accessibility proved to be a challenge: Hsiao-Ling Chang, Adam Clark, Jeannine-Marie Dennis, Lisa Michelle Garner, Karen 
S. Kenaston, Mayumi Kikuchi, Chan Kiat Lim, Lisa R. MacArthur, Dean Allan Nichols, Tomoko Uchino, Aryo Wicaksono, Brian James Winegardner, and Wen-Hui Yu;

The numerous pianists I contacted because they premiered or recorded a Nocturne by Liebermann and who agreed to share their views, insights, and first-hand experience with me:

Hung-Kuan Chen, Richard Dowling, James Giles, Marc-André Hamelin, Williams Hobbs, Stephen Hough, Norman Kriegger, David Korevaar, Lowell Liebermann, Iwan Llewellyn-Jones, Sandro Russo, David Syme, Nadejda Vlaeva, and Andrew Wilde;

Theodore Presser which granted me permission to use excerpts of Liebermann's music in my text;

Composer Lowell Liebermann for writing such beautiful and inspiring music, also for all his help, time and generosity when sending me unpublished versions of Nocturnes no. 9 and no. 10;

Jacqueline, my mother, and Jean-Yves, my father, for their unconditional love;

And finally, my dearest friend Renée, whose friendship and support were always indefectible. 
“Ohne Musik wäre das Leben ein Irrtum.”

Friedrich Nietzsche, Götzen-Dämmerung

*"Without music, life would be a mistake."

Friedrich Nietzsche, Twilight of the Idols. 


\section{TABLE OF CONTENTS}

Page:

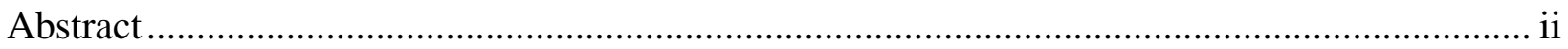

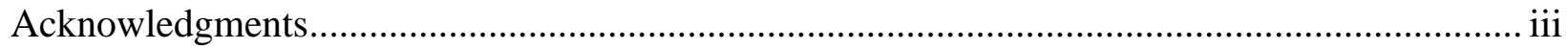

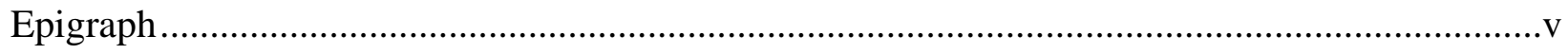

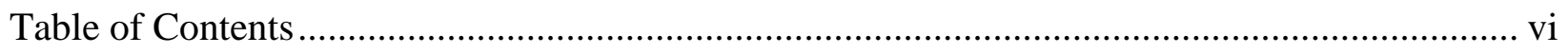

Table of Musical Figures ............................................................................................ viii

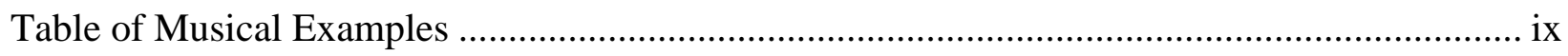

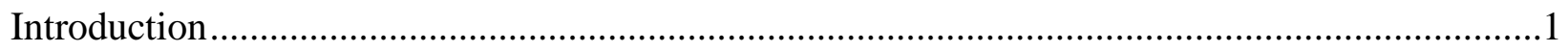

Chapter One: $\quad$ Life

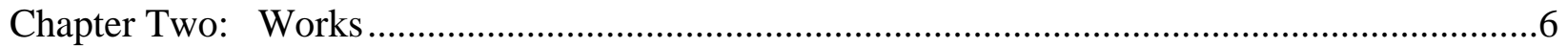

Chapter Three: Review of Literature .......................................................................... 11

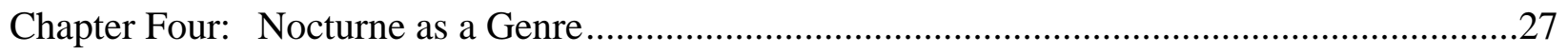

Chapter Five: The Eleven Nocturnes for Solo Piano........................................................47

5.0 Summary of Field-Chopin-Fauré Nocturne lineage .....................................47

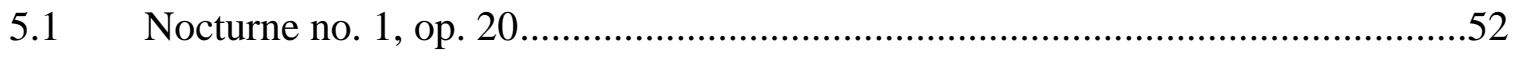

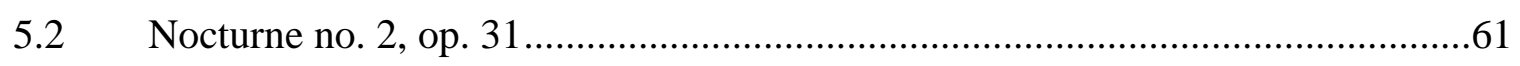

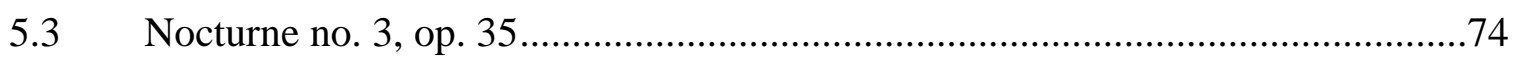

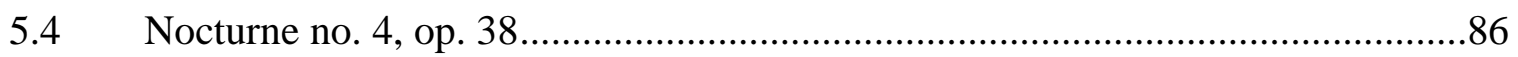

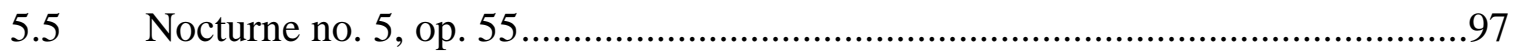

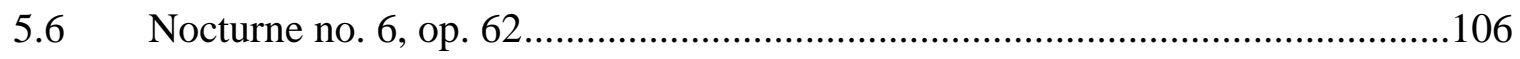

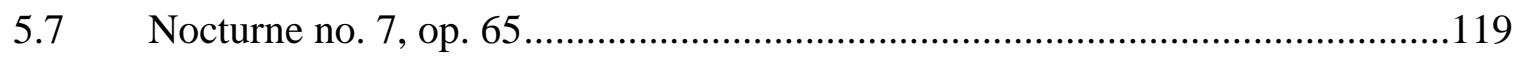

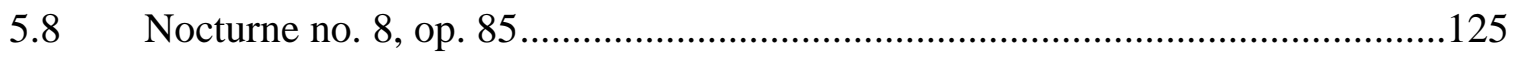

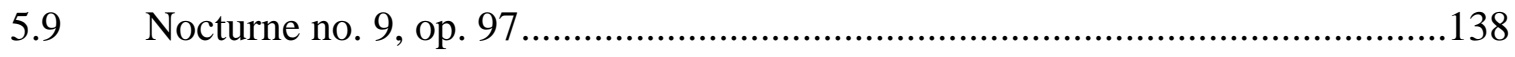

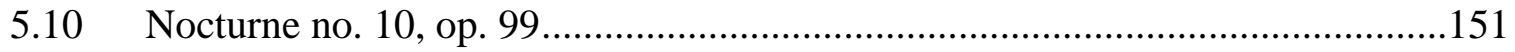

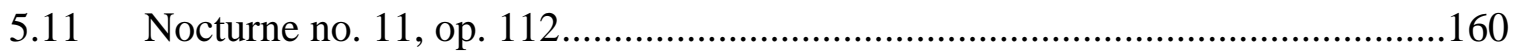




\section{MUSICAL FIGURES}

Figures: $\quad$ Page:

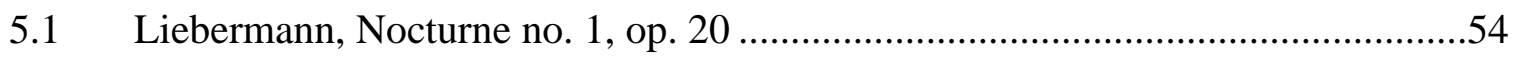

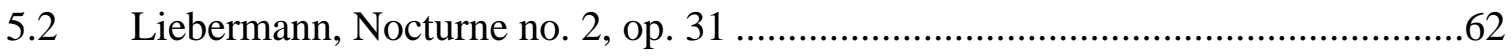

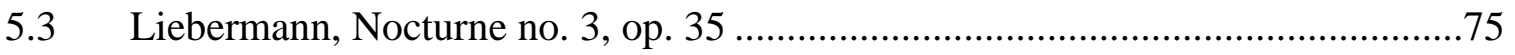

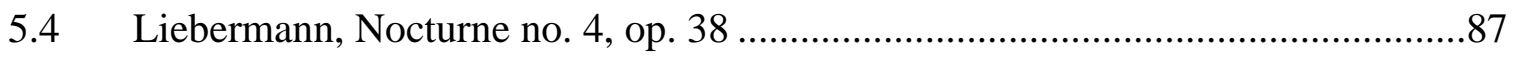

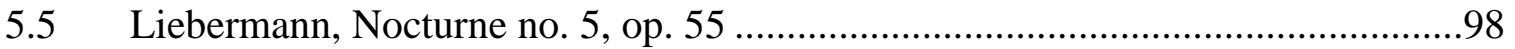

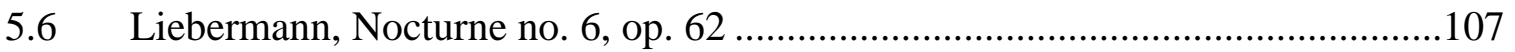

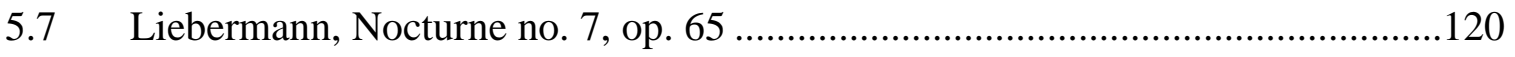

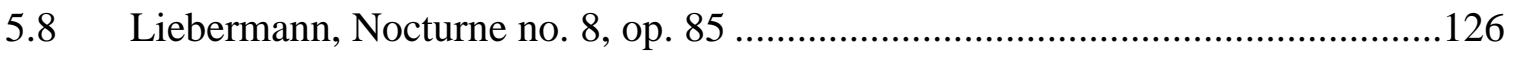

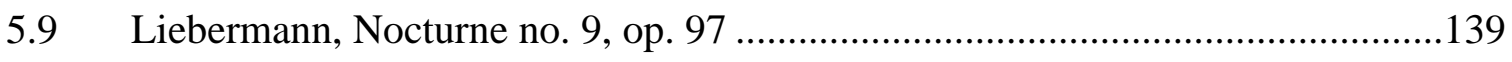

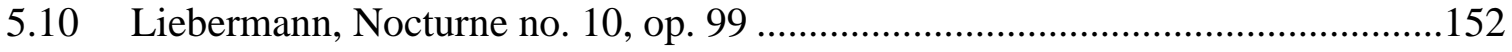

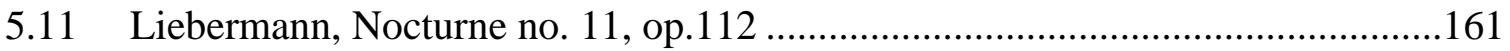




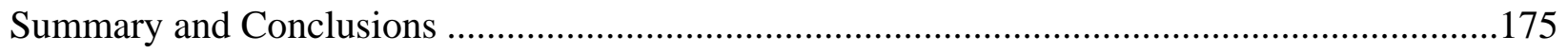

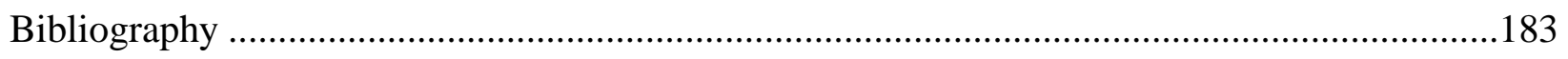

Appendix A: Works for Piano of Lowell Liebermann .....................................................196

Appendix B: Important Contributors............................................................................201

Appendix C: C-1 Table of Field's Nocturnes................................................................211

C-2 Table of Chopin's Nocturnes ........................................................215

C-3 Table of Fauré's Nocturnes............................................................219

C-4 Table of Liebermann's Nocturnes ....................................................221

Letter of Consent from Theodore Presser ........................................................................224 


\section{MUSICAL EXAMPLES}

Example:

Page:

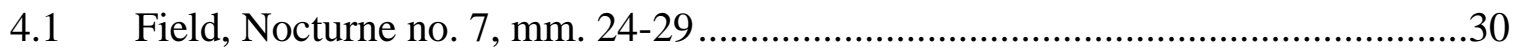

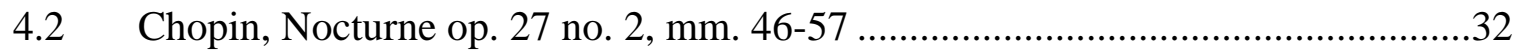

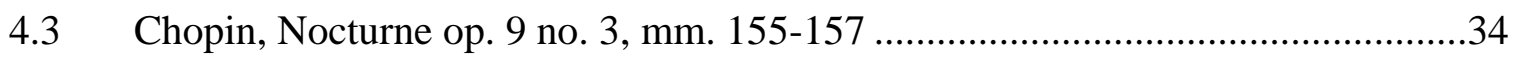

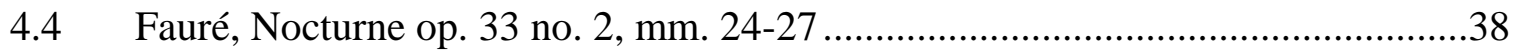

4.5 Chopin, Polonaise-Fantaisie op. 61, mm. 1-2 .............................................40

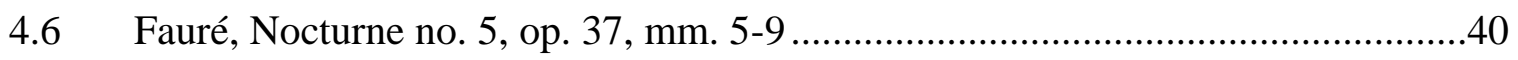

4.7 Fauré, Nocturne no. 13, op. 119, mm. 1-9 …..............................................

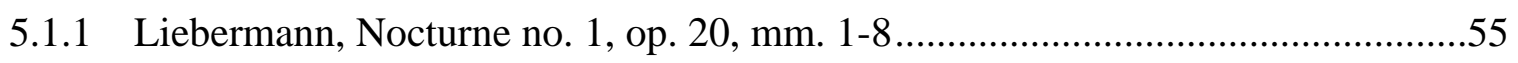

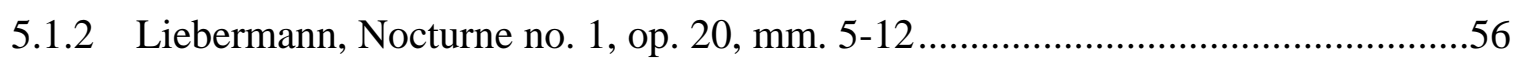

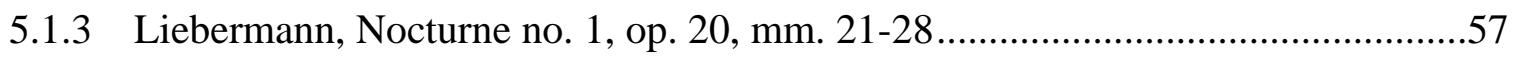

5.2.1 Liebermann, Nocturne no. 2, op. 31, mm. 1-6............................................64

5.2.2 Liebermann, Nocturne no. 2, op. 31, mm. 14-18 ........................................65

5.2.3 Liebermann, Nocturne no. 2, op. 31, mm. 21-23 ...........................................68

5.2.4 Liebermann, Nocturne no. 2, op. 31, mm. 24-28 ......................................69

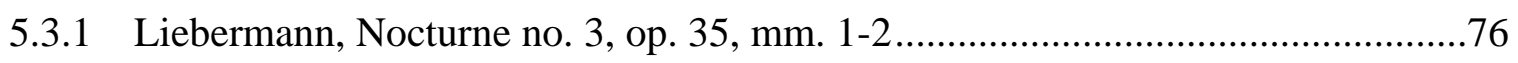

5.3.2 Liebermann, Nocturne no. 3, op. 35, mm. 1-7 ........................................... 77

5.3.3 Liebermann, Nocturne no. 3, op. 35, mm. 16-23 ...........................................78

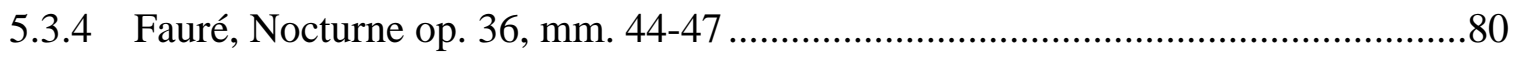

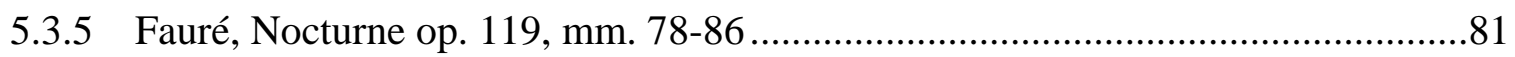

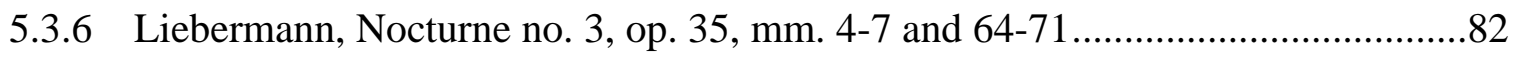

5.3.7 Liebermann, Nocturne no. 3, op. 35, mm. 16-23 …..................................... 85

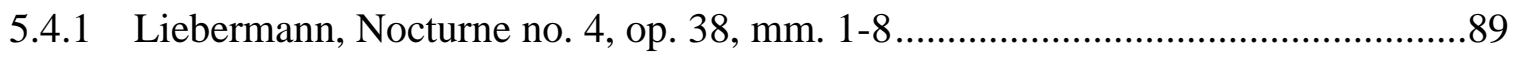




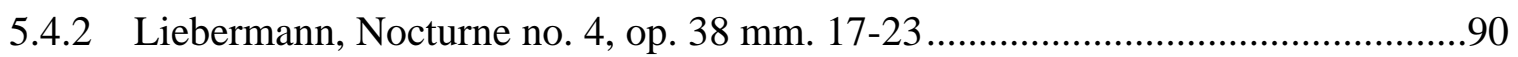

5.4.3 Liebermann, Nocturne no. 4, op. 38, mm. 24-29................................................91

5.4.4 Liebermann, Nocturne no. 4, op. 38, mm. 41-46 ..................................................93

5.4.5 Liebermann, Nocturne no. 4, op. 38, mm. 49-53 ………………………..........95

5.4.6 Liebermann, Nocturne no. 4, op. 38, mm. 63-67 ..............................................96

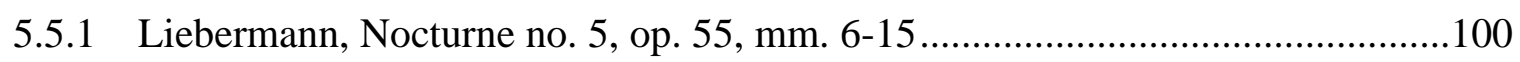

5.5.2 Liebermann, Nocturne no. 5, op. 55, mm. 35-40 ...............................................101

5.5.3 Liebermann, Nocturne no. 5, op. 55, mm. 49-52 …………………….............102

5.5.4 Liebermann, Nocturne no. 5, op. 55, mm. 68-73 ……………………….........103

5.5.5 Liebermann, Nocturne no. 5, op. 55, mm. 89-98 ………………………….......104

5.6.1 Liebermann, Nocturne no. 6, op. 62, mm. 1-10...............................................109

5.6.2 Liebermann, Nocturne no. 6, op. 62, mm. 7-18 ……......................................110

5.6.3 Liebermann, Nocturne no. 6, op. 62, mm. 30-42 ….......................................112

5.6.4 Liebermann, Nocturne no. 6, op. 62, mm. 56-63 …………….........................114

5.6.5 Liebermann, Nocturne no. 6, op. 62, mm. 74-77 …….......................................116

5.6.6 Liebermann, Nocturne no. 6, op. 62, mm. 78-88 ……………….....................117

5.7.1 Liebermann, Nocturne no. 7, op. 65, mm. 5-14 ...............................................121

5.7.2 Liebermann, Nocturne no. 7, op. 65, mm. 20-23 ………………......................122

5.7.3 Liebermann, Nocturne no. 7, op. 65, mm. 79-87 ............................................124

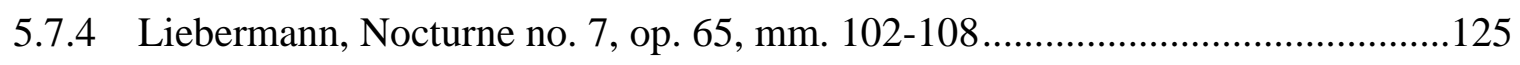

5.8.1 Liebermann, Nocturne no. 8, op. 85, mm. 1-12 …........................................128

5.8.2 Liebermann, Nocturne no. 8, op. 85, mm. 13-24 ............................................130

5.8.3 Liebermann, Nocturne no. 8, op. 85, mm. 29-36 ..............................................131

5.8.4 Liebermann, Nocturne no. 8, op. 85, mm. 57-62 …..........................................133

5.8.5 Liebermann, Nocturne no. 8, op. 85, mm. 107-109 .........................................134 
5.8.6 Liebermann, Nocturne no. 8, op. 85, mm. 121-125 ..........................................136

5.9.1 Liebermann, Nocturne no. 9, op. 97, mm. 1-18 ................................................140

5.9.2 Liebermann, Nocturne no. 9, op. 97, mm. 43-46 ............................................142

5.9.3 Liebermann, Nocturne no. 9, op. 97, mm. 69-82 .............................................144

5.9.4 Liebermann, Nocturne no. 9, op. 97, mm. 103-109..........................................146

5.9.5 Liebermann, Nocturne no. 9, op. 97, mm. 137-144 .........................................148

5.9.6 Liebermann, Nocturne no. 9, op. 97, mm. 145-155 ............................................149

5.10.1 Liebermann, Nocturne no. 10, op. 99, mm. 1-9 ...............................................153

5.10.2 Liebermann, Nocturne no. 10, op. 99, mm. 10-18 …………….......................154

5.10.3 Liebermann, Nocturne no. 10, op. 99, mm. 19-24 ............................................156

5.10.4 Liebermann, Nocturne no. 10, op. 99, mm. 48-60 ……………........................158

5.11.1 Liebermann, Nocturne no. 11, op. 112, mm. 1-6 .............................................163

5.11.2 Liebermann, Nocturne no. 11, op. 112, mm. 21-28 ………………………......164

5.11.3 Liebermann, Nocturne no. 11, op. 112, mm. 33-40 ...........................................165

5.11.4 Liebermann, Nocturne no. 11, op. 112, mm. 48-54 ..........................................168

5.11.5 Liebermann, Nocturne no. 11, op. 112, mm. 87-91 …………………...............171

5.11.6 Liebermann, Nocturne no. 11, op. 112, mm. 103-112 .......................................173 


\section{INTRODUCTION}

In recent years, Lowell Liebermann has become a familiar name among musicians and the general public. Numerous concerts and recordings helped disseminate his music and its reception has consistently been favorable: performers like to play Liebermann's music as much as listeners enjoy the sonorous worlds it offers. Pianists, in particular, find Liebermann's music quite idiomatic for the instrument. Within the whole corpus of his piano music, perhaps because of the intimate nature associated with the genre itself, the Nocturnes seem to have gained an undisputable favor.

Since 1987, Liebermann has composed eleven piano Nocturnes, making him the most significant recent contributor to the genre. In the past, only two scholars have shared their views on the first five Nocturnes; moreover, to this day, there is no research covering the remaining six Nocturnes. ${ }^{1}$ Thus, one goal of this research is to introduce these later Nocturnes to the reader, providing their analysis for the first time. This paper will also look at the corpus of the Nocturnes by Liebermann as part of a continuation of the tradition of nocturne-writing, initiated in the nineteenth century by composers like John Field, Fryderyck Chopin and Gabriel Fauré.

Chapter One, Life, gives a brief biographical sketch of Liebermann while Chapter Two, Works, discusses the body of his compositions and includes a listing of the performers involved in the creation of his musical works. Chapter Three, Review of Literature, consists of the review of the existing literature devoted to this important American composer. In Chapter Four, Nocturne as a Genre, a brief history of the nocturne as a genre is drawn; major stylistic features of that genre are emphasized while a historical lineage is outlined. In order to do so, the three

1 Dean Alan Nichols gives analyses of Nocturne no. 1 to no. 5 in: A Survey of the Piano Works of Lowell Liebermann (DMA research project, University of Kentucky, 2000); and Chan Kiat Lim discusses briefly Nocturne no. 4 in: Twentieth-Century Piano Nocturnes by American Composers: Echoes of Romanticism (DMA thesis, University of Cincinnati, 2004). 
composers most intimately associated with the nocturne are studied: Irish composer, John Field; Polish-born composer, Fryderyck Chopin; and French composer, Gabriel Fauré. Finally, the main body of this research paper, Chapter Five, The Eleven Nocturnes for Piano of Lowell Liebermann, is devoted to the analysis of the eleven Nocturnes for solo piano by Lowell Liebermann. The purpose of this study is two-fold: firstly, to get a better understanding of Liebermann's compositional style, and secondly, to comprehend how Liebermann can be viewed as an important composer in the genre of the nocturne, continuing and elaborating on the tradition of Field, Chopin and Fauré.

In the course of this research project, melody, rhythm, harmony, form, texture and specific compositional techniques and tools such as ostinato, octatonic scales, third-related harmonies, multi-layering, motivic transformations and canon are all investigated and used to characterize Liebermann's musical language in general and more precisely in regard to nocturnewriting. Conclusions are presented in the last chapter of this paper.

Following the Bibliography, in the Appendices, the reader will find: a listing of all the piano works by Liebermann; more elaborate information — such as commission, first performance, dedication and recordings available — is provided for the Nocturnes (Appendix A); short biographical sketches of performers significantly related to the dissemination of Liebermann's music (Appendix B); and tables highlighting musical features such as tempi, dynamics and forms encountered in Nocturnes of Field (Appendix C-1), Chopin (Appendix C-2), Fauré (Appendix C-3) and Liebermann (Appendix C-4). 


\section{CHAPTER ONE}

\section{LIFE}

American composer, pianist and conductor, Lowell Liebermann was born on February 22,

1961, in New York City. ${ }^{2}$ He was raised in a family very inclined towards the arts, and music

lessons were to be part of his life quite early. In fact, piano lessons began when he was eight.

Later on, he would recall trying to compose little piano pieces even before he could read music. ${ }^{3}$

Although Liebermann claims that he was not a child prodigy, he had already, at the age of

thirteen, decided that he would become a composer. His first piano instructor was Ada Sohn-

Segal. ${ }^{4}$

At the age of fourteen, his family moved to Westchester (NY); there, Liebermann

embarked on the study of composition with a local teacher, Ruth Schöntal. ${ }^{5}$ It was under her

2 Biographical information was compiled from four scholarly sources [Jeannine-Marie Dennis, The Life and Music of Lowell Liebermann with an Emphasis on his music for the Flute and the Piccolo (DMA thesis, University of Cincinnati, 1999), 5-8; Lisa Michelle Garner, A Stylistic Analysis and Discussion of the Sonata for Flute and Piano, op. 23, Sonata for Flute and Guitar, op. 25, and Soliloquy for Flute Solo, op. 44 (DMA thesis, University of Texas, 1997), 5-8; Lisa MacArthur, Lowell Liebermann: His Compositional Style as Derived from Three Flute Works and Applied to Other Selected Instrumental Works (DMA diss., University of Kentucky, 1999), 8-9; and, Dean Alan Nichols, A Survey of the Piano Works of Lowell Liebermann (DMA research project, University of Kentucky, 2000), 8-9]; and two websites devoted to Liebermann. The thesis of Jeanne Marie Dennis and Michelle Garner, the dissertation of Lisa R. MacArthur and the research paper of Dean Alan Nichols, all contain interviews with the composer. The composer's internet website <www.lowellliebermann.com> and his publisher's website <www.presser.com> share almost identical biographical information.

3 Nichols, 8.

4 Ada Sohn-Segal had been a concert pianist in her prime. She studied with Joseph Hoffmann and Ignacy Jan Paderewski and had even been associated with George Gershwin. (Garner, 5.)

5 Ruth Schöntal (June 27, 1924 in Hamburg, Germany-July 11, 2006) was a pianist and a composer. Because of the emergence of Nazism, Schöntal and her family had to flee Germany (1935) and Sweden (1938). She eventually traveled to a variety of places: the USSR, then Mexico City where she gave performances of her own compositions. On Paul Hindemith's recommendation, she was admitted to Yale. He taught her for many years. She supported herself and her family throughout her life - she wrote for television and commercials, played the piano in various bars and clubs, and taught privately in New York. Her style is a fusion of several different techniques, both traditional and contemporary (not unlike Liebermann himself). Schöntal was a prolific composer whose works are widely performed and recorded and consistently well received. Her catalogue of works includes three operas, numerous works for orchestra, and more than twenty-five works for piano. 
guidance that his opus one, the Piano Sonata no. 1, was written. With this piece, Liebermann won first place in the Music Teachers National Association (MTNA) in 1977 and made his New York debut as a pianist-composer at Carnegie Recital Hall (now Weill Recital Hall).

After graduating from high school, he spent one year at SUNY-Stony Brook, studying composition with David Diamond, and then followed him to the Juilliard School. ${ }^{6}$ At this prestigious institution, while pursuing his studies with Diamond, he also studied composition with Vincent Persichetti ${ }^{7}$ and piano with Jacob Lateiner. ${ }^{8}$ Liebermann completed his Bachelor in Music in 1983, his Master of Music in 1985 and his Doctorate of Musical Arts in 1987, all at Juilliard School. During his years of formation at Juilliard, he also received private instruction in conducting from Laszlo Halasz. ${ }^{9}$ He occupied the post of assistant conductor of the Nassau

6 David Diamond (July 9, 1915-June 13, 2005) was an American composer. He was born in Rochester, New York and studied at the Cleveland Institute of Music and the Eastman School of Music under Bernard Rogers, also receiving lessons in New York City from Roger Sessions and Nadia Boulanger in Paris. He won a number of awards including three Guggenheim Fellowships, and is considered one of the preeminent American composers of his generation. Many of his works are tonal or modestly modal. Among his works are eleven symphonies (the last in 1993), concertos including three for violin, eleven string quartets, music for wind ensemble, other chamber music, piano pieces and vocal music. A long-time member of the Juilliard School faculty, his other notable students include Kenneth Fuchs, Daron Hagen, Adolphus Hailstork, Anthony Iannaccone, Alasdair MacLean, Charles Strouse, Francis Thorne, Eric Whitacre and, to a certain extent, Glenn Gould (string quartet op. 1).

7 Vincent Persichetti (June 6, 1915-August 14, 1987) was an American composer, a teacher and a pianist. An important musical educator and writer, Persichetti was a native of Philadelphia. He was known for his integration of various new ideas in musical composition into his own works and teaching, and for training many noted composers in composition at the Juilliard School. His students at Juilliard included Larry Thomas Bell, Charles L. Bestor, Louis Calabro, Ronald Caltabiano, Richard Danielpour, Robert Dennis, Kenneth Fuchs, Philip Glass, Bruce Haack, Toshi Ichiyanagi, Karl Korte, Jing Jing Luo, Thelonious Monk, Hall Overton, Einojuhani Rautavaara, William Schimmel, Peter Schickele and Michael Jeffrey Shapiro. He also taught composition to conductor James DePreist at the Philadelphia Conservatory.

8 Jacob Lateiner (May 31, 1928 in Havana, Cuba) is a pianist. He studied at the Curtis Institute of Music in Philadelphia with Isabelle Vengerova. He was responsible for commissioning, premiering and recording Elliot Carter's Piano Concerto in 1967 with Leinsdorf conducting. He also premiered the Third Piano Sonata of Roger Sessions. He has been teaching at the Juilliard School since 1966 and at Mannes College the New School of Music since 1994. Robert Taub is another one of his notable students. Lateiner has a very marked lifelong interest in chamber music; his name is associated with the violist William Primrose, the violinist Jascha Heifetz and the cellist Gregor Piatigorsky. Interestingly, Liebermann's chamber catalogue is quite extensive.

9 Laszlo Halasz (June 6, 1905 in Debrecen, Hungary - October 26, 2001, Port Washington, NY) is a pianist, a conductor and a music director. He studied with Bartók, Dohnányi and Kodály. He was the assistant to Szell, Toscanini and Walter. He was music director of the Sakharoff Ballet, the Vienna Volksoper, the NBC Symphony, and the St. Louis Grand Opera and was appointed the first music director of the New York City Opera. For this institution, Halasz established several elements, crucial to its artistic personality: inexpensive tickets, productions of opera in English translation and at least one production in English in every season, and a platform for young 
(Long Island) Lyric Opera in 1982 and thereafter and throughout his career he has remained a frequent conductor and performer of his own music. Within the last twenty years or so, Liebermann has managed to secure a niche as one of the most played, recorded (more than 60 releases so far) and published living American composers. His compositions come out on a regular basis and have been championed by a number of well-known performers. ${ }^{10}$

Numerous honors and prizes were given to Liebermann throughout the years, including the Charles Ives Fellowship from the American Academy and Institute of Arts and Letters, the Grand Prize in the Delius International Composition Competition, and the Outstanding Award from the Yamaha Music Foundation.

Liebermann acted as a composer in residence for the Dallas Symphony Orchestra from 1998 to 2002, in which capacity he has also served Sapporo’s Pacific Music Festival, the Sarasota Performing Arts Center, the Music for Angel Fire Music Festival in New Mexico in 2009 and many other organizations. More recently, the Mannes College of Music appointed him composer in residence for the academic year 2011-2012; this residency involved masterclasses and events for the Mannes students, as well as public concerts of his music.

When this research paper was written, Liebermann was living in Weehawken, New Jersey, with his partner, the pianist and conductor William Hobbs, and their two dogs, Daphne, an Australian Shepherd and Phoebus, an American Eskimo.

singers. But perhaps his most important contribution was his insistence that the company's repertory include not only the standard works, but new ones as well. Later on, Halasz was active as a record producer for the Remington label in Europe and in the United States. He also kept conducting at opera houses in Frankfurt, Barcelona, Budapest, London and South America. Finally, as a teacher, he was on the conducting faculty at the Peabody Conservatory, in Baltimore, and the Eastman School of Music, in Rochester.

10 A list of performers closely linked to the works of Liebermann is provided in the section devoted to his works. The reader will also find a much more comprehensive listing at <www.presser.com> (integrated into the worklist). 


\section{CHAPTER TWO}

\section{WORKS}

At the moment of this DMA research document, Liebermann has written some 116 works and most of them have been published and presented to the public. ${ }^{11}$ His compositions are almost evenly scattered between four classes of performing forces. Among those works, symphonic pieces are represented by twenty-five pieces. There are twenty-nine works written for different chamber music formations and some twenty-eight works for keyboard (only two for organ, the rest being for piano). Liebermann's catalogue is completed by vocal music with twenty different opus numbers encompassing some 60 songs and two full length operas (The Picture of Dorian Gray and Miss Lonelyhearts).

The number of recordings for some compositions seems to indicate that several of these works have now become standard repertoire for their instruments. For example, the Sonata for Flute and Piano op. 23 and Gargoyles op. 29 for solo piano have been performed and recorded considerably. $^{12}$

Since his Juilliard School graduation, Liebermann has written almost exclusively commissioned work. Well-respected performers, conductors and musical organizations have commissioned and premiered pieces from him. The following list of performers, ensembles,

11 Liebermann himself assigns opus number to his work, an archaic practice rooted in the past, not unlike many of his compositional gestures. A listing of Liebermann's works for piano is found in Appendix A. For a complete listing of all his compositions, the reader should consult <www.lowellliebermann.com> or <www.presser.com>. Liebermann's works have all been published by Theodore Presser except Album Leaf op. 66 for Cello and Piano which has been published by Faber. Opp. 89 and 102 still await publication while opp. 74 and 75 are available thru rental only. Concerning opp. 5, 6, 7, 8, 89, 91, 96, 100 and 108, no premiere information is to be found at this moment.

12 Some sixteen recordings of the Sonata for Flute and Piano and some eleven recordings of the Gargoyles exist to date. 
conductors and organizations has been compiled solely of names of people who premiered works by Liebermann. ${ }^{13}$ This very impressive list speaks for itself. The sheer number of first-rank performers, ensembles, orchestras, conductors, festivals and organizations who solicited Liebermann's musical skills testifies of the caliber of Liebermann's musical writing and of his acceptance by the musical community as a very significant composer, one of America's leading voices in contemporary music.

Among the important people associated with the creation (premiere) of Liebermann's music one can find:

- Pianists: Michael Barrett, Jefferey Biegel, Steven Blier, Hung-Kuan Chen, Carl Cranmer, Richard Dowling, James Giles, Marc-André Hamelin, Eric Himy, William Hobbs, Stephen Hough, ${ }^{14}$ Robert Koenig, David Korevaar, ${ }^{15}$ Normand Krieger, Daniel Lessner, Lowell Liebermann, ${ }^{16}$ Iwan Llewellyn-Jones, Erica Nikrenz, Peter Orth, J.J. Penna, Sandro Russo, Brian Seger, Sar-Shalom Strong, David Syme, Jean-Yves Thibaudet, Colette Valentine, Sabine Vatin, Nadejda Vlaeva, Andrew Wilde;

- Organists: Vincent de Pol, David Friddle;

- Flutists: Jan Gippo (piccolo), Sarah Baird Fouse, David Fedele, James Galway, ${ }^{17}$ Katherine Kemler, Paula Robison, Hanna Turonek;

13 This list was compiled from Presser's website. It is organized by instruments, within which names are arranged alphabetically. Individuals of particular significance in regard to the dissemination of Liebermann's musiceither through recording premiere of numerous works, commissions or repeated collaborations - receive individual footnotes.

14 Stephen Hough is responsible for premiering the Piano Concerto no. 1 and no. 2, the Paganini Rhapsody for Piano and Orchestra, the Piano Sonata no. 2, the Three Impromptus op. 68 and the Cello Sonata no. 2. He also has numerous recordings of Liebermann's works. A complete listing, with his bio, is to be found in Appendix B.

15 David Korevaar is a crucial name in regard to the propagation of Liebermann's music. He has recorded all the piano music up to op. 68 (including Nocturnes no. 1 to no. 7, Gargoyles, Three Impromptus, Apparitions, Album for the Young, Piano Sonata no. 1 and no. 2), numerous songs and chamber music pieces. He is responsible for the creation of Four Apparitions op. 17, for which he is also the dedicatee. A complete listing, with his bio, is to be found in Appendix B.

16 Since he is a very skilful pianist, it is not a surprise then that Lowell Liebermann has also participated in the premiere of many of his works, mainly songs: opp. 11, 18. 21, 22, 51, 53 and 57, a few chamber music pieces: Cello Sonata no. 1 and no. 3, and only three piano solo works: Piano Sonata no. 1, the Transcription to Evening Prayer and Dream from "Hansel und Gretel" op. 37, and the Nocturne no. 10, op. 99. He also has made quite a significant contribution to the recording of his own works, as a partner with vocalists and as a conductor. A complete listing is to be found in Appendix B.

17 James Galway is associated with Liebermann's music in many aspects: the commission of the Concerto for Flute op. 39 and the Trio op. 83, the premieres of opp. 39, 40 and 48 (Concerto for Flute and Harp), and many recordings. He is also the dedicatee of a few works. A complete listing, with his bio, is to be found in Appendix B. 
- Clarinettist John Mannase;

- Horn player Leslie Norton;

- Trumpeter Philip Smith;

- Harpist Kathy Kiensel;

- Guitarist Eliot Fisk;

- Violinists: Joshua Bell, Henri Gronnier, Earl Hough, Chantal Juillet, Xiao-Dong Wang;

- Violists: David Blinn, Neal Gripp, Henri Gronnier, Marka Gustavsson;

- Cellists: Andres Diaz, Matt Herren, Steven Isserlis, Linda Kruger;

- Contrabassist Richard Frederickson;

- Bass-Koto player Miki Maruta;

- Carillonist David Hunsberger;

- Vocalists:

- Sopranos: Christiane Goerke, Susan Mello, Korliss Uecker;

- Mezzo-soprano Phyllis Pancella;

○ Tenor Robert White; ${ }^{18}$

- Baritones: Robert Barefield, Jeffery Morissey, Lester Lynch, William Sharp, Mel Ulrich;

- Bass-Baritone David Neal;

- Bass Dennis Raley;

o Narrator Michael Newsome;

- Conductors: Anthony Aibel, Marguerite Brooks, Glenn Cortese, Andrea Delfts, Charles Dutoit, JoAnn Faletta, Gary Garner, Raymond Leppard, Lowell Liebermann, Andrew Litton, Grant Llewellyn, Kurt Masur, Paul McRae, Rueben Reynolds, Mstislav Rostropovich, Gerard Scharwz, Leonard Slatkin, Ron Spiegelman, Peter Stafford Wilson, Yoshimi Takeda, Edo de Waart, Lyndon Woodside, Paul Zukovsky;

- Orchestras: BBC, Dallas Symphony and Chorus, Indianapolis Symphony, Juilliard, Kalamazoo Symphony, Lake Forest Symphony, Long Beach Symphony, Milwaukee Symphony, Minnesota, New Jersey Symphony, New York Philharmonic, NHK Symphony, l'Opéra de Monte-Carlo, National Symphony, Philadelphia, Saint-Louis Symphony, Toledo Symphony, Westchester Symphony, Westerville Symphony, West Texas A\&M University Band;

18 Tenor Robert White has collaborated with Lowell Liebermann on numerous occasions for the creation or the recording of some of the vocal works. He participated into the first performances of opp. 40, 53, 57 and 78 . He also made several recordings with the composer at the piano and he is the dedicatee of op. 57. A complete listing, with his bio, is to be found in Appendix B. 
- Ensembles: Boston Gay Men's Chorus, Bradshaw and Buono Duo (piano), Brook Chamber Chorus, Chelsea Chamber Ensemble, Concertante (Harrisburg Pennsylvania), Eroica Trio, Franciscan Quartet, Hexagon, Ithaca College Choral Series, Julliard Opera Center, Kodo Ensemble, Lark Quartet, Newman-Oltman Guitar Duo, New York Duo, New York Chamber Symphony, New World String Quartet, Orion Quartet, PerlmanNikannen-Bailey Trio, Ridge Quartet, Shanghai Quartet, Sparx Duo, Stony-Brook Chamber Chorus, Warwick Music Festival Orchestra and Chorus, Williamsville East South and North Symphonic Winds, and the Ying Quartet.

In the genre of symphonic music, Liebermann has written three Symphonies opp. 9, 67, and 113, and numerous other pieces for orchestra: Pegasus op. 7, The Domain of Arnheim, Revelry op. 47, Loss of Breath op. 58, and Dorian Gray: a Symphonic Portrait op. 70 (suite from the opera). Many works for piano and orchestra are also to be found, among which are three Piano Concerti, opp. 12, 36, and 95, and the Rhapsody on a Theme by Paganini op. 72. Several other concerti exist for other solo instruments and orchestra: a Concerto for Flute op. 39, a Concerto for Flute and Harp op. 48, a Concerto for Piccolo op. 50, a Concerto for Trumpet op. 64, and a Concerto for Violin op. 74. Songs have also made their ways into the symphonic catalogue (opp. 7, 11 and 18).

In the area of chamber music, one finds four Cello Sonatas opp. 3, 61, 90 and 108, a Sonata for Viola and Piano op. 13, a Sonata for Flute and Piano op. 23, a Sonata for Contrabass and Piano op. 24, a Sonata for Flute and Guitar op. 25, a Sonata for Violin and Piano op. 46, a Sonata for Flute and Harp op. 56, two Trios for Piano, Violin and Cello opp. 32 and 77, two Trios for Flute, Cello and Piano opp. 83 and 87, a Trio for Horn, Violin and Piano op. 101, four String Quartets opp. 5, 60, 102 and 103, a Piano Quartet op. 114, a Piano Quintet op. 34, three works for voice and string combinations, The Velveteen Rabbit for narrator and fifteen instruments op. 115, and numerous other works.

The vocal catalogue is made of 20 different opuses containing a total of about 60 songs. As mentioned earlier, a few of those works for voice and piano also appear in chamber or 
orchestral versions. There are also five numbers of choral music among which are the Missa Brevis and the Whitman Oratorio.

Liebermann being an excellent pianist, it does not come as a surprise that the keyboard works hold a very important position in his output. There are three Piano Sonatas opp. 1, 10 and 82, the Four Apparitions op. 16, the Variations on a Theme by Bruckner op. 19, the Album for the Young op. 43, the Three Impromptus op. 68, the Variations on America by Charles Ives op. 96. There is also a transcription of the Evening Prayer and Dream from "Hansel und Gretel" (Humperdinck's opera) and, of course, the object of this present research: the eleven Nocturnes opp. $20,31,35,38,55,62,65,85,97,99$ and $112 .{ }^{19}$

The remaining items for keyboard include the Four Etudes on Brahms Songs op. 88, the Three Songs of Robert Franz op. 91, and the Variations on a Theme by Schubert op. 100, of which op. 91 still awaits premiere and publication. For two pianos, there are the Three Lullabies op. 76, and the Variations on a Theme by Mozart op. 41. Daydream and Nightmare op. 94 is set for 2 pianos eight hands, and finally there is the De Profundis op. 16, for organ solo.

19 In an interview given to Dean Alan Nichols in 2000, Liebermann said that he is planning to compose a cycle of twelve Nocturnes for solo piano. Nichols, 164. 


\section{CHAPTER THREE}

\section{REVIEW OF LITERATURE}

It is not surprising that a composer with an immensely growing reputation, with more than 116 opuses covering all genres of the repertoire (orchestral, chamber music, piano solo, instrumental music, vocal music and two full length operas) has, up to this day, twelve doctoral research papers, one portfolio of recorded performances and exegesis (master degree) and one honor bachelor's paper devoted to the study of his music. These will be addressed chronologically.

The first research paper was completed in 1997 when Liebermann was starting to emerge as a leading composer in the USA, and the most recent one was released in May 2011. Eight of those research papers address piano music, three of them are devoted to the flute repertoire, and one studies the Concerto for Trumpet and Orchestra, while the remaining one discusses text setting in music of an orchestral nature. Among those papers, two stand out as more comprehensive, thoroughly documented, and insightful. They provide a very helpful overview of the terrain for this present research and establish guidelines for comprehending Liebermann’s compositional style. ${ }^{20}$

The first paper to discuss Liebermann’s music deals with flute music. Lisa Michelle Garner's Lowell Liebermann: A Stylistic Analysis and Discussion of the Sonata for Flute and Piano, op. 23, Sonata for Flute and Guitar, op. 25 and "Soliloquy" for Flute Solo, op. 44 offers

20 Lisa MacArthur, Lowell Liebermann: His Compositional Style as Derived from Three Flute Works and Applied to Other Selected Instrumental Works (DMA diss., University of Kentucky, 1999) and, Dean Alan Nichols, A Survey of the Piano Works of Lowell Liebermann (DMA research project, University of Kentucky, 2000). 
valuable tips for flute performers and presents basic analysis of those three works. ${ }^{21}$ This DMA thesis contains interviews with composer Lowell Liebermann and flutists Paula Robison and Katherine Kemler, who commissioned and premiered those works. In Garner's paper, Liebermann's style is explained as a continuation of Classical and Romantic traditions. She identifies uses of traditional techniques such as augmentation, diminution, retrograde and sequence as well as variants of the Sonata Allegro and Rondo forms. She mentions that contrast is provided by contrasting material (per se) and frequent changes in textures; works are tightly organized with cyclic material, overlapping, fusion and transformation. Tonally, Liebermann combines functional harmony with polytonality, closely related keys (major and minor combined), and stresses important intervallic relationships (such as tritones). Garner claims that these three works exploit greatly the expressive abilities of the flute such as long sustained lines; they display a wide range of dynamics, and demand a high level of musical maturity. To her, they are well-constructed, sophisticated works of art but accessible to any audience. To prove that point, she claims that even then, in 1997, these works were already making their way into the standard flute repertoire. Moreover, there is of course the expected (and very succinct) biographical sketch.

The most interesting feature of that paper could very well be the "Annotated Bibliography of Consulted Performance Reviews” found in “Appendix D.” This bibliography is a valuable source of information where one can gather data about performers, dates, locations, performance forces and get a clear feeling of the reception of the work at its premiere. Thirtyfive separate entries are there, providing an accurate account of how Liebermann's music (at least in regard to those three works for flute) had made its way into public acceptance.

21 Lisa Michelle Garner, A Stylistic Analysis and Discussion of the Sonata for Flute and Piano, op. 23, Sonata for Flute and Guitar, op. 25, and Soliloquy for Flute Solo, op. 44 (DMA thesis, University of Texas, 1997). 
The second paper on Liebermann, also devoted to flute music, is the aforementioned dissertation by Lisa MacArthur: Lowell Liebermann: His Compositional Style as Derived from Three Flute Works and Applied to Other Selected Instrumental Works. This dissertation succeeds in doing exactly what the author had planned to do: achieving "an understanding of the instrumental compositional style of Lowell Liebermann, of whose work there has been little academic research.”22

With rigorous methods, inherited from Jan LaRue’s Guidelines for Style Analysis, ${ }^{23}$ form, sound, harmony, melody, rhythm and growth are all discussed at length. The selection of works provides a chamber work (Sonata for Flute and Piano, op. 23), a concerto (Concerto for Flute and Orchestra, op. 39) and a combined concerto work (Concerto for Flute, Harp and Orchestra, op. 48), offering a broad view of Liebermann’s compositional style for flute. Preceding the parametric discussion of each piece is background about the commission and the premiere of each work and information regarding the reception of the work as found in published performance reviews.

Throughout the dissertation, the terminology used is explained and follows closely that of Jan LaRue, although MacArthur modifies somewhat LaRue’s methods by separating the form of each piece from its growth process. A diagram of the form of each work or movement is introduced for clarity and for highlighting similarities and differences within the music. In MacArthur's dissertation, the terms sections, subsections and smaller sections are used consistently to render analysis of the formal aspect of a work or a movement. She also provides the reader extensions of her conclusions from the analyses of those flute works to other genres: piano solo (Bruckner Variations, op. 19 and Gargoyles, op. 29); orchestral music (Domain of

22 For a complete bibliographical entry, see note 20. MacArthur, 2. Interestingly, one work (op. 23) has previously been discussed by Garner.

23 Jan LaRue, Guidelines for Style Analysis, $2^{\text {nd }}$ ed. (Warren, MI: Harmonie Park, 1992). 
Arnheim, op. 33 and Revelry, op. 47); and selections from the chamber catalogue (Sonata for Violin and Piano, op. 46). The approach remains strictly organized and thorough. Many of her ideas will be referred to in the main body of this paper (use of ostinati, combination of major and minor tonalities, process of chord mutation, combination of major key and its parallel Lydian mode, juxtaposition of dissimilar material, pedal tones to provide unity, placement of adjacent harmonies of a pianistic nature, use of extreme dynamics to establish the form, use of third relationships to create cadences, additive texture and layering, etc.).

Finally, the three appendices contain compilations of Liebermann’s compositions organized by genre or chronologically, and a selective discography of recordings.

Interestingly, a thesis also addressing three works for flute appeared the very same year. The Life and Music of Lowell Liebermann with an Emphasis on His Music for Flute and Piccolo by Jeanne-Marie Dennis talks about the Sonata for Flute and Piano, op. 23, the Soliloquy, op. 44 and the Concerto for Piccolo and Orchestra, op. 50 from a performer's point of view. ${ }^{24}$

In her thesis, Dennis emphasizes the importance of Liebermann as a flute composer. She claims that his music for flute stretches the performer to the limits of his or her expression and technique, yet is still capable of moving the listener with beauty and craft. She also clearly states that the purpose of her dissertation is not to analyze each flute and piccolo piece of Liebermann in great detail but rather to provide a brief discussion of his life and general characteristics of his style and philosophy. The author offers useful performing tips undoubtedly valuable to flutists about fingering, difficult trills, and sections where one has to watch one's intonation.

In 1999, Mayumi Kikuchi completed her research project, The Piano Works of Lowell Liebermann: Compositional Aspects in Selected Works, which presents briefly Liebermann and

24 Jeannine-Marie Dennis, The Life and Music of Lowell Liebermann with an Emphasis on his music for the Flute and the Piccolo (DMA thesis, University of Cincinnati, 1999).The performance guide portion of this thesis occupies pages 35 to 73 of the 74-page dissertation, pages 75 to 97 being the bibliography and the appendices. 
the contemporary compositional scene, characteristics of Liebermann's music (pianistic writing, rhythm, texture, form, thematic process and tonal center) and exemplifies her conclusions with analysis of the Gargoyles, op. 29 and the Piano Sonata no. 2, op. $10 .^{25}$

In Kikuchi's eyes, Liebermann’s music can be seen as a continuation of the music of the early twentieth century. For her, the pianistic writing is of a lyrical and melodic nature. The several layers of melody and accompaniments (ever so apparent in the Nocturnes) combined with the independence of each line create the illusion that the music is being played by more than one player-not unlike the three-hand effects of the mid-nineteenth century championed by Liszt and Thalberg. Use of wide dynamic and keyboard ranges, layering of melodic lines and accompaniments, are also distinctive features of his style. Kikuchi states that in regard to the use of traditional elements, he follows the path of Shostakovich and Britten, and that, in regard to lyricism, virtuosity and percussive treatment of the instrument, he can be linked to Prokofiev and Bartók.

Of special interest is the fact that Kikuchi gave an all-Liebermann piano recital in which she played: Nocturne no. 1, Piano Sonata no. 1, Four Apparitions, Variations on a Theme by Bruckner and Gargoyles, providing her with a genuine hands-on understanding of how this music comes to life. The program notes which were written for this recital are very succinct but also insightful. The research project is completed by an interview with the composer which sheds new light on certain perceptions one might have concerning Liebermann’s philosophy and approach to composition. ${ }^{26}$

25 Mayumi Kikuchi, The Piano Works of Lowell Liebermann: Compositional Aspects in Selected Works (DMA research project, University of Illinois, 1999).

26 About his own musical language and evolution, Liebermann said: "My overall music was probably more contrapuntally obsessed and more dissonant, and then I began exploiting tonality. But the overall aesthetic has never really changed much" ( Kikuchi, 83). The composer also mentions that pianists should be keenly aware of and pay close attention to the markings, dynamics, phrasing and pedalling-if they are indicated. (Ibid, 88.) 
In May 2000, Dean Alan Nichols released his research project dealing with the complete piano music of Liebermann: A Survey of the Solo Piano Works of Lowell Liebermann. ${ }^{27}$ In it he covers all the piano music up to opus 55: the Sonatas for Piano no. 1, op. 1 and no. 2, op. 10; the Four Apparitions, op. 17; the Variations on a Theme by Bruckner, op. 19; the Gargoyles, op. 29; the Album for the Young, op. 43; and the Nocturnes no. 1, op. 20; no. 2, op. 31; no. 3, op. 35; no. 4, op. 38; and no. 5, op. 55.

Along with MacArthur, Nichols establishes a clear approach to understanding Liebermann’s music. He goes into lengthy details explaining the terms Romantic, Classic, Impressionism and Modernism. While this was very useful then, it has become now almost trivial to do so, for Liebermann's true personal voice has emerged and is now recognized and respected on its own. There is no more a need for neo-classicist, neo-romantic or neo-tonalist label. And, maybe because of Nichols and MacArthur's papers, one can justly see the birth of a true "Liebermania."

Detailed analysis of the language, numerous musical examples, and a few helpful performing tips: all these contribute to show Nichols's keen understanding of Liebermann's complex piano writing. Nichols has given a wonderful stepping-stone to anyone who wishes to invest in the study of Liebermann's piano music —and musical style in general. Because it deals specifically with the piano repertoire, and therefore it discusses the first five Nocturnes, there will be many references to Nichols's paper in the course of this research, sometimes agreeing, sometimes stating simple discrepancies, and at other times having a totally different position in regard to formal analysis or other musical content.

For Nichols, Liebermann's music is fresh and innovative while containing stylistic elements of the past. The fusion of those traditional features and more contemporary techniques

27 For a complete bibliographical entry see note 20. 
in harmony and thematic development creates a style that is musically sophisticated, yet appealing and accessible to the general listener.

Liebermann's language is looked at in great depth and special attention is devoted to stylistic elements which find their roots in the piano music of the Romantic era. Influences of Chopin, Liszt, Schumann, Brahms, Debussy, Scriabin, Rachmaninoff and Ravel are strongly suggested. Moreover, comparisons to Copland, Barber and David Diamond are also drawn. In May 2003, Wen-Hui Yu released her dissertation, A Stylistic Analysis of Piano Concerto no. 2, op. 36 by Lowell Liebermann. ${ }^{28}$ In order to achieve this detailed analysis of the second Piano Concerto, close study of thematic relationships, harmonic vocabulary, pianistic writing and orchestral textures and writing are explored. Discussions of chromaticism, tonal centers, octatonic structures and poly-chordal techniques, and of pan-triadic sections both tertian and quartal are all present. Conventional rondo form, variation form and ternary form as well as cyclic treatment are all used and, combined with a twelve-tone row, serve to organize the concerto as a whole.

Yu isolates different techniques used by Liebermann in his writing and associates them with different aspects of the music such as musical genre (the Romantic period with the nocturne), sound resources of the instrument (Impressionism with the subtle tone color), technical approach to the instrument (Neo-Classic style with the scherzo-like light touch) and aesthetic grounding (Minimalism and the use of ostinato or repetitive patterns).

It should be noted that Yu's review of literature relies solely on liner notes and interviews directly linked to the work.

In the same year, Karen S. Kenaston completed her dissertation: An Approach to the

28 Wen-Hui Yu, A Stylistic Analysis of Piano Concerto No. 2, op. 36 by Lowell Liebermann (DMA dissertation, University of Northern Colorado, 2003). 
Critical Evaluation of Settings of the Poetry of Walt Whitman: Lowell Liebermann's Symphony

No. $2 .{ }^{29}$ It is the only study, up to this day, which deals with extra-musical considerations. For

Kenaston, the poetic imagery acts as primary stimulus to the composer's artistic imagination.

Liebermann conveys poetic ideas through instrumentation, harmony, texture, tempo, rhythm and word-painting. Musically speaking, nothing is added to the battery of tools and stylistic features that have already been labelled as being Liebermann's signature. However, this look into the combination of text and music offers a very interesting view on Liebermann's use of a panoply of unifying devices to create larger structures: cadential patterns, pedal tones, ostinati (both rhythmic and melodic, used singly, or in combination) and third relationships, and larger elements growing out of the smaller ones which are usually heard at the beginning of the piece.

Kenaston agrees with and quotes MacArthur in many instances, especially in regard to the use of octatonic and other synthetic (that is, non-diatonic) scales, tone clusters, augmented triads, major-minor ambiguity blurring tonal relationships, and rhythmically unifying devices such as ostinato figures, recurring patterns, and motor rhythms. It would be useful to see a comparable study of Liebermann’s songs. Finally, the bibliography is quite extensive and includes many books devoted to literature as an art form.

The following paper which mentions Liebermann does so in a much more general way. Chan Kiat Lim’s Twentieth-Century Piano Nocturnes by American Composers: Echoes of Romanticism covers the birth and rise of the nocturne and of nocturne-type pieces. ${ }^{30}$ The aesthetic environment of the nineteenth century is clearly established and the expected lineage to Field-Chopin is strongly presented. And yet, surprisingly, Maria Szymanowska is mentioned but

29 Karen S. Kenaston, An Approach to the Critical Evaluation of Settings of the Poetry of Walt Whitman: Lowell Liebermann's Symphony no. 2 (DMA dissertation, University of North Texas, 2003).

30 Chan Kiat Lim, Twentieth-Century Piano Nocturnes by American Composers: Echoes of Romanticism (DMA thesis, University of Cincinnati, 2004). 
Gabriel Fauré's thirteen nocturnes are not. After listing the "Romantic" characteristics of the genre, Lim moves on to a selection of piano Nocturnes by American composers. Among the chosen ones, one can have a glimpse at music by Samuel Barber, Amy Beach, Aaron Copland, Norman Dello Joio, Richard Faith, Herbert Haufrecht, Robert Helps, Lee Hoiby, Ulysses Kay, Lowell Liebermann, Halsey Stevens and Judith Lang Zaimont. This is a well-researched paper, clearly written, straight to the point, very useful for any serious pianist. Lim’s mandate was to display a variety of Nocturnes (twenty-two) by a broad spectrum of composers (twelve). This can explain why, even though in 2004 Liebermann's Nocturnes one to eight were easily accessible to the general public, in his dissertation Lim only discusses Nocturne no. 4 in a more lengthy way. On the other hand, he includes Nocturnes no. 1 to no. 7 in two tables (p. 53 and p. 83). The first table displays opening tempo marking, tempo and expressive markings found in middle sections, other expressive markings, and dynamics for the opening section, the closing section and the complete range of dynamic encountered within the Nocturne. The second table shows the formal structure, sorted into ABA', similar to ABA' and others. It also indicates the presence of introduction and coda.

The next paper, submitted for the Bachelor's degree with honors in 2004, is considerably less readily available. The author, Aryo Wicaksono, graciously sent it to me. Lowell Liebermann's Gargoyles op. 29 for Solo Piano is a performer's paper. ${ }^{31}$ Without any doubt, the usual information on Liebermann as a pianist and composer is there to be found, but kept to a minimum. Then, the author gives his full attention to the task at hand, the analysis of the piece, which is enhanced with some performing tips.

Compositional background, basic form and structure, tonal analysis, comparisons of Gargoyles op. 29 to the Piano Concerto no. 1 op. 12 and no. 2 op. 36 are encompassed in the 
main body of the paper. The following section, " $19^{\text {th }}$ and $20^{\text {th }}$ century pianistic heritage in Gargoyles," retraces some of the pianistic gestures and compares them to Brahms's Handel Variations op. 24 and Paganini Variations op. 35, and to Liszt's Mephisto-Waltz no. 1. Wicaksono points out elements in the devilish theme in Gargoyles derived from Liszt's Spanish Rhapsody, the "Tarentella” from Venezia \& Napoli, Gnomenreigen and the Mephisto-Waltz. A few comparisons are also made to link Liebermann's music to the piano music of Bartók (the Suite op. 14 and the Bagatelles op. 6). The conclusion offers performance suggestions regarding phrasing and tempo while reaffirming the importance of the initial set (0-3-4 /1-3-4) which permeates the whole first movement. This paper is completed by a bibliography of six entries, mainly one website (the composer’s), one interview, three newspapers, and liner notes from Stephen Hough's recording of the Piano Concerti no.1 and no. $2 .{ }^{32}$

A few trivial but delightful details are thrown in, such as Liebermann's keen interest in oil paintings — seen by Wicaksono as a possible explanation for the array of colors, timbres or images encountered in Liebermann's music. Some hypothesizes are scattered throughout the paper but neither explained in a satisfactory manner nor supported by reliable sources. For example, the link to Bartók’s music leads the author to refer to the use of the golden mean, but there is no successful demonstration of how this amazing structural device manifests itself in Liebermann's music. At the end of the paper, the complete score of Gargoyles is provided with handwritten annotations by Wycaksono. The set and some of its transpositions are identified; presence of the octatonic scale is also indicated as well as some "tonal" areas (chords, keys). Finally, some larger formal considerations are at times suggested (introduction, theme, sections, transitions, etc.). This must be considered incomplete, since many sections of music are left

32 Lowell Liebermann: Piano Concerti, Stephen Hough piano, BBC Scottish Symphony, Lowell Liebermann conductor, Hyperion CDA66966, 1997. 
unmarked or unaccounted for. Moreover, a major shortcoming of this paper lies in the fact that the main sources of scholarly research background are limited to liner notes from Stephen Hough's recordings. ${ }^{33}$

In 2007, Tomoko Uchino completed her DMA document on a set of character pieces by Liebermann: An Analysis of the Three Impromptus for Piano op. 68 by Lowell Liebermann. ${ }^{34}$ In the document, Uchino gives background information of the work as well as a succinct biography of the composer and discusses him as a pianist. She links Liebermann to a nineteenth-century line of pianist-composers which she uses as a validation for the claim that Liebermann's writing for the piano is quite idiomatic — unlike many contemporary composers. Then she provides a brief history of the impromptu as a genre using numerous musical examples drawn from Voříšek, Schubert, Chopin, Glazunov, Scriabin, Fauré and Poulenc. Some of those examples come from the vocal literature which is interesting in itself because it emulates the vocal nature also associated with the nocturne. The main body of her paper is the analysis of Liebermann's Three Impromptus op. 68, especially in regard to formal organization, motivic transformation, piano textures and harmonic progressions. References to other piano works by Liebermann are also given. Her research document is completed by three interviews, one with the composer, and the others with pianists David Korevaar and Antonio Pompa-Baldi.

In 2008, Adam Clark released his Modern Marvels: A pedagogical guide to Lowell Liebermann's Album for the Young, op. $43 .{ }^{35}$ This 102 -page graduate thesis is very well structured, detailed and proves to be a much-needed tool for teachers wishing to introduce their students to the music of this great American composer. Each of the eighteen numbers from the

33 See note 32.

34 Tomoko Uchino, An analysis of three Impromptus for Piano op. 68, by Lowell Liebermann (DMA document, University of Arizona, 2007)

35 Adam Clark, Modern Marvels: A Pedagogical Guide to Lowell Liebermann's Album for the Young, op. 43 (DMA graduate thesis, University of Cincinnati, 2008). 
collection of character pieces is presented through compositional background, descriptions and leveling. The leveling is mainly based on technical considerations according to two resources: Jane Macgrath's The Pianist's Guide to Standard Teaching and Performance Literature and the National Music Certificate Program’s (NMCP) Piano Syllabus 2004. ${ }^{36}$ Technical and interpretive solutions are offered, as well as notable compositional features. For the quality of the work, this dissertation stands side-by-side with Lisa MacArthur's and Dean Allan Nichols’s papers.

In 2009, Natalie Zwar submitted her portfolio of recorded performances and exegesis, The Perspective of the Composer and Performer: The Interpretation and Performance of Selected Flute Works by Lowell Liebermann and Robert Beaser. ${ }^{37}$ This short 42-page paper comes with three CDs. ${ }^{38}$ The first two CDs include excerpts of two recitals in which Zwar performed music by Liebermann and Robert Beaser and are used to illustrate some aspects of the discussion, and the last CD includes excerpts from the interviews and lessons with composers Lowell Liebermann and Robert Beaser. For her exegesis, Zwar draws on the interviews and lessons that she conducted herself in the USA with the two composers. She also relies on knowledge and performing experiences from a few performers closely associated with Liebermann’s flute music: Paula Robison, Katherine Kemler and Susan Rotholz.

The first part of the paper mainly touches on a few points concerning three works for flute: of Liebermann, the Sonata for Flute and Piano, op. 23 and Soliloquy, op. 44, and of Beaser

36 Jane Magrath, The Pianist’s Guide to Standard Teaching and Performance Literature, Van Nuys: Alfred Publishing Co., Inc., 1995; National Music Certificate Program's (NMCP) Piano Syllabus 2004.

37 Natalie Zwar, The Perspective of the Composer and Performer: The Interpretation and Performance of Selected Flute Works by Lowell Liebermann and Robert Beaser (Master paper, University of Adelaide, Elder Conservatorium of Music, Faculty of Humanities and Social Sciences, 2009).

38 The respective programs of the two recitals which Zwar played were: \#1: Liebermann's Sonata for Flute and Guitar, op. 25; Beaser's Variations for Flute and Piano; Liebermann's Soliloquy, op. 44 and Trio no. 2, op. 87, for Flute, Cello and Piano; \#2: Liebermann’s Concerto for Flute and Orchestra (piano reduction), Trio no. 1, op. 83, for Flute, Cello and Piano, and Sonata for Flute and Piano, op. 23. 
the Variations for Flute and Piano. Zwar's approach to the "composer's intention" is primarily concerned with a very limited number of aspects. In Liebermann's case, very "local” instances related to phrasing, balance, indications (unusual markings), contrast, tempo, notation and dynamics are briefly looked upon; in Beaser's case, structure, theme, each variation and the cadenza are also succinctly discussed.

Zwar's paper functions very much like the journal of a flutist preparing a recital devoted to music of Liebermann and Beaser, in which one can find a few performing tips, comments from the composer and indications from the player where one has to be careful and pay close attention to some interpretative or technical details. In the second part of her paper, Zwar compares passages which she previously discussed in the lesson with the composer to her live performance and rendition of the same work. She makes reference to the $\mathrm{CD}$ in order to illustrate how faithful to the composer's intentions her performance managed to stay. The paper is completed by a short bio of each composer and a bibliography made primarily of recordings, scores and a very limited number of articles and dissertations.

The penultimate dissertation was issued in 2010, and was written by Hsiao-Ling Chang. Lowell Liebermann's Concerto for Piano no. 1 op. 12: A Historical and Analytical Study looks at this work from a motivic point of view: how a three-pitch motive (A\#, B, C) generates the whole melodic, harmonic and formal organization of this three-movement work. ${ }^{39}$ Chang states that: "although Liebermann defines tonal areas by emphasis rather than by functional progressions, functional tonality is frequently evoked." ${ }^{40}$ In this very instance, A\# is seen as vii, B is $\mathrm{i}$, and C is ii (Neapolitan, although not inverted), in the key of b. They are used as chords and also generate "tonal" areas. Numerous progressions within and between those areas are

39 Hsiao-Ling Chang, Lowell Liebermann's Concerto no. 1 for Piano and Orchestra, op. 12: A Historical and Analytical Study (DMA thesis, University of North Texas, 2010).

40 Chang, 44. 
encountered in the whole concerto. This very small musical cell operates on various levels and this quite economical material can be seen as a lever for larger structures. Chang uses an interview with the composer (appended in the dissertation) as a reference for undertaking the analysis. Chapter IV ("analysis at the intra-movement level”) and Chapter V ("analysis at the inter-movement level”) constitute the main body of the dissertation. Even though the musical material itself is quite non-tonal in its appearance, Chang succeeds in demonstrating how the material is used to organize the work in a clearly tonal manner. This manner of writing music proved to be quite new and definitely crucial in further developments in Liebermann's compositional style. ${ }^{41}$

Also very interesting is the mention of Beethoven's sketchbooks as having a significant impact on Liebermann's approach to working out themes. Finally, of specific value for this study is the discussion of Liebermann's fondness for Gabriel Fauré's music. ${ }^{42}$ Both composers have contributed greatly to the evolution of the nocturne as a genre. Therefore, it is important to seeif not a direct influence- - then somewhat of a spiritual lineage acknowledged.

To this day, the last known completed research concerning Liebermann deals with his Concerto for Trumpet and Orchestra. Brian James Winegardner's A Performer's Guide to Concertos for Trumpet and Orchestra by Lowell Liebermann and John Williams has a chapter which covers the concerto as a musical genre, the development of the trumpet and its role as a solo instrument, and the trumpet concerto in the twentieth century. ${ }^{43}$ After explaining the methodology used for each piece and each composer, Winegardner gives a biographical sketch, an overview of the concerto, musical analysis of each of the three movements, and practice and

\footnotetext{
41 Ibid, 2.

42 Ibid, 56.

43 Brian James Winegardner, A Performer's Guide to Concertos for Trumpet and Orchestra by Lowell Liebermann and John Williams (DMA essay, University of Miami, 2011).
} 
performance considerations. Interviews with Liebermann, Ryan Anthony (who premiered Liebermann's concerto) and Michael Sachs (who premiered the concerto by Williams) can be found in the appendix section. A partial list of trumpet concerti written since 1990 completes that section. In his paper, Winegardner also makes numerous comparisons between the orchestral score and the piano reduction, pointing out differences and discrepancies.

The performing tips will be welcomed by any trumpeter who wishes to perform and interpret the score efficiently. Even though his essay was completed in 2011, Winegardner states that only three doctoral papers devoted to the study of Liebermann's music were available. At that time, at least ten doctoral papers were easily accessible and moreover, two of them would have proven quite valuable and pertinent, for they discuss other concerti by Lowell Liebermann. ${ }^{44}$

Finally, to draw the review of the literature devoted to Lowell Liebermann and his music to an end, one should mention that Mr. Liebermann has entries in the Baker's Dictionary of the $20^{\text {th }}$ Century Classical (1997), the International Who's Who in Classical Music (2003), the Who's Who in America of Music and Musicians (2001), the New Grove Dictionary of Music and Musicians (2001) and the Oxford Companion to Music (1994). Moreover, numerous magazine and newspaper articles dealing with his music have appeared throughout the years. They mainly review premieres, show public acceptance of some seminal works, or retrace the genesis of important works.

There also are two websites which are undeniably essential as a starting point for any research on Liebermann for they are peppered with countless tidbits of information and are

44 The thesis of Dennis (1999) and the dissertation of MacArthur (1999) were consulted by Winegardner and they both discuss the Concerto for Flute and Orchestra and the Concerto for Flute, Harp and Orchestra. However, the Concerto for Piccolo and Orchestra by Liebermann is analyzed solely by Dennis. Dissertations by Yu (2004) and Chang (2010) examine respectively the Piano Concerto no. 2 and no. 1. 
brought up to date on a regular basis: the composer's website-www.lowellliebermann.com, and his editor's website-www.presser.com. 


\section{CHAPTER FOUR}

\section{NOCTURNE AS A GENRE}

Since the beginning of the nineteenth century, the nocturne as a genre has been exploited ${ }^{45}$ Usually, this type of music is slow-paced, meditative and quiet, thus suggesting the night. Melodies are most of the time given to the right hand and are generally graceful and highly embellished. They emulate the vocal style of the period, more precisely, the one found in the bel canto cantilenas of Italian operas. The left hand provides a variety of accompaniments, either based on broken-chord patterns (the Alberti-bass type) or arpeggios. In order to re-create the atmosphere of the night, a generous utilization of the pedal (sometimes both pedals) is required.

According to Liszt in his preface of the 1859 Leipzig edition of Field's Nocturnes, “The nocturne as a genre possibly opened the way for all productions of character pieces which have appeared under various titles such as: Songs Without Words, Impromptus, Ballades, etc.”46 Almost every pianist-composer of the period wrote in that genre: Liszt himself (Liebestraümesubtitled Notturno), Schumann (Nachtstücke op. 23), Mendelssohn (Songs Without Words opp. 19, 30, 38, 53, 62, 67, 85 and 102), Kalkbrenner, Thalberg, Bertini, Döhler, and, later on, Satie, D'indy, Poulenc, Glinka, Balakirev, Tchaikovsky, Rimsky-Korsakov, Scriabin, Grieg and countless others.

The most significant contributors to the repertoire of nocturnes for piano are John Field (eighteen) to whom the paternity is attributed, Fryderyk Chopin (twenty-one) who elevated the

45 For a detailed history of the origin and evolution of the nocturne from its appearance in the 18th century to its crystallized format for piano in the 19th century, see Lim, 1-22; and Deborah Lynn Wallach, The Development of the Nocturne for Solo Piano from 1800 to 1850, (Master of Music Thesis, University of Illinois, 1995), 3-17. 46 John Field, Eighteen Nocturnes for the Piano foreword by Theodore Baker and preface by Franz Liszt, (New York, NY: Schirmer's Inc. 1902). 
genre to new summits, and Gabriel Fauré (thirteen) who followed in the tradition while insufflating a new enigmatic harmonic language and more diversified and complex forms. Although many other composers have paid tribute to the nocturne, because they have granted us with only a few isolated examples, they cannot be considered important contributors to the genre. Closer to us, Lowell Liebermann, with his eleven Nocturnes for piano, can undoubtedly be viewed as the most important contemporary contributor to the genre. For him, the nocturne seems to be the best suited vehicle to express his interest in exploiting subtle timbres and delicate atmospheres. ${ }^{47}$

The purpose of this research will be to study Liebermann's eleven piano Nocturnes; examine them as a continuation of the lineage Field-Chopin-Fauré; give a detailed analysis of the musical language and organization, and, therefore, get a better understanding of Liebermann's piano style and of its evolution; and try to pinpoint specific stylistic features that Liebermann added to the genre.

Character pieces in general and the nocturne more specifically, are true aftermaths of the French Revolution (after 1789). They were an answer to the social changes of the period, a product delivered by the cultivation of music-making in homes and at musical soirées, an offering to the rising middle class. ${ }^{48}$ Out of the increased popularity of the improved pianowhich in its turn generated a herd of amateur pianists—out of a need for music suited for intimate setting and alongside with the need for concert pianists and composers to have a repertoire that could please less sophisticated audiences, the nocturne for piano emerged. ${ }^{49}$ Irish composer John Field was born in Dublin on July 26, 1782 and died in Moscow, on January 23, 1837. He was one of the most popular pianists of the first half of the nineteenth 
century and he is remembered today as being the father of the nocturne. ${ }^{50}$ Between the years

1812 and 1835, Field wrote eighteen nocturnes, establishing the genre and showing the way for numerous composers after him. Not only the name but also the whole style and fabric of these pieces were strikingly new and original. ${ }^{51}$

Close study of the music itself reveals that Field's Nocturnes are small-scale pieces, usually played at a slow to moderate tempo and set in simple ternary form (most of them of the ABA' type). The phrasing carries aesthetics of the Classical era, being very periodic. Simple ornaments such as mordents, grupettos (especially turns) and appoggiaturas are added to the melodic line. Occasional cadenzas (recalling bel canto gestures) are also present. Harmonically, Romanticism is expressed in Field's music through chromatic inflections, extended chords and a few ambiguous progressions. Most of Field's Nocturnes tend to be homogeneous in mood (similar accompaniment patterns throughout and narrow dynamic range). Arpeggiated figures accompany the melodies unobtrusively, very often in triple division, using Alberti-bass figures or repeated block chords. ${ }^{52}$ The following musical example (4.1) displays the typical texture associated to Field’s Nocturnes.

50 The information is gathered from Robin Langley, “John Field” (Grove Online) and Baker’s foreword to Field's Nocturnes.

51 Lim, 23.

$52 \mathrm{Ibid}, 26-27$. A comprehensive table is provided at the end of this paper. The reader can see a summary of some important musical aspects of each Nocturne: opening tempo marking, meter and key, indications specific to the contrasting middle section (if any), opening and closing dynamic markings, dynamic range, form, other interesting features and comments. Field's Nocturnes can be found in Appendix C1, Chopin's in C2, Fauré's in C3 and, finally, Liebermann's in C4. In her master's thesis, Wallach (18-67) mentions that Field also experimented with faster tempo and that there is formal ambiguity created by the fact that harmonic changes and changes in texture often do not coincide with the melodic material. Wallach also emphasizes the presence of tonic pedal points in opening and closing sections of the Nocturnes, traits that were not expanded upon significantly by other composers or completely disappeared after Chopin and therefore, did not become characteristics of the genre. 
Musical example 4.1: John Field, Nocturne no. 7, measures 24-29

(Typical Nocturne-texture of John Field)
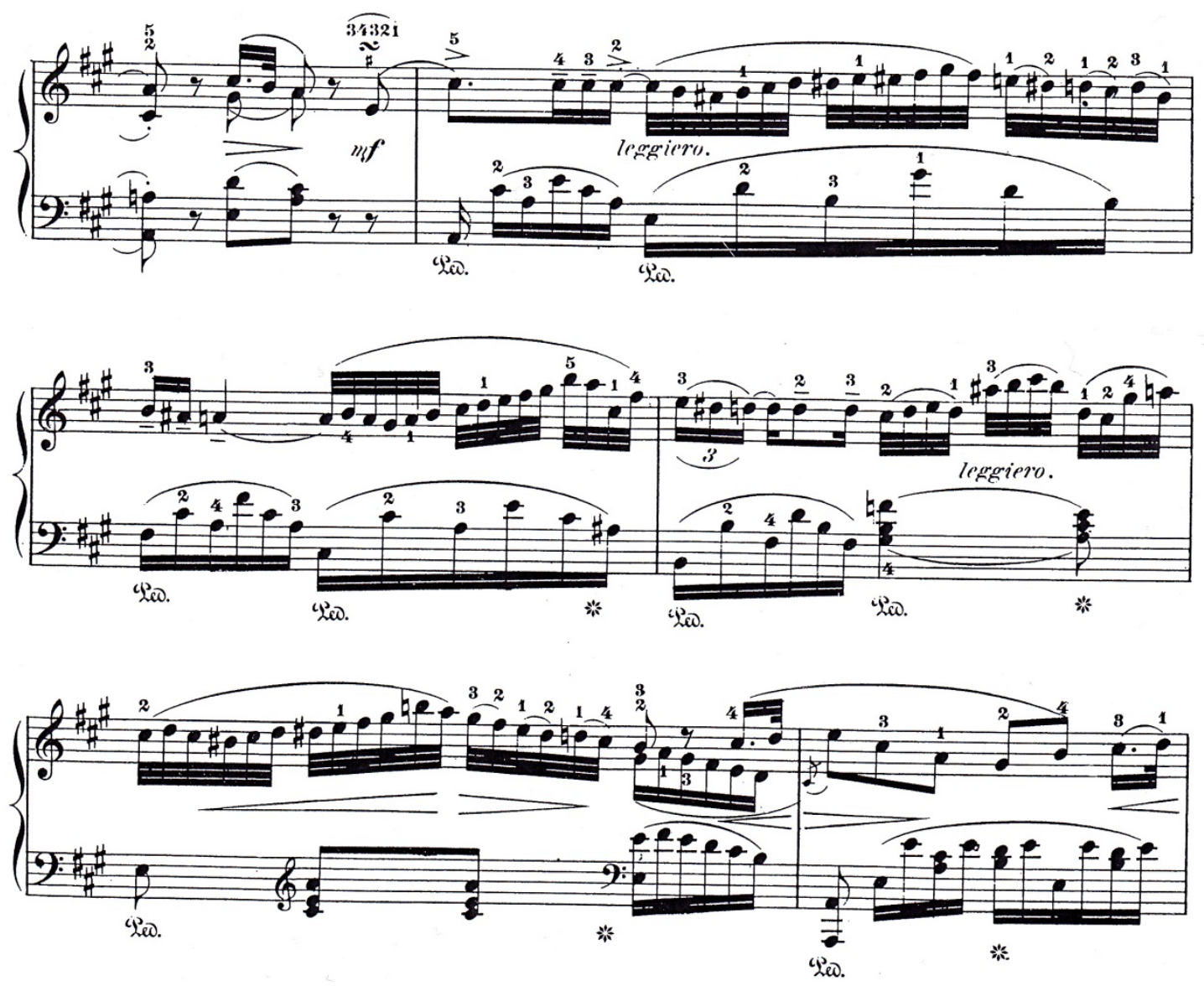

This was the framework handed to Chopin. Composer and pianist Fryderyck Chopin was of Polish origins but spent most of his active life working in Paris, teaching private piano lessons and giving a few concerts. Born on March 1, 1810, in the village of Zelazowa Wola, he died on October 17, 1849, in Paris. As a composer, Chopin wrote almost exclusively for piano, the exceptions being a few chamber music numbers, some songs, and a few works for piano with orchestra. His piano writing shows craftsmanship, ingenuity and never ceases to amaze and puzzle pianists. Amongst all Chopin's works, the Nocturnes are the most introspective, the most 
condensed, and the most genuinely subjective. ${ }^{53}$ Between the years 1827 and 1846, Chopin composed twenty-one nocturnes of which nineteen are usually included in collections. The following musical example (4.2) shows a typical Chopin Nocturne-texture.

53 F.E.Kirby, A Short history of Keyboard Music, (New York, NY: MacMillan, 1966), 281-284; and John Gillespie, Five Centuries of Keyboard Music, (New York, NY: Dover, 1965) 225-227, were consulted for musical notes. Kornel Michalowski and Jim Samson “Fryderyck Francizek Chopin,” (Grove Online) was used for biographical information. 
Musical example 4.2: Chopin, Nocturne no. 8, op. 27 no. 2, measures 46-54 (Typical Nocturne-texture of Chopin)
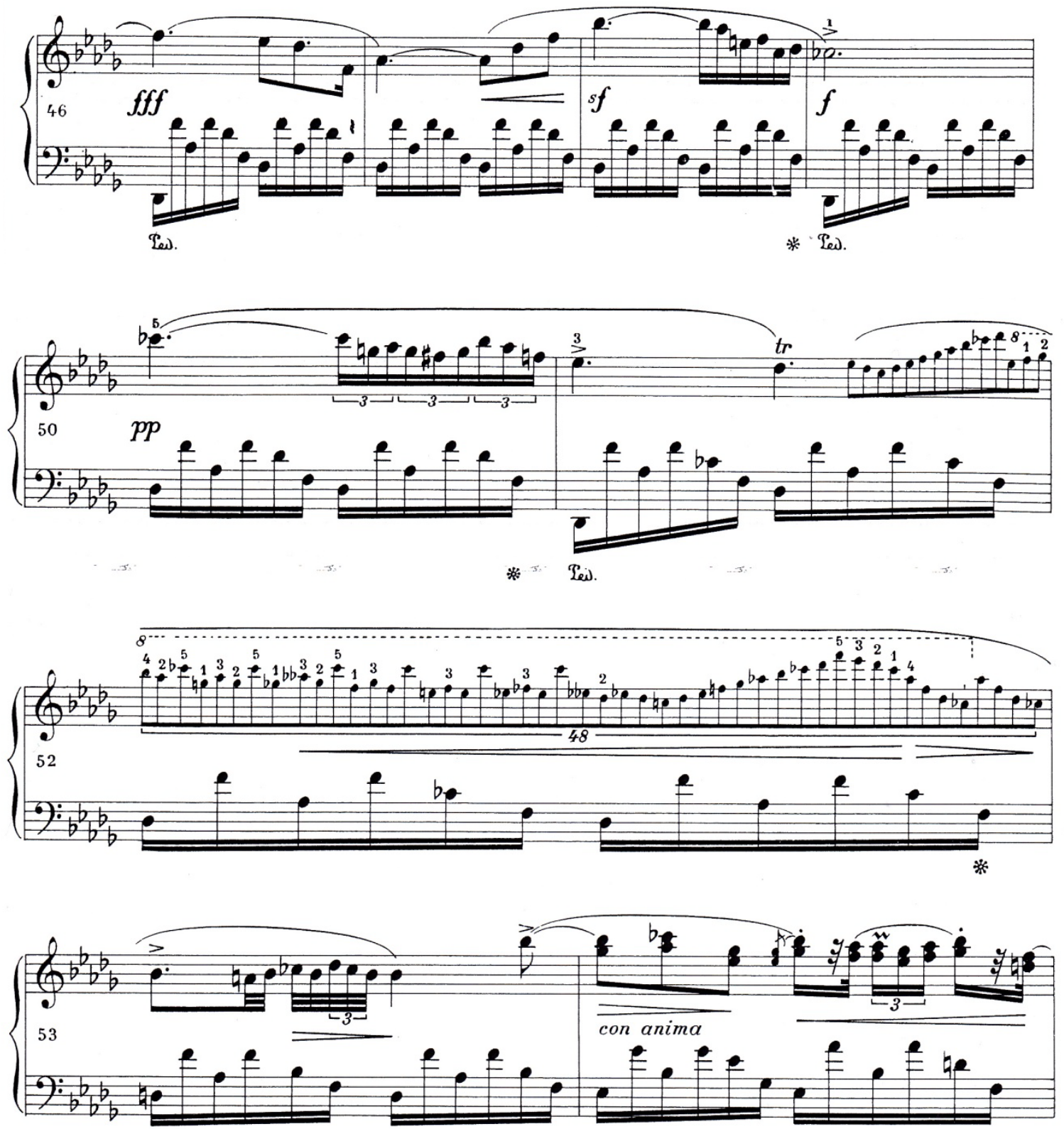

There is no doubt that Chopin was familiar with Field's Nocturnes. Some of the early Nocturnes display striking similarities (accompaniment patterns, textures, treatment of the melody, even home key). The influence of Field is undeniable but under the hands of Chopin, the nocturne became something else. In these pieces, Chopin captured even more vividly the singing 
quality of the piano. His love and knowledge of Italian opera is evident (particularly of Bellini and Rossini). He ventured into exploring different registral timbres. His harmonic palette is very rich. The pedal is omnipresent and indicated in a more consistent manner than was seen in the Nocturnes of Field.$^{54}$ The emotions expressed in those gems are of greater subtlety and depth. As Lim mentions so pertinently: “Chopin’s Nocturnes innately typify Romanticism through their dramatic content, emotional intent, cantabile melody, flexibility of rhythm, imaginative texture, ornamentation, freedom of form, and richness of harmony." 55

In his Nocturnes, Chopin uses accents, tenuto, sforzando very similar to the ones encountered in bel canto arias. Moreover, those accents are used also in a very similar manner to their vocal counterpart, to establish agogic accentuation. Sometimes, the entrance of a melodic note over a regular bass pattern is delayed slightly in order to create some un-synchronization of the parts between the hands. ${ }^{56}$

Unlike Field, who avoided contrast within a single Nocturne and preferred to achieve continuity through a consistent tempo and mood, Chopin bathes in a wide range of emotions; in order to express them, he employs markings such as appassionato, agitato, con forza, stretto, stringendo, and con fuoco. The purpose is to create excitement and drama. ${ }^{57}$ Moreover, one can see an attempt at portraying the feeling of improvisation with elaborate decorative passages (passing tones, neighboring tones, escaped tones, appoggiaturas, suspensions, retardations and anticipations, turns, trills, etc.), not unlike short inner cadenzas in a cantilena. Sometimes, Chopin calls for such a passage to be played senza tempo and con rubato, as can be seen in the

54 Field includes pedal markings in approximately only half of his Nocturnes but even while doing so, he does not do it consistently within a single work. Perhaps he felt that by 1832, the use of the pedal was an established convention and he did not feel it necessary to notate it precisely. However, Chopin, who began publishing Nocturnes at that time, notated pedal in his Nocturnes (and other pieces) much more accurately (Wallach, 24). 55 Lim, 29.

56 This expressive gesture will be re-interpreted by Liebermann through the use of polyrhythm and will be discussed later. Liebermann's Nocturne no. 2 is a simple but good representative of this trademark.

57 Lim, 31. 
following musical example (4.3).

Musical example 4.3: Chopin, Nocturne no. 3, op. 27, no. 3, measures 153-157
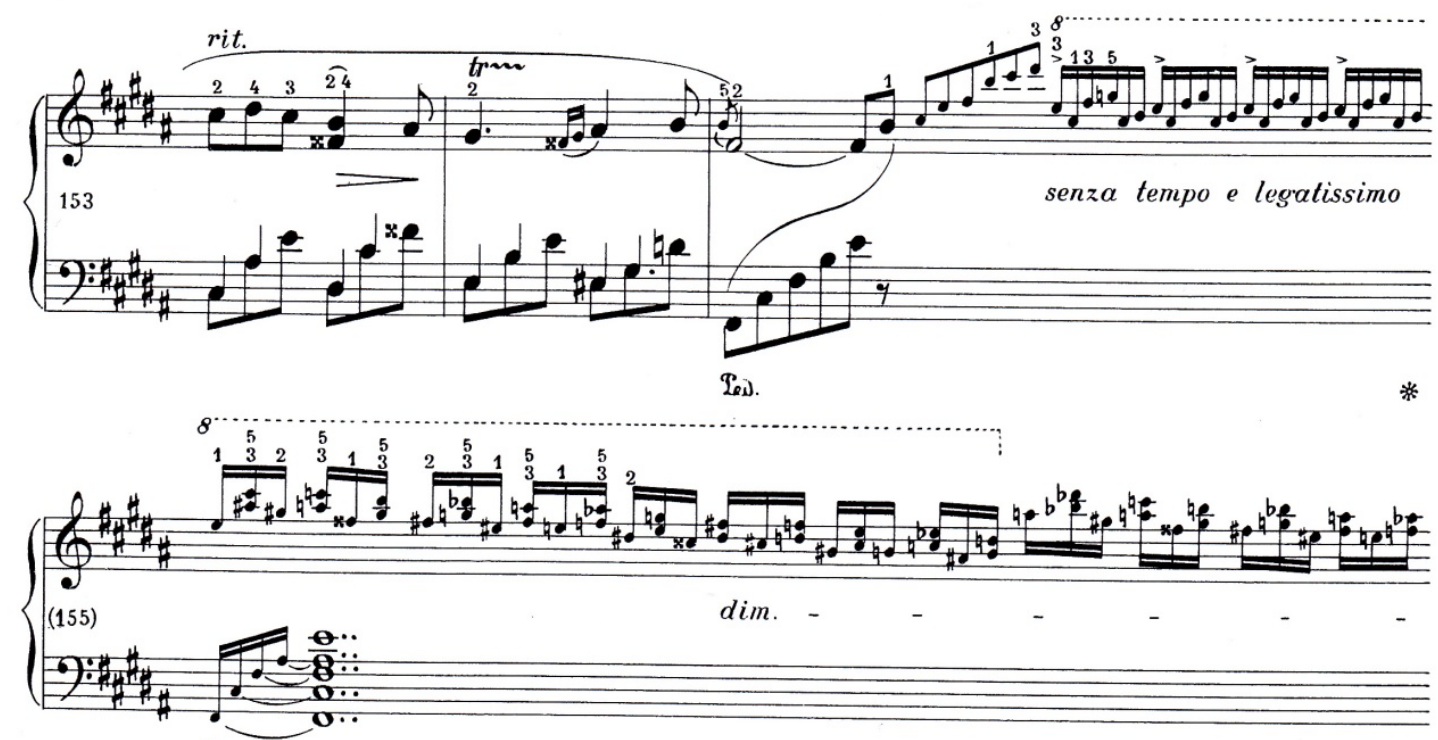

Tai).

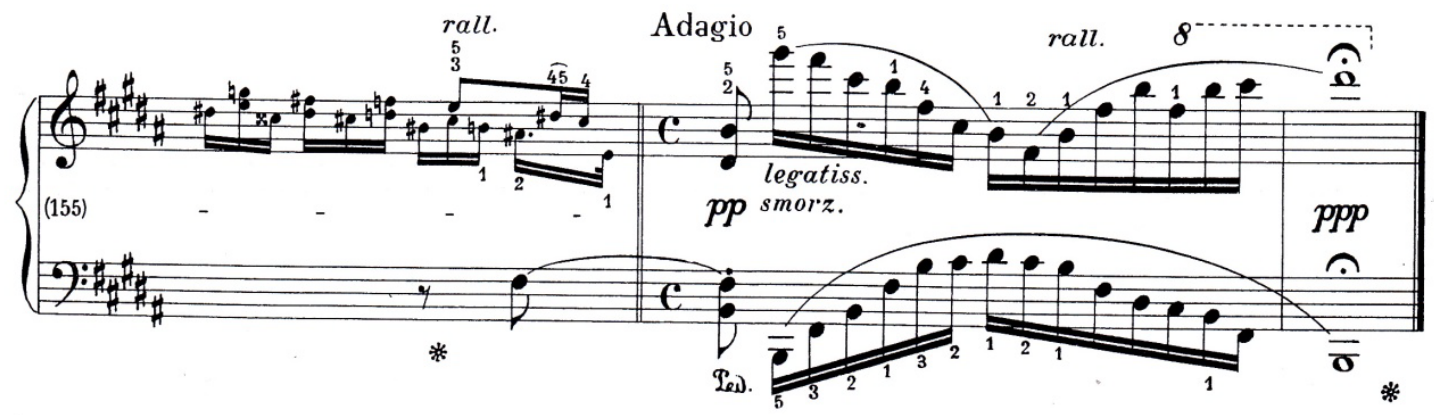

Terms like delicatissimo, legatissimo, leggerissimo, dolcissimo and placement of staccato marks inside a slur all help to create a style of grace and refinement. Much of Chopin’s lyricism comes from an irregular phrasing and persistent use of unusual phrase-length. Maybe derived from the operatic art as well, his sense of phrasing, overlapping, phrase-extension, and phrasecontraction, avoids skilfully the symmetrical restraints of classical composers and gives a 
tremendous sense of fluidity and continuity. ${ }^{58}$ The overall effect is one of a written-out omnipresent rubato.

Greatly varied within and among Nocturnes, the accompaniments serve to provide harmonic support. A whole panoply of resources is deployed: arpeggios, “oompah” figurations, extended Alberti-bass patterns, chorale texture.

In regard to the form, Chopin uses simple structures which, unlike Field's, include a contrasting middle section. Some are monothematic, but most of them are in strict ternary form (ABA' type, or ABB', or $\mathrm{ABC}$ ). In the final section, the return of the opening material is always revisited by a generous ornamentation. Wallach mentions that usually Chopin utilizes a single texture within a section, thus making it easier to delineate the formal structure of the work. ${ }^{59}$

To discuss in detail the harmonic language of Chopin is beyond the scope of this research paper. However, it should be mentioned that, although rich within its delimitations, the harmonic vocabulary of Chopin is actually simple and its components are few in number: diatonic triads and their inversions; preference for the Neapolitan sixth, the flattened submediant, chords with added sixth, the minor form of the subdominant in the major mode, as well as German and French augmented sixth chords. Harmonic sequences are to be found at climaxes and often a chain of diminished sevenths is used to enrich the harmonic palette. ${ }^{60}$ Moreover, a special note should be made about the fact that Chopin used the Lydian mode in some of his compositions. We shall consider this specific feature in more details while addressing Liebermann's Nocturnes in the following chapter.

Under Chopin’s hands, the nocturne becomes something of a more dramatic nature, on a grander scale, richer in contrasts and emotions, a greater artistic moment. This is the point of 
departure for Gabriel Fauré, the French composer for whom this genre of music must have been important, because he wrote thirteen of those pieces, revisiting the genre and bringing it to the doors of the twentieth century. ${ }^{61}$

Gabriel Fauré was born on May 12, 1845, in Pamiers and died in Paris, on November 4, 1924. He was a French composer, organist by profession, pianist by necessity, and a wellrespected teacher; he also proved to be quite influential for many composers of the twentieth century. Throughout his career as a composer, Fauré wrote Nocturnes for piano; the first Nocturne was composed in 1875 and the last one in 1921. There are thirteen of them, through which one can clearly see the evolution of his musical language. ${ }^{62}$

Respective works of Field and Chopin are quite well-known and it appears that the stylistic features and components of their Nocturnes have been discussed at length. However, the same cannot be said about Fauré's and in order to draw a clear lineage (Field-Chopin-Fauré) and extend that link to Liebermann, a more detailed investigation of Fauré's Nocturnes is necessary.

The first five Nocturnes composed by Fauré follow the tradition of Field, with a welldefined cantabile melody, and take Chopin's approach in regard to form: that is, ABA' with a contrasting middle section. Probably because of his instrumental technique as an organist, or maybe even more in account of his rigorous training in counterpoint (at the Schola Cantorum), the writing of the left hand no longer remains a mere accompanying bystander. The interplay of

61 In Lim's research paper Fauré is barely mentioned and is not at all the subject of investigation. This may be because Fauré did not bring any new pianistic tools to the already well-established genre, however, his unique style of writing for the piano, the "new" importance given to the interplay of lines, the constant search for new sonorities and suaver atmospheres, the multi-layered conception of the music and the seminal idea of imitation (embryo of canon at times) cannot be ignored, for they proved to be quite influential for other composers of nocturnes-if only Liebermann.

62 The same cannot be said about Field who remains almost consistently the same. In regard to Chopin, however, the style of writing becomes more precise, fuller in texture, the left hand taking more the role of a partner than just a mere accompanying party (see Nocturnes op. 48 no. 1 and op. 62 no. 2). Jean-Michel Nectoux, "Gabriel Fauré" (Grove Online) was consulted for biographical notes. Joseph Anthony Valicenti, The Thirteen Nocturnes of Gabriel Fauré (DMA essay, University of Miami, 1980); and Richard Henry Crouch, The Nocturnes and Barcarolles of Gabriel Fauré (PhD dissertation, University of Washington, 1980), were used for analysis. 
melodic lines, including the presentation of simultaneous lines in the two hands, creates something very personal to Fauré, quite original in fact. The overruling melodic interest is shifted to more obscure zones (one could say more "nocturnal” zones). The melodic material itself is less directive and not as well-defined as Chopin's, and in that regard, could very well be perceived as showing a tendency towards Symbolism. Demarcation between melody and accompaniment becomes more subtle. Surely, there is always a melody but it seems to emerge out of no one place, born from the union of the numerous lines. ${ }^{63}$

Moreover, with later Nocturnes, a definite distillation of the style itself is observed. From the early Chopinesque Nocturnes (numbers 1 to 5) Fauré moves the nocturne to a more ethereal state, more concerned with textures and sonorities than with pianistic gestures (Nocturnes 9 to 13). The Nocturnes are less and less "pianistic" and more and more "artistic."

Nocturne no. 1, op. 33 no. 1 has only one tempo (lento), a single mood but different textures, including octave doubling in upper register, double-notes, a passage in heterophony with some rhythmic displacements, and even a virtuoso cadenza—an unusual moment in Fauré's music. It is cast in ABA' form and the return of the opening material (A') is ingeniously varied. The addition of a short coda alluding to the B section is a distinct feature of the Fauré Nocturne and will take a more significant importance in the Nocturnes to come. ${ }^{64}$

Nocturne no. 2, op. 33 no. 2 is clearly set in ABA' form with an added codetta; the double-bar and changes of tonality testify to it. Key-scheme delimits the sections: B, b and return of B after a long expressive trill which becomes part of the melody. This work shows great craftsmanship in the inner parts, the accompaniment being passed from one hand to the other.

63 This multi-layer style of writing may have played a certain influence on Liebermann's style, as we shall see later. 64 Valicenti, 22. The codas have also played an important role with Field and Chopin. Wallach identifies four different uses: cadential, cadenza or arpeggiated/scalar passage, new melody or previously heard material (Wallach, 89-97). 
The opening of section B (measures 13 to 22) only presents the harmonic skeleton of what is to come. A gracious new melody is added to it (measure 24) and while doing so Fauré establishes a sensation of music as multi-layer fabric. A few ornamented passages are to be found in this gem, but once again, the nature of the ornamentation is more pianistic than vocal (measures 27 and 32). The following example (no. 4.4) shows a perfect interplay of melody and accompaniment, typical of Fauré's Nocturne-texture.

Musical example 4.4: Fauré, Nocturne no. 2, op. 33, no. 2, measures 23-28 (Typical Nocturne-texture of Fauré)
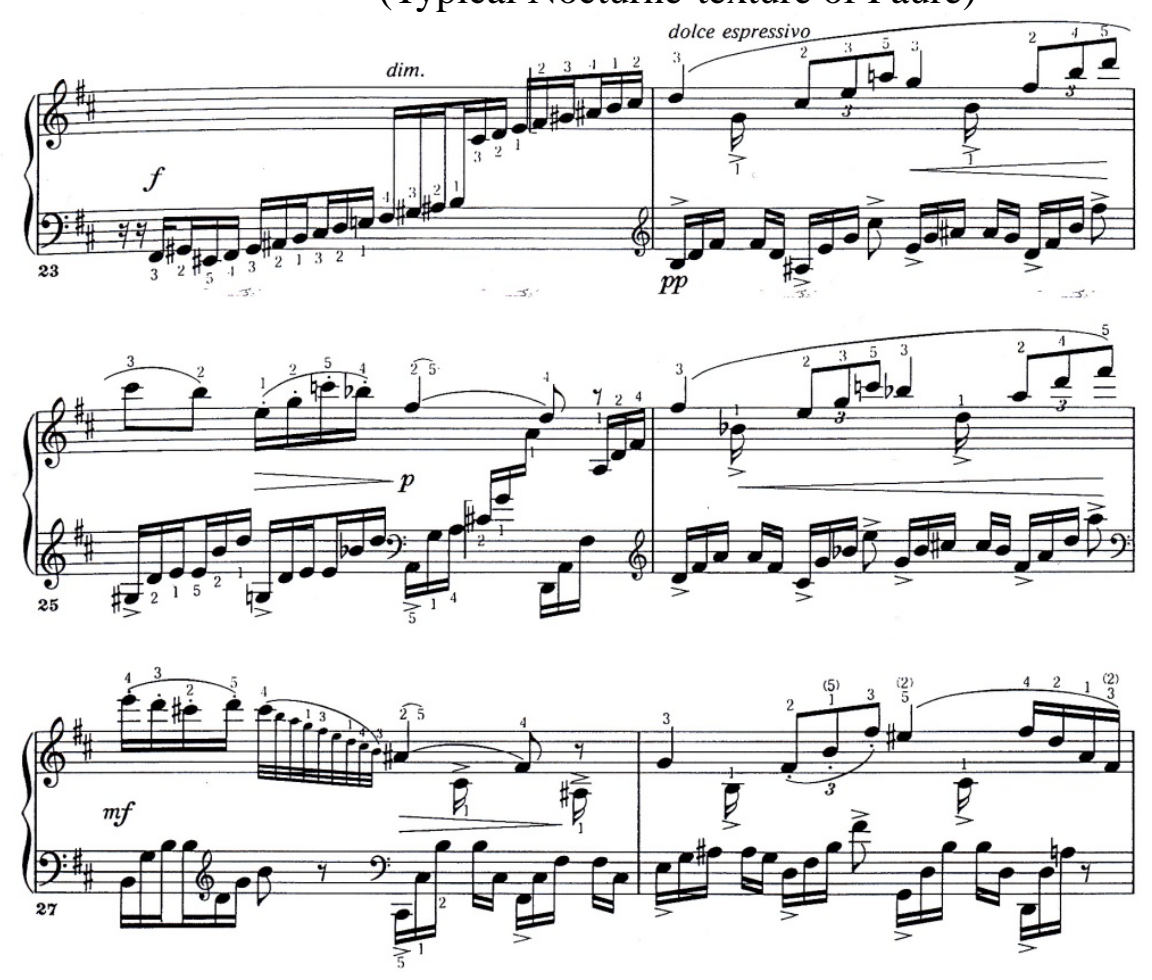

Nocturne no. 3, op. 33 no. 3 refers back to the single-mood type of nocturne closer to the model set off by Field, the small salon-type nocturne. Some contrast in the B section is achieved by giving the melody to the left hand. 
Nocturne no. 4, op. 36 has clear-cut sections. The opening Eb Andante molto moderato section, with its block chords and upward arpeggios becomes undulating arpeggios in the following eb tranquillamente section. Ideas of imitation are included in the cantando section and serve as building ground for the new theme played $f f$ (measure 56), right before the return of the opening material (measure 65). ${ }^{65}$ Imitation (almost canonic) plays a significant structural role in this Nocturne. The accompaniment texture of section B cleverly makes an appearance in the coda, but this time dressed in major mode (measures 84 to 88 ), and the coda itself reaches grander proportion (measures 78-98).

Nocturne no. 5, op. 37 also shows sectional divisions of the ABA' type, with key signature and meter changes. The $3 / 4 \mathrm{~B} \gg$ Andante quasi Allegretto becomes $6 / 8 \mathrm{~b} b$ for the Allegro ben marcato il canto section. Here again, the complicity between the parts plays a crucial role in the dramatic build up and, out of the excitement created by those quite busy inner parts, a beautiful, generous melody emerges.

A certain sense of improvisation is embedded in the core of the opening of this Nocturne. Those arpeggios going up, from which the rhythm seems to be disintegrating itself, passing from sixteenth to eighth, to quarter notes and to rest with fermata, are not without recalling a similar motion from Chopin's Polonaise-Fantasy op. 61 (measures 1, 2, 7, 8 and similar). The following musical examples (4.5 and 4.6) show those similarities.

65 This theme, melody and rhythm, is typical of Fauré, and is quite similar to the one found in the Ballade for Piano and Orchestra, op. 19 (measure 37 and similar.) 
Musical example 4.5: Chopin, Polonaise-Fantasy, op. 61, measures 1-7
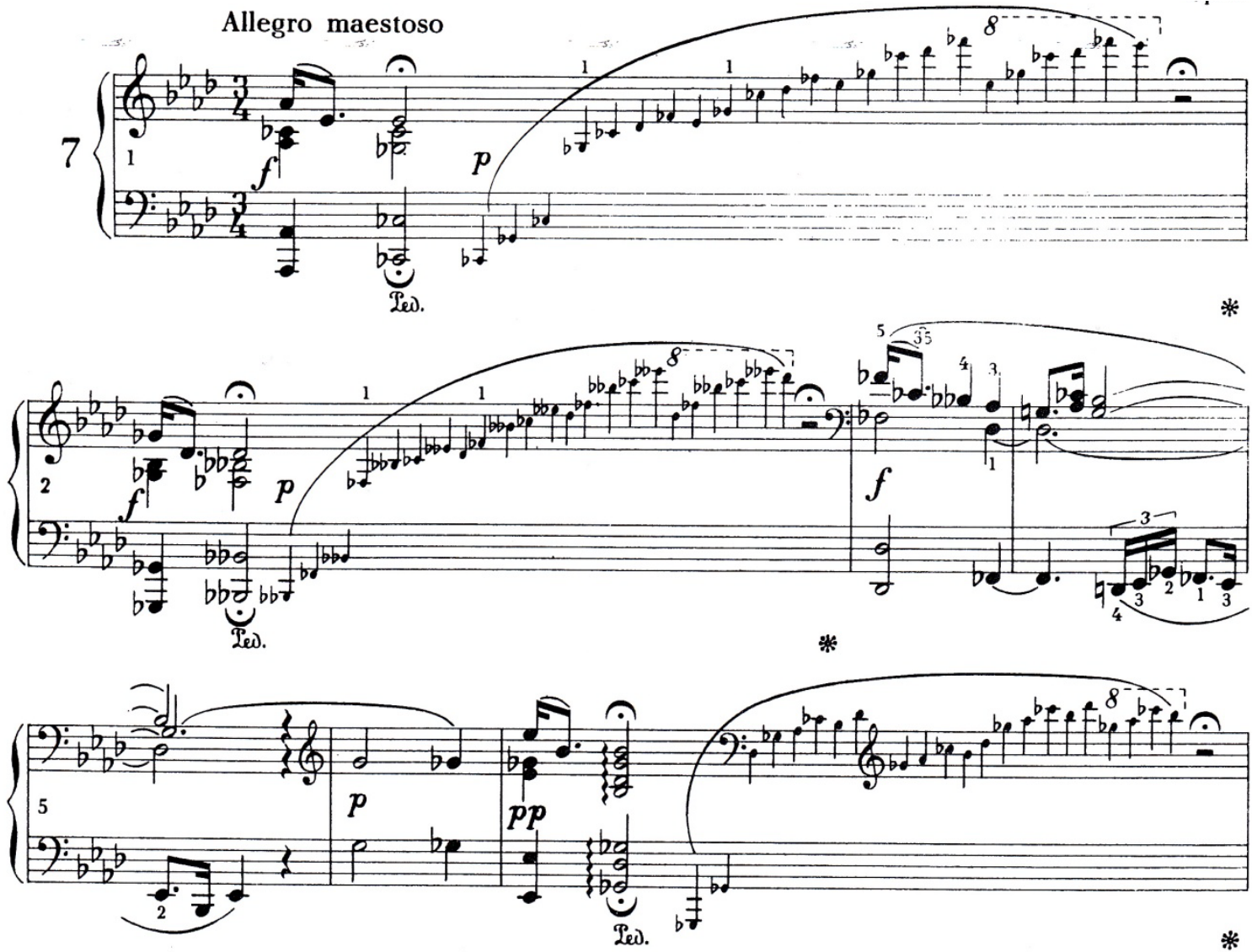

Musical example 4.6: Fauré, Nocturne no. 5, op. 37, measures 1-9
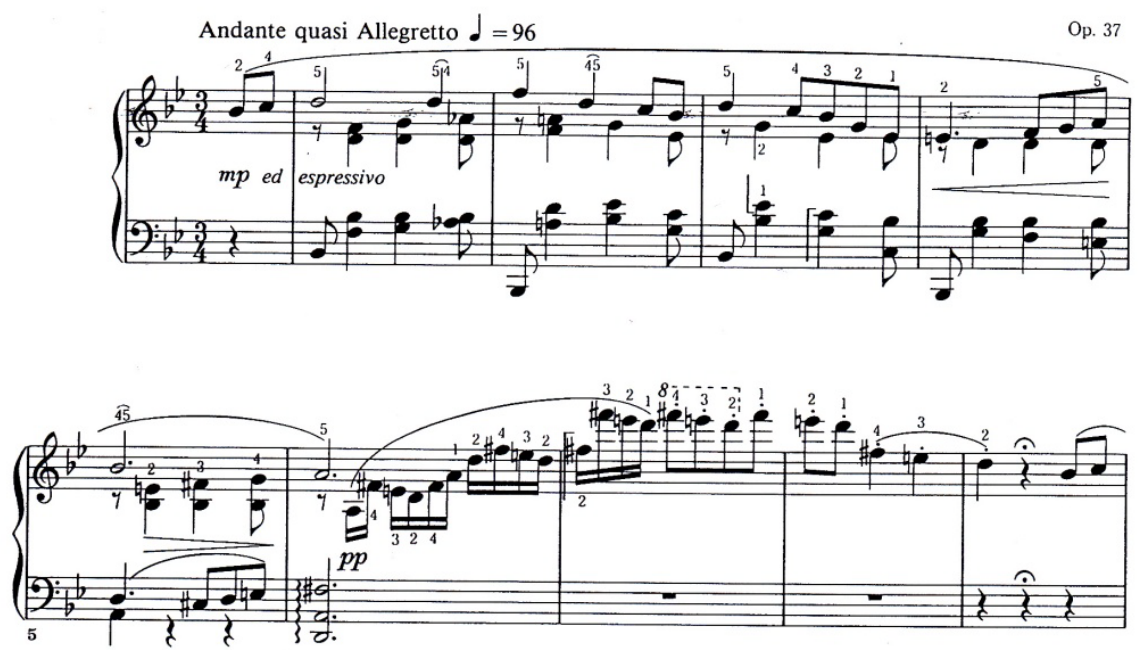
Nocturne no. 6, op. 63 is a true Fauréan masterpiece and in that regard can be perceived as the archetype of Fauré's conception of the nocturne. It encompasses all the features of a textbook nocturne and also contains all the personal stylistic characteristics of Fauré's style: on one hand, lyrical melody, simple accompaniment patterns, ABA' form, ${ }^{66}$ and on the other hand, intricate complicity between melody and accompaniment, undulating harmony, numerous key and meter changes to set up different moods and atmospheres, feeling of multi-layered writing, dramatic construction, melody emerging from the underneath activity, jeu perlé français (measures 63-79 and similar), ingenuity and diversity in the treatment of the accompanying material and great care for the overall structure-an important theme might appear partially at crucial moments, used like a building cell (measures 80-87), or will be played entirely as a climax setting up the return of the opening material (measures 111-114). This music, written in 1894, is full-bodied "romantic" nineteenth-century piano music.

Nocturne no. 7, op. 74 is very much in the same vein as its immediate predecessor (op. 63). It is a very romantic work, full of grand pianistic gestures. The melodic material itself seems a little more motivic. The singable lines are less generous than the ones encountered in Nocturne no. 6, less defined, and a little more "symbolist." Although the work can fit into ABA' coda formal scheme, there is also presence of a complex structure (similar to op. 63), filled with wandering harmonies as well as superimposition of previously heard material (melodic cells) over the accompanying figures (rhythmic and textural) previously associated with a different section, thus creating the effect of music of a multi-layer nature (see measures 24-28).

66 The work itself falls into ABA' formal scheme but to view it as such does not render justice to the cleverness and complexity of its structure. There are nine meter changes, seven tempo changes and six changes of key signature within this work, and numerous quotations of material previously heard in preceding sections. See Appendix C3 (form). 
Nocturne no. 8, op. 84 no. 8 is a very puzzling work. It was included in a series of eight pieces (huit pièces brèves) written over a period of 33 years (1869-1902). Obviously, many stylistic changes occurred during that timespan, making the set look like a collection of oddments. Then, even though the title leads one to expect a short piece, the brevity of the work is striking, especially after the grandeur and ample proportions of the two previous Nocturnes. ${ }^{67}$ Not only is the Nocturne short but also thin: scalar passages and arpeggiated figures are exchanged subtly between hands; a very simple, ambiguously modal melody emerges from that fabric. The idea of multi-layered fabric is present and is created by the exploitation of many registers at the same time. Constant shifting from sharps to flats permeates the whole work and contributes to this feeling of indecision and wandering. This work seems to be throughcomposed with no divisions or clear cadences, regulated by uninterrupted changes of mood or tempo.

The distillation of the pianistic style started with op. 84 continues with the remaining Nocturnes until the last one. Generally speaking, those works are shorter than their earlier predecessors and the writing is much more economical (exception may be made for op. 107). Judiciously, Philippe Mougeot speaks of a "meditation rising to an almost spiritual contemplation of nature.”68

Nocturne no. 9, op. 97 has literally little contrast, but includes one key-signature change (from b to B), and no meter changes. The rhythm is very simple, based solely on constant alternation of eighth notes and eighth rests. At times, the music appears like a simple vocal duet

67 In fact, so far the Nocturnes were taking from five minutes for the shortest (Nocturne op. 33 no. 3), up to ten minutes for the longest (Nocturne op. 74. This number (op. 84, no. 8) requires approximately two minutes and thirty seconds to be played.

68 “Une méditation qui s'élève à une contemplation de nature quasi-spirituelle,” taken from: Fauré, 13 Nocturnes, Jean-Philippe Collard piano, EMI CMS 7691492. [A meditation rising to an almost spiritual contemplation of nature.] Ou s'agirait-il plutôt d'une contemplation quasi-spirituelle de la nature? [Or could it pertain more to a contemplation of which the nature is almost spiritual?] 
between the soprano and the bass lines, surrounded by a quiet, subdued accompanying part in the middle register of the piano (made of partial block chords). This through-composed piece contains a single melodic impulse made of short motives, and conveys a single mood, which is not without recalling Field's conception of the genre.

Nocturne no. 10, op. 99 and Nocturne no. 11, op. 104 no. 1 are very similar in their concision, intentions and construction. Op. 99 bears two key changes (from e to E and back to e) and there are no changes of key in op.104 no. 1; no meter changes can be observed and the rhythms used, although a little more varied than op. 97, never thicken the fabric of the music. One can also see clear melodies (soprano and bass line), while the accompanying figures are, most of the time, confined within the middle register of the instrument. Typical gestures associated with Fauré's style abound, such as a sensation of multi-layer music writing, and ambiguous harmony made of a mixture of major mode, minor mode and modal inflections. Unexpected modulations and tonal shifts are exploited to an extraordinary degree. ${ }^{69}$ The pianistic writing often requires that the pianist redistribute differently the parts between hands. As we shall see, in his Nocturnes (and in many other piano works), Liebermann calls for the same approach.

What remains then, in Fauré, of the model inherited by Field and transformed by Chopin?

The melodic line does not carry the same "vocal" qualities and surely is not at all embellished, decorated or operatic in any sense. Accompaniments are no longer of the simple “oompah” figuration. One can find arpeggios, but they are truncated, such that most of the time they live in the middle register of the piano or are exchanged between hands through small motives. They seldom serve to establish a constant meter or rhythmic continuity. ${ }^{70}$ Many of the later Nocturnes do fit into the simple ABA' form, but the vagueness of the material itself (melody

69 Crouch, 64.

70 If they do, it would be for a very brief moment, used with insistent repetition, leading up to the climax. 
and harmony) makes it difficult to perceive the form clearly. Moreover, within the simple formal container there is a complexity created by the use of recurring cells of the main themes, superimposition of dissociated material, a multi-layered conception of the music, and a constant feeling of wandering. As mentioned earlier, through his stylistic evolution, Fauré becomes more concerned with the evocation of the night, the meditation and contemplation it can inspire, than with the vocal singable (cantando) celebration of it.

In the last years of his life, Fauré composed two more Nocturnes: Nocturne no. 12, op. 107 (1915) and Nocturne no. 13, op. 119 (1921). They represent two opposite views on the genre: the first recalling the very pianistic, romantic and extroverted view from his middle period (opp. 37, 63 and 74) and the second evoking the more economical, reflexive and introverted view of the late period (opp. 97, 99 and 104 no. 1). However, it is needless to say that Fauré's harmonic and melodic language pierces through all of those pages. Indeed, form and conception rendered those Nocturnes amazingly different than earlier ones.

Nocturne op. 107 is a grand Nocturne, very similar in structure and writing to opp. 63 and 74. Even though it is written as a through-composed piece with only two tempo changes, there are many sections in the piece, well-blended with the use of long crescendi, accelerandi, con anima and such devices. It fits into the formal model of ABA' coda, although without stark formal divisions or cadences; the coda recapitulates all the themes. The writing looks back to earlier days with a more active piano part. Indeed, Crouch calls it the return of the bravura style. ${ }^{71}$ Texture is clearly established and still relies on plentiful exchanges between hands and redistribution. The harmony is quite complex, constantly undulating, and major mode and minor mode often cohabit in a very near proximity (measures 1-2, 99-100, and similar). ${ }^{72}$ 
A strong rhythmic freedom is embedded into the fabric of this Nocturne. Simple rhythms are superimposed to create a very thick, multi-layered musical paste: groups of four quadruplets on music written in triple division of the beat (measures 5, 10, 16, and similar); duplets alternating with triplets over groups of sextuplets (measure 26), etc. ${ }^{73}$

The opening measures of Nocturne op. 119 are closer in nature to organ music_-or fourpart chorale - than to piano music. It is a moment of pure contemplation. There is nothing of a pianistic nature until measure 22, when a little arpeggiated figure comes in. The writing is very sober, inundated with counterpoint and imitation. ${ }^{74}$ Time is suspended in this work until the arrival of the allegro middle section. Short arpeggiated figures are meandering in the top and middle registers and are being passed from one hand to the other while the melody seeps out. A quite substantial section built on points of imitation between the melody and the bass serves as a preparation for the dramatic construction until the return of the meditative opening material (measure 127). Four bars of a measured cadenza-like passage make their way in, right before the recapitulation (measures 119 to 122$)$.

Could it be a reminiscence of the past? Maybe so; nevertheless, this is the testimony of a great composer. It is the last work for solo piano written by a man who lived through half of the nineteenth century and a quarter of the twentieth, who saw incredible stylistic changes occur and participated in many of them, and whose Nocturnes offer indisputable proof of that amazing stylistic evolution. ${ }^{75}$ The following musical example (4.7) displays that four-part chorale-like texture, and also illustrates a writing which is neither "pianistic" nor characteristic of the nocturne-writing encountered so far.

also a scale or some kind of melodico-rhythmic ostinato.

73 Liebermann's Nocturnes (especially nos. 4, 5, 8 and 11) will display a very similar rhythmic layering.

74 This is another device that Liebermann exploits to the maximum (Nocturnes nos. 3, 4, and 5).

75 Only the Piano Trio in D minor op. 120 and the String Quartet in e minor op. 121 were completed after this Nocturne. 
Musical example 4.7: Fauré, nocturne no. 13, op. 119, measures 1-13 (Compare the texture to musical examples 4.4 and 4.6)
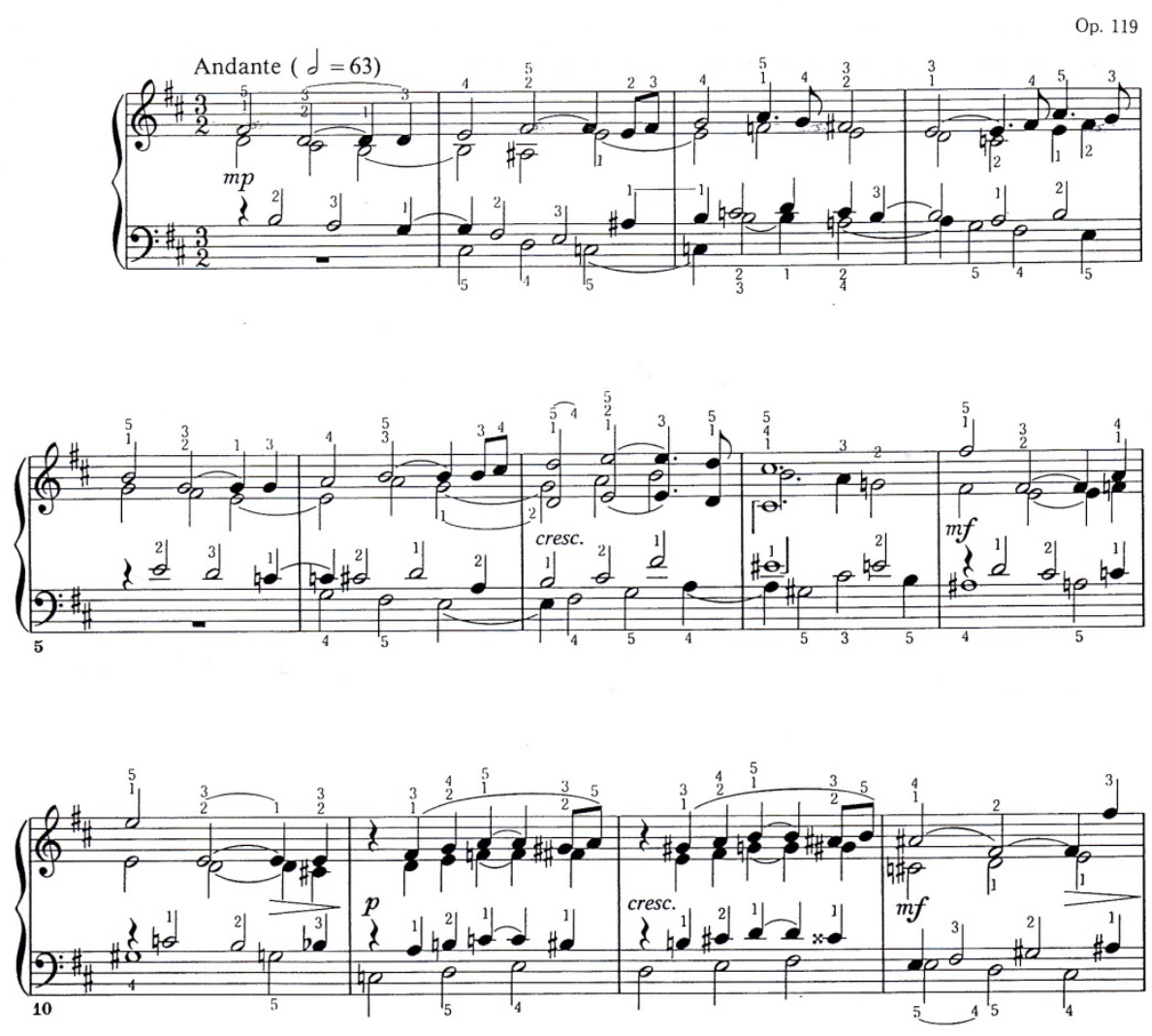

It seems that the tradition of nocturne-writing stagnated —or indeed was almost dead— for quite a long period of time since the epoch of Fauré. Surely, a significant number of composers wrote nocturnes, but none made it a sought-after vehicle to single-handedly bring the genre up to date; that is, not until the advent of American composer Lowell Liebermann. The next chapter will look at Liebermann's eleven Nocturnes for solo piano as a continuation of the Field-Chopin-Fauré lineage. Detailed analysis of the music will be provided. The goal is to link Liebermann to the great tradition of nocturne-writing and, at the same time, develop a keener understanding of his musical language and of its evolution. 


\section{CHAPTER FIVE}

\section{THE ELEVEN NOCTURNES FOR SOLO PIANO}

When composer Lowell Liebermann wrote his first piano Nocturne he could not have known what a journey he was beginning. From 1986 till 2011 he composed eleven Nocturnes for solo piano; by doing so, he solidly re-established the long-lost tradition of nocturne-writing. ${ }^{76}$ Sonatas, concertos, etudes, and many other genres of music have long stayed in favor among composers. But nocturnes, perhaps because of social changes, have seemed to receive only isolated visits from individual composers. Liebermann stands out as being the only composer since Fauré to show a sustained interest in the genre.

This chapter will study each of the eleven Nocturnes for piano solo of Lowell Liebermann in chronological order. Melody, rhythm, harmony, accompaniment, internal organization and larger formal aspects, multi-layering, ostinato, canonic treatment, and other stylistic features will be examined. The goal is, firstly to draw a clear picture of Liebermann's style of piano writing and also of its evolution, and secondly to see how Liebermann can be grafted to the already mentioned nocturne lineage, Field-Chopin-Fauré.

\subsection{Summary of Field-Chopin-Fauré Nocturne Lineage}

As a summary, we have seen that Field gave life to the nocturne. We have also seen that Field's Nocturnes use a limited, and therefore well-defined, set of stylistic possibilities. We shall

76 Liebermann's interest in the "nocturne quality" also manifested itself in his Sonata no. 2, op. 10 (called SonataNotturna), the Nocturne Fantasy for Two Guitars, op. 69, the Night Songs for Voice and Piano op. 78, the Nocturne for Orchestra op. 84 (an orchestration of the Nocturne for Piano no. 4, op. 62), and the Night Music for Flute, Clarinet and Piano op. 109. 
therefore refer to Field's model when talking about a work set in simple ternary form, homogeneous in mood with narrow dynamic markings, in which the melody, vocal in nature, is embellished and supported by a simple accompanying part made of arpeggios, "oompah" figurations or block chords.

This model was further expanded by Chopin. What we shall call the Chopin model is also in three-part form but the middle section is contrasting in mood and character, often being more dramatic. The melody, while still singing, is greatly embellished. Accompaniments are more complex, and they also show greater diversity even within a single work. They sometimes play a more important part in the fabric of the music: doubling the melodic material (Nocturne op. 48 no. 1, poco più lento); carrying the melodic interest (Nocturne op. 48 no. 2, più lento and Nocturne op. 55 no. 1, più mosso) or presenting a very elaborate and decorated countermelody (Nocturne op. 62 no. 2, agitato). Dynamic range is also wider, translating into more passion, more drama.

Finally, what will be called the Fauré model is the later, leaner version left by this composer. Surely, early on, Fauré did write Nocturnes in a very Chopinesque way (Nocturnes opp. 33 no. 1,33 no. 2,33 no. 3, 36, 37, 63 and even 74), but he left his personal imprint on the genre with a more ethereal approach. The writing for the piano became sparser; no trace of (vocal) ornamentation is to be found affecting or surrounding the melody. Accompaniment and melody are more intimate partners, constantly exchanging material, although in a very subtle manner. The music is constructed with layers of melodic lines distributed in all registers of the instruments. Ideas of imitation - to the point of being almost canonic - also appear from time to time. Formal structure still remains of the ABA' type; however, the inner organization is rendered quite complex. One can observe the use of recurring cells for dramatic construction (motivic 
transformations) and the appearance of truncated or complete appearances of important themes at climaxes, often played for setting up the return of the opening material.

Finally, the emergence of the nocturne as a musical work for solo piano also coincides with the on-going evolution of the instrument itself and especially of the pedaling system. Therefore, the pedal plays an indissociable role in the conception of the nocturne-as much for the composer as for the performer - to gather harmonies, wide-spread chords and arpeggios covering the complete range of the piano, and, moreover, to create a somewhat nightly atmosphere. The importance of the pedal in nocturne-writing is a characteristic shared by all three composers and de facto, by all three models.

As mentioned before, to go into a very exhaustive analysis of the musical languages of Field or Chopin would be beyond the scope of this paper, however, a cursory glance at Fauré's language is essential, for Liebermann seems to share with Fauré numerous similar approaches towards harmony, multi-layering of textures, use of imitation as a structural building block and sequential constructions.

Although many authors have divided Fauré's creative life into three different periods, these divisions are not pertinent for the purpose of this study. ${ }^{77}$ There is an undeniable evolution and drastic changes are easily observed. However, a simple listing of the most characteristic features and comparisons will suffice to highlight the striking similarities and to establish Liebermann's point of departure.

Fauré is known for his distinctive harmonic language. In his introduction, Valicenti says that "his peers were disturbed by his unusual harmonic progressions which were in fact nothing

77 The division of Fauré's creative life into three different periods is the approach taken by Crouch and by Nectoux [Jean-Michel Nectoux, Gabriel Fauré; Les voix du clair-obscur, Cambridge University Press, Flammarion, 1990]. 
more than the natural outgrowth of the tertian harmony." ${ }^{, 78}$ Often, Fauré's harmonies are considered non-functional in the traditional sense established in the Classical era. In Fauré's music, it is common to see chords which might only have a local effect and are used more for coloration (definite sense of sonority for its own sake) than for harmonic progression. ${ }^{79}$ Despite their linear or coloristic motivation, these chords nevertheless have labels. He has a marked predilection for the chromatic mediant (third-related chords that result from modal borrowing or chromatic alteration), the augmented V chord (often used enharmonically, see Nocturne no. 1, measures 44-52), ${ }^{80}$ the chromatic sub-mediant and its dominant, or the tonic pedal in conjunction with $\mathrm{V}^{7} .{ }^{81}$ Numerous instances of Neapolitan chords and minor mode with a sub-mediant tonicized are encountered. ${ }^{82}$

The quest to create larger structures often leads to the evasion of the tonic or to the use of large sequences (motivic in nature) ${ }^{83}$ In the same vein, repetitions (sequences) are quite typical of Fauré and they allow him to delay or suspend harmonic progressions. ${ }^{84}$

It has been said of this music that "melody and harmony are so intimately wedded to each other that they are inseparable, and one without the other is unthinkable" (Nocturne no. 2 and Nocturne no. 6) ${ }^{85}$ This manner of approaching the pianistic writing unmistakably shines through Fauré's corpus of piano compositions (and Liebermann's as well). Fauré's accompaniments are often characterized by a continuously sliding and sidestepping chromaticism. It can be observed on countless occasions either in immediate shifts from major to minor within triads of the same

78 Valicenti, vi. The following musical considerations are drawn mainly from Crouch.

79 Crouch, 22 and 47.

80 Ibid, $23,33$.

81 Ibid, 24.

82 Ibid, 28.

83 Ibid, 30, 49.

84 Ibid, 32.

85 Ibid, p.33. References to specific Nocturnes are mine. 
root (therefore affecting the melody as well) or when generously borrowing melodic elements from the church modes. ${ }^{86}$

All of these characteristics have the effect of creating an amazing enharmonic versatility — what some would call ambiguity. There is also a marked interest in counterpoint and canonic treatment (above all between the soprano and the bass line). ${ }^{87}$ This propensity does not come as a surprise on account of his strict upbringing and training as a church organist at the Schola Cantorum. This kind of writing also leads easily to multi-layered textures. ${ }^{88}$

In regard to rhythmic organization, the music often relies on a well-defined recurring cell that functions almost like an ostinato. ${ }^{89}$ Rhythmic complexity comes from the piling up of lines more than from the rhythms themselves, which are always simply metrically controlled.

The more mature style of Fauré displays textures that are refined, distilled, rarefied, and even bare at times. Sonority and color take precedence over harmonic function. Third-less and open-fifth vertical structures, parallel chords, whole-tone scales, whole-tone chordal successions can all be encountered. ${ }^{90}$ Dissonances can be also be overwhelming and generate a sort of tonal "blind-spot" between two (somewhat) more stable tonal landmarks on each side. ${ }^{91}$

Finally, most of the Nocturne production of Fauré displays a strong affection for the ABA' formal scheme inherited from Chopin. Often the form will be expanded with an introduction and a coda. The coda grows larger with the more mature Nocturnes, becoming a very important structural anchor for the whole work, recalling themes previously heard, working out the motivic or thematic material, or presenting material never heard before. Moreover, the overall structure is

86 Ibid, 22, 45, 55. (Cross-relations are unavoidably created by the proximity of these motions. Ibid, 68.)

87 Ibid, 193.

88 Ibid, 46.

89 Ibid, 71.

90 Ibid, 197-198.

91 Ibid, 81-82. 
rendered quite complex through the utilization of recurring themes or motives within different sections of the piece. ${ }^{92}$

There is a world of difference between the first Nocturne of Fauré and his last one.

Throughout his fifty-some years as a composer, the thirteen Nocturnes accompanied his maturing process as a composer and as a man, and, more than any of his other musical compositions, they testify of that growth. Thus, one must agree with Valicenti when he states: "Fauré abandons the concept of the form as a 'night piece' which the term 'nocturne' implies. Charged as they are with emotion and personality, they should be regarded as 'mood pieces,' if such a label can be applied with meaningful definition." 93 Since Fauré is the last great link in the nocturne tradition before Liebermann, and a link that is so largely neglected, these stylistic features of texture, piano technique (including the technical development of the instrument), harmonic language, melodic structure, rhythm, and form all prove to be a necessary background to understand Liebermann's contributions to the genre. It is now time to proceed and to give a closer look at Lowell Liebermann's eleven Nocturnes for piano.

\subsection{Liebermann Nocturne no. 1, op. $20^{94}$}

Liebermann was 25 and still studying at the Juilliard School when he composed this Nocturne. Although Chang claims in her paper that with the composition of his Concerto no. 1 for Piano and Orchestra, opus 12, Liebermann's compositional style changed and that he was employing a "distinctive tonal language of his own," this position cannot be endorsed without

92 Ibid, 195.

93 Valicenti, 80.

94 Unlike for the following Nocturnes, Liebermann did not give a number to that work. In this research document, it is referred to as Nocturne no. 1. 
qualifications. ${ }^{95}$ Perhaps Liebermann's style of composition was undergoing a great metamorphosis from the earlier years but his language was not fully developed as we know it now. Even his op. 20, Nocturne for piano no. 1, still shows evidences of his early and more dissonant style and does not display the distinctive organized harmonic construction of his op. 31 (Nocturne no. 2) that we recognize now as his trademark. Therefore, the "big change" could be seen more as an evolutionary process and has most likely happened gradually between those two early Nocturnes (opp. 20 and 31).

Nocturne no. 1 has 104 measures and requires about seven minutes to be performed. It is dedicated to David Syme, who also premiered it on November 21, 1986 at the Terrace Theatre, John F. Kennedy Center for the Performing Arts in Washington D.C. ${ }^{96}$

Before going into the detailed analysis of each Nocturne, a table highlighting the formal cast and the important elements will be given. This should help the reader comprehend more easily the following discussion. In the musical figures, the abbreviation "m.i." will be used in place of "musical idea." Measure numbers are given in parenthesis and starting harmonies are indicated in brackets (when pertinent). Musical figure 5.1 shows the formal aspect of Nocturne no. 1 .

95 Ibid, 195.

96 David Syme is an American pianist based in Houston, TX. See Appendix B for more information or consult the artist's personal website at: http://www.symepiano.com 
Musical figure 5.1: Liebermann's Nocturne no. 1

\begin{tabular}{|c|c|c|}
\hline $\mathbf{A}$ & $\mathbf{B}$ & $\mathbf{A}^{\prime}$ \\
\hline $\begin{array}{l}\text { m.i. } 1(2-5 ; 6-9 ; 10-13 ; \\
\text { 14-22) } \\
\text { - m.i. } 2(23-27) \\
\text { - m.i. 1' and 2 (28-31; 32-38; } \\
\text { 39-43) }\end{array}$ & $\begin{array}{l}\text { m.i. 1', m.i. } 3(44-48 ; \\
\text { 49-55; 56-59; 60-63; 64-66; } \\
\text { 67-68) } \\
\text { pedal points }\end{array}$ & $\begin{array}{l}\text { - } \text { m.i. 1(69-72; 73-76; 77-82; } \\
\quad 83-87) \\
\text { - } \quad \text { m.i. 1' }(88-94) \\
\text { - } \text { m.i. } 2 \text { : }(95-98 ; 99-104)\end{array}$ \\
\hline
\end{tabular}

Marked Adagio con molto rubato, this Nocturne begins in the quiet expected manner with a gentle accompaniment figure, a revisited Alberti-bass which underlines a very enigmatic harmony. As mentioned by Nichols, at times this accompaniment clearly outlines chords, while in other passages it remains tonally vague to the point of defying analysis and baffling any sense of conventional harmonic direction. ${ }^{97}$ The following musical example (5.1.1) displays the first melodic idea and its barcarolle-like accompanying pattern.

97 Nichols, 91. 
Musical example 5.1.1: Liebermann's Nocturne no. 1, measures 1-8
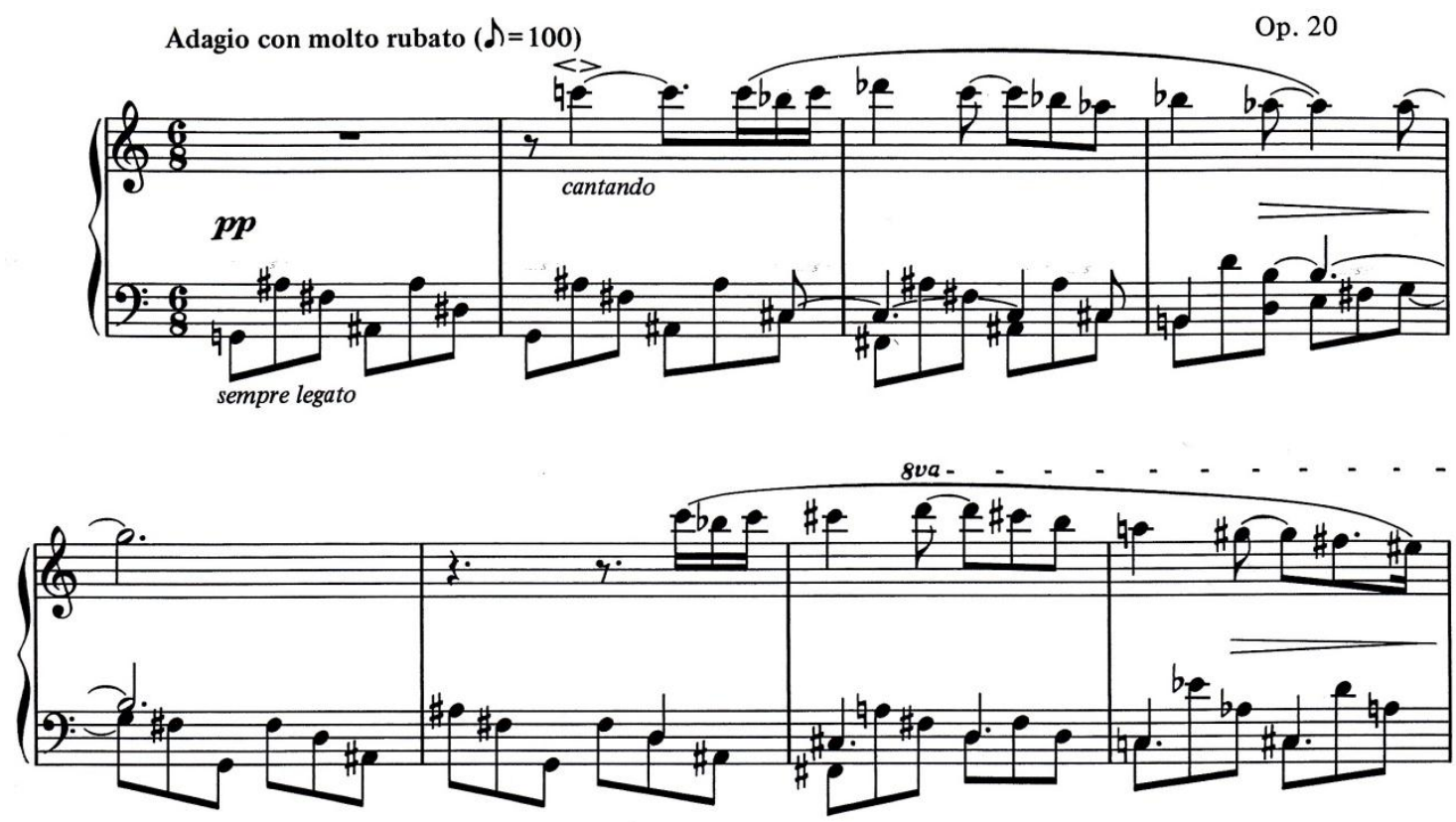

(C)1987 by Theodore Presser Co., Used With Permission

A cantando melody enters at measure 2 . This melody, mostly conjunct with occasional expressive octave leaps (which are in fact essentially octave displacements of the step-wise melodic line), will be labelled melodic idea 1. Musical example 5.1.2 shows the second appearance of melodic idea 1. It should be noted that the flats in the first appearance now turn to sharps in the second presentation of this material. 
Musical example 5.1.2: Liebermann's Nocturne no. 1, measures 5-12

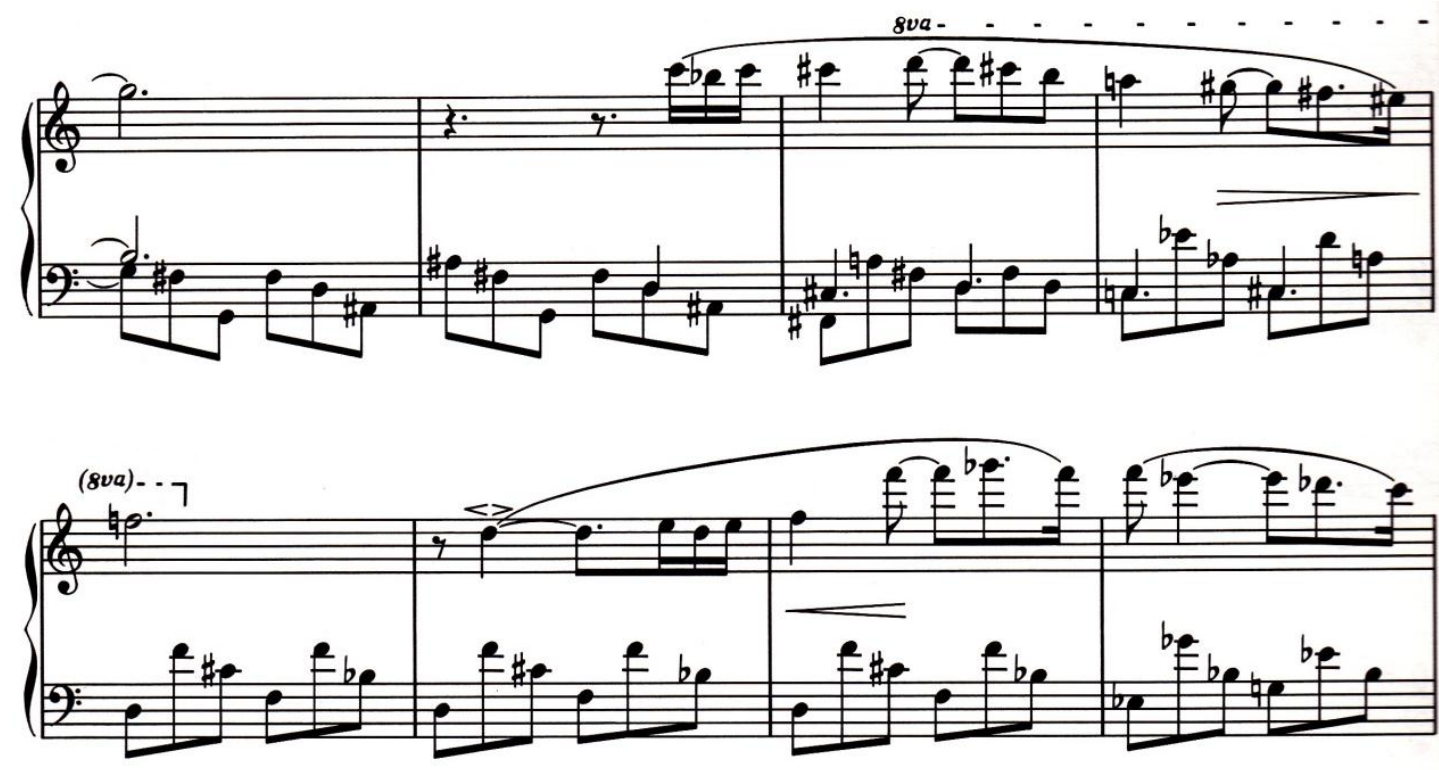

(C)1987 by Theodore Presser Co., Used With Permission

In the first part of the piece, this material is heard five times (beginning in measures 2, 6 , 10, 14 and 16), always presented with small variants: with expressive leaps of octave or ninth, partially played or elaborated upon. Each appearance is preceded by a rest, a feature quite vocal in nature. This melody is not rooted in any specific key either (just like the accompaniment). Moreover, there is a constant purposeful shifting of the use of sharps and flats. While this indicates the melodic direction (for example, in measure 3: in the melodic line, $\mathrm{D} b$ going to $\mathrm{C}$; and later on, at measure 7, the $\mathrm{C \#}$ going to $\mathrm{D}$ ), at the same time, this ambivalent use of enharmonic spellings confers a vagrant quality similar to what we previously observed in Fauré's melodies. At measure 18, there is a ppp mark and a calando mark bringing a change of texture and of material. The ensuing sesquialtera gives variety to the otherwise regular rhythmic personality of the melody (measures 21-22). 
The following subsection displays a construction of a multi-layer nature: intervals in the highest stratum of the piano, octave in the bass, and a melodico-rhythmic ostinato figure in the middle register - this figure is made of a portion of an octatonic scale: D-E-F-G-Ab (melodic idea 2). The following musical example (5.1.3) displays melodic idea 2.

Musical example 5.1.3: Liebermann's Nocturne no. 1, measures 21-28
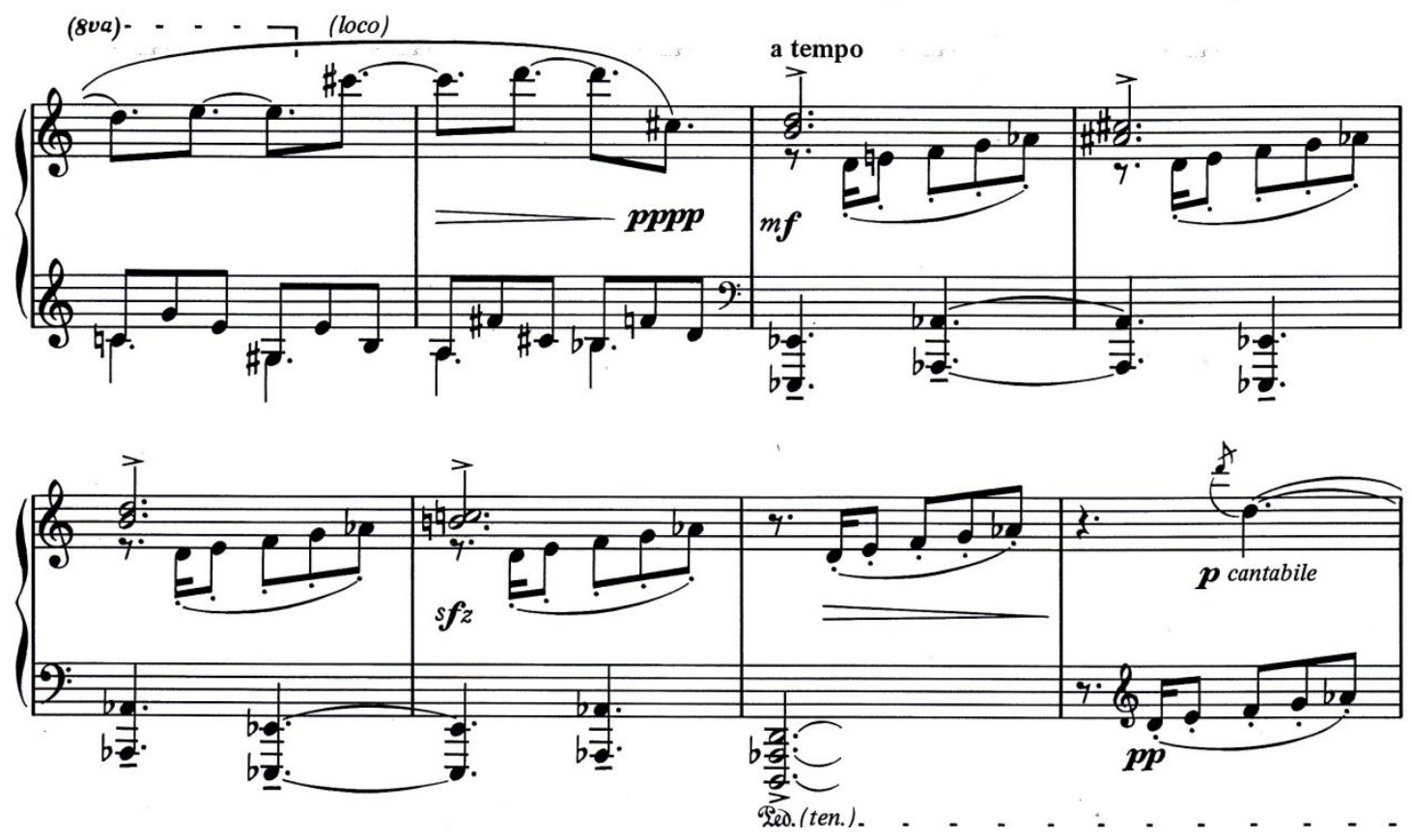

(C1987 by Theodore Presser Co., Used With Permission

This ostinato is repeated nine times, passing from the right hand to the left hand at measure 28 (a gesture seen in Fauré's as well). A pedal effect is called for at measure 27, when the pianist is asked to hold the pedal down (tenuto). A chord, subset of the octatonic scale, is played is the bass and held with the sustained pedal for five measures. On top of this "harmony," a recall of melodic idea 1 is heard, ornamented with appoggiatura leaps of descending octaves (measure 28). This atmosphere goes on until measure 32 where a slightly modified version of 
melodic idea 1, played in octaves, is heard. At the same time, a texture made of repeated pitches is beginning to play a significant role. This quite unobtrusive device (pedal point) is used either to suggest harmony (partial or complete, built on fifths or octaves) or to keep the rhythm alive and going - although some ties seem to do just the opposite at times (see measures 33, 35, 38 and 39). The melodic chordal interval (fifths and octave) dies away and becomes a pedal point on a single pitch (A) at measure 50, shortly after the same chord from measure 27 has been heard again (measures 46 and 49).

Performers should pay close attention to pedal makings in that section. From measure 44 onwards, section B, Liebermann asks for a pedal tenuto and for a very long pedal afterwards. In fact, this pedal is also structurally very important; it permeates the entire B section—framed between two symmetrical zones, made of similar material (melodic idea 1,2, and 1', although the order of the musical material is slightly different when the A section comes anew). A new melodic idea (melodic idea 3) makes its appearance at measure 50 over a pedal point on pitch A. This idea is based on three chords played with grace notes (Ab, F, c\#). ${ }^{98}$

A transitional passage, loosely based on melodic idea 1 is played at measures 56 to 63 . At the beginning of this passage, both hands alternate in an evenly syncopated manner, briefly changing the feeling of $6 / 8$ to $3 / 4$. With the exception of measure 57 , the hands play in contrary motion, in the key of A major, until they settle back onto a rocking ostinato pattern built on an augmented fourth (D-G\#) which re-establishes the barcarolle-like motion of the 6/8.

The first four notes of the melodic idea 1 along with their accompanying counterpart are heard at measure $64-65,{ }^{99}$ followed by a measure rest (measure 66); then, the accompanying

98 If the c\# is respelled $\mathrm{d} b$, one can see tertian relationships in those three chords. The main notes of measures 5051 (thirds of the chords) become the initial grace notes in measures 52-53.

99 The first three notes were previously heard in the fabric of the music, accompanied by portion of a chord at measure 62 . 
pattern with melodic idea 3 superimposed (measure 67) and another measure rest (measure 68) occur right before the "real" return of the opening material at measure $69,\left(A^{\prime}\right)$. This section, measures 64 to 68, bathed in pedal as well (just like measures 27-31 and 44 onwards), works very efficiently; there, the "nocturnal" effect is quite powerful. Mere suggestions of melodic idea 1 and 3, combined with those complete measures of rest (measures 66 and 68) in which the sonorities are reverberating and floating around offer a partial explanation of that success.

The return of the opening material is almost left untouched, not decorated, contrary to what one would expect in such nocturnes (even Field was elaborating on returning material). Only the formal aspect of it is being revisited: measures 69-83 are a literal repetition of measures 2-16; measures 84-97 rework 17-22; measures 88-94 rework 32-49; measures 95-99 recall 23-27; and finally, measures 100 and following rework 64-68. Pedal point (octave D) appears at measure 88 in the upper register while the left hand plays melodic idea 1 . Shortly after, in measure 95, melodic idea 2 returns, shortened to six measures, with its rhythm disintegrating. Liebermann ends this section in a manner similar to how he ends the first part of section A (measure 21-22) and section B (measure 64). The final gesture, F\#, d\# and single pitch Gperhaps to reinforce the key of G, which was never there but acted only as a key signature-is very puzzling and a little unsatisfying, although it recalls the figuration, rhythm and register of measures 50-53 and also replays the very first pitches of the work.

A note should be made about the very long pedal mark at measure 88 , followed by ped. tenuto al fine at measure 95 . There is also the presence of this $f f$ sub. marking at measure 95, quite unusual for the ending of a nocturne, although it fades away gradually with a molto dim. to pp. These two points are early indications of what is to come in regard to Liebermann's use of pedal and dynamics in the genre of the nocturne. 
According to Nichols, Nocturne no. 1, op. 20 is convincing because of its lyricism and impressionistic style, and it is representative of Liebermann's compositional style for it includes elements in the tradition of nocturne-writing and also elements of his own creation. ${ }^{100}$ I can only agree partially with Nichols's view. Surely Liebermann shows a clear understanding of the style of the nocturne: a well-defined melody, singing in nature, over a somewhat discreet, unobtrusive accompaniment pattern, set in a simple ABA' form. However, I find that piece not yet characteristic of Liebermann's style: the harmonic language is much more wandering than his later, more directive manner; this early effort relies more heavily on extended transitional material and pedal points, and the rhythm is so consistent, especially when compared to the contrasts employed in later works, that it can become monotonous. ${ }^{101}$

This piece was written when Liebermann was still a student. When reflecting back on his style of composing of the time, Liebermann himself seemed to believe he was less convincing when writing in a more dissonant language. ${ }^{102}$ The very presence of that minor second interval (measures 26 and 98), played $s f z$ cannot be associated with the Liebermann of the following and more "convincing" Nocturnes. Nevertheless, the atmosphere of the nocturne is achieved, all the required elements are present: a very lyrical melody, a gentle accompaniment, a simple ternary ABA' form and a generous use of pedal. The dynamic markings which range from $f f$ to $p p p$ would suggest an attempt at making this Nocturne quite dramatic, in the lineage of Chopin; however, the musical material used, very similar throughout, almost negates that and gives the effect of a work more homogeneous in mood, and therefore closer in spirit to Field's.

100 Nichols, 94-95.

101 Discussion of this point must be postponed until the analysis of Nocturne no. 2, at which point the characteristics of Liebermann's style will become more apparent.

102 In an interview with Chang, Liebermann says: "I felt pressured to stick wrong notes into a passage to make it sound more modern or otherwise be accused of being old-fashioned" (Chang, 1). 
It took some nine years for Liebermann to revisit the genre of the nocturne for solo piano. As we shall see his compositional style had fully developed by then and had become something much more personal and organized, especially in its harmonic aspect.

\subsection{Nocturne no. 2, op. 31}

When asked if writing a piano piece for a specific performer oriented the way he was composing, Liebermann said no, it did not. ${ }^{103}$ On the other hand, one might suspect that writing a musical work to honor the memory of someone would somehow give a certain direction or bring a little flavor to the act of composing. Nevertheless, this being said, the fact remains that, beginning with Nocturne no. 2, Liebermann seems to launch a trend of associating the nocturne with a work dedicated to the memory of loved ones. Only looking within the corpus of the Nocturnes themselves, nos. 2, 3, 4, 5, 6, 8, 10 and 11 all have been written in such intention. ${ }^{104}$ Written in 1990 and published in 1996, Nocturne no. 2, op. 31 has only 44 measures but requires about seven minutes to be performed. It was commissioned by the Alumni Young Artists Inc., in memory of Steven De Groote ${ }^{105}$ and was premiered by Hung-Kuan Chen on March 28, 1990 at Alice Tully Hall, in New York City. ${ }^{106}$ In this work, Liebermann shows ingenuity in piano writing that was not displayed in its predecessor, Nocturne no. 1 . The material is much

103 Garner, 8-9; Kikuchi, 82; Winegardner, 178.

104 In an interview given to Kikuchi, Liebermann said about that specific issue: "It was just a form (the nocturne) I always liked, and a number of them are dedicated to people who have died. I kept getting commissions for short pieces in memoriam to people. So it seemed that a nocturne would be very appropriate for that." Kikuchi, 89-90.

105 Steven De Groote was a South African pianist. Born in 1953, he died in 1989 of organ failure due to AIDS complications. He was from a Belgian family which has been inclined very much towards classical music - his grandmother was a recipient of the Prix de Rome, his father was a conductor, and Steven himself toured often with his brother, a cellist. After winning the Van Cliburn competition in 1977, his career took off and he was heard on all the major international scenes, as a soloist and also with major orchestras and numerous chamber groups. He left behind some nine recordings. He is also remembered for his teaching at the University of Arizona and at the Texas Christian University (where he succeeded Lily Kraus) in Fort Worth.

106 Hung-Kuan Chen is a Chinese pianist, born in Taipei and raised in Germany. He won numerous important piano competitions. See Appendix B for more information or consult the artist's personal website at:

http://www.blackstoneartistsmanagement.com/hkchen/index.html 
more sharply defined (melody, rhythm and harmony) and is used with a clearer profile: formal aspect, key relationships, dramatic construction and super-imposition of many elements (multilayering). The following figure (5.2) highlights the formal aspect of Nocturne no. 2. Starting harmonies are indicated to highlight relationships.

Musical figure 5.2: Liebermann's Nocturne no. 2

\begin{tabular}{|c|c|c|}
\hline $\mathbf{A}$ & B & $\mathbf{A}^{\prime}$ \\
\hline $\begin{array}{ll}\text { - } & \text { intro (1-5) } \\
\text { - } & \text { m.i. } 1(6-9)[\mathrm{B} b] \\
\text { - } & \text { m.i. } 2(10-13)[\mathrm{F} \#] \\
\text { - } & \text { m.i. 1 (14-17) [C] } \\
\text { - } & \text { m.i. 2' (18-21) [C] }\end{array}$ & $\begin{array}{ll}\text { - } & \text { m.i. 2' (22-24) [C] } \\
\text { - } & \text { m.i. } 3(25-28)[\mathrm{B} b] \\
\text { - } & \text { m.i. 2' (29-32) [Ab] }\end{array}$ & $\begin{array}{ll}\text { - } & \text { m.i. } 1(33-37)[\mathrm{Bb}] \\
\text { - } & \text { m.i. } 2(38)[\mathrm{F \#}] \\
\text { - } & \text { coda m.i. 3(39-40) [B b] } \\
\text { - } & \{\text { cf. intro }(41-44)\end{array}$ \\
\hline
\end{tabular}

The whole work can be understood as being of the ABA' formal type, with three principal melodic ideas (the third one being closely related to the first one) and a simple accompaniment pattern which is constantly adjusted to accommodate the melodic material. Throughout the Nocturne, the musical material is tightly unified either by stepwise or by tritone relationships. Liebermann uses numerous sonic possibilities of the instrument, exploiting all registers. The musical gestures show great embellishments throughout but in a very new way (not seen in Nocturne no. 1) —one would say in a very "pianistic" way, more for coloration and atmosphere than carrying any vocal quality. An excellent example is the figuration first introduced in measure 25. These qualities demonstrate Liebermann's profound debt to Fauré's Nocturnes. 
Precise pedal markings are abundant and are used in several structural ways, beginning with establishing atmosphere by blurring conflicting harmonies (measures 18, 30-31 and similar). They also serve to establish contrast in between different sections' use of the same material. This can be seen by comparing measures 10 and 18 , or 12 and 20 , with transpositions of the same material, wherein the seven pedal markings in measure 10 and 12 create a quicker harmonic rhythm than the single pedaling in measure 17-18 and 20.

The piece begins with a short introduction of five measures, played by the left hand alone, which eventually establishes the key of $\mathrm{B} b$. The tertian ambiguity F-D, F-D $b$ is later understood as part of a complex $\mathrm{B} b$ chord with both its major and minor mediant members. The accompaniment outlines the chord and also includes a few foreign tones. The range is quite narrow but soon expands - for clarity of its implicit lines or for sonic purposes or both — after the melody enters (measure 6). The following musical example (5.2.1) shows the introduction and the beginning of musical idea 1. 
Musical example 5.2.1: Liebermann's Nocturne no. 2, measures 1-6
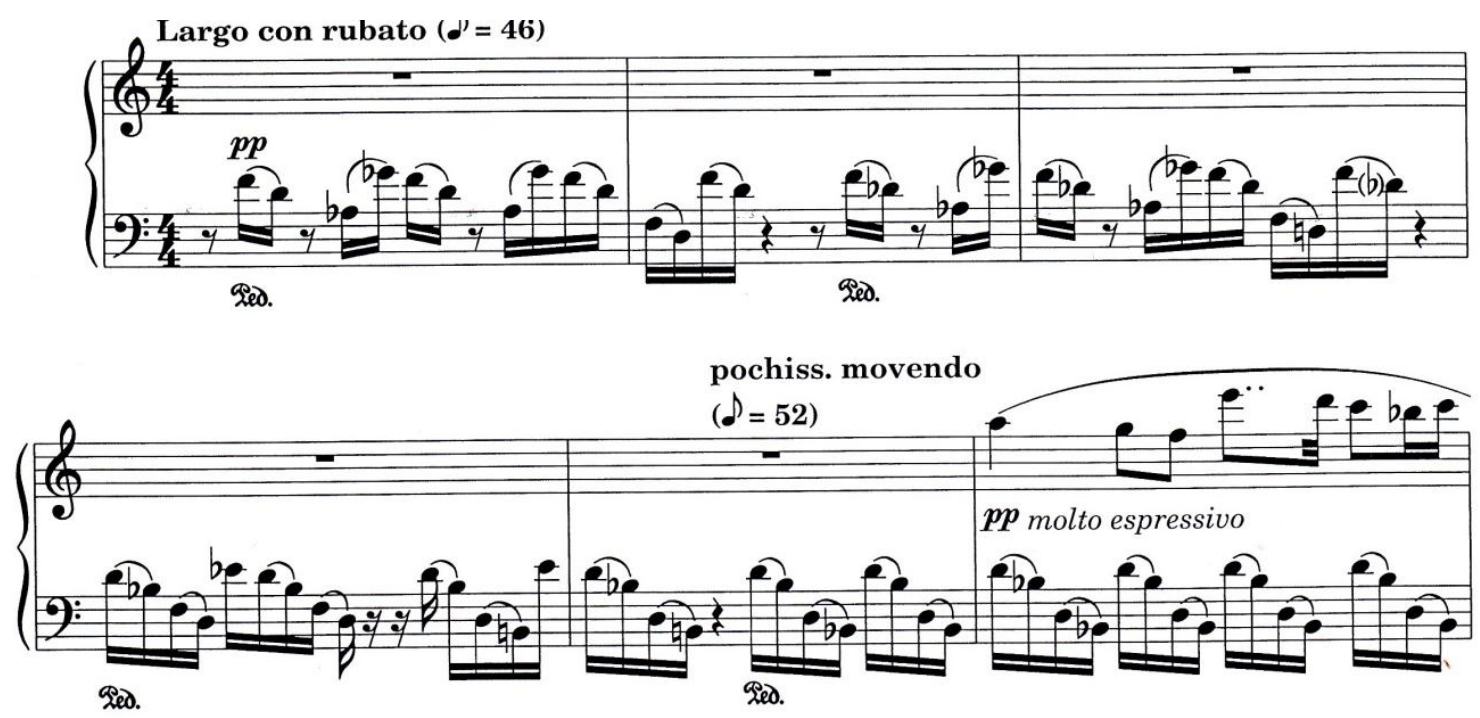

C1 1996 by Theodore Presser Co., Used With Permission

In regard to harmony, three elements play a crucial role in creating the larger structure:

tertian relationships (with the help of enharmonic respelling), tritone and whole-step

relationships. From measure 6 onwards, one sees a motion from $\mathrm{B}^{b}$ to $\mathrm{G}^{\mathrm{b}}$ (also understood as $\mathrm{F} \#$ )

to D (and "back") to F\# and then to ED (D\#), a clear tertian march. A similar motion is

encountered at measures 13-18, although at that moment a tritone ${ }^{107}$ higher: $\mathrm{C}$ to $\mathrm{A} b(\mathrm{G \# )}$ to $\mathrm{E}$

and back to $\mathrm{C}$. This harmonic progression is achieved through common tones: the $\mathrm{B} b$ of the first chord becomes the mediant of the following $\mathrm{G}^{b}$, this $\mathrm{G}^{\mathrm{b}}(\mathrm{F \#})$ becomes the mediant of the $\mathrm{D}$ major chord that follows, of which the mediant F\# becomes the root of the next F\# (Gb) chord, of which the mediant $A \#(B b)$ becomes the fifth of the $E b$ chord. This kind of harmonic progression is typical of Liebermann and permeates the whole fabric of this Nocturne which, as we will see, relies heavily on tritone relationships to create continuity and connectedness.

Musical example 5.2.2 displays another instance of musical idea 1 (relationships of a whole step

$107 \mathrm{~Gb}(\mathrm{~F} \#)$ is at the distance of a tritone to $\mathrm{C}$. 
up from the previous appearance at measure 6) and melodic idea 2 (relationships of tritone in regard to the previous presentation at measure 10).

Musical example 5.2.2: Liebermann's Nocturne no. 2, measures 14-18
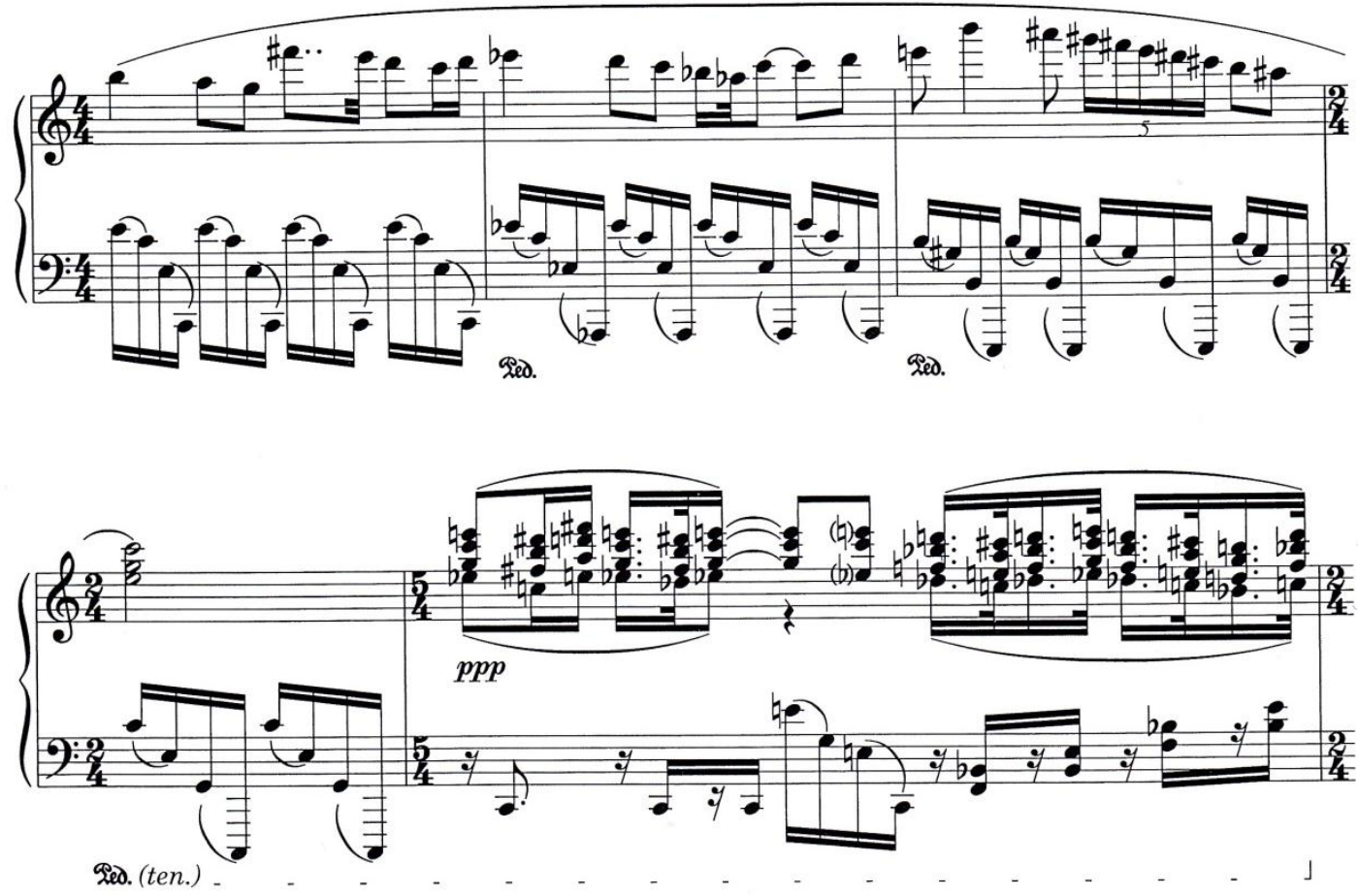

C1996 by Theodore Presser Co., Used With Permission

The music found from measures 14 to 16 is a restatement of the material heard at measures 6 to 8; but this time, melody and harmony are presented a whole-step higher. The ultimate measures of both segments — which was labelled melodic idea 1—are showing tritone relationships: measure 9 being in F\# and measure 17 being in $\mathrm{C}$.

On a more local aspect, starting at measure 18, numerous chords are made of both their major and minor elements, which are to say that a $\mathrm{C}$ chord will often include the tones $\mathrm{E}$ and 
Eb. ${ }^{108}$ This "new" sound which was not seen in the previous Nocturne will be encountered on many occasions in the following ones (for example see: Nocturne no. 3, measures 15-19, 20-23, 24-26, etc; Nocturne no. 4, the ostinato pattern at measures 1-3, 24-26, 38-43, 44-45, 46-47, etc; and Nocturne no. 11 measures 21-23).

Melodic idea 1, quite lyrical, beautifully simple, is made of scalar elements with occasional leaps of sevenths (octave displacement of this step-wise moving line) or fifths. A very distinctive feature of this melody is the constant presence of the raised fourth, a characteristic of the Lydian mode. ${ }^{109}$ This melodic idea is heard at measures 6-9, and then repeated one-step higher at measures $14-17 .{ }^{110}$ The superimposition of the "Lydian" melodic material to a more tonally conventional accompaniment conveys a feeling of bi-tonality: the accompaniment written in $\mathrm{B} b$ and the melody which seems to belong to the key of F. Moreover, the presence of this characteristic Lydian feature, the raised fourth, is also mimicked on a larger organizational level through the omnipresent unifying tritone relationships. It seems that the use of the Lydian mode could not only link Liebermann to Fauré but to Chopin as well. Chopin's use of the raised fourth is well documented in regards to his Mazurkas - a genre where he was quite adventuresome harmonically and melodically speaking. Among the plentiful examples, one can cite: Mazurkas op. 24 no. 2, op. 41 no. 4, op. 56 no. 3, and op. 68 no. $2 .{ }^{111}$ That being said, it also appears that Chopin's use of the Lydian mode in his Nocturnes is a more discreet and sparser.

The raised fourth degree is present but seems to be used more for melodic direction, acting either as a lower or as an upper neighbor tone (for example: Nocturnes op. 9 no 1, measure 4; op 9 no.

108 When the same material was heard previously at measures 10-13, chords were constructed in a more traditional manner, simply majors or minors. In this very instance, the harmonic treatment helps delineate larger structures. 109 We observe this predilection for the raised fourth in many other melodies of Liebermann. Nocturne no. 3 is another striking example. In Liebermann's music, the raised fourth carries melodic, harmonic and structural implications.

110 I believe that there is an error at measure 15 in the melody: a dot is required after the $\mathrm{B} b$ of the third beat, in order to make the rhythm exact, for it is the very same as the one found at measure 7.

111 Richard L. Crocker, A History of Musical Style, (New York: Dover, 1966), 448; Kirby, 295. 
3, measure 88; op. 15 no.1, measure 25; op. 27 no. 1 , measures 30 and 34; and op. 9 no. 3 , measure 9). Therefore, these manifestations of the raised fourth fall more into the category of traditional established practice of ornamentation of the period (nineteenth century) than of a "pure" Lydian approach. If the connection to Chopin cannot be established through the usage of the Lydian mode, a different and very interesting melodic link between Chopin and Liebermann could very well be the emphasis of both the minor and the major third degree of the scale. A striking example is provided in the opening of Nocturne op. 27 no. 1, (measure 3); in this instance, Chopin boldly uses both mediants in the melody, while Liebermann confines the use the two thirds to the accompaniment.

In Liebermann's Nocturne no. 2, melodic idea 2, narrower in range, is presented in a chordal manner with its short sinuous line in the soprano. It immediately follows musical idea 1, and is heard at measures 10-13 and then repeated a tritone higher in measures 18-21 with some adjustments (the harmonic motion outlining the progression F\#-E $b$ and is responded to by a progression $\mathrm{C}-\mathrm{B} b$ at measures $18-21$ ). The next time melodic idea 2 is heard, it is slightly varied (musical idea 2' at measures 22-24) and it is much more dramatic in its presentation (dynamic and accompaniment); this dramatic texture marks the beginning of section B.

Thus, section A, pp molto espressivo is made of two musical ideas alternating with one another, supported by downwards arpeggios which highlight tertian motion and stepwise or tritone relationships. Once again, the importance of tritone relationships should be noted. There is a big change of character at measure 22. Dynamic marking is $f f$, with marcato signs over each element. Close in nature to melodic idea 2, it is also different for it includes dissonances of minor seconds throughout. The following musical example (5.2.3) shows musical idea 2'. 
Musical example 5.2.3: Liebermann's Nocturne no. 2, mm. 21-23
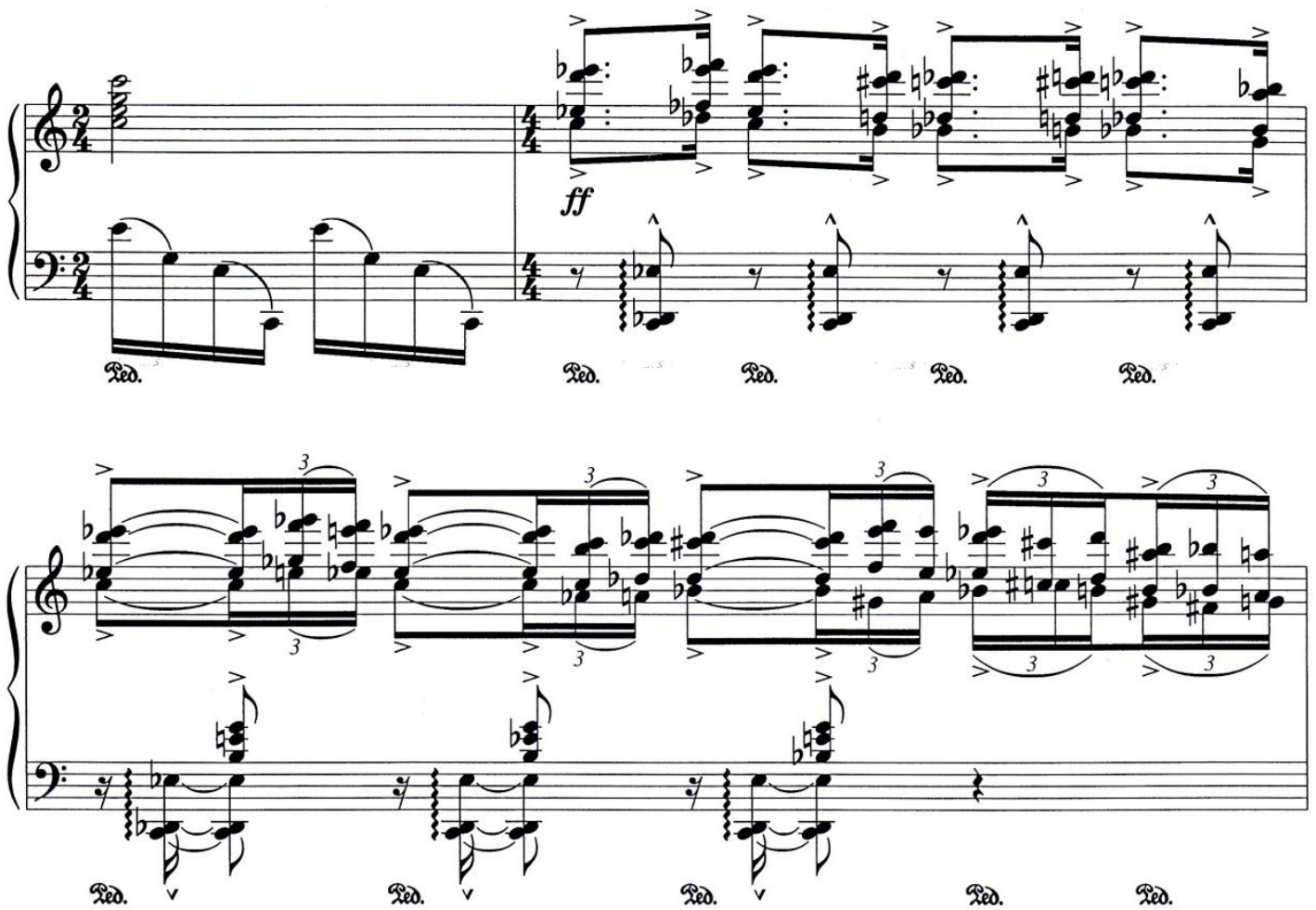

C1996 by Theodore Presser Co., Used With Permission

One extra bar of this material is played pp, at measure 24 like an echo, creating a very impressionistic effect and setting the way for a new melody (melodic idea 3), in B b, highly embellished with octave leaps covering the span of three octaves to return. However, the scalar elements of this material derive directly from musical idea 1. Musical example 5.2.4 displays melodic idea 3. 
Musical example 5.2.4: Liebermann's Nocturne, no. 2, mm. 24-28
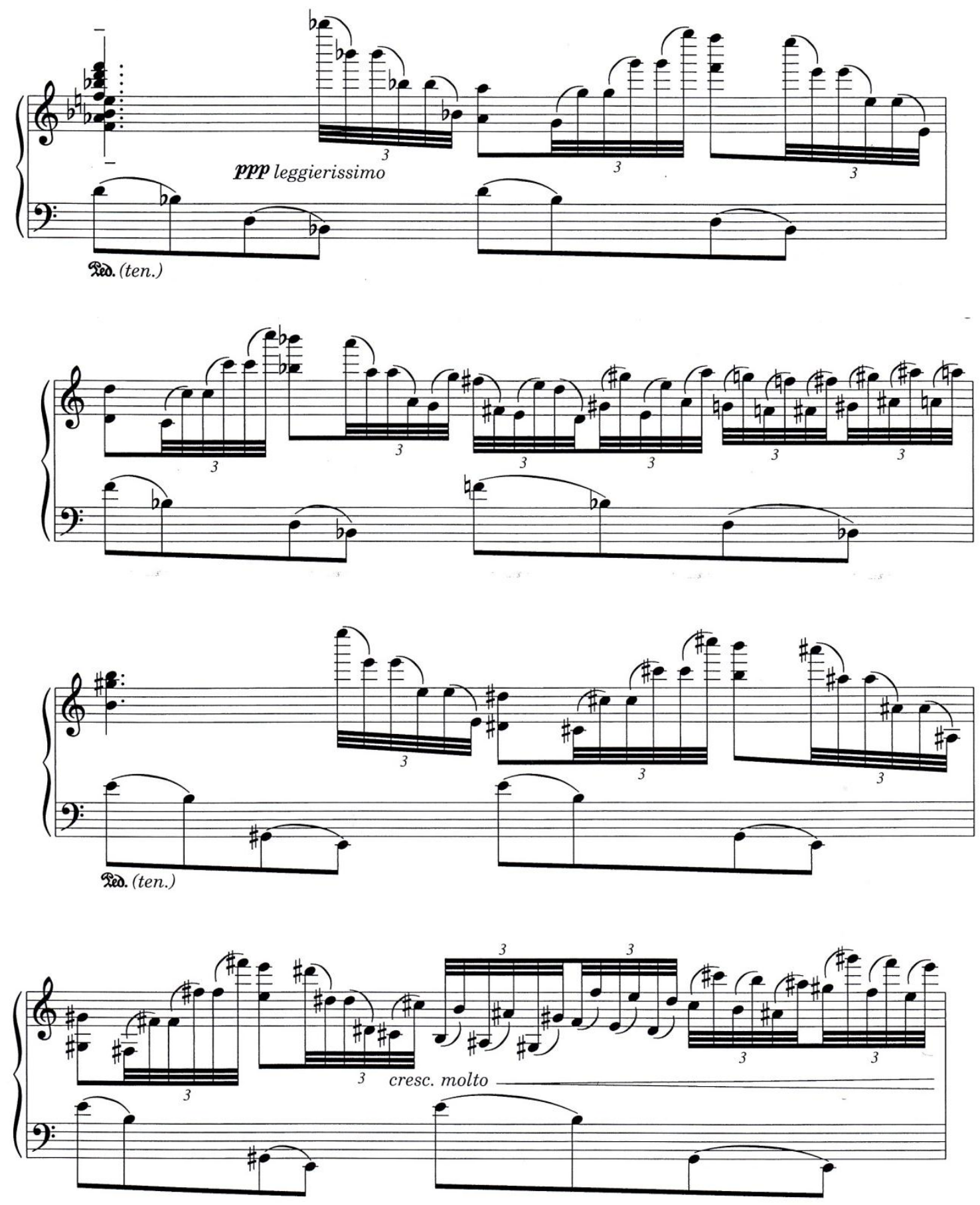

C1996 by Theodore Presser Co., Used With Permission 
The modified melodic idea 2 (2') appears again at measures 29-32, in a quite dramatic setting: ff, marcato. At measure 29, one can see a rapid alternation between the harmonies of $A b$, $\mathrm{C}, \mathrm{A} b, \mathrm{~B} b, \mathrm{~F}+, \mathrm{e}, \mathrm{B} b, \mathrm{~F}^{+}, \mathrm{e}, \mathrm{Eb}$ (in the upper parts). Sometimes conflicting harmonies are even played together. Later on, a sustained long pedal, held down for two whole measures, blurs the harmonies of C-F\# (measure 30) plus B b-E (measure 31), once again highlighting tritone and step-wise motions. The small and quick arpeggiated gesture of the left hand already seen at measure 22 becomes, at measure 29 and onwards, an arpeggio covering a distance of more than four octaves. This is quite effective pianistic writing. At measure 29, the motion in the lower part of the keyboard to which melodic idea 2' was superimposed-played by both hands in big block chords - is a good illustration of Liebermann's conception of music of multi-layer nature. ${ }^{112}$ Measures 29 to 31 not only represent the dramatic climax of the work but also include the busiest harmonic and pianistic activity.

At measure 32, a B b chord is clearly heard; the pedal marking is precise and calls for a "clean" harmony. This is in preparation for the return of the opening material. In this section, $p \boldsymbol{p}$ (la melodia ben legato e cantando), melodic idea 1 is played with its accompaniment in the very same manner as it was done at the beginning of the piece (measure 6) and, on top of it, in a very high register, a new layer is added: octave filigrees are cleverly decorating the musical material. Thus, Liebermann combines material from measure 6 with that of measure 25 while providing a nice challenge for the performer because the right hand has to play the melody pp, calmly, beautifully and at the same time, manage to play those rapid octaves ppp without affecting the clarity of the line.

112 I believe there is another error at measure 29: there should be natural signs in front of both E's, middle register, played by the left hand, part of the second beat, last sixteenth note. 
Two measures of polyrhythm (5 against 4), an expansion of elements heard at measure 8 and at measure 16, appear right before the head motive from melodic idea 2 is played again at measure 38, this time, augmented (sixteenth notes became quarter notes). Those two measures encompass another tertian motion (D-F-A b-C $b$ before settling in D). Interestingly, the common tones are now shifted to fifths and thirds, instead of thirds and roots as seen in the previous harmonic motions: A from D Major chord becomes the mediant in F, of which, the C (fifth) becomes the mediant in $\mathrm{A} b$, of which Eb becomes the mediant in $\mathrm{C} b(\mathrm{~B})$ and so on, the roots ascending rather than descending. Moreover, this progression of major chords, by way of its construction, is also underlying the duality of major-minor mediants. The D chord (mediant F\#) is followed by $\mathrm{F}$ Major, on which the mediant $\mathrm{A}$ is followed by $\mathrm{A} b$, from which the mediant $\mathrm{C}$ is followed by $C b$ from which the mediant $E D(D \#)$ is followed by $D$.

Finally, in what can be perceived as a small coda of 6 measures, melodic idea 1 is heard again, in $\mathrm{B} b$, with its octave embellishments. The rhythm disintegrates in a sort of written-out ritardando, passing from groups of sextuplets, to quintuplets, to quadruplets, to triplets, to slower duplets and into a single quarter note held tenuto in the pedal, while the music is completely disappearing to almost nothing, diminuendo (al) niente. ${ }^{113}$

It is quite fascinating to see that in this Nocturne, local events are reproduced on a larger level. Specifically, the melodic inflection of the raised fourth (a distance of three full steps) is mimicked in those tritone relationships when similar material is being replayed. For example, melodic idea 2 is heard in the key of F\# at measure 10 and when it comes back at measure 18, it is played in the key of C. Moreover, similar tritone relationships can be observed when comparing material found at measure 12 in d\# and measure 20 in a, and also in the interplay of

113 For the two chords in measure 43, I take the lower element D of the right hand with the left hand first, then, I pass it to the right hand without sounding it anew. One gets a better voicing that way. 
adjacent harmonies $\mathrm{B}$ b-E at measures 25-26 and 27-28, C-F\# at measure 30, and B b-E at measure 31 .

It has already been posited that Nocturne no. 1 is not very characteristic of Liebermann's style. A scrutinizing look at the handling of the dynamics also provides munitions to this hypothesis. While the dynamics rest in the softer side of the spectrum, ranging from pppp to a very short and episodic (one beat) ff subito in Nocturne no. 1, beginning with Nocturne no. 2 and later Nocturnes, a clear attempt at making the genre more dramatic (with content and also with dynamics) can be observed. The louder sections occupy a much larger portion of the respective works. In Nocturne no. 2, the range of dynamics is from ppp to fff, and the fortissimo and fortississimo sections last for five very long measures. Other following Nocturnes will reach a level of intensity rarely seen before in character pieces of the same genre (for example: see Nocturne no. 3 measures 53-57 and Nocturne no. 4 measures 46 to 54).

Of Nocturne no. 2, Faubion Bowers of Musical America said: "This plaintive, mournful excursus into neo-Romanticism is half-Scriabin, half-Chopin, and wholly Liebermann" and I completely agree with him. ${ }^{114}$ The dues to Chopin might be obvious in regard to the dramatic conception of the middle part and to the embellishments which are added to the melody. However, many harmonic and structural gestures do in their nature emulate Fauré's; with its multi-layer conception, and a truly personal approach to harmony and relationships between material, this is the first true Nocturne — of a long series - that carries the indisputable imprint of its creator.

Liebermann's musical language has emerged more assertively through his Nocturne no. 2 and a few new characteristics of Liebermann's style will be learned from a close look at his http://www.presser.com/composers/info.cfm?Name=LOWELLLIEBERMANN\#Reviews 
Nocturne no. 3. As mentioned by everyone who has studied the music of Liebermann, his compositional style is made of elements of the past mixed with elements of the present flavored with his own personal touch. ${ }^{115}$ A summary of what has been observed already in Nocturne no. 2 and a preparation for what will be seen in the later Nocturnes is instructive.

Among the elements of the past, one can identify:

- long lyrical melodies often simple and diatonic or, sometimes more disjointed and chromatic;

- the harmony is quite consonant using basic triads; extended chords are rare;

- the rhythms display regularity and are organized around a steady beat; some occasional changes of meter occur but they usually do not affect the flow of the beat;

- a predilection for shorter forms (ABA'), with each section often made up of two or more musical ideas;

- the conception of the piano sound is quite romantic (especially in the Nocturnes); it is most likely to be expressed by a basic melody and a simple accompaniment structure.

Among the new elements and the more personal approach one can observe:

- incorporation of chromatic alterations (raised fourth) and unexpected turns; appoggiatura-like descending half steps; melodic organization which displays modal borrowings - particularly form the Lydian mode (raised fourth) and the Aeolian (lowered third, lowered sixth and seventh); utilization of the octatonic scale;

- root progression is typically by third rather than fifth; simultaneous use of major and minor modes within a single chord are a typical trademark and are abundant; ambiguous enharmonic spelling is common along with chord mutation and distant key relationships; adjacent harmonies share common tones;

- impressionistic use of the harmony, often done by blurring many chords into the same pedal; the damper pedal (and, to a lesser extent also, the una corda) plays a crucial role in giving coloristic effect and can even delimit larger structural elements;

- within the same metrical framework there can be many rhythmic complexities like: polyrhythm, diminution and augmentation; certain short passages could be called developmental; imitation or canonic treatment of the material is quite common;

- ostinati play an integral part of the texture and of the structure of the piece; they also serve to establish (or reinforce) tonality;

115 The following list was made from information collected from: Chang, Clark, Dennis, Garner, Kenaston, Kikuchi, Lim, MacArthur, Nichols and personal observations. 
- increase of the rhythmic activity is used to generate energy and its opposite to decrease the intensity;

- dynamic extremes are plentiful;

- the music is made of multi-layer or stratified textures;

- ornamentation is present but more pianistic in nature and therefore more for creating an atmosphere than purely to embellish a melody;

- pedal tones provide unity within and between smaller sections.

Nocturnes no. 3 to no. 8 all share similar compositional features and conception. ${ }^{116}$ And, although there is a stylistic evolution, they still perfectly fit into the above-mentioned elements. Starting with Nocturne no. 9, there seem to be numerous experimentations with the genre, something similar-in some aspects—-to what we saw with Fauré's later Nocturnes; this will be further addressed in the course of this research paper.

\subsection{Nocturne no. 3, op. 35}

In 1991, Mr. and Mrs. Arthur Gurwitz commissioned Liebermann to compose a piece to honor the memory of their son, Andrew Russell Gurwitz, ${ }^{117}$ to be played as part of the San Antonio International Keyboard Competition; it became Nocturne no. 3, op. 35, a musical work of 131 measures and a duration of about six minutes and thirty seconds. It was first performed by Richard Dowling on October 19, 1991, at the Ruth Taylor Concert Hall of Trinity University, San Antonio, Texas. ${ }^{118}$ This Nocturne was described as "unutterably lovely" and "exquisite" by the critics. ${ }^{119}$ Musical figure 5.3 shows the formal aspect of Nocturne no. 3 .

116 This does not deny the fact that Nocturnes no. 6 and no. 8 are more motivic in nature. Many stylistic features labelled as Liebermann's are still abundant in those two Nocturnes, regardless of the treatment of the material.

117 Even though Andrew Russell Gurwitz studied piano briefly, he held a degree in History from University of Texas. After graduating he went to work for the family business, Southern Music Company. He died tragically at the age of 28 of complications related to Pilonidal cyst. His parents - of whom the mother holds a Bachelor degree in piano - commissioned a piece to be played as part of the San Antonio International Piano Competition. Lowell Liebermann was the first of nine composers to write a piano work for the competition. [Email exchanges with Mrs. Gurwitz, July 2011]

118 Richard Dowling is an American pianist, based in New York and in Texas. See Appendix B for more 
Musical figure 5.3: Liebermann's Nocturne no. 3

\begin{tabular}{|c|c|}
\hline $\mathbf{A}$ & $\mathbf{B}(15-38)$ \\
\hline $\begin{array}{l}\text { - } \operatorname{intro~(1-2)~[B]} \\
\text { - } \quad \text { m.i. } 1(3-9 ; 10-14)[B]\end{array}$ & $\begin{array}{l}\text { - } \text { m.i. 2 (17-20) [C]; (21-26) [B] } \\
\text { - } \quad \text { canon on m.i. } 1 \text { (27-30) [Bb] } \\
\text { - } \quad \text { m.i. 2' (31-38) [D] }\end{array}$ \\
\hline $\mathbf{C}$ & $\mathbf{D}$ \\
\hline $\begin{array}{l}\text { - } \text { m.i. 1+2' (39-43) [F] } \\
\text { - canon on m.i. } 1 \text { (44-65) [B b-E-B b-B] }\end{array}$ & $\begin{array}{l}\text { 3-voice canon on m.i. } 1 \text { (66-97) [B-E] } \\
\text { 8-note ostinato bass }\{\text { B-D-C\#-A-G\#-D-D\#-C }\}\end{array}$ \\
\hline $\mathbf{A}^{\prime}$ & $\mathbf{B}^{\prime}$ \\
\hline - m.i. $1(98-106 ; 107-112)[\mathrm{B}]$ & $\begin{array}{l}\text { - } \text { Duet m.i. 2+2' (113-124) [E] } \\
\text { - } \text { m.i. } 1(123,125)[\mathrm{D}] \\
\text { - } \operatorname{coda}[\mathrm{B}]\end{array}$ \\
\hline
\end{tabular}

Nocturne no. 3 is made of four distinct sections of music of which the first two return at the end, thus producing the form $\mathrm{ABCDA} \mathrm{B}^{\prime} \cdot{ }^{120}$ Very similar musical material to that seen in Nocturne no. 2 is encountered here (third-related harmonies, tritone relationships and multilayered textures); in addition, canonic treatment plays a crucial role in this musical work.

information or consult the artist's personal website at: http:// www.richard-dowling.com/

119 Mike Greenberg, San Antonio Express-News; Diane Windeler, San Antonio Light; taken from: $\mathrm{http}: / / \mathrm{www}$.presser.com/composers/info.cfm?Name=LOWELLLIEBERMANN\#Reviews

120 By merging A and B sections together, Lim's reading of the form becomes ABCA' (table p.83). In my opinion, this view does not take in consideration the structural importance - and differences - of the return of the B section at the end, in which the two subordinate musical ideas are interacting in a very tight and beautiful canon. It should be noted that numerous quotations of material contained in previous sections generate a form quite similar to Fauré's approach. 
A short introduction of two measures establishes the key of B through a very ingenious rhythmic grouping of elements of the major chord. This simple accompaniment figure, based on a three-note motive going down in the soprano line and a simple alternation between the pitches D\# and F\# in the alto part, creates some sort of polyrhythmic effect; considering the value of the sixteenth notes (32), the soprano line is schematized by: $2+2+2+3+3+2+2+4+4+2+2+2+2$, while the alto line is expressed by: $6+3+2+8+3+3+7$, both played by the right hand, at the same time. This motion gives impulse to the melody and provides material that will be fashioned into a new accompaniment in the following section (section B: measures 17-38). The following musical example (5.3.1) displays the opening rhythmic gesture.

Musical example 5.3.1: Liebermann's Nocturne no. 3, measures 1-2

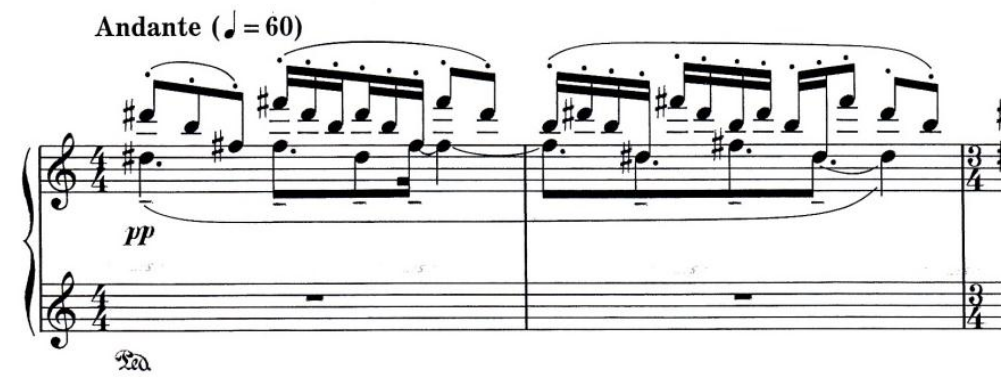

(C)1994 by Theodore Presser Co., Used With Permission

The first melodic idea (melodic idea 1) enters, played by the left hand, at measure 3 with the typical raised fourth from the Lydian mode and a few chromatic inflections (lowered second, lowered sixth and lowered seventh, almost Phrygian in spirit, see measures 7, 12, 13 and 14). It follows its course through a series of third-related harmonies, as similarly seen in Nocturne no. 2 (that is, through common tones), with some occasional adjacent harmonies set apart at distance of a half step. Hence, the melody is accompanied by triads of B, D, C\#, A, Ab, D, Eb, C, B. 
Musical example 5.3.2 displays melodic idea 1.

Musical example 5.3.2: Liebermann's Nocturne no. 3, measures 1-7
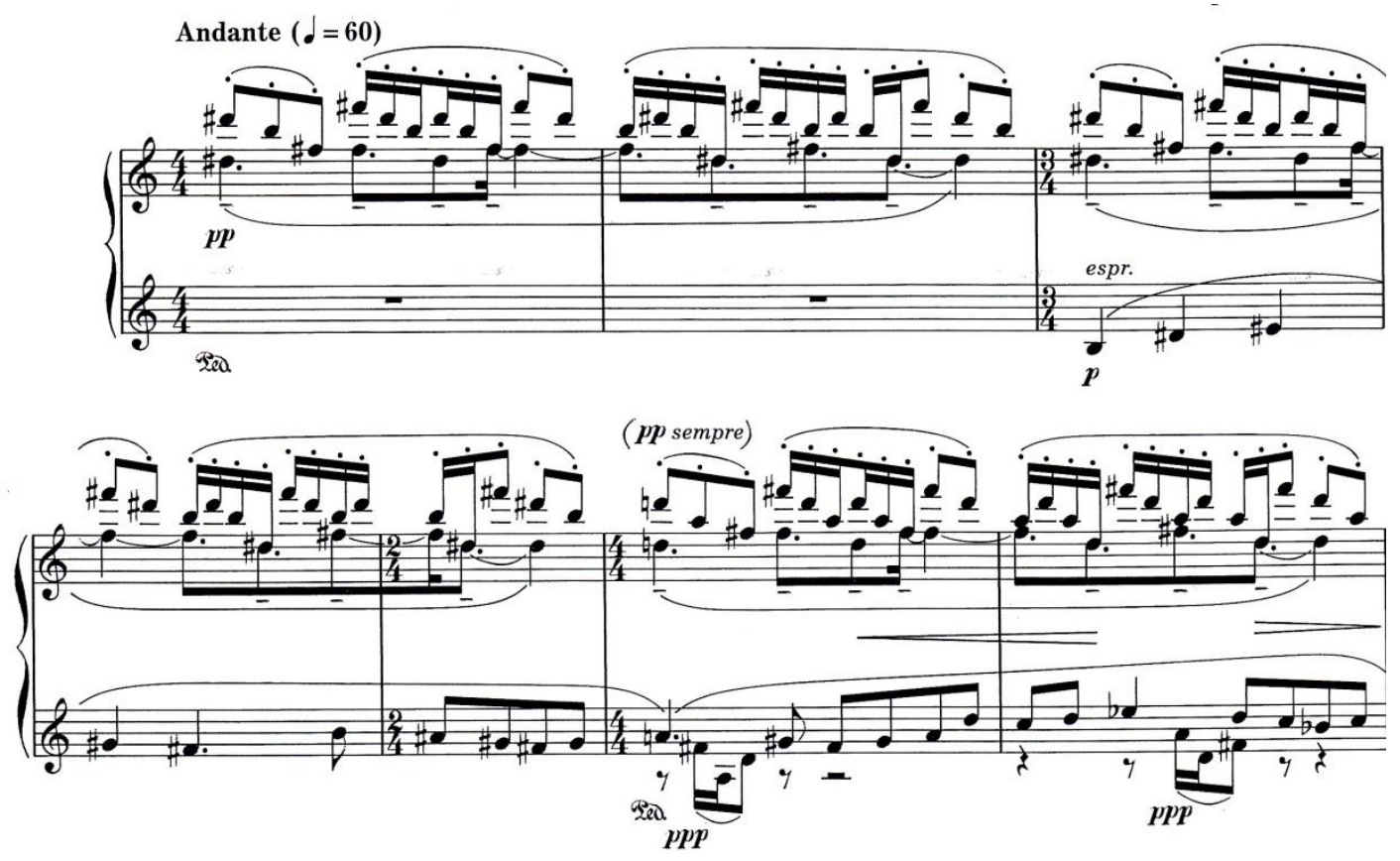

(C)1994 by Theodore Presser Co., Used With Permission

The section beginning at measure 15 (section B) shows Liebermann building chordal entities made of their major and minor mediants. They are cleverly dispatched between different registers of the piano in order to create a very sensuous musical fabric on top of which two new melodies, very similar in style, make their appearances. The first secondary melody (melodic idea 2) is heard at measure 17 (C major-minor with raised fourth, lowered sixth, and lowered seventh—spelled as raised sixth), repeated again a half-step lower at 21 (B). Obviously, those "modal inflections" could also be viewed as chromatic neighbor tone motions: Ab and F\# as upper and lower neighbors of G, and A\# as lower neighbor to B. The following musical example (5.3.3) shows melodic idea 2 and the new accompaniment pattern. 
Musical example 5.3.3: Liebermann's Nocturne no.3, measures 16-23
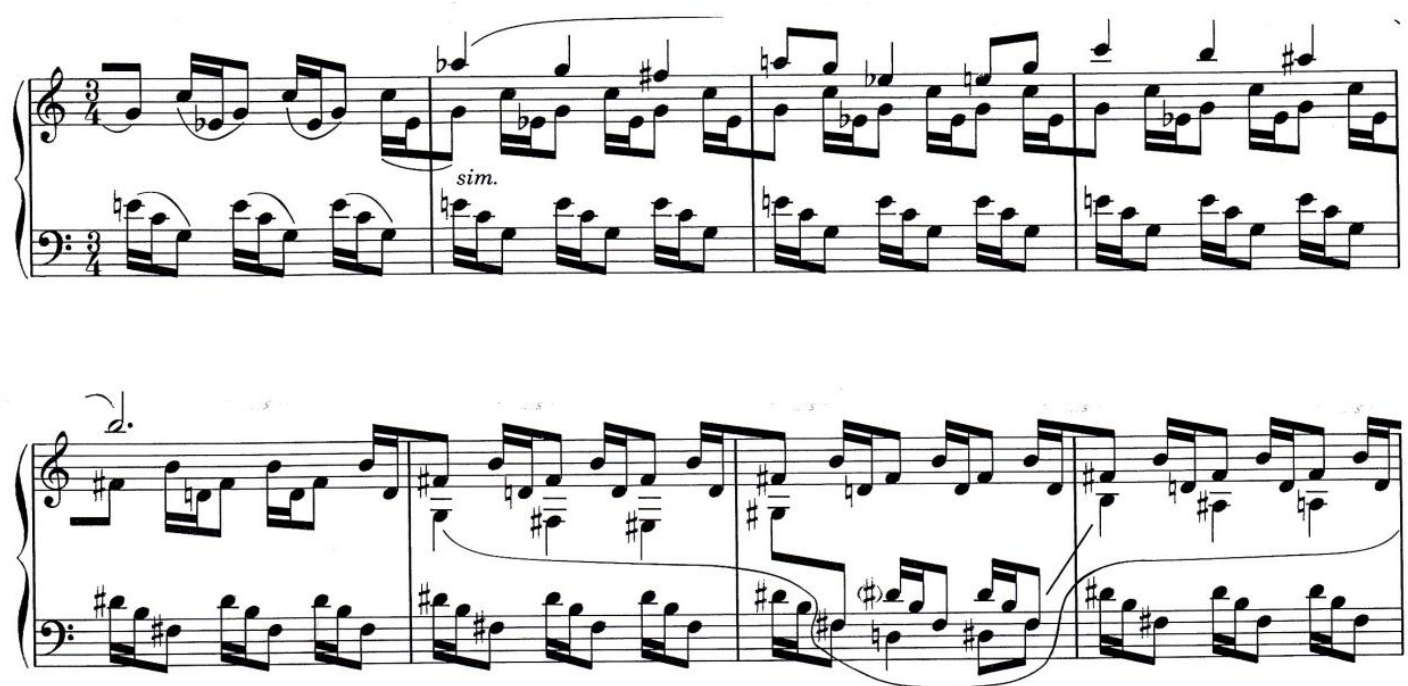

(C1994 by Theodore Presser Co., Used With Permission

A very interesting feature, which will bear a significant importance in this work and in the Nocturnes to come, is used by Liebermann for the first time in this genre. I am referring to canonic writing. There is a short return of the first five notes of melodic idea 1 at measure 27, and it is treated canonically, in the bass register, at the distance of an octave and three beats apart (one measure). At measure 29 the harmonic background is enriched with the inclusion of the seventh into the major-minor chordal entity.

At measure 31 melodic idea 2' is heard for the first time. It unfolds smoothly until measure 39, where a change of texture in the accompanying part occurs, initiating section C. This section brings the Nocturne to a dramatic climax with increasing dynamic intensity (from ppp to $s f f f z$ ) and increasing rhythmic activity (eighteenth notes to dectuplets). It also conveys a feeling of acceleration by tightening the canon. At first, the parts are $31 / 2$ beats apart at measure 44, with a dynamic mark of $\boldsymbol{m p}$; and then they are $21 / 2$ beats apart at measure 49 , with a 
dynamic mark of $\boldsymbol{m f}$; they move closer, to be $1 / 2$ beat apart at measure 51 , with a dynamic mark of $f f$ cresc.; finally, hands play together at measure 53 with a dynamic mark of $f f f$. All those elements (tightening of the canon, rhythmic activity, dynamics) are combined together in this passage, which culminates in a cadenza-like section alternating $\mathrm{B}$ and $\mathrm{F}$ chords - another instance of those significant tritone relationships — set into the extreme registers of the piano, at measure 56. Thereafter, the hands travel in opposite directions, coming closer, until they meet in the middle pp e legatissimo, at measure 58, after a diminuendo molto. The harmonic shifting of tritones is followed by a passage of triads related successively by thirds and semitones $(\mathrm{B}, \mathrm{F}, \mathrm{B}$, D, C\#, A, A b, D, Eb, C, F, B). This brings us to a section built on an ostinato pattern (section D). Ostinati have played an important role in Liebermann's writing in the past, but not until this point within the Nocturne per se. ${ }^{121}$ At measure 66, we have an eight-bar entity, melodic and rhythmic, repeated four times (measure 66, 74, 82 and 90), which remains immovable; meanwhile a full-scale three-voiced canon is unfolding. Nichols mentions that at times Chopin has used counterpoint to enrich the inner voices of an accompaniment. ${ }^{122}$ Nichols also uses the Ballade op. 52 (Ballade no. 4, measures 135 and following) of the same composer to illustrate canonic insertion into a character piece; however he failed to give a pertinent illustration of a canonic use taken from the nocturne repertoire.

As we have seen in the previous chapter, Fauré, more than any other nocturne composer, has shown interest in counterpoint, imitation and canonic treatment in his Nocturnes on numerous occasions. He never used the canon per se as intensely and systematically as

\footnotetext{
121 Surely, one can argue that the constant recurrence of the opening accompanying figure can be perceived as an ostinato but the fact that it changes to accommodate the harmonic setting of the melody somewhat negates the very nature of the ostinato. Nevertheless, if measure 1-2 motive is a rhythmic ostinato, then measure 66-73 is a melodico-rhythmic ostinato almost acting as a chaconne bass line. It is repeated unchanged four times consecutively (measures 66-97).

122 Nichols, 107-109.
} 
Liebermann has, but nevertheless he planted the idea in that fertile soil. Clear examples of imitation appear in one of his early and one of his late Nocturnes. The following examples (5.3.4 and 5.3.5) show such imitation in an early and in a late Nocturne by Fauré.

Musical example 5.3.4: Fauré's Nocturne no. 4, measures 44-47, an early Nocturne

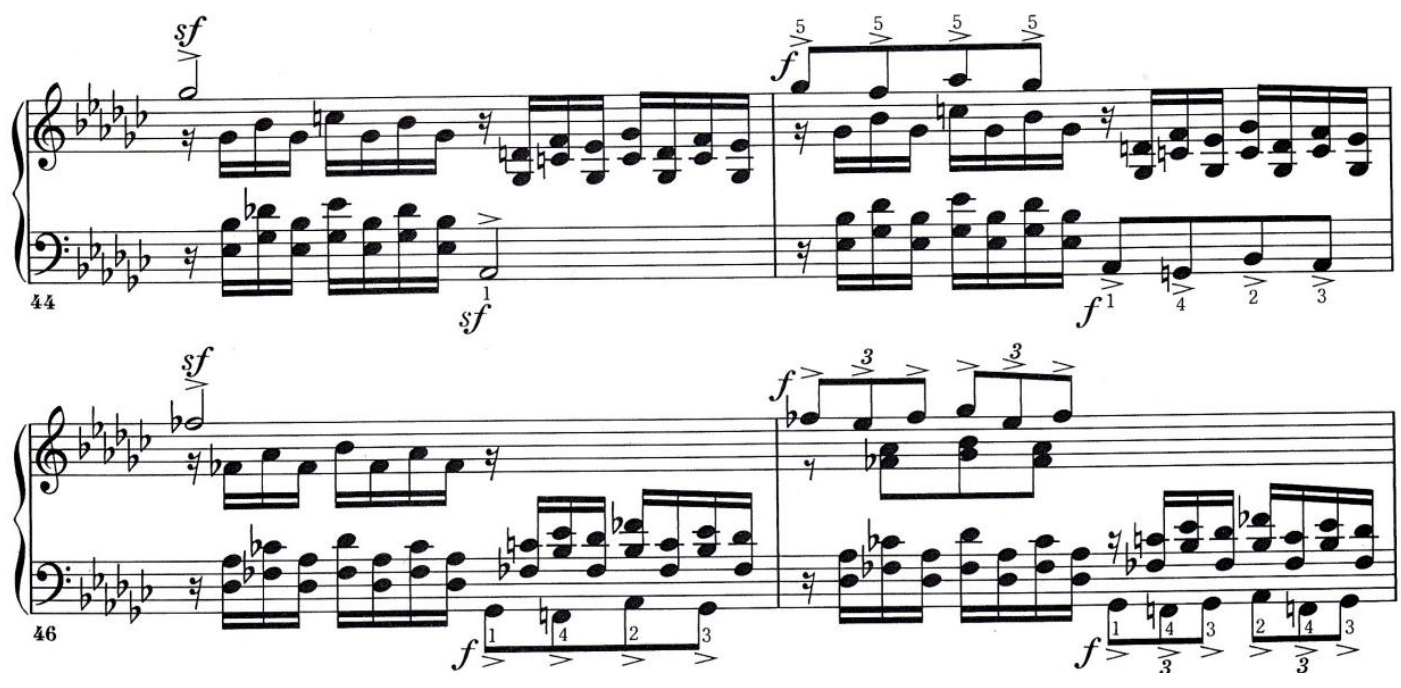


Musical example 5.3.5: Fauré's Nocturne no. 13, measures 78-86, a late Nocturne
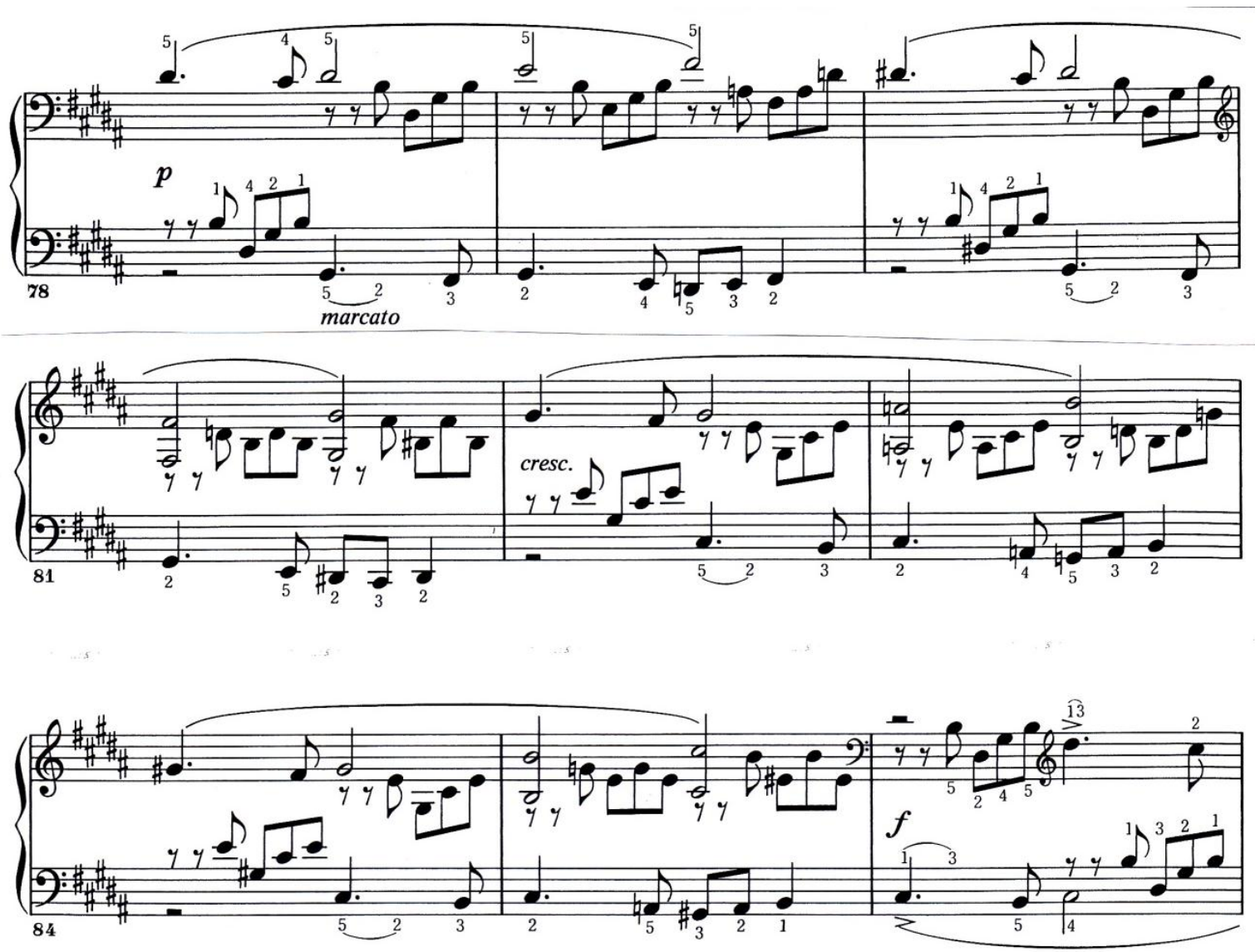

In Liebermann's Nocturne no. 3, the canon played over this quiet ostinato bass line is the perfect setting to prepare the return of the opening material, utilizing a simpler texture combined with thematic transformation of the theme. After the big pianistic gesture of dramatic proportions (measures 39-57, ppp to $s f f f z$ ), the texture thins out and recedes to $\boldsymbol{p}$ at measure 66 for the first entry of the theme of the canon. Then, it gradually moves to $\boldsymbol{m f}$ at measure 74 for the second entry and reaches $\boldsymbol{f}$ at measure 82 for the final presentation. It culminates in $\boldsymbol{f f f}$ at measure 90 , at which point we hear the ostinato bass line for the last time, followed by a recall of the motive (melodic and rhythmic) used in the opening of the piece. Some members of the bass line have to be respelled to accommodate the harmonic clarity, but the ostinato is unaffected ( $\mathrm{G} \#$ becomes $\mathrm{A} b$; 
$\mathrm{D \#}$ becomes $\mathrm{E}$ b). Of the theme of the canon itself, a close look at the material reveals that it is taken from melodic idea 1 . Indeed, it is a very clever thematic transformation of measures 4-5-6, starting with the very recognizable jump of perfect fourth (F\#-B), followed by the moving downward motion (A\#-G\#), skipping the next two members and ending on A. The following musical examples (5.3.6) illustrate that thematic transformation.

Musical example 5.3.6: Liebermann's Nocturne no. 3, measures 4-7 and 64-71

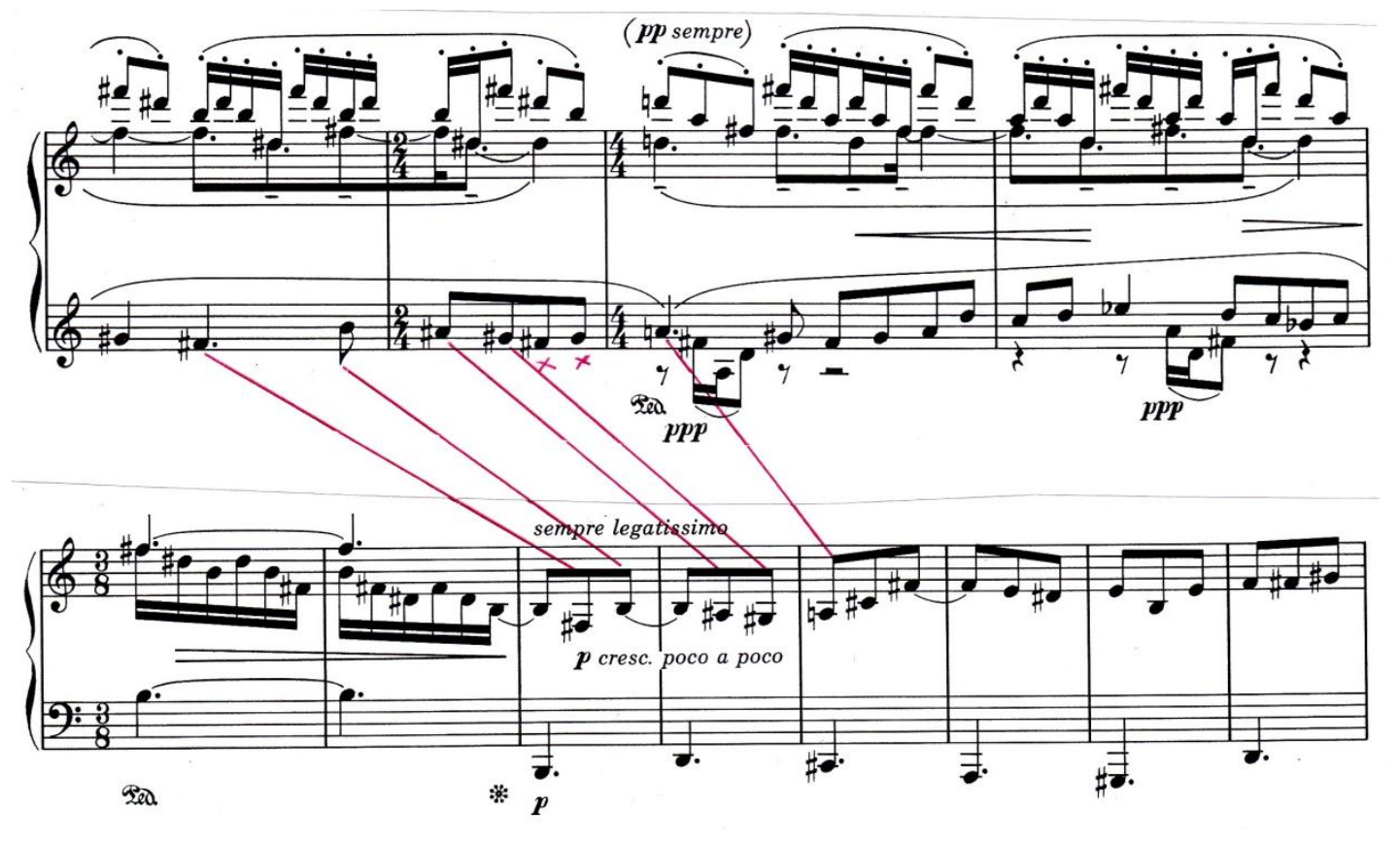

C1994 by Theodore Presser Co., Used With Permission

The new cell is then extended twice, according to a traditional tonal pattern (I-V-IV) containing a few chromatic and diatonic passing tones. The very recognizable jump of a fourth highlights most clearly those tonal progressions: F\#-B at measure 66 (I), C\#-F\# at measure 68 (V), and B-E at measure 70 (IV). After the completed three-voiced canon has unfolded itself, the familiar progression of mostly tertian-related chords and harmonies set a semitone apart brings us back to the home key (C\#, D, C\#, F, A b, B b, Ab, G and B, measures 90-97). 
The A section returns at measure 98 and until measure 111 it is an exact restatement of the introduction and of the melodic idea 1 except for the low $\mathrm{b}$ in the bass (measures 98-99), the last remnant of the previous ostinato (section A'). At measure 112 the melody and harmony take an unexpected turn (section $\mathrm{B}^{\prime}$ ). One expects $\mathrm{G}$ in the melody accompanied by the $\mathrm{C}$ chord (measure 15). The $\mathrm{G}$ is replaced by $\mathrm{G \#}$ and the supporting harmony, accordingly, moves to $\mathrm{E}$. One measure is taken out from the original A section and Liebermann inserts a beautiful duet made of the two secondary themes. Melodic idea 2' sings in the high register while melodic idea 2 responds in the middle register, one measure later. The underlying harmonies undulate semitones apart (E, Eb) for a few measures (measures 113-121) and then reach D at measure 122. Then, the first five notes of melodic idea 1 are heard (measures 123 and 125), accompanied by the expected progression of third-related harmonies (D-F-D-B D-F\#—understood as Gbmeasures 123-127) mixed with tritone-relationships (F\#-C at measures 127-128) and again, harmonies set a semitone apart (C-B at measures 128-129). The little departure which occurred at measure 112 (G\# instead of $\mathrm{G})$ makes it possible for Liebermann to return to the home key of B at the end of the work (instead of reaching the key of $\mathrm{B}^{b}$, as obtained in the parallel passage at measure 44).

Despites some 40 changes of meter, encompassing $4 / 4,3 / 4,2 / 4,5 / 8,7 / 8$ and $3 / 8$, there is no change in the feeling of the pulse (with its constant eighth notes) until the very end of the Nocturne, when the ritardando arrives. In regard to the utilization of the pedal and the blurring of harmonies, Liebermann seems to limit himself to the merging of major and minor mediants into the chordal entity. There is a clear distillation of the earlier practice, like the one seen in of Nocturne no. 2. In Nocturne no. 3, Liebermann does not use the pedal to convey fluctuations affecting the harmonic rhythm nor does he utilize the pedal to establish larger structural units. 
Finally, something has to be mentioned about the pianistic nature of this Nocturne and about the few challenges it offers to pianists. First of all, Liebermann does not use key signature. He prefers to write accidentals in the score itself, even when the feeling of the key (or at least, feeling of a triad) is quite prominent and obvious. He indulges in this practice perhaps because of the vagrant nature of his harmony, but, from a purely pianistic point of view, this has the effect of making his music much more difficult to read. ${ }^{123}$ The second point, which also has something to do with rewriting, is the matter of redistribution of the material between the hands. This kind of piano writing takes its roots well into nineteenth-century piano music. This was an era where pianism was grandiloquent, flamboyant and even bombastic at times. Numerous examples relying on similar need for redistribution of material could be drawn from the music of Liszt, Mendelssohn, Rachmaninoff, Schumann and countless others. Only a pianist with large hands can play the music the way it is written (measures 17 onwards). Moreover, even this largehanded pianist would still encounter some big challenges when attempting to play some passages. For example, at measure 25 , one has to play the trill in the high register and, at the same time, manage the accompaniment. The span from high $\mathrm{Cb}$ and low $\mathrm{D} b$ (almost two octaves down) is just too big for a human hand. The score obviously asks for a reworking of what has to play what. Here is one way it can be achieved: the added written-in line shows which material has to be transferred to the other hand, keeping in mind that the melody should still be clearly heard and the level of sound in the accompaniment should not be affected by the exchanges in between hands. This problem of hand redistribution is something quite common in other Liebermann works for piano (see Piano Sonata no. 2, op. 10; Gargoyles op. 29; Nocturne no. 4, op. 38; Nocturne no. 7, op. 65; Three Impromptus op. 68; Nocturne no. 11, op. 112). In the following 
example (5.3.7), the added written-in line shows a more practical redistribution of the material between the hands, also allowing a better legato.

Musical example 5.3.7: Liebermann's Nocturne no. 3, measures 16-23
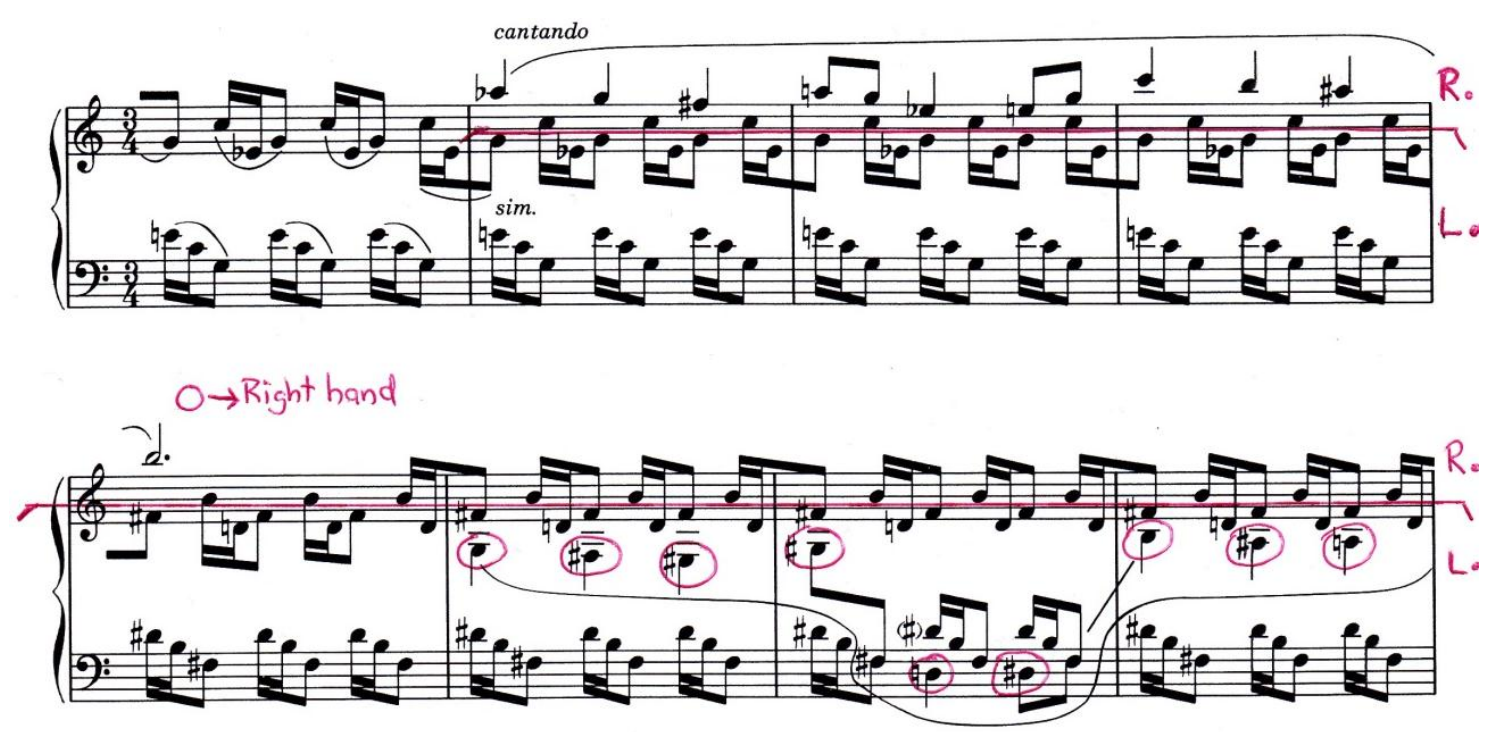

(C1994 by Theodore Presser Co., Used With Permission

Not unlike Fauré, Liebermann's early Nocturnes share some striking similitude with one another. We already saw similar tertian harmonic motions in Nocturnes no. 2 and no. 3. We also witnessed a predilection for the inclusion of melodic raised fourth. Often within a section, the music displays tritone relationships. It is also common to see the same material reappear later in the course of the nocturne, rewritten in a key a semitone apart. There is also a penchant for multilayer textures and the use of ostinato. Here, even more so than in Nocturne no. 2, the chordal entity which includes both major and minor mediants (the so-called split-third triad) becomes Liebermann's personal aural signature. In Nocturne no. 3, we saw the new use of the canon, which is being used to build a construction of a dramatic nature right before the return of important musical material. And finally, we realized that the music on the page cannot be played 
as written, but demands some decision-making from a performer's point of view, since the material needs to be redistributed in between the hands without affecting the personality of each member of the stratified structure.

\subsection{Nocturne no. 4, op. 38}

Nocturne no. 4, opus 38 was commissioned by the North West Arts Board of Great Britain for pianist Andrew Wilde who premiered it on November 22, 1992, at the Queen Elizabeth Hall in London. ${ }^{124}$ This $67-$ measure musical work requires about six minutes to be performed and is perceived by Nichols as "the most convincing" amongst the early Nocturnes. ${ }^{125}$ Ostinati, multi-layer structures which require redistribution of the material between the hands, ingenious pianistic embellishments, third-related harmonies, chordal entities including both their major and mediant elements, chromatic inflections and modal borrowings in the otherwise diatonic melodic fabric, canonic treatment of themes and full-bodied romantic gestures of a virtuoso nature are all present but with an intensity never seen before. Similarly to Fauré's Nocturne no. 6, this piece could be seen as the composer's best representative of the mastery of his compositional skills: the perfect merging of art, form, passion and drama. The following figure (5.4) displays the formal aspect of Nocturne no. 4. If section B, B' and B' are respectively seen as subsections of A, A' and A", then the overall form would become AA'A".

\footnotetext{
124 Andrew Wilde is an English pianist. He is listed as a freelance performer and teacher at the University of Manchester. See appendix B for more information. 125 Nichols, 110.
} 
Musical figure 5.4: Liebermann's Nocturne no. 4

\begin{tabular}{|c|c|}
\hline $\mathbf{A}$ & B \\
\hline $\begin{array}{l}\text { Intro (1)[C] } \\
\text { - } \quad \text { m.i. } 1(2-5 ; 6-9)[C] \\
\text { - } \quad \text { m.i. 2(10-13) [C-B] } \\
\text { - } \quad \text { transition (14-16) [e-B-e] }\end{array}$ & - m.i. $3(17-23)[B]$ \\
\hline $\mathbf{A}^{\prime}$ & B' $^{\prime}$ \\
\hline $\begin{array}{l}\text { recalls intro : }(24)[B \text { b] } \\
\text { - m.i. } 1 \text { (25-28); extension }(29-32)[B \text { b] }\end{array}$ & - m.i. $3(33-39)[B]$ \\
\hline A $^{\prime \prime(40-55)}$ & B'" \\
\hline $\begin{array}{l}\text { - } \text { m.i. } 1(42-45 ; 46-49)[\mathrm{C}] \\
\text { - } \\
\text { - } \\
\text { - } \operatorname{tri} .2(50-53)[\mathrm{G}-\mathrm{B}] \\
\end{array}$ & $\begin{array}{l}\text { - m.i. } 3(56-62)[B] \\
\text { Coda }(63-67)[B-C]\end{array}$ \\
\hline
\end{tabular}

The piece opens with a small four-note cell going down, a melodic ostinato upon which the whole section A is built. This ostinato highlights the major-minor chord associated with Liebermann's music (in this case, C). ${ }^{126} \mathrm{~A}$ sort of Aeolian quality emerges from the music. It

126 Although Liebermann spells it G-Fb-Eb-C, which does not carry any modal or harmonic implications, it is in fact G-E-Eb-C, a C chord encompassing both tertian elements in C. The most plausible explanation for that spelling would be of a desire to make the musical text less encumbered by accidentals. In using this manner of writing, Liebermann only needs to use $\mathrm{Fb}$ and $\mathrm{E} b$ once in each measure. Using the other way (E, Eb) would force him to use flat, then natural and flat again. Therefore the alterations would have to be changed three times. 
comes from the chromatic inflections of the lowered sixth and lowered seventh - the lowered third having already been established from the ostinato motive. But it might also be subtly felt from the harmonic motion I-V-I (measure 1-4-6) in which the V is cleverly disguised with an added lowered sixth. Harmony unfolds in a very narrow register and, as expected, through sharing of common tones. The first section undulates between the key of $\mathrm{C}$ (tonic and dominant) and the harmony of $\mathrm{B}$, back and forth (measures 1 to 16). The first musical sentence (melodic idea 1) is constructed like antecedent (measures 2-5, in C) and consequent (measures 6-9, from C to B). The consequent displays rapid melodic embellishments. It is in fact an appoggiatura and a leap of an octave going down. The second musical phrase (melodic idea 2) is built in a similar manner: antecedent-consequent (measures 10-11 and 12-13) and key relationships (C to B); although the phrasing suggests a single four-measure melodic entity. The harmony rests for a while in the key of $\mathrm{B}$, where a short transition is played (measures 14 to 16 ), underlying a traditional harmonic motion of iv-I-iv (e-B-e), something Liebermann does not do on a regular basis. The following example (5.4.1) includes the ostinato pattern and melodic idea 1 (antecedent and consequent). 
Musical example 5.4.1: Liebermann's Nocturne no. 4, measures 1-8
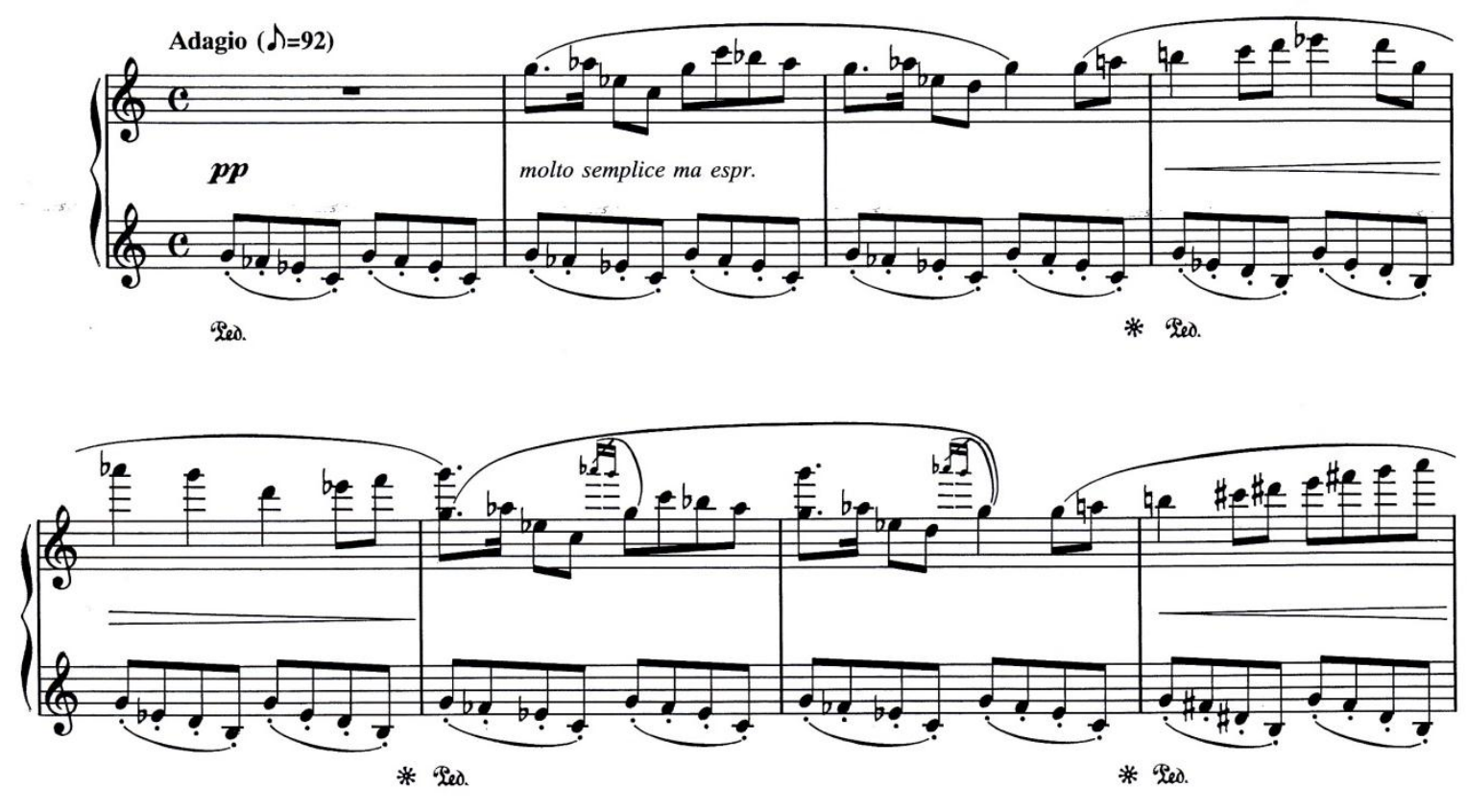

(C1994 by Theodore Presser Co., Used With Permission

At measure 17, section B begins. Like section A, it is also built on an ostinato of four notes; but this time, the ostinato is played in the low register of the piano. The pitch B is emphasized by its upper and lower neighboring tones ( $\mathrm{C}$ and $\mathrm{A \#})$, in a very regular rhythmic motion of eighth notes. During the following seven measures, melodic idea 3 wanders through numerous harmonies, moving smoothly with the help of parallelism (A b-A and E-Eb-D-D b), common tones (Ab-G\#), or third-related harmonies (B-D-F\# and $\left.\mathrm{D}^{b}-\mathrm{B} b\right)$. This material will be embellished and further developed in the closing section. At measure 20, a chord with a suspended fourth is played and resolved traditionally downward to the mediant. This harmonic entity and the following downward melodic motion will also be given a particular emphasis at the end of the Nocturne. Musical example 5.4.2 displays melodic idea 3 with its accompanying ostinato pattern. The important chord with suspended fourth and its downward resolution can be found at measure 20 . 
Musical example 5.4.2: Liebermann's Nocturne no. 4, measures 17-23
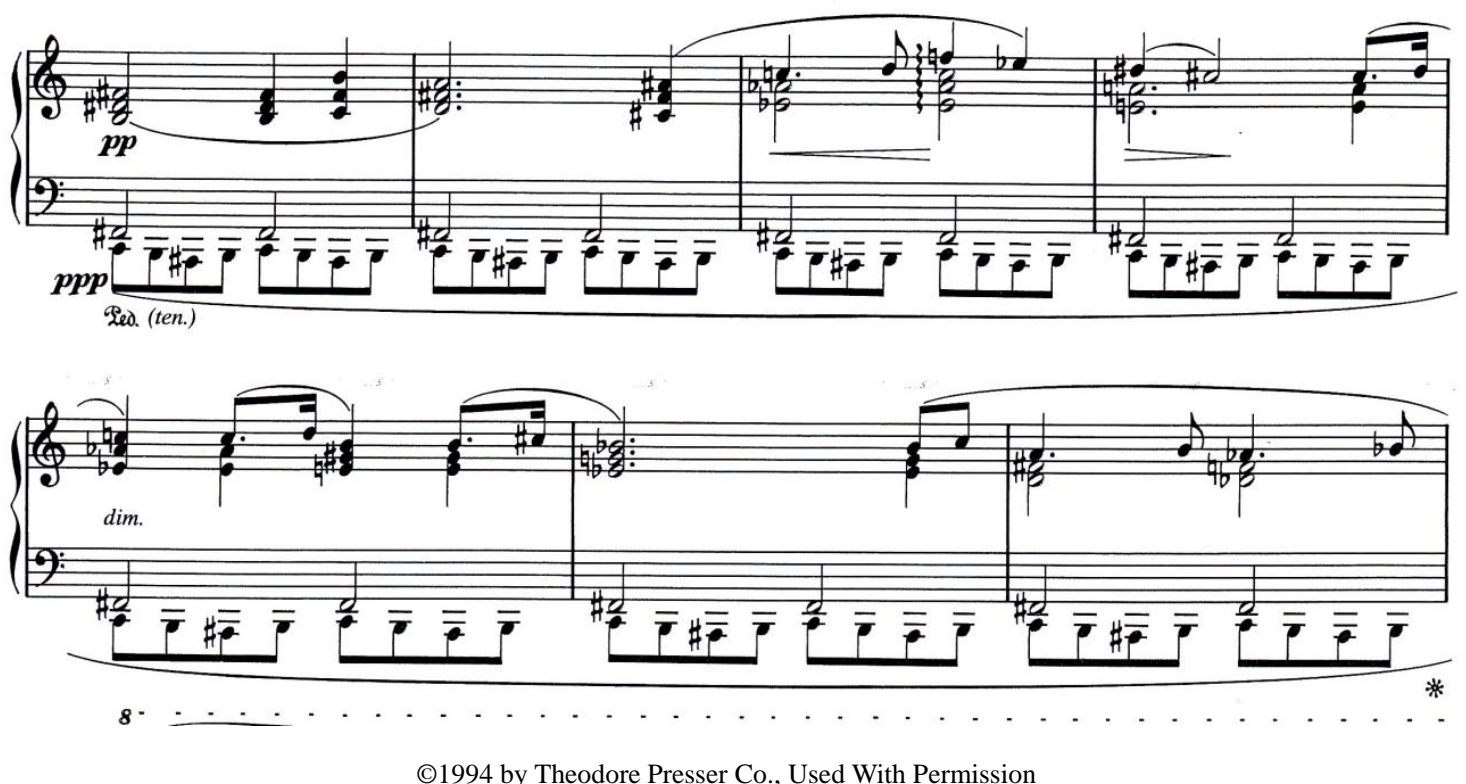

C1994 by Theodore Presser Co., Used With Permission

At measure 24, we reach the key of $\mathrm{B} b$. That measure serves to establish the new texture (atmosphere) which consists of three different layers (section A'). Firstly, starting in the low register, and covering a span of two octaves, the opening ostinato is played, inverted-which is to say, going upward (B b, D b, D, F) — to which a lowered sixth $\left(G^{b}\right)$ is added. ${ }^{127}$ Secondly, in the high register, a mirror image of this ostinato is heard $(B b, G b, F, D, D b)$, displaced rhythmically by one sixteenth note. And thirdly, melodic idea 1 enters, one bar later, while the little ostinato-duet continues. The melody is played in the middle register and has to be executed alternating hands at times. The outer textures are marked ppp while the melody is marked $\boldsymbol{p}$ (ben cantando). As mentioned earlier, this kind of writing was very popular in the nineteenth century and used by many virtuoso composer-pianists such as Liszt and Thalberg, and later on by

127 One could also look at it as a combination of the two forms of ostinato found in measures 1 and 4 , each transposed such that the lowest pitch is $\mathrm{Bb}$. 
Rachmaninoff and is referred to as the three-handed effect. ${ }^{128}$ Following is musical example 5.4.3 which displays the beginning of section A' with its ostinato duet and melodic idea 1.

Musical example 5.4.3: Liebermann's Nocturne no. 4, measures 24-29
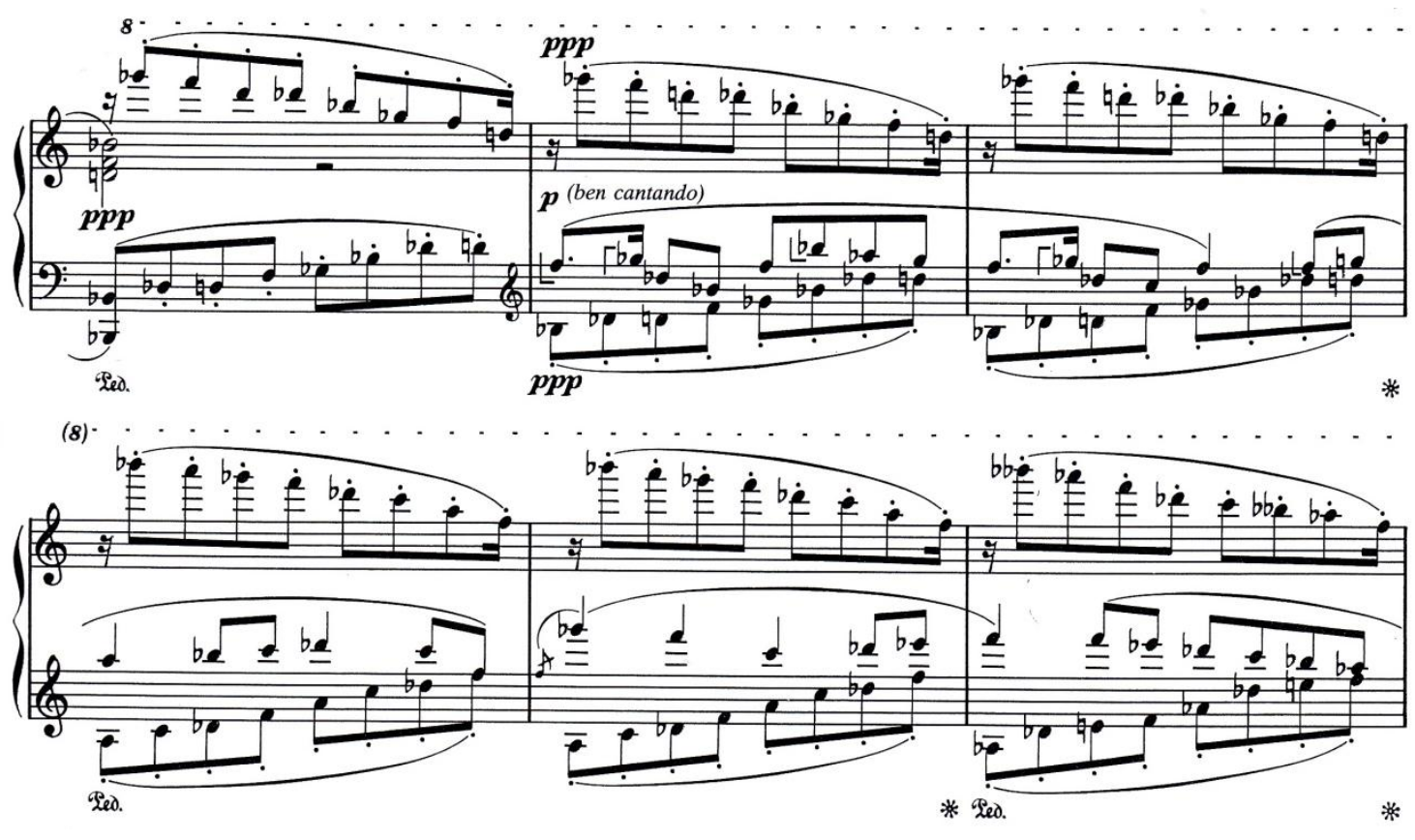

C1994 by Theodore Presser Co., Used With Permission

When the melodic material was first presented, it was accompanied by a harmonic shift from $\mathrm{C}$ to $\mathrm{B}$. This time, the harmonic motion is more complex. There is a chromatic slide of the bass from $\mathrm{B} b$ to $\mathrm{F}$. At the same time, the same harmonic motion suggesting $\mathrm{I}-\mathrm{V}$ is heard (measures 25-27) and, thereafter, follows a succession of wandering chordal elements. This extension seems to go through the harmonies of $\mathrm{D} b, \mathrm{E}, \mathrm{C}$ and $\mathrm{B}$, while the overall tonal impression remains vague and the atmosphere hazy. This sensation of haziness could partly be explained by the fact that these harmonies also include a chromatic neighbor tone to one of the 
upper notes and common tones between two adjacent triads, by the generous use of the pedal, and finally by the syncopation between the outer lines (ostinati).

The following section (B'), starting at measure 33, is based on melodic idea 3, played in the soprano and affected by slight rhythmic transformation. The raised fourth is also incorporated into the melodic fabric while the left hand accompanying pattern displays arpeggiated harmonies encompassing both major and minor mediants and their lowered sixth. This section is rhythmically more challenging for its superimposition of sextuplets and quadruplets; it passes quickly through the harmonies of $\mathrm{B}, \mathrm{D}, \mathrm{F} \#, \mathrm{~A} b, \mathrm{~A}$ and finally settles in $\mathrm{C}$ for the return of melodic idea 1.

Since the beginning of the Nocturne, we have heard four large "tonal" areas: C-B-B b-B. It is noteworthy that these zones mimic the very same pitches outlined by the ostinato motive on which section B is built on. Using the different recurrences of the melodic material, "tonal" areas can be defined and are seen at measures 1 (C), 17 (B), 24 (B b), 33 (B), 40 (C), 54 (B), and the final resolution at $65(\mathrm{C})$.

At measure 40 (section A"), the key of C is restated. A bar later, a new decorative motive appears in the upper register. It is made with the rapid appoggiatura and downward octave leap already seen, combined with a short cell of a simple alternation of tonic-dominant (C-G) to which the dominant's lower neighbor is added (F\#). Another bar later, melodic idea 1 (antecedent) appears, cleverly incorporated into the fabric of the accompanying pattern of the left hand. The melody has to be played mainly by the left-hand thumb. This passage provides another good illustration of Liebermann's multi-layered and three-hand-effect writing as demonstrated by the following musical example (5.4.4). 
Musical example 5.4.4: Liebermann’s Nocturne no. 4, measures 41-46
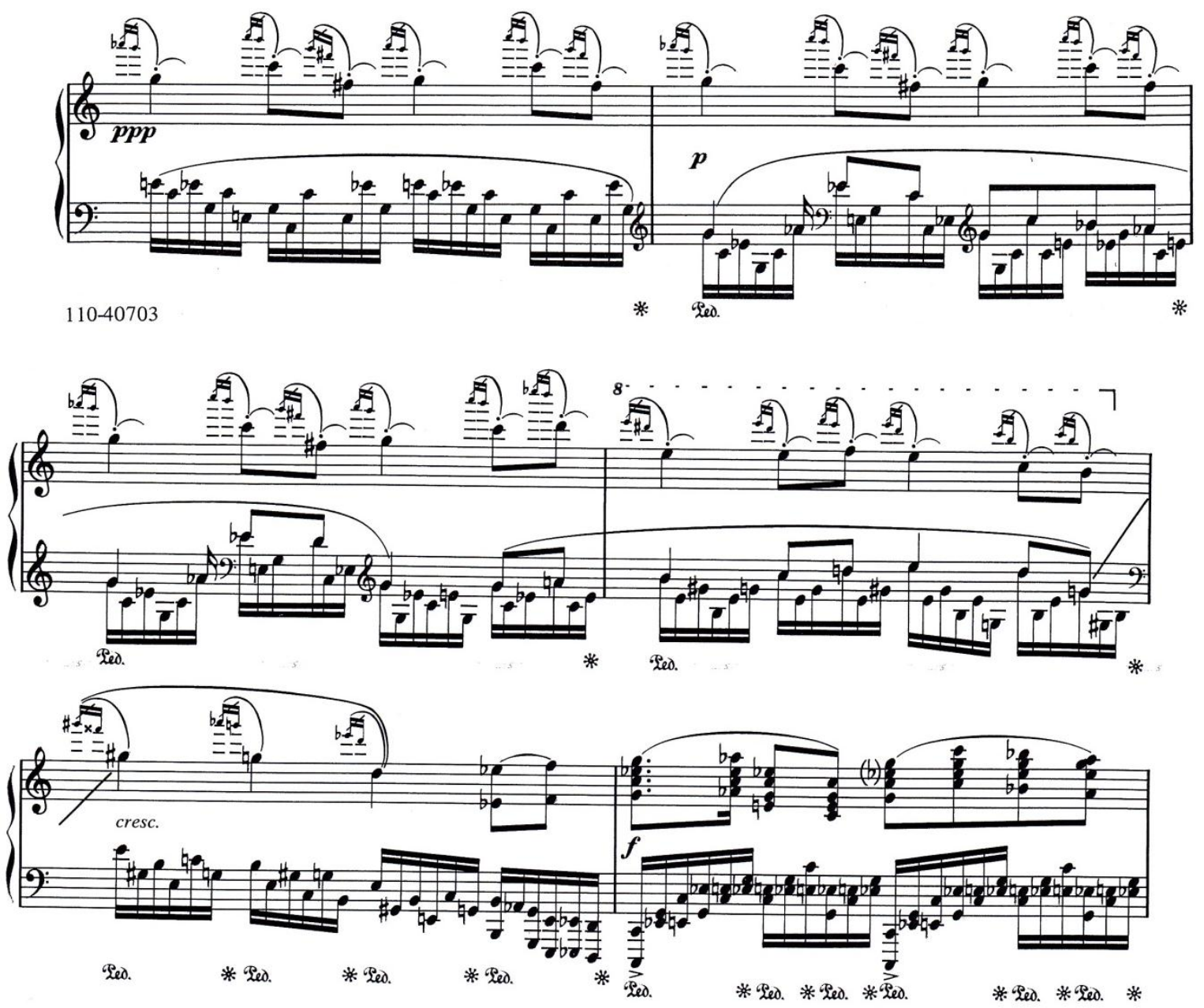

C1994 by Theodore Presser Co., Used With Permission

The harmony moves briefly from $\mathrm{C}$ to $\mathrm{E}$ (measures 43-44) and back to $\mathrm{C}$ to prepare for the most dramatic moment of the Nocturne, at measure $46 .{ }^{129}$ Melodic idea 1 (consequent) and melodic idea 2 are played in full chordal presentation in the right hand while the left hand plays a tortuous accompaniment made of double-notes underlying the now-familiar major/minor

129 This new turn of the harmonic motion comes from a little melodic change on the third beat of measure 44 . Originally in the melody one would expect Eb (measure 4) but in this very instance, Liebermann uses E natural, thus calling for a slight change of harmony. It also allows him to arrive at measure 46 in a grander manner, with a harmonic motion right before the beginning of the climax. 
harmony typical of Liebermann. Dynamic markings in this section range from $f$ to $f f f f$, culminating in the sffffz of measure 54 .

The thematic transformation resembles Fauré's technique in regard to dramatic construction in that it is achieved though repetition (measures 50-52) and alternating third-related harmonies (B-G). At measure 53, the double-notes accompaniment pattern is shifted to the right hand while the left hand is given the quadruplet chordal gesture.

It is quite unusual to find such a dramatic construction in a nocturne, although Nocturne no. 3 (measures 53-57) provides an earlier example. ${ }^{130}$ Solely considering Liebermann's gigantic dynamic range in the Nocturnes, it would be difficult to trace back a connection to the spirit of Field. Musical example 5.4.5 displays a portion of that dramatic construction.

130 The only resembling moment of a dramatic peak achieved through extreme dynamic marking combined with pianistic writing might be found in Chopin's Nocturne no. 13, op. 48 no. 1. 
Musical example 5.4.5: Liebermann's Nocturne no. 4, measures 49-53
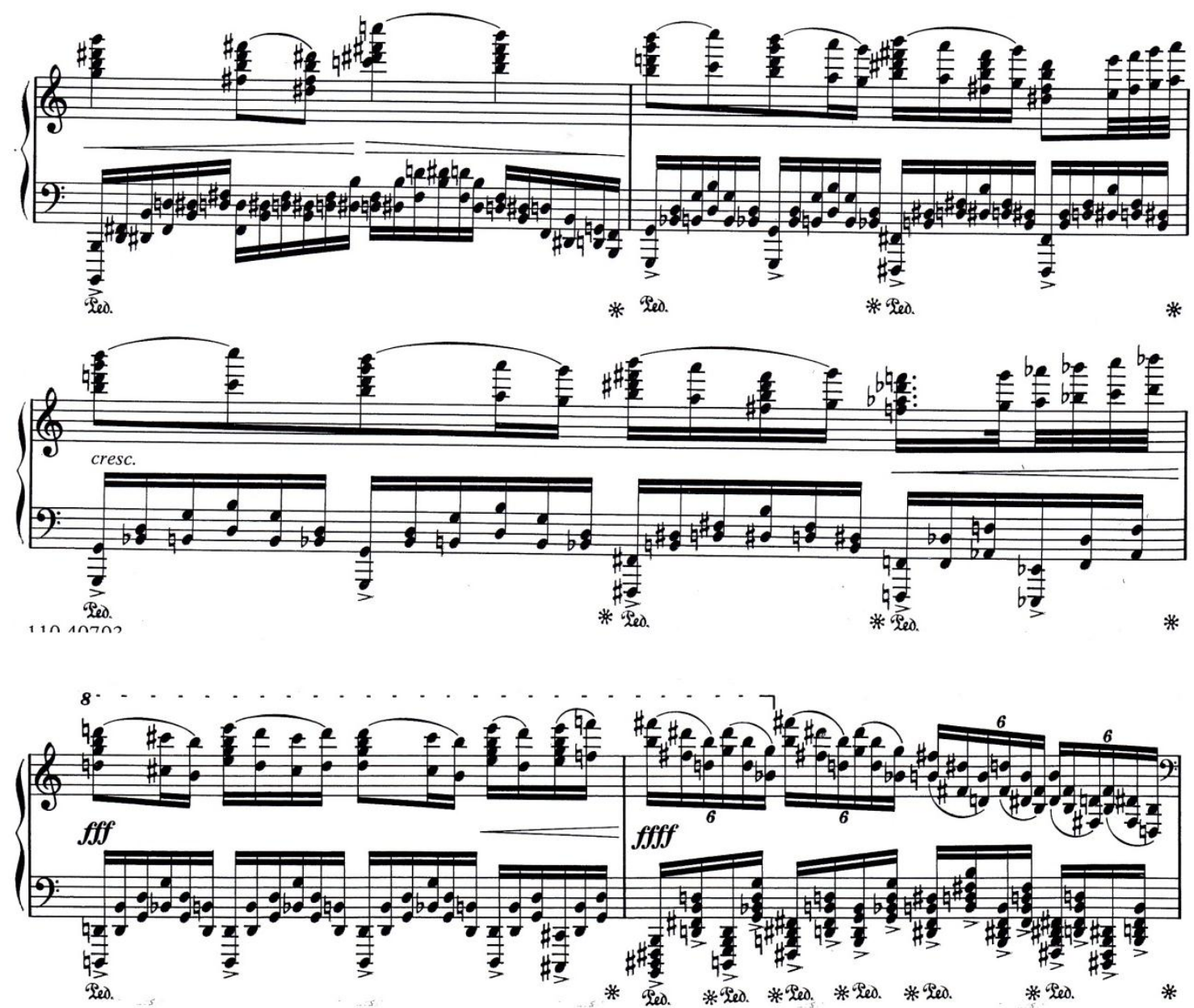

(C)1994 by Theodore Presser Co., Used With Permission

At the end of this section, a B major chord is heard, played sffffz; at the same time, the four-note ostinato from section B appears anew (B"). Melodic idea 3 enters at measure 56, this time accompanied with the appoggiatura motive of the A section. Here, Liebermann is citing and uniting material from different sections of his work. This approach recalls Fauré, who also often quoted material from different sections and combined them in the coda. The ostinato goes uninterrupted for ten measures, on top of which, a prolongation of the dominant of B (with lowered fifth) and wandering harmonies is heard; in fact, measures 56 to 59 are a repetition of 
measures 17 to 20 , with a different continuation. As mentioned earlier, there is a chord with a suspended raised fourth which plays an important role in this last section. ${ }^{131}$ Although it was heard before, in this passage, from measure 56 until measure 67, there are no fewer than twelve occurrences of chordal entities of the same nature. The chord which is heard the most frequently is made of the elements $\mathrm{E}+\mathrm{A}+\mathrm{D} \#$, the $\mathrm{D} \#$ resolving to $\mathrm{C} \#$. The newly obtained chord $(\mathrm{E}+\mathrm{A}+\mathrm{C} \#)$ is the lowered vii in B. Therefore, at measure 63-67 on can hear harmonic motion of bvii (\#4)-I twice, until it is finally heard, at measure 66, however resolving to $\mathrm{C}$ (the home key of the Nocturne). The pedal needs to be held for the last three measures, blending the harmonies together, and arguably leaving a feeling of uncertainty and non-resolution. Musical example 5.4.6 shows the material and pedaling of the last measures of the work.

Musical example 5.4.6: Liebermann’s Nocturne no. 4, measures 63-67

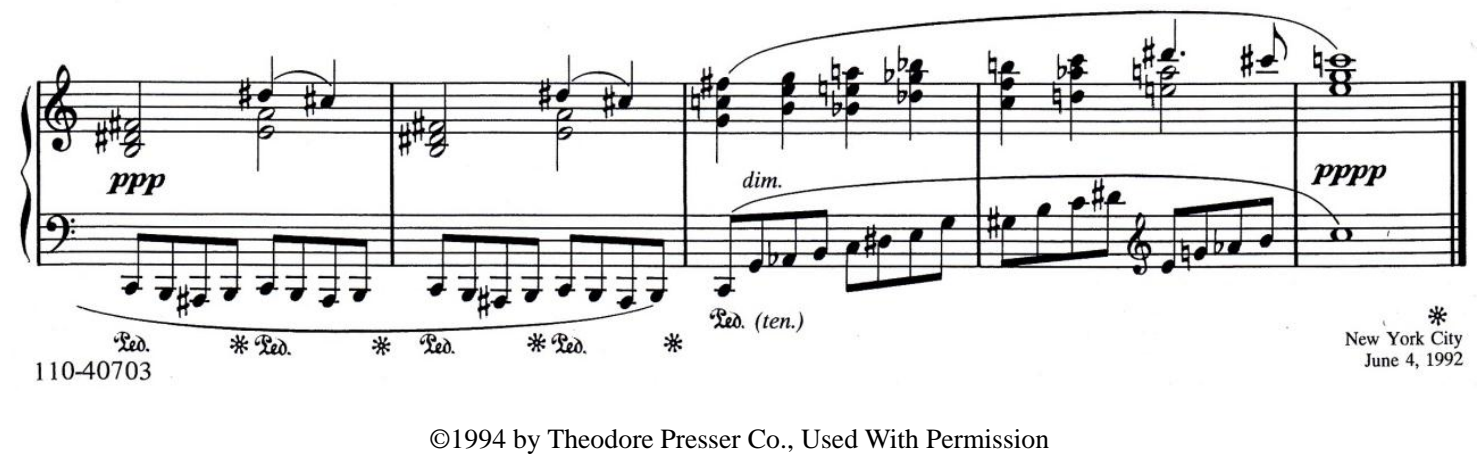

In regard to pedal, Liebermann's intentions are clearly marked in the score. The pedalor the rare lack thereof-is used in numerous ways: to blend the members of a chordal entity (measures 1-3, 24-26, etc.); to merge conflicting harmonies and create a hazy sound (measures 17-23, 65-67,etc.); to delineate different sections or different usages of musical material (no

131 It is also possible to see this chord as being of a quartal nature (fourth and augmented fourth), although the downward step-wise resolution implies a more tonally-oriented reading. Moreover, this particular suspension could easily recall Wagner's Prelude to Tristan at measure 17. 
pedal at measures 14-16, 56-62, etc.); and to highlight and diversify the harmonic rhythm (measures 48-53, etc.).

Nocturne no. 4 is a very remarkable musical work: not only is the lyrical quality abundant and appealing, but the pianistic challenges are numerous and its dramatic conception is quite intense. Structurally speaking it relies openly on the use of ostinato and canon in a more assertive manner than its predecessors. The harmonies and their respective progressions are now familiarly recognized as being Liebermann's and, through them, he utilizes ingenious ways of dressing up melodic ideas. Finally, this Nocturne displays Liebermann's multi-layered language handled with the utmost mastery.

\subsection{Nocturne no. 5, op. 55}

Nocturne no. 5 was written in 1996 and was commissioned by the Adele Marcus Foundation in memory of that great piano teacher. ${ }^{132}$ Pianist Norman Krieger premiered the work on February 22, 1997, at Carnegie Hall in New York City. ${ }^{133}$ This piece is 116 measures long and takes about seven minutes to be performed. It resembles its predecessors in melodic and harmonic utilizations of the material; there is also presence of canonic treatment and multi-layer writing (as seen as in Nocturne no. 3 and no. 4). However, this Nocturne is significantly less dramatic than Nocturne no. 4. William T. Spiller of the Journal of the Music Library Association stated that "this Nocturne requires a highly refined Chopinesque touch and imagination to fulfill the crystalline coloristic possibilities" and Clavier Magazine called it "an excellent piece for any

132 Adele Marcus was born on February 22, 1906 and died on May 3, 1995. She was an American pianist but better known as the teacher for many other famous pianists. Born in Kansas City, she was of Russian descent. She studied piano under Josef Lhévinne and Arthur Schnabel. She was on the faculty at the Juilliard School in New York City. Her famous pupils included: Augustin Anievas, Stewart Gordon, Horacio Gutiérrez, Stephen Hough, Byron Janis, Santiago Rodriguez, Thomas Schumacher and many more.

133 Norman Krieger is an American pianist based in South Carolina. See Appendix B for more information or consult the artist's personal website at: http:/www.normankrieger.com/ 
advanced student or pianist to play for recitals or competitions." ${ }^{134}$ The following figure (5.5) shows the formal aspect of Nocturne no. 5. The significantly long transition (measures 44-56) and coda (101-116) bring symmetry to the work and if ABA' is taken as a self-contained unit, then the overall form could be perceived as AA' (1-57).

Musical figure 5.5: Liebermann's Nocturne no. 5

\begin{tabular}{|c|c|c|}
\hline $\mathbf{A}$ & $\mathbf{B}$ & $\mathbf{A}^{\prime}$ \\
\hline $\begin{array}{l}\text { Intro }(1) \\
\text { - } \quad \text { m.i. } 1(2-5 ; 6-9)[D] \\
\text { - } \quad \text { canon }(10-13 ; 14-17) \text { [D] } \\
\text { - } \quad \text { extension }(18-19)\end{array}$ & $\begin{array}{l}\text { m.i. } 2(20-24 ; 25-29 ; \\
\text { 30-34) [Eb] }\end{array}$ & $\begin{array}{l}\text { - m.i. } 1(35-38 ; 39-42)[\mathrm{D}] \\
\text { - } \text { extension }(43) \\
\text { transition m.i. } 3(44-45) \\
\text { thirds (46-48) } \\
\text { m.i. } 1 \text { bass line (49-52; } \\
\text { 53-56) }\end{array}$ \\
\hline $\mathbf{A}^{\prime \prime}$ & $\mathbf{B}^{\prime}$ & $A^{99}$ \\
\hline $\begin{array}{ll}\text { - } & \text { m.i. } 1(57-60 ; 61-64)[b] \\
\text { - } & \text { extension } 65 \\
\text { - } & \text { transition }(66-68)\end{array}$ & - m.i. $2+1(69-84)$ [Eb] & $\begin{array}{l}\text { - m.i. } 1(85-88 ; 89-92)[\mathrm{D}] \\
\text { - canon }(93-100)[\mathrm{D}] \\
\text { Coda quoting previous } \\
\text { material (101 transition+ } \\
\text { m.i. 2-109 thirds-113 m.i.1) } \\
\text { [D b-C-D] }\end{array}$ \\
\hline
\end{tabular}

134 William T. Spiller, Journal of the Music Library Association; Clavier taken from: http://www.presser.com/composers/info.cfm?Name=LOWELLLIEBERMANN\#Reviews 
The work is rooted in the key of D major and displays a strikingly tonal opening. Although there are a few surprising harmonic twists, no note outside the scale is to be seen until measure 9 (arrival on the harmony of $A b) .{ }^{135}$ At the very beginning, a D-major arpeggio is played, embellished with the presence of the sixth of the scale. This acts as an ostinato. The triple division of the beat is somewhat reminiscent of the "simpler" Nocturnes of Field, Chopin and Fauré. The primary melodic idea enters at measure 2 and unfolds quietly according to antecedent-consequent scheme (melodic idea 1). The antecedent is heard over a pedal of $\mathrm{D}$, measures 2 to 5 , while the consequent is accompanied by a chromatic descending line (C\#-C-B) with the required adjustments in the harmonic foreground, measures 6 to 9 . The accompanying pattern retains enough elements of the ostinato to be understood as such, specifically retaining the use of a third over the bass note plus the pitches A and B. At measure 9, the first harmonic surprise occurs when the music moves from B to the harmony of Ab (retaining pitches A and B). This chord is not only used for coloristic effect but also carries voice-leading possibilities and, interestingly, it highlights a tritone relationship with the well-established home key of D.

Right after this brief moment, melodic idea 1 is played again but this time it is part of a little canon, two beats apart. ${ }^{136}$ The two melodic lines are located one octave apart. A similar harmonic surprise to the one seen at measure 9 happens at measure 17, this time in $\mathrm{D} b$. A short extension based on the last motivic cell of the idea is added and the music reaches the key of Eb for the second melodic idea. It can also be noted that the semitonal motion of the bass in measures 5 to 9 becomes motion by whole step in measures 16 to 19 . Musical example 5.5.1 displays the first canon of the work, based on melodic idea 1.

135 The $\mathrm{C}$ natural at measure 7 is obtained through the chromatic sliding of the bass line begun at measure 5, D-C\#C-B.

136 The entrances (at measures 10 and 14) are one beat apart, but the main body of the canon is set two beats apart. 
Musical example 5.5.1: Liebermann's Nocturne no. 5, measures 6-15

Canon on melodic idea 1
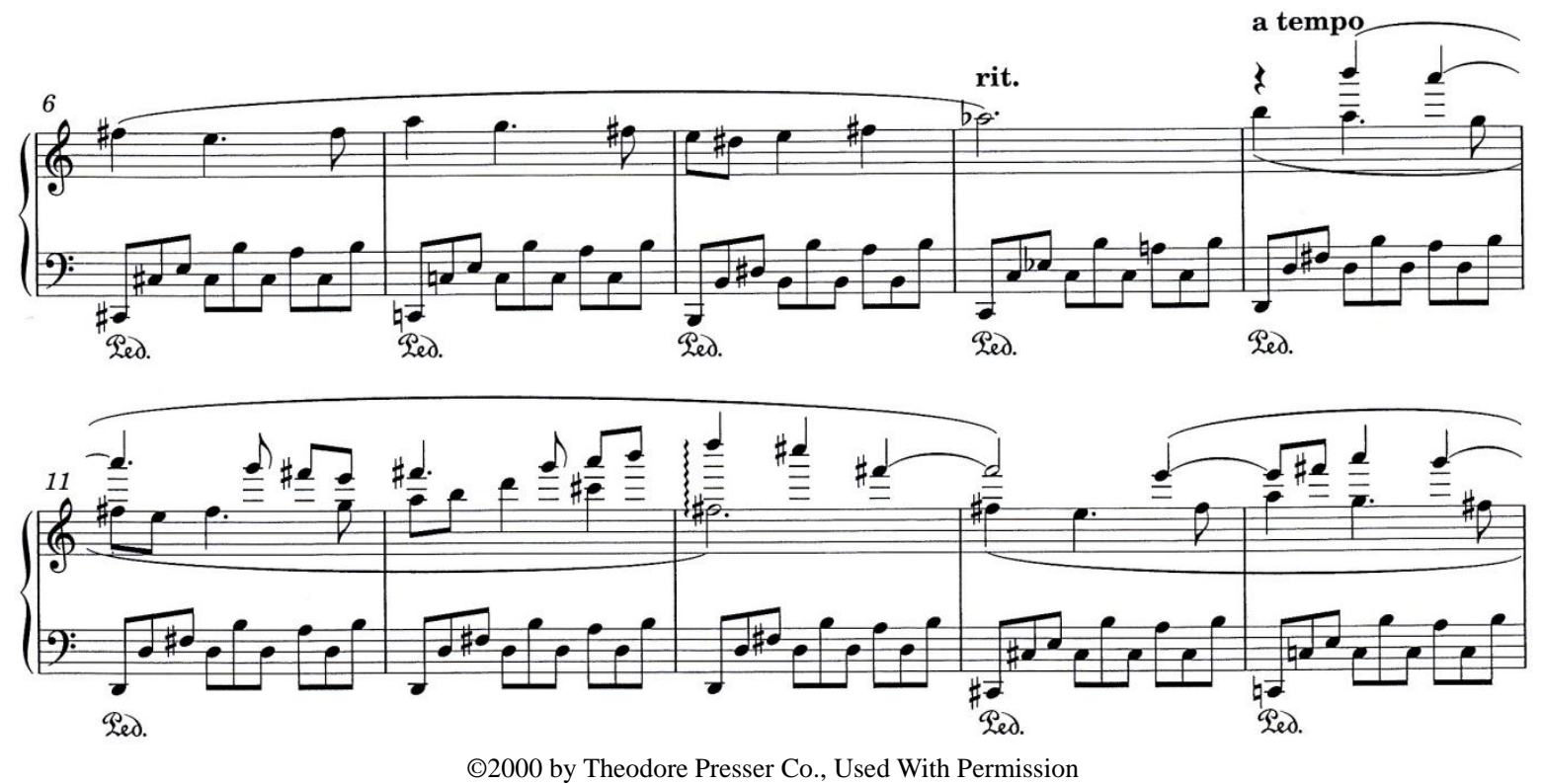

The following section (B) contains what can be seen as melodic idea 2; this idea takes the role of a little interlude between two presentations of melodic idea 1. It starts in the key of Eb, with a melody almost as diatonic as melodic idea 1, except for a few chromatic inflections of lowered second and lowered sixth, and a few Lydian modal borrowings of the raised fourth. Those inflections are created by the chromatic sliding of the bass: Eb-D-D b-C.

The opening melodic musical material returns at measure 35 (section A').

Accompaniment and melody are untouched but a complete new layer is added in the upper register, a quartal decorative filigree. ${ }^{137}$ This stratified structure does not call for a redistribution of the material but it asks for a precise balance in between melody and decorative material.

However, the biggest challenge might prove to be the handling of the polyrhythms generated by this kind of writing. In this case, we have groups of (eight) thirty-seconds over groups of triplets

137 The melodic components of this new layer initially combine perfect and augmented fourths, recalling the important chord encountered in the B section of the previous Nocturne, and upon which the whole concluding section was based. 
and duplets. ${ }^{138}$ The following musical example (5.5.2) displays melodic idea 1 with the new added filigree decoration of section A'.

Musical example 5.5.2: Liebermann's Nocturne no. 5, measures 35-40
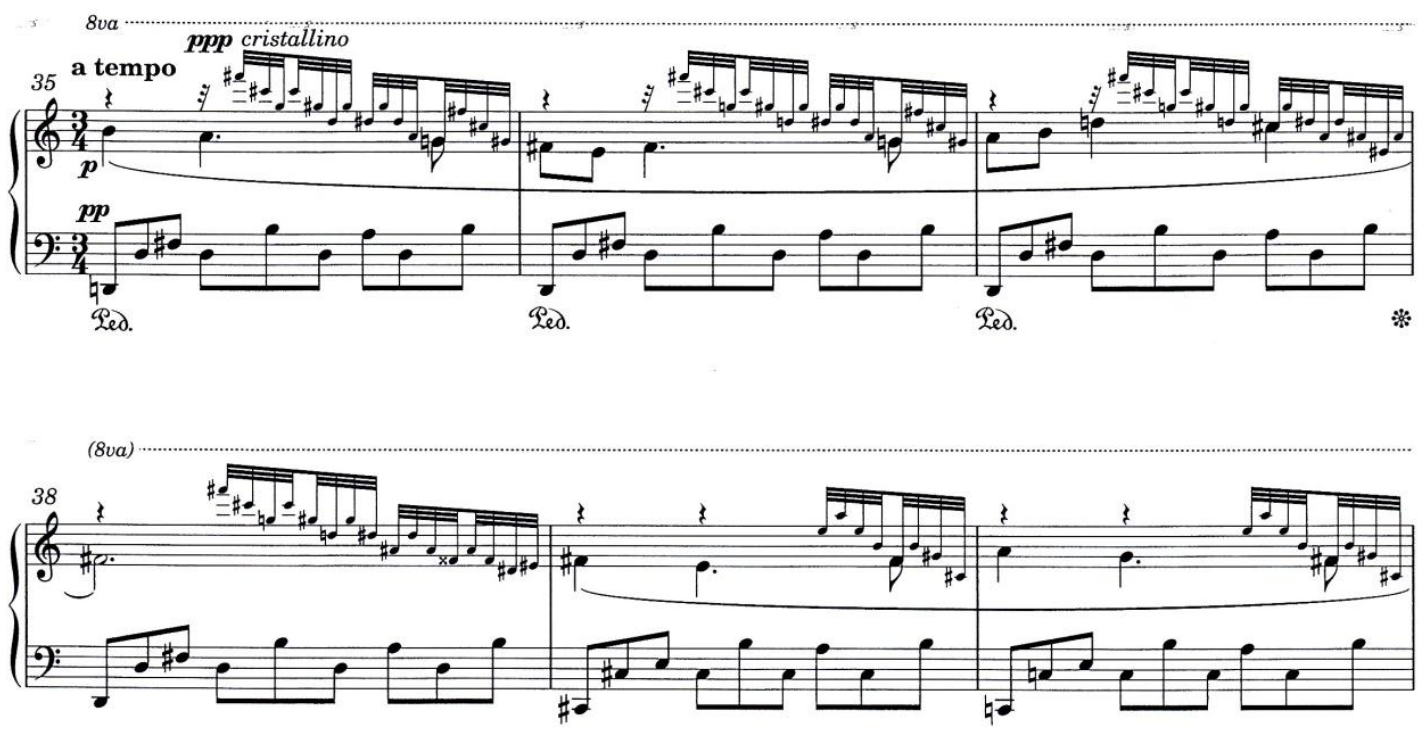

@2000 by Theodore Presser Co., Used With Permission

After the complete 8-bar theme is played, there is a little extension at measure 43 (based on the last motivic cell from measure 41 and also closely linked to the head of melodic idea 2 at measure 20). It is thereafter followed by a brief transition made of two ideas: the first one highlights the $\mathrm{C}$ chord going down over the $\mathrm{C}$ arpeggio going up and settles on a melodic ostinato made of $\mathrm{G}$ and $\mathrm{A} b$ (lowered sixth) - this idea will be recycled in the closing section; the second idea looks like an etude in major thirds for the right hand. On account of the chromaticism (bass line of melodic idea 1, measures 5 to 8 , and head of melodic idea 2, measure

138 At measure 50, on the first beat there is an $\mathrm{Fb}$, which, if it were strictly parallel to measure 3 , would have been an $\mathrm{F}$ natural. This is perhaps to provide a transition to the reharmonization in minor mode beginning in measure 57. 
20), it would also be possible to link those two ideas to material previously heard. Once again, a polyrhythmic texture appears. At measure 49, the two-note ostinato is combined to the decorative thirds filigree in the right hand while the left hand plays melodic idea 1 , in octaves in the bass register, in the key of $\mathrm{D} b$, a half-step lower than in its original presentation. This two-note chromatic ostinato not only recalls the head of melodic idea 2 (at measure 20) but also highlights the larger tonal relationships between melodic idea $1\left(\mathrm{D}\right.$, measure 1) and melodic idea $2\left(\mathrm{E}^{b}\right)$ and the chromaticism previously observed in the bass line. The following example (5.5.3) includes the decorative filigree in thirds in the upper part, the chromatic ostinato in the middle part and melodic idea 1 in the bass line.

Musical example 5.5.3: Liebermann's Nocturne no. 5, measures 49-52
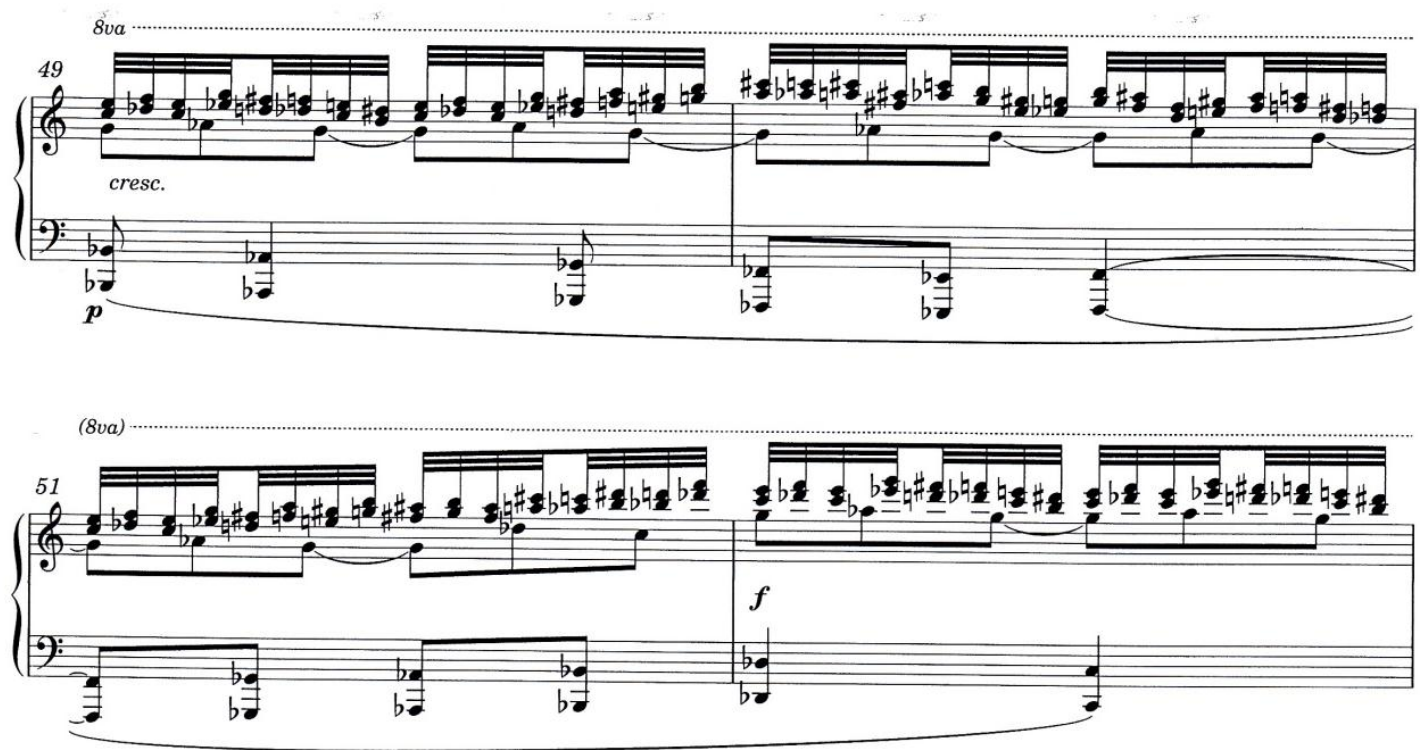

C2000 by Theodore Presser Co., Used With Permission

This section ends on a harmonic surprise at measure 53, combined with a whole-tone scale going down which allows the bass line to slide from $\mathrm{B} b$ to $\mathrm{B}$. It is followed by a short 
extension using the upper line of the thirds decorative line (one step lower than measure 46), and leads us to the next section with the return of melodic idea 1 (section A"). The melody is played by the right hand thumb and is harmonized with the opening accompanying pattern in the parallel minor key (b). Although the harmonic background has shifted, Liebermann still retains the same two pitches A and B. A layer is added to it, in the upper register; this layer is made from the upper line of the decorative third line which, in this instance, becomes a one-bar melodic ostinato for the entire section. The chromatic slide of the bass line is kept and adjusted accordingly to the minor key. The bass proceeds downwards from $\mathrm{B}$ to $\mathrm{A \#}, \mathrm{A}, \mathrm{A} b$, passes briefly through what can be perceived as the harmony of $\mathrm{C}$ (including both mediants and the raised fourth, at measure 65), and reaches the harmony of Eb at measure 66. At this point the music settles on a simple ostinato of the tonic and mediant, reinforcing the key of Eb (section B'). ${ }^{139}$ At measure 69, melodic idea 2 enters, unaltered for a short two measures, until melodic idea 1 joins in at measure 71 , in the middle register of the piano, for a beautiful and cleverly written duet. Example 5.5.4 displays the beginning of this duet between melodic idea 2 and melodic idea 1.

Musical example 5.5.4: Liebermann's Nocturne no. 5, measures 68-73

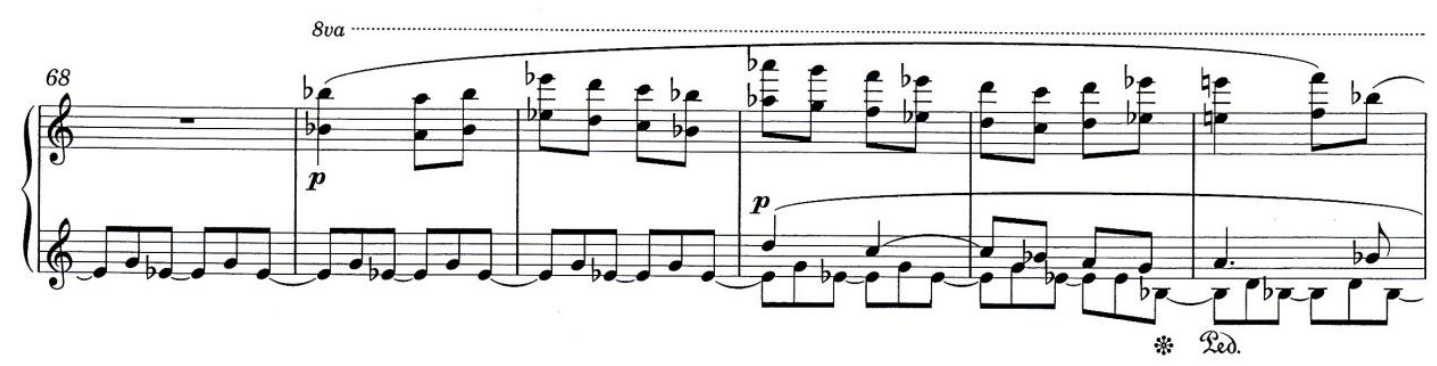

C2000 by Theodore Presser Co., Used With Permission

139 The initial ostinato combined tonic, mediant, dominant and submediant (1, 3, 5 and 6). In measure 46 and following, Liebermann used the upper two notes (5 and 6); here the lower two notes (1 and 3) are used. 
This duet unfolds smoothly in its three-layer texture until measure 85, where a clear return of the opening material occurs (section A"'). For the entire duration of the eight-bar theme, the music remains exactly the same as in its original appearance. At measure 93 another canonvery similar to the one encountered at measure 10 - appears, but one more voice is added. At this moment, the original simplicity of the melodic material reveals all its significance. Liebermann could not have written such a "smooth-sounding" canon if the material had been more chromatically or modally complicated. The dissonances created thereby would have been more numerous and, most likely, more difficult to handle for the listener. The "apparent" tonal simplicity of the material (melody and accompaniment) makes it easier for each line of the canon to unfold smoothly without upsetting the semplice or the delicatezza requested by the composer. The following musical example (5.5.5) displays a portion of the three-voice canon.

Musical example 5.5.5: Liebermann's Nocturne no. 5, measures 89-98
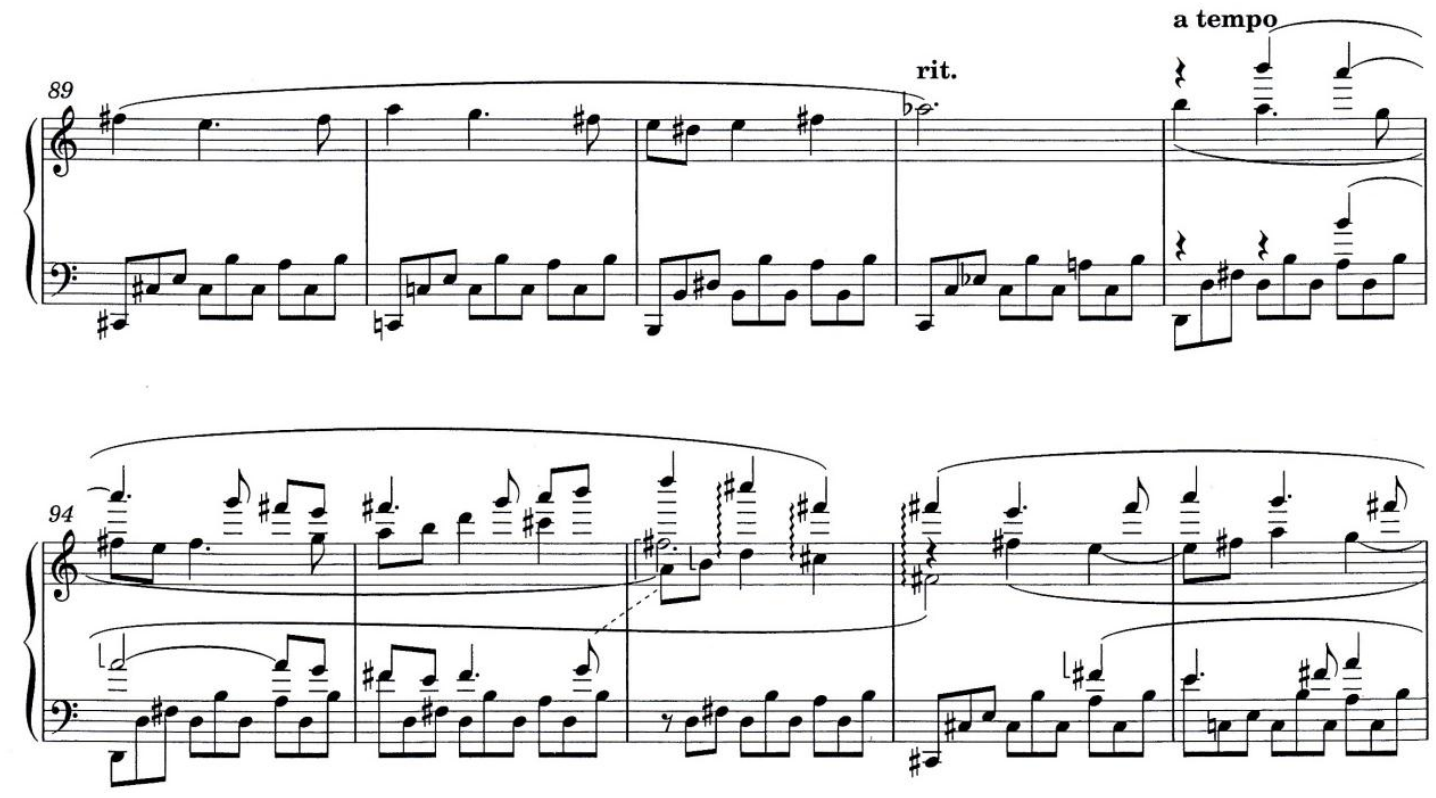

(C2000 by Theodore Presser Co., Used With Permission 
The canon reaches its completion at measure 100 on a $\mathrm{D}^{b}$ chord leading to the coda. The little melodic idea (melodic idea 3) introduced at measures $44-45$ is reused here: a simple arpeggio going down, accompanied by the melodic ostinato (tonic and mediant). The tail of this idea turns into melodic idea 2 , while the accompanying line slides chromatically from $\mathrm{D} b(\mathrm{C \#})$ to C. Those past four measures (measures 101 to 104) are repeated in the key of C (half step lower - the transitional material and the head of melodic idea 2, at measures 105 to 108). It should also be pointed out that the voice-leading of the accompaniment from measures 108 to 112 summarizes the elements found in the bass line from earlier in the piece, such as the wholesteps of measures 16 to 19 , and the minor thirds (expressed enharmonically as C-D\#). At measure 109, for a short two measures the decorative line made of thirds comes again over an ostinato (D-Eb), and the music settles anew in the home key of D. Melodic idea 1 shortened to four measures, makes a final return, presented in a pure diatonic D.

In this Nocturne, ostinati, canon, voice-leading of the bass and multi-layer textures appear to play a more significant musical and structural role than third-related harmony and extreme dynamic contrasts. Nichols sees it as "deliberately simple, almost archaic... more subdued". ${ }^{140}$ Pertinently, Nichols also states the fact that the dynamics are quite "controlled" in this Nocturne - the loudest marking being $f$ - and that the stratified structures are numerous, therefore making considerable demands on the performer's sense of rhythm and balance. However, Nichols neglects to acknowledge the growing structural importance given to multilayered textures and moreover, to the canon (imitations). Just as was seen with Fauré's later Nocturnes, the formal scheme of the nocturne can no longer be contained in a textbook ABA' form. The several recurrences of themes, the superimposition of melodic ideas, and the canonic

140 Nichols, 117. 
treatment of those ideas render the formal layout much more organically knitted and intrinsically complex. Moreover, just as Fauré does in many of his Nocturnes, in the coda of Nocturne no. 5 Liebermann quotes all the important musical material which have been previously heard: melodic idea 3 (measures 100-1-102; 105-106), melodic idea 2 (measures 103-104; 107-108), the ostinato accompanying pattern (101-110), the filigree pattern in thirds (measures 109-110) and melodic idea 1 (measures 113-116). Finally, in this instance, as previously noted, Liebermann assembles his material in two distinct ABA' forms, separated by a transition and terminated by a recapitulating coda, thus rendering it possible to understand the overall structure of the piece as being of the AA' type.

\subsection{Nocturne no. 6, op. 62}

Nocturne no. 6 was written in 1998; this work was commissioned by Richard Goula and it is dedicated to the memory of Lynn Hantell. It was premiered by pianist James Giles on November 15, 1998, at Alice Tully Hall, New York City. ${ }^{141}$ This work contains 109 measures of music and requires some eight minutes to be performed.

The previous Nocturnes all rely on long lyrical melodies which are treated like themes. Liebermann's experimentations in the genre consist mainly of finding ingenious ways to present the material, including several diversified accompanimental figures, clever multi-layered textures, canons and the superimposition of important melodic material. In regard to other piano works by Liebermann, there are a few characteristic traits such as the use of octatonic scale or motivic transformations which were identified by researchers and have not been encountered so far in the genre of the nocturne. However, with Nocturne no. 6, we see a new attitude towards the 
compositional approach. Long melodies, if present, are constructed out of small cells, mere motives of three or four notes, while techniques of motivic transformation permeate the whole work. Moreover, third-related harmonies occupy a less important role in the work. The diatonic fabric itself appears to have shrunk in prevalence and synthetic scales (octatonic) are more openly present. Dissonances are also more pungent than what has been seen so far-except perhaps for a small passage in Nocturne no. 2 (measures 22-23), in which minor seconds in the soprano part were played $f f$. The following musical figure (5.6) shows the formal aspect of Nocturne no. 6.

Musical figure 5.6: Liebermann's Nocturne no. 6

\begin{tabular}{|c|c|}
\hline $\mathbf{A}(10-28)^{*}$ & $\mathbf{B}$ \\
\hline $\begin{array}{l}\text { Intro (1-9) motives a, b, c, c } c^{1} \\
\text { - m.i. } 1(10-16 ; 17-20) \text { [eb] } \\
\text { - extension (21-28) }\end{array}$ & $\begin{array}{l}\text { - } \text { motives }(29-40) \text { [e b] } \\
\text { - extension }(41-42)\end{array}$ \\
\hline $\mathbf{C}$ & $\mathbf{A}^{\prime}$ \\
\hline $\begin{array}{l}\text { - m.i. } 1 \text { duet (43-55) [C] } \\
\text { - } \quad \text { extension (56-63) [eb] }\end{array}$ & $\begin{array}{l}\text { - } \text { m.i. } 1(64-69)[\mathrm{e} \text { ] } \\
\text { - } \quad \text { extension }(70-73 ; 74-77 ; 78-83) \\
\text { - m.i. } 1(84-90 ; 91-95)[\mathrm{e} b] \\
\text { Coda (96-109) m.i. } 1+\text { motives }\end{array}$ \\
\hline
\end{tabular}

*The introduction is not part of the A section, since it is not used again in section A'. 
The Nocturne opens with an introduction of nine bars. It establishes the tonic center (Eb) through the use of a pedal point in the left hand. ${ }^{142}$ On top of this Eb-centered tonic pedal point, Liebermann introduces the material which will later be developed in the Nocturne. The first melodic motion from $\mathrm{E} b$ to $\mathrm{A}$, an augmented fourth, followed by a downward step motion, is the first motivic cell (motive a). At bar 2, there is a small rhythmic cell that will be used again (measures 70-73) as transitional material (motive b). Measure 3 brings back the opening melodic gesture of the jump of a fourth and it is followed by a three-note melodic idea going down, C-B b-A, (motive c); this will be the basis of a very important cell to come. Motive b appears again at measure 4, right before motive c, to which F\# is added; this now four-note motive, which carries a crucial role in the Nocturne, (motive $\mathrm{c}^{1}$ ), will be heard in its entirety twice, and partially once, ending on a low A, held for 10 beats while a Eb arpeggio pattern prepares the way for the first melodic theme. Obviously, motive a and motive $\mathrm{c}^{1}$ are closely related by the interval of the fourth: in motive $\mathrm{c}^{1}$ the interval of the fourth is present but it is filled in by other melodic elements. The following musical example (5.6.1) displays the introduction and motives $\mathrm{a}, \mathrm{b}, \mathrm{c}$ and $\mathrm{c}^{1}$.

142 Wallach discusses the importance of tonic pedal points in opening and closing sections of the Nocturnes by Field and Chopin. For her, this device was an important feature of the genre. However, even though Fauré used pedal points, he did not rely on tonic pedal points as systematically as his predecessors; neither did Liebermann - that is to say, up to this point. But neither Fauré nor Liebermann restricts the usage of pedal points to opening or closing sections. 
Musical example 5.6.1: Liebermann's Nocturne no. 6, measures 1-10 The motives (motives $\mathrm{a}, \mathrm{b}, \mathrm{c}$ and $\mathrm{c}^{1}$ ) are identified in the example.

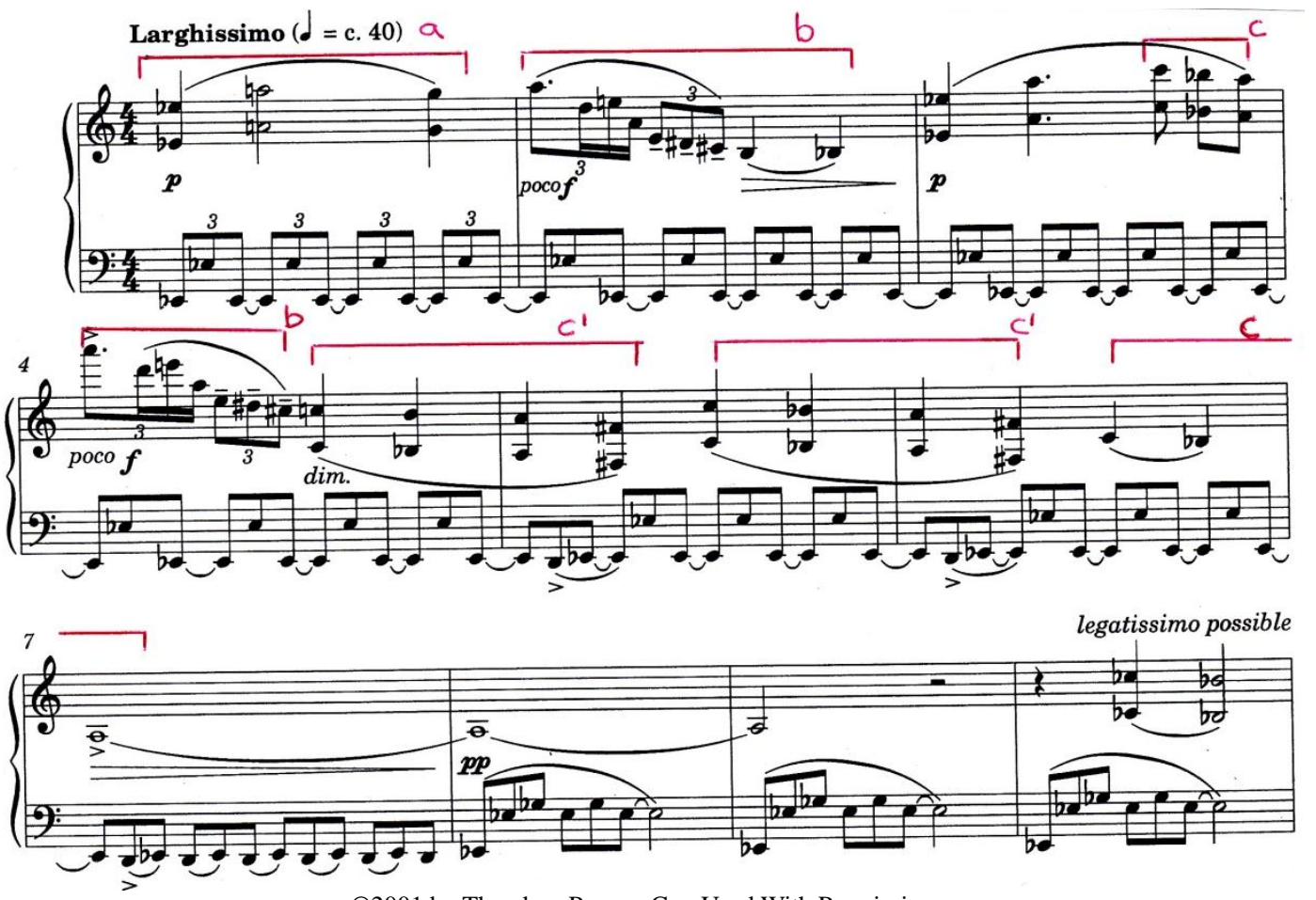

○2001 by Theodore Presser Co., Used With Permission

The following section (A) is more lyrical than the introduction. The lyrical thematic material (melodic idea 1) makes clear references to previous motives, particularly the fourth (raised or natural - motive a) and the four-note motive (motive $\mathrm{c}^{1}$ ). Melodic idea 1 unfolds smoothly (at measures 10-15, then 17-23 and 24-28) while going through many transformations over a sliding bass line moving down as follow: Eb-D-D b-C-D; D-C-B-D; D b-B b-A-A b-G. The way in which the line leaves gaps which it then fills in, creates motion and gives a sense of completion. When the melody is considered with the underlying harmony, intervals of raised fourths and lowered sixths seem to give their flavor to the whole passage (for example, see measures 10,11, 17, 18 for the sixths, and measures 12, 19 for the fourths). The melodic motion of lowered sixth, suspended and resolving to the fifth, juxtaposed with motive $\mathrm{c}^{1}$ and its many permutations, makes this theme easily recognizable; it also gives coherence to the theme while 
making it easy to vary subsequent statements. The following musical example (5.6.2)

shows melodic idea 1 , beginning in measure 10 .

Musical example 5.6.2: Liebermann's Nocturne no. 6, measures 7-18
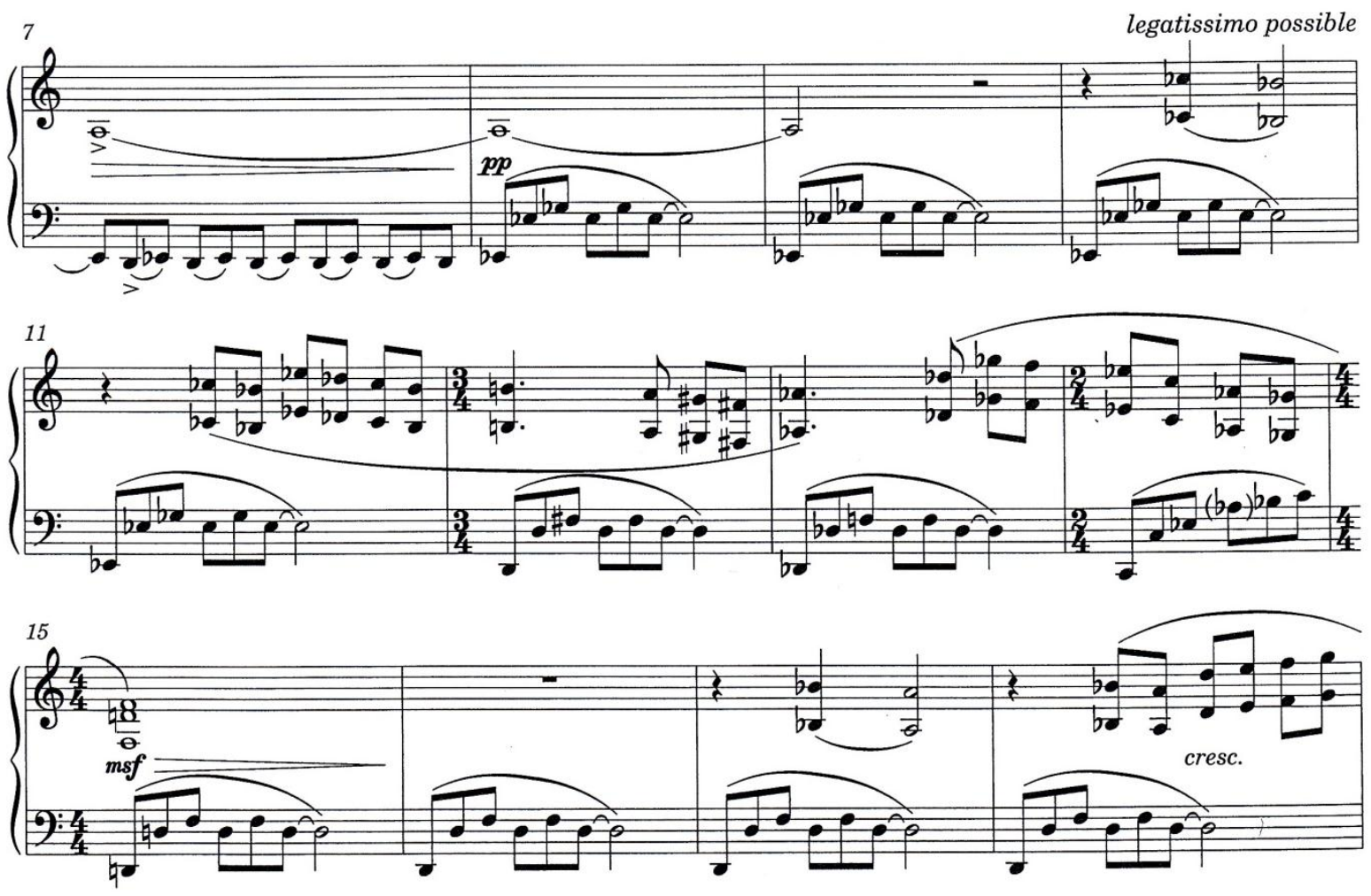

(C2001 by Theodore Presser Co., Used With Permission

The simple accompaniment pattern based on the bass note and the third above it, in

triplets, presented for the first time at measure 8 , has also now become a very recognizable

feature of the work and provides the main texture for this entire section. ${ }^{143}$ At measure 27 , the

left hand plays a rapid octatonic scale, which rests on a trill and leads to the next section. This

143 While in most cases the bass note is the root of the chord, there are a few instances when it differs. For example: at measure 14 , the bass note $\mathrm{C}$ is the third of the $\mathrm{Ab}$ chord; and perhaps also at measure 12 , where the $\mathrm{D}$ could be heard as the third of the B minor chord. 
scale is not the usual octatonic scale of alternating half-steps and whole-steps and arguably

comes from the melodically significant pitches of the melody in measures 10 to 15 (Cb/B b-EbAb-/F-ED//C/Ab-F/D) plus G. And then it changes, beginning on F\# within the undicilet to what might be called a segment from a D-Lydian scale. At measure 29, the texture changes,${ }^{144}$ marking section B; the left hand plays repeated harmonic intervals (minor thirds and major seconds), or clusters (major seconds and minor seconds) which go upward mostly chromatically (Eb-E-F-Gb and then G\#-A-B b-B-C-C\#), while the right hand sings another transformation of melodic idea 1. The melodic line is greatly expanded by constantly evading cadences or resting points and by juxtaposing familiar melodic gestures right next to one another (mainly: head of melodic idea 1, jump up — motive a, and downward step motive $\left.\mathrm{c}^{1}\right){ }^{145}$ The section culminates at measure 37 with another transformation of melodic idea 1, played in octaves and tripled by the left hand, $f f$. Two more presentations of portions of the main melodic idea are heard in measures 41 and 42, played decrescendo, passing through the key of $\mathrm{e} b$ and leading us to the following section. Musical example 5.6.3 displays a few motivic transformations from section B.

144 A good indicator that there is a change of a section is the texture in the accompanying part. For example, the introduction is accompanied by pedal points; in section $\mathrm{A}$, the melodic idea is unfolding on top of arpeggio patterns; and in section $\mathrm{B}$, the accompanying material is made of repeated intervals and clusters.

145 This is not without recalling Fauré's technique of expanding a melody (see Nocturne no. 6, measures 88-99 and 106-110); it is also reminiscent of Shostakovich's expansion technique. 
Musical example 5.6.3: Liebermann's Nocturne no. 6, measures 30-42
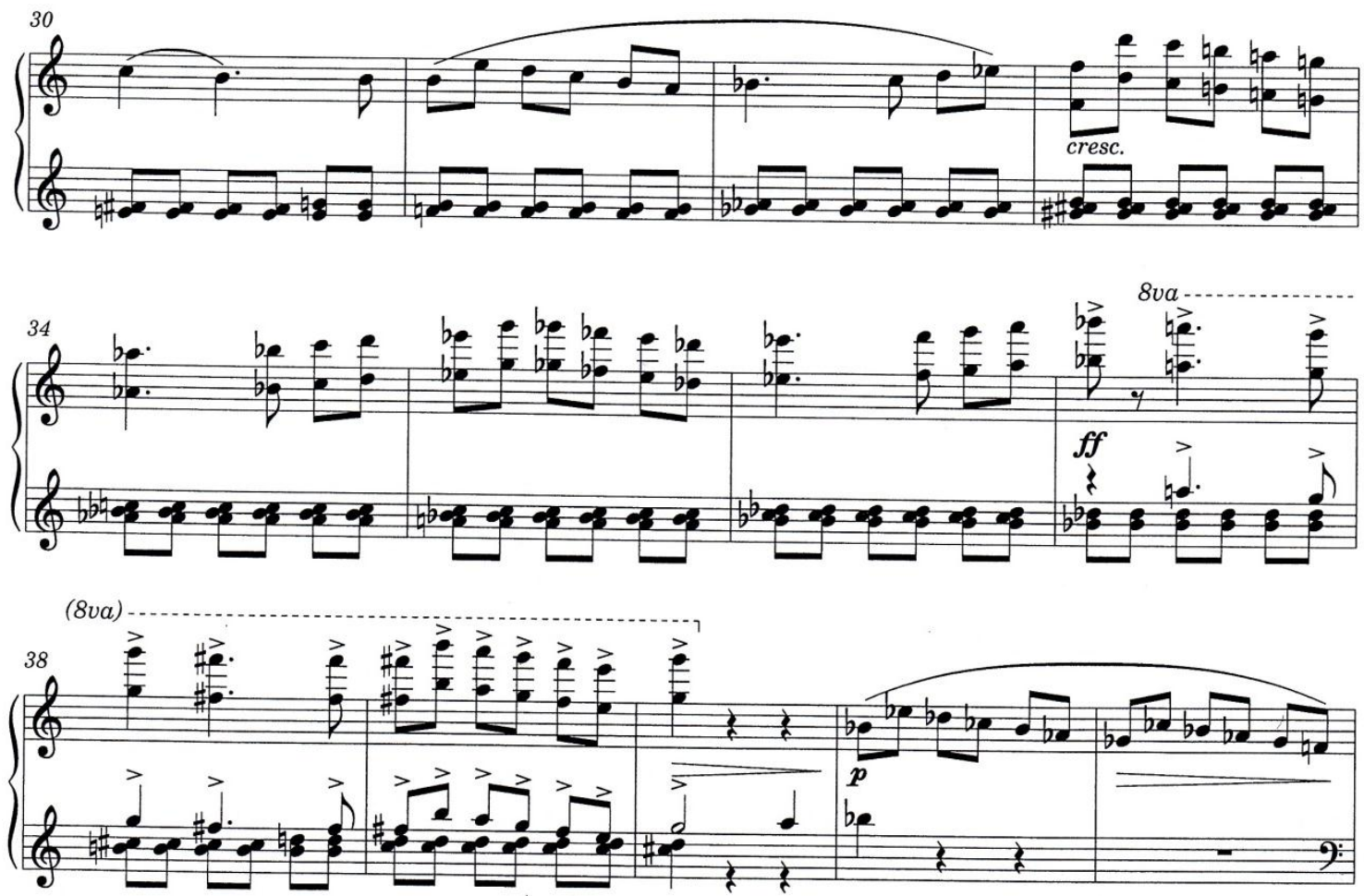

(C2001 by Theodore Presser Co., Used With Permission

Section $C$ is signalled by a small change of tempo in measure 43 , a feature unusual in Liebermann's Nocturnes so far. In fact, no tempo changes were encountered in any of the Nocturnes except for a few in: Nocturne no. 1(the calando at measure 18; a tempo at measure 23; and rit. /a tempo at measure 31-32), Nocturne no. 2 (the pochiss. movendo at measure 5), and in Nocturne no. 5 (rit. /a tempo at measures $92-93$ and rit. at measure 114). This section is marked "movendo cantando." The familiar accompanying pattern is slightly modified by octave displacement of the upper note, but still relies on the bass note and the third above it; however, at some points, the third is replaced by the interval of a fourth (measures 46,50 and 51). Over this comforting texture a little duet unfolds. The duet is imitative, almost canonic. The respective voices play material taken from motives a and melodic idea 1 . The melody follows an 
antecedent-consequent type of presentation (measures 43-47 and 48-49 and extension 50-55), in which the consequent is expanded by adding familiar melodic cells and avoiding cadences. This is played over a long descending chromatic bass line ( $\mathrm{C}-\mathrm{B}$ and $\mathrm{D}$ b-C-B-B $\mathrm{b}-\mathrm{A}-\mathrm{A}$ - $-\mathrm{G}-\mathrm{F} \#)$. In that passage, beginning at measure 45 , the implied harmonies recall familiar gestures used by Liebermann: third-related harmonies connected by common tones (C-E-Db-A-C-E). The augmented fourth, so characteristic of motive a, is also used for harmonic coloration (measures $44,49)$. The process of expanding the consequent, which is also conjugated with the chromatic bass line, serves to bring the music to its second climatic moment. After a long crescendo of eight measures, at measure 56, a transformation of motive $\mathrm{c}^{1}$ is heard $f f$ accompanied by a clear pedal of e $b$ chord (home-key). This passage does not try to conceal dissonances or a sensation of quasi-bitonality (G over e $b$ at measures 58-61). Moreover, within this web of dissonances, one can also hear the familiar triad made with both major and minor third ( $E b$ with $G$ and $\left.G^{b}\right)$. The drama recedes when the familiar accompanying texture of bass note (in this case, tonic) and third is heard at measures 62-63. The following musical example (5.6.4) shows the dissonant passage from section $\mathrm{C}$, numerous transformations of motive $\mathrm{c}^{1}$ and the repeated eb chord with its lowered-neighbor appoggiatura. 
Musical example 5.6.4: Liebermann's Nocturne no. 6, measures 54-63
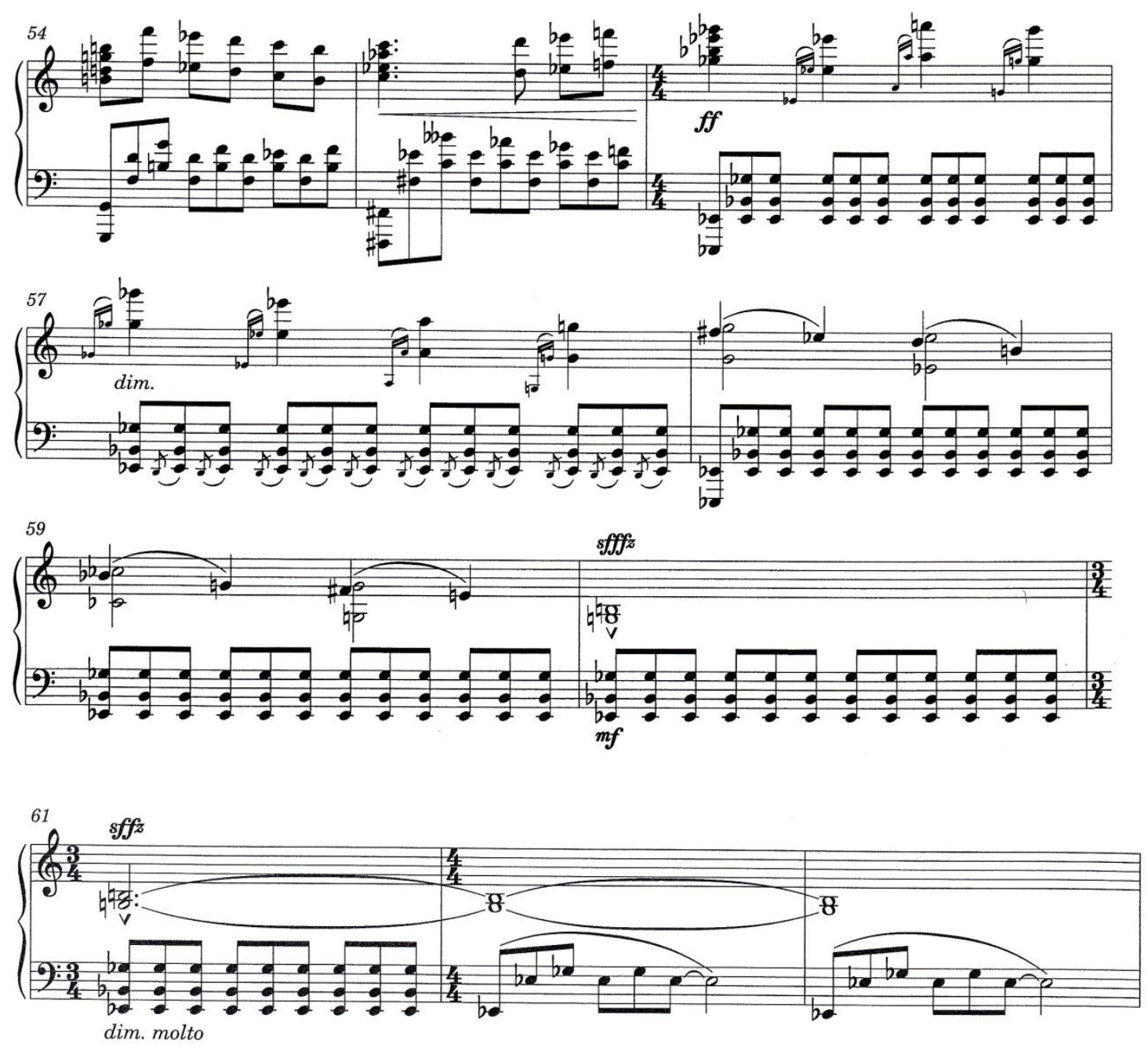

C2001 by Theodore Presser Co., Used With Permission

Melodic idea 1 enters anew at measure 64, (section A'), very similar in its presentation to that in measures 10-13, except for the inclusion of the third under the soprano line (quite Brahmsian in nature), a few enharmonic respellings, and the unexpected turn which carries the music to the partial harmony of $A b$ minor (tonic and mediant, measure 69).

The recognizable bass-note-third accompaniment pattern is heard while the music goes through some extensions, organized in a three-fold manner (measures 70-73, 74-77, and 78-83). The head of this passage is based on motive b, which was briefly introduced at measures 2 and 4 . 
The following scalar material is quite diatonic, firstly using the scale of $\mathrm{A} b$ minor, secondly of $\mathrm{C}$ (presence of the raised fourth at the end), thirdly of G\# minor (respelling A $b$ minor), and lastly, of $\mathrm{C}$ again. The incomplete harmonies underneath do not always coincide with the upper material, for they present bass note and minor third played over Ab, B b, B, C, C\# and D. Those four measures are followed by another four measures of transition, but with a different texture. The left hand plays an octatonic scale going up (alternating whole-steps and half-steps), first in thirds, then in sixths, and finally in ninths alternating with octaves, while the right hand plays a melodic cell inspired from the main melody. ${ }^{146}$ This passage strongly relies on sequences. Although the melodic material is similar, it becomes therefore quite difficult to perceive it as such because the melodic interest has been shifted because of a new rhythmic grouping.

The melodic cell goes through numerous transformations. A gigantic excitement is generated by the juxtaposition of those cells. They are varied rhythmically, shortened, and played louder and louder, until the dynamic level reaches $f f f$ at measure 78 . The texture during build-up is quite thick and a complex web of polyrhythms can be observed. At the beginning of this section, the rhythms were combined in a very equal manner: triplet eighths and sixteenths (measures 74-75). The following measures see an increase in complexity: there are three different layers, and the combination can read thus: four against three against six; then five again three against six; again four against three against six; and finally eight against three against six. The following musical example (5.6.5) displays a portion of the build-up to the climax with its octatonic scale, the transformations of the motivic cell, the sequences and the complex superimposition of the numerous aforementioned rhythms.

146 I believe that a few errors in regard to accidentals appear in the score: at measure 74, second beat, fourth sixteenth should read as D natural and third beat second sixteenth should read as F natural. 
Musical example 5.6.5: Liebermann's Nocturne no. 6, measures 74-77
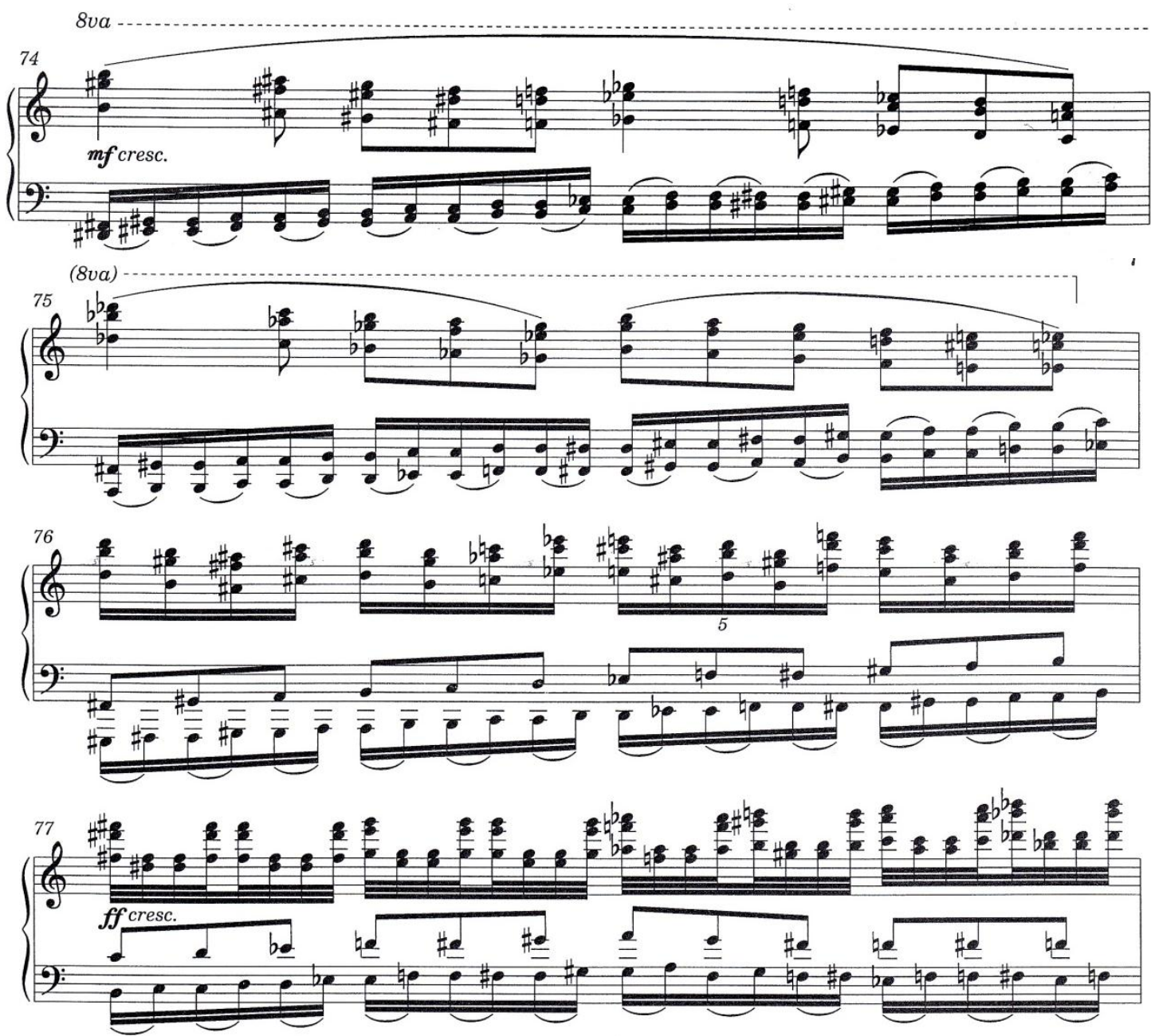

(C)2001 by Theodore Presser Co., Used With Permission

This dramatic construction leads to the ultimate climax of the piece in measure 78. For the next four measures, a pedal point of $\mathrm{E}$ is established in the left hand. During the first measure of this pedal point, the right hand plays a $b b$ chord in its first inversion in the very high register, the pitch $\mathrm{F}$ in the middle of the instrument, and e b chord in the very low register. All these elements are played accentuated: fff, sffz and sfffz. In the next measure only the first two elements are sounded again, in a much softer dynamic. In the following two measures, while an 
important decrescendo is in progress (beginning at measure 78), the accompanying pattern of tonic and third in eb appears again, and is followed by the same pitch F. This gesture is played two times and thereafter, the pedal point of E disappears. The bass slides chromatically to Ebalong with a partial harmony of $\mathrm{e} b$-while the $\mathrm{b} b$ chord in first inversion rings in the upper register. The atmosphere quiets down, dissonances disappear and, at measure 84, the familiar and soothing melodic idea 1 comes anew (section A"). The following musical example (5.6.6) shows that gigantic decrescendo when dissonances and accents disappear and melodic idea 1 reenters.

Musical example 5.6.6: Liebermann's Nocturne no. 6, measures 78-88
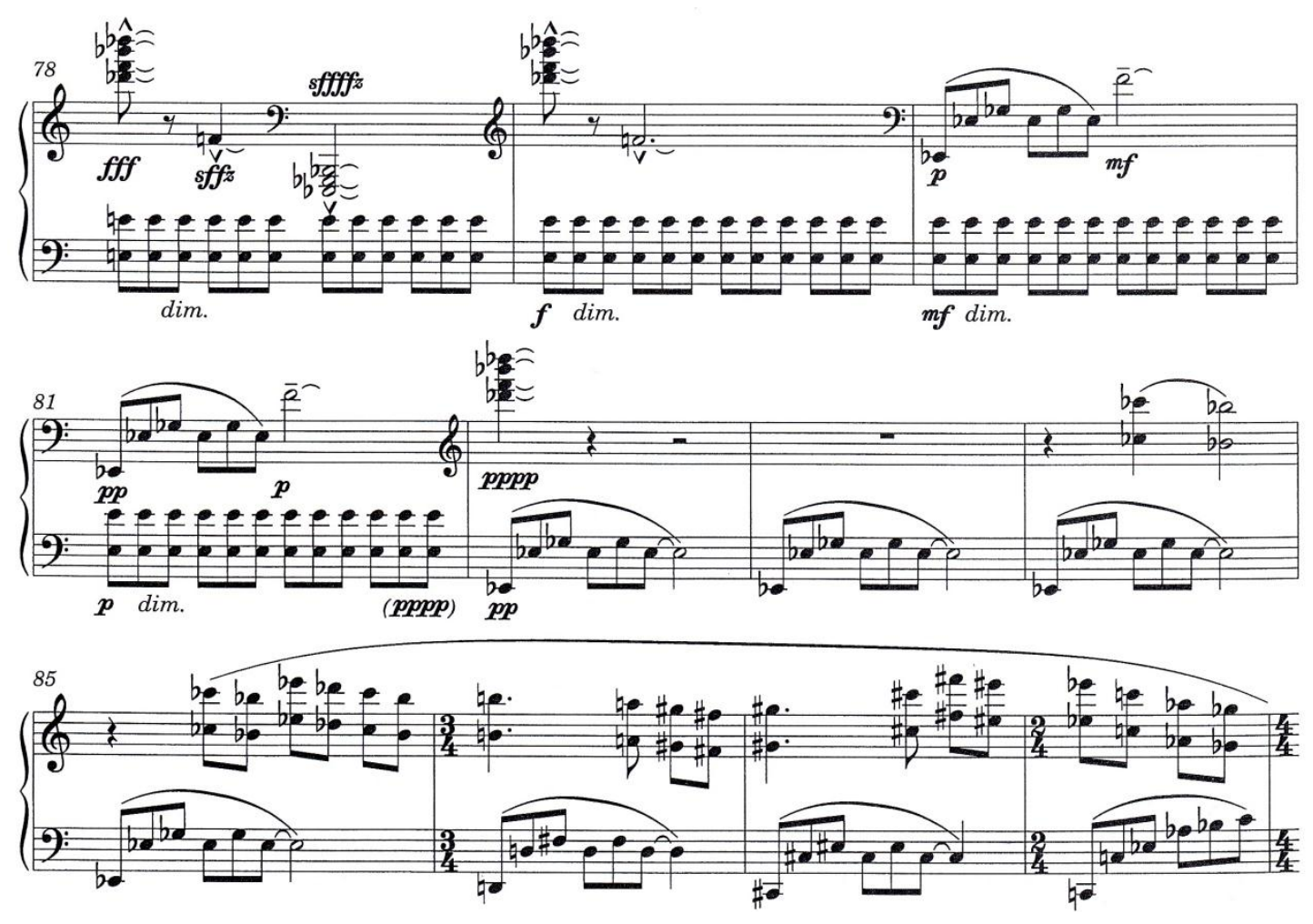

(C2001 by Theodore Presser Co., Used With Permission 
The following material (measures 84-93) is the same as that found at measures 10-19, but with the right hand played an octave higher. At measure 93, the A $b$ becomes enharmonically G\# and allows Liebermann to depart slightly from the original material. ${ }^{147}$

The closing section (coda), cantando, is based melodic idea 1 , first in $\mathrm{d}$, and then in $\mathrm{G}$. The familiar accompanying pattern is confined to the lower part of the right hand in the middle register while the left hand plays a rhythmic echo of the first two pitches, in octaves, suggesting and alternating the two mediant members of the "understood" harmony. At measure 104, melodic idea 1 metamorphoses into motive $\mathrm{c}^{1}$, while the opening $\mathrm{E} b$ pedal point resumes. Just as in the introduction, it is heard twice completely and once partially (only the first three members are sounded). The last A is held while the familiar accompanying tonic-third pattern is played three more times. Along with its last appearance, a melodic motion C $\mathrm{b}$-A natural is heard. Those two pitches summarize the entire melodic coloration of the Nocturne: the suspended lowered sixth (melodic idea 1) and the augmented fourth (motive a and motive $\left.\mathrm{c}^{1}\right) .{ }^{148}$

Nocturne no. 6 is still very Liebermann-sounding, but its workmanship is quite different than the previous Nocturnes (including Nocturne no. 1). Here the dissonances are expressed more frankly, at times almost pungently; Liebermann is even flirting with bitonality. The melodic material itself is more dissonant in nature and more motivic in its organization. It is however associated with simple accompanying textures. Unlike Nocturnes nos. 2 to 5, third-related

147 The arrival on $\mathrm{Db}$ at measure 89 , rather than the parallel D-natural in measure 15 , is also a hint to the performer that something new is happening. Obviously, this $\mathrm{D} b$ chord should sound fresh and distinct from the $\mathrm{C \#}$ at measure 87. Moreover, in the following passage, Liebermann begins an intensive play with major/minor thirds, starting with the F, previously a minor third (measure 15), now a major third (measure 89).

148 The extensive use of $E$ b-G b-A suggests that the referential sonority of the Nocturne is a diminished triad, or even a fully-diminished seventh chord, but the addition of $\mathrm{Cb}$ produces an enharmonic equivalency to an inverted B dominant seventh. The last six measures of the piece offer a striking example of this "diminished" quality: from measure 104 onward, $\mathrm{Eb}, \mathrm{Gb}$ (sometimes $\mathrm{F} \#$ ) and $\mathrm{A}(\mathrm{B} b \mathrm{~b}$ ) seem to be the referential- $\mathrm{a}$ diminished triad. If one includes the pitch $\mathrm{C}$ as a main element, the ensuing referential becomes that of a fullydiminished seventh chord. Finally, concerning the remaining pitches, D is seen as a lower neighbor tone and $\mathrm{B} b$ as a passing tone. 
harmonies, even though they are present, do not appear to play a crucial structural role. They are less prominent and less significantly used. The same observation can be made for the multilayered textures and the idea of imitation. One more element to support the thesis that this Nocturne is different from its predecessors is the fact that no indications of pedal markings are found in this work. In Nocturne no. 1 to Nocturne no. 5, Liebermann wrote precisely his sonorous intentions in regard to pedal, at times exploring unashamedly the blurring of conflicting harmonies. Even though the tonic pedal point appears to play a significant role in the fabric (of the 109 measures, 31 include a pedal point on Eb), however, in this musical work, the real achievements seem to be the experimentation with motivic relationships and transformations.

\subsection{Nocturne no. 7, op. 65}

Nocturne no.7 was composed in 1999, commissioned by the Welsh Arts Council and first performed by Iwan Llewelyn-Jones on September 29, 1999, at the North Wales Festival, in St. Asaph Cathedral, in Wales. ${ }^{149}$ This work is 134 measures long and requires about six minutes to be performed.

The overall atmosphere of this Nocturne is surprisingly subdued for Liebermann. ${ }^{150}$ There is no loud dramatic climax, for the dynamics range from $\boldsymbol{p p p}$ to $\boldsymbol{p}$, excepting only a fourmeasure crescendo to $f f$, followed by a subito $\boldsymbol{p p}$. Some of the significant features of the work are the redistribution of material between the hands, the numerous hand crossings, and the multilayered textures; but the accompanimental gestures have a tendency to merge into a single

149 Iwan Llewelyn-Jones is a British pianist. See Appendix B for more information, or consult the artist's website at: http://www.iwanpiano.com/. The score attributes the first performance and the dedication to Iwan LlewellanJones, which, I believe, is a misspelling.

150 According to William T. Spiller, it has "a lighter texture, with some drama in the ternary form's middle section. The subtle and choreographically demanding mix of touches poses a challenge in this atmospheric work." (Journal of the Music Library Association) taken from: http://www.presser.com/composers/info.cfm? Name $=$ LOWELLLIEBERMANN\#Reviews 
sonorous entity. In fact, a distinguishing feature of this particular Nocturne is the application of imitation only to accompanimental figures, rather than the imitation and canon we see in Nocturnes no. 3 to 6 . There are two tempo changes (including a return to the starting tempo), a new feature which began to appear in the genre with Nocturne no. 6 . The following musical figure (5.7) illustrates the formal organization of Nocturne no. 7.

Musical figure 5.7: Liebermann's Nocturne no. 7

\begin{tabular}{|c|c|c|}
\hline $\mathbf{A}$ & B & $\mathbf{A}^{\prime}$ \\
\hline 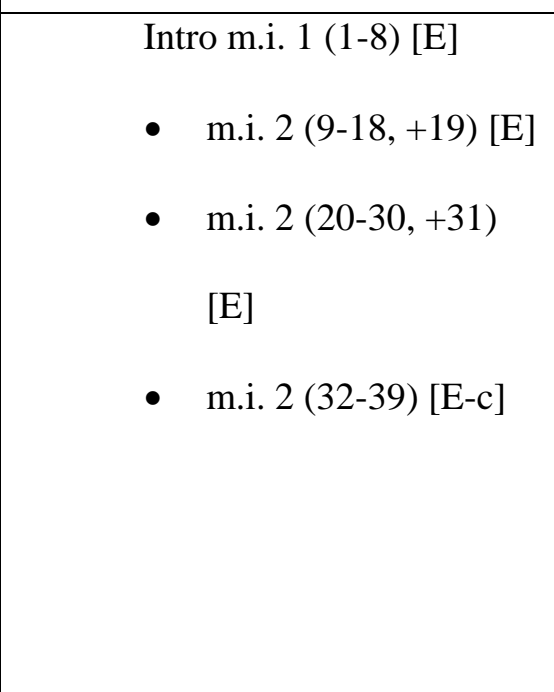 & 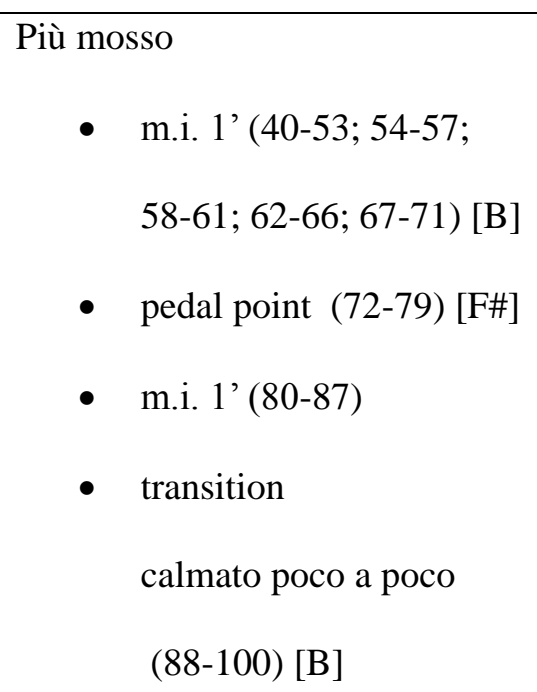 & $\begin{array}{l}\text { Intro, m.i. } 1 \text { (97-103) } \\
\text { - } \text { m.i. } 2 \text { (104-114) [E] } \\
\text { - } \text { m.i. } 2(115-124)[E] \\
\text { - } \quad \text { extension pedal point } \\
\quad(125-126) \\
\text { Coda (127-134) [E] }\end{array}$ \\
\hline
\end{tabular}

The Nocturne starts Adagio con rubato with a short introduction of eight measures which establishes the key of $\mathrm{E}$ through the presentation of an accompanying figure based on the arpeggio in the upper register. This ostinato of seven notes is created by the alternating interactions of two superimposed lines, starting with the soprano line, which plays the descending arpeggio of $\mathrm{E}$ (G\#-E-B-G\#) while the alto line also plays members of the $\mathrm{E}$ harmony (pitches B-G\#-B). At measure 2, the left hand plays a melodic line (melodic idea 1) which seems 
to be rooted in the key of Eb (G-A b-G-F-Eb-F), followed by a succession of four harmonies displaying tertian relationships (F-A b-C-E). The melodic line will be the basis of the B section (beginning at measure 40) and will undergo several thematic transformations. Both hands come to a tonal agreement at measure 6 when the left hand plays a low E chord and the right hand plays a simpler accompanying pattern, this time two octaves lower than the first note of the piece.

The other important melodic idea (no. 2) enters at measure 9, (section A), played by the left hand. It encompasses some modal inflections: the raised fourth, and the lowered sixth and seventh - familiarly heard in previous Nocturnes by Liebermann. The hands are playing in very close proximity, forcing the left hand to cross over at times. The harmony slides briefly and subtly to $\mathrm{C}$ (measures 16 and 17 ) before returning to $\mathrm{E}$ at measure 18 for the second presentation of the principal melodic idea (at measure 20). Musical examples 5.7.1 and 5.7.2 display two consecutive presentations of melodic idea 2.

Musical example 5.7.1: Liebermann's Nocturne no. 7, measures 5-14 Compare to the second presentation of the same melody
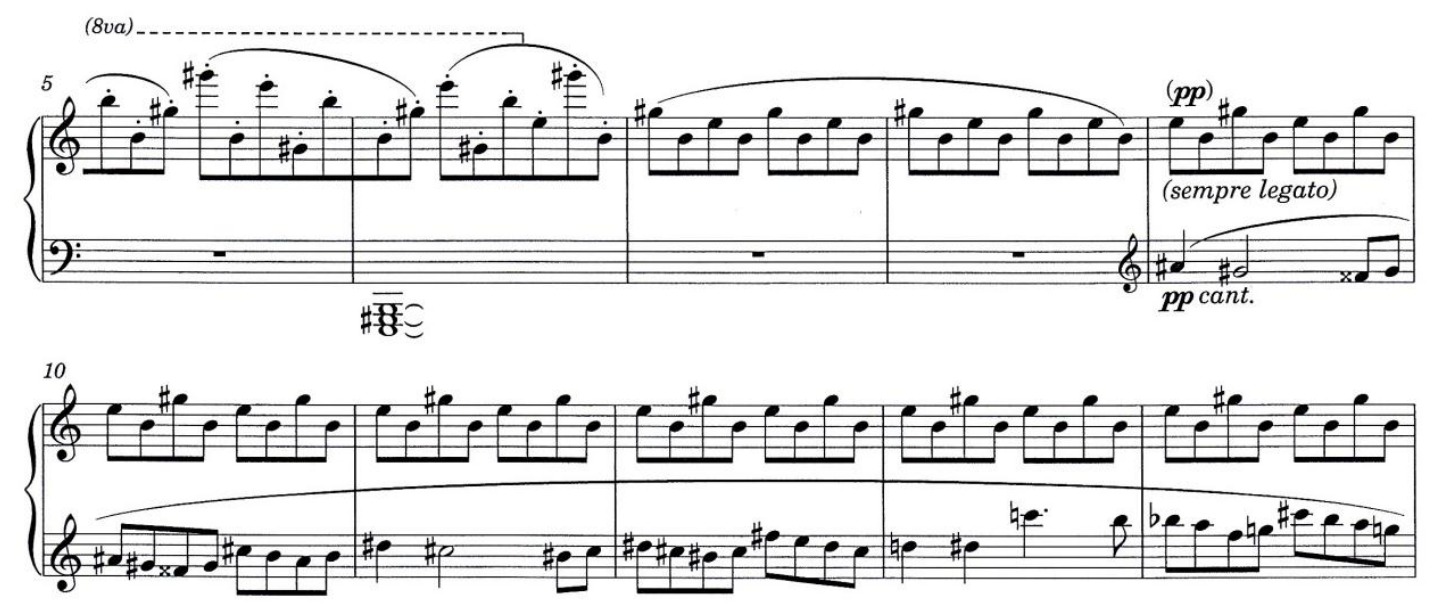

C2001 by Theodore Presser Co., Used With Permission 
Musical example 5.7.2: Liebermann's Nocturne no. 7, measures 20-23

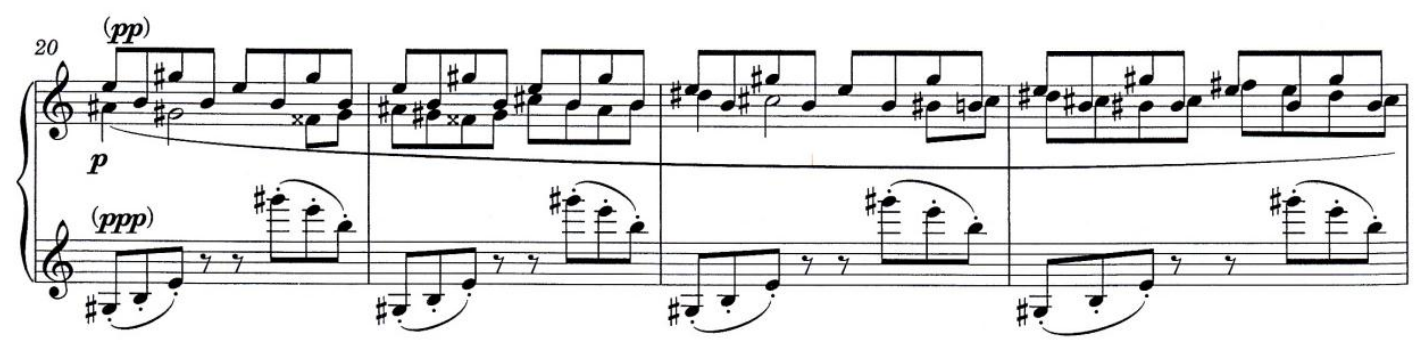

C2001 by Theodore Presser Co., Used With Permission

When the melodic idea 2 appears anew, the accompaniment figure and the melody are played by the right hand, while the left hand plays simple arpeggios in the middle and high registers, passing back and forth over the right hand. This is another example of Liebermann's ingenious use of multi-layer texture. Harmonies slide chromatically with the bass line and visit the harmonies of E, Eb, D and B. A rare case —in Liebermann's output —of a traditional harmonic progression (V-I) arises at measures 29-30 when melodic idea 2 resumes while a new accompanimental cell is added to the left hand. Similar V-I progressions will be heard at measures 100-101 and at measures 130-131, always in the key of E. At measure 36 the melody moves from the alto line to the soprano (espr.), in the key of $\mathrm{c}$. The harmony slides down a semitone for the first tempo change, Più mosso (quarter note $=$ c. 80 ); this signals the beginning of B section.

Section B is built upon the melodic material that first appeared in the left hand in the introduction (melodic idea 1, measures 2-4, and the following tertian relationship of measures 46). In its complete presentation, it consists of a diatonic line highlighting the intervals of semitone going up, coming back down, then down a step, down a step and once more, down a step. Thus, the line reads G-Ab-G-F-Eb (measures 62 to 66). Throughout the section, this idea will be elaborated upon with chromatic expansion, tonicization of the pitches, or addition of a 
few melodic members. However, the overall shape of the line remains quite recognizable. At measures 40 to 53 , this idea recurs, but the entrance is delayed by a prolongation of the first pitch (B), which is repeated three times. The soprano voice presents the melodic line (doubled in octaves), and the notes change in the middle of the measure. The latter part of the melodic idea 1 is expanded chromatically (measures 47 to 53 ). The accompanying harmonies are mainly made of major chords, related by thirds, chromatic or tritone relationships (B-G-Db-D-Ab-E-c\#-d-B-D b-D-Eb). Moreover, the outer voices mainly generate intervals of tritones and sixths, with occasional seconds, thirds and fourths.

At measure 54, there is another tempo change, più mosso, and the first four notes of idea 1 are heard, over a simple eb arpeggio. This is followed by four measures of superimposed conflicting harmonies: E-C-A-F in the left hand going up, while the right hand plays G-B-Eb-G going down. While these third-related harmonies emulate the harmonic motions encountered at measures 4-6, the superimposition of those harmonies reflects relationships of third, semitone, tritone and whole tone respectively. After that passage, the left hand settles on a simple arpeggio of F, (measures 62-66), while at the same time the right hand plays the head five notes of melodic idea 2. Again, there is a little inclusion of material made from superimposed harmonies during measures 67 to 71.The left hand plays upward arpeggios of Eb, A, F\#, Eb and B, while the right hand plays downward arpeggios of $\mathrm{D}, \mathrm{F} \#, \mathrm{~B} b, \mathrm{D}$ and $\mathrm{F \#}$. At this point, the music settles on an F\# pedal point. Eight bars later, melodic idea 1 enters again, firstly slightly decorated with rapid filigree arpeggios; later on, it turns into a little duet episode from measures 84-87, treated in a canonic manner. The following musical example (5.7.3) shows melodic idea 1, the pedal point, the filigree decoration and the beginning of the little duet/canon. 
Musical example 5.7.3: Liebermann's Nocturne no. 7, measures 79-87

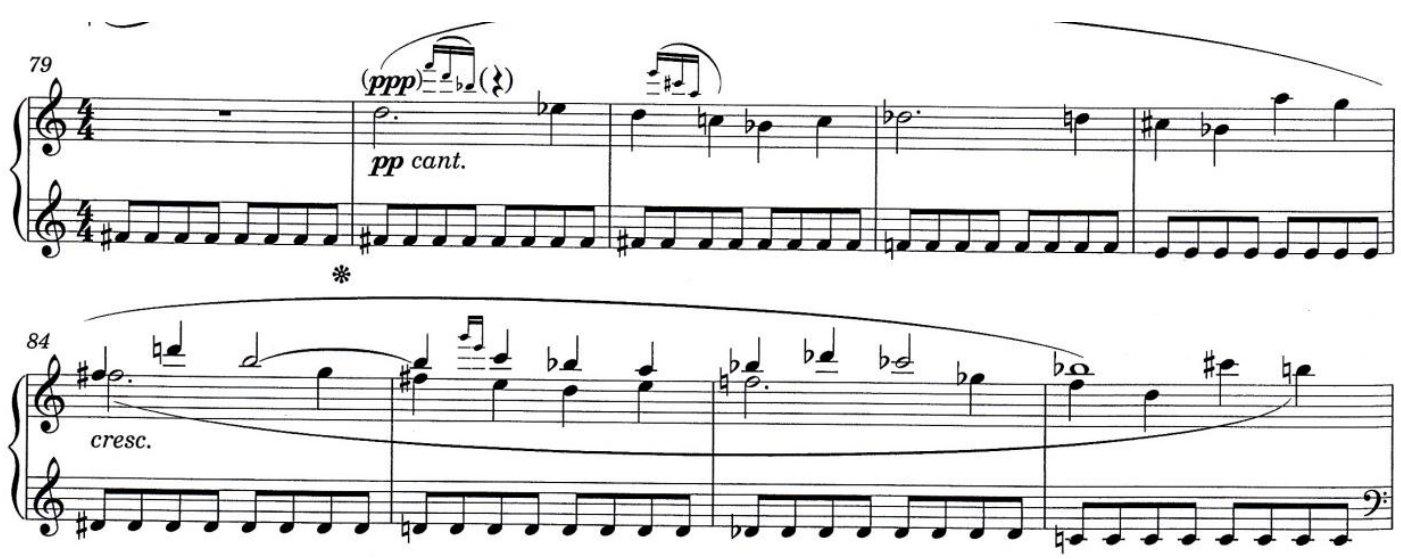

C2001 by Theodore Presser Co., Used With Permission

A passage of a transitional nature appears at measures 88 to 100 . The texture is different and the score indicates calmato poco a poco. The left hand arpeggiates B-Ab-Eb while the middle harmony is composed of major triads (B, A and G), revealing two simple structures with interesting combinational features. On top of this conflicting material, the right hand sings a joyous motive which does not bear any resemblance to material heard before. At measure 97, another presentation of melodic idea 1 is played by the left hand. The melody becomes the lower element of a harmonization of major chords. The final gesture recalls the third-related harmonies of the introduction (F-A b-C). However, this time the progression proceeds through B to E, leading way to the following section and bringing back melodic idea 2 . The melodic and harmonic materials are exactly the same, but Liebermann finds a new way to challenge pianists with a more complex accompaniment. Six different layers can be identified, of which five are simple arpeggios that are assigned to specific registers and that surround the melody, which unfolds quietly in the middle of the piano. The following musical example (5.7.4) shows melodic idea 2 in this new presentation. 
Musical example 5.7.4: Liebermann's Nocturne no. 7, measures 102-108

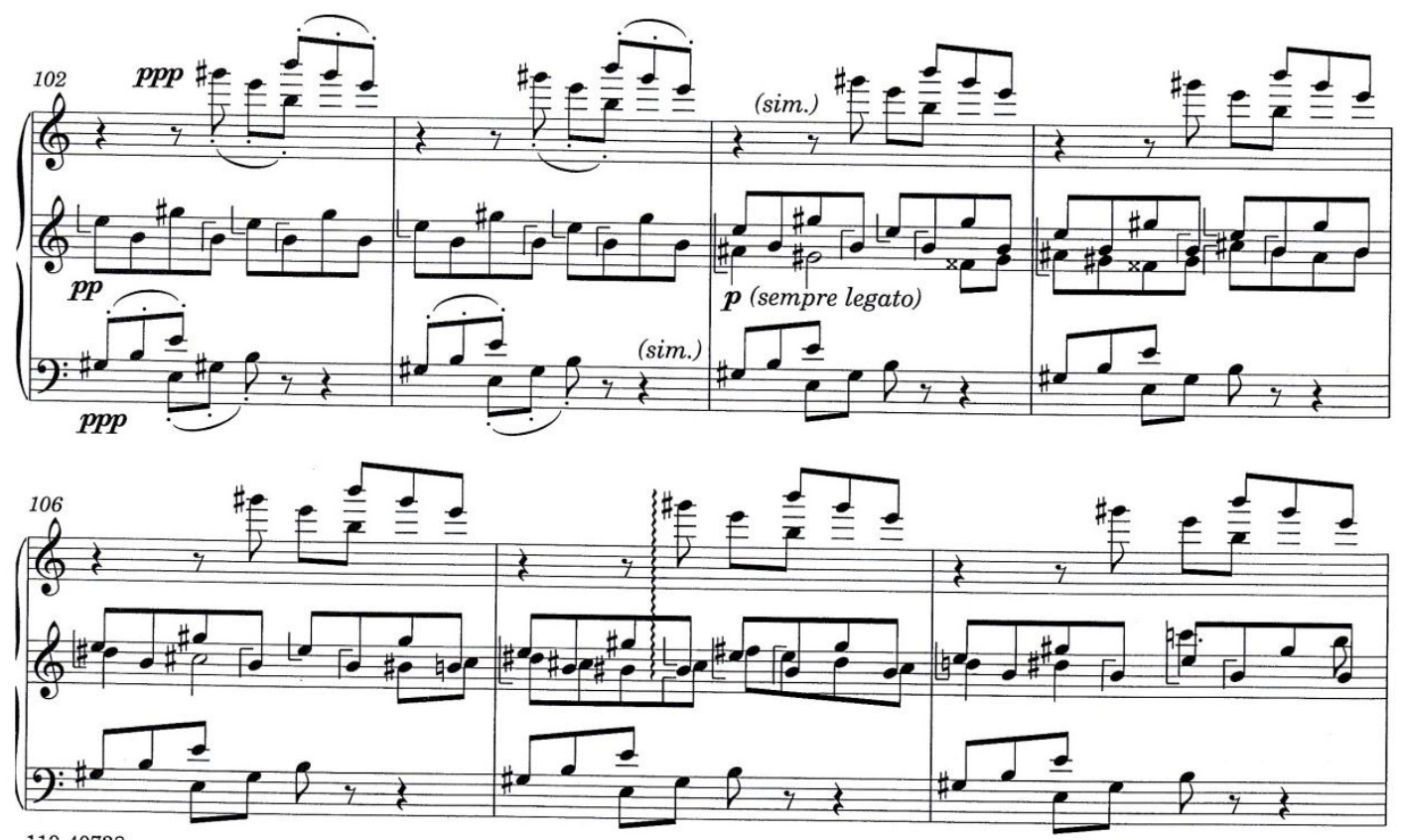

(C2001 by Theodore Presser Co., Used With Permission

At measure 113, triplets enter in the accompanying parts, providing yet one more challenge to handle. Thereafter, the texture remains unchanged until measure 125 . Then the texture becomes radically simpler and melodic idea 1 sings one last time under a pedal point of B. The remaining eight measures constitute a coda, very B-centric in regard to melody_recalling the opening intervals of semitones of melodic idea 1, and emphasizing the tonic-dominant-tonic motions: E (e)-B-E. ${ }^{151}$

\section{$5.8 \quad$ Nocturne no. 8, op. 85}

Nocturne no. 8 was composed in 2003 as a result of a commission in memory of John

151 On his recording of the work, Korevaar plays different pitches in the beginnings of measures of measures 132133, left hand: G\#-B-E in measure 132, B-E-G\# in measure 133. 
Rochel Landry by his parents. ${ }^{152}$ It was premiered by Marc-André Hamelin at the Mannes Festival of Piano Music, in New York City. ${ }^{153}$ This work of 159 measures requires about eight minutes to be performed. ${ }^{154}$ While Donald Rosenberg of the Cleveland Plain Dealer says it "nods to ethereal Chopin tweaked with anguished harmonies," the Birmingham News qualifies it as "dreamy and sumptuous, yet vaguely disturbing," and in reviewing this very Nocturne, the Seattle Times said, "this wonderful thing about all of Liebermann's music is that he writes beautifully yet unpredictably; the Nocturne lulled us with quiet musical darkness while wandering into a wistful dissonance, and did not avoid the fitful storms that sometimes come after nightfall." ${ }^{155}$ The following musical figure (5.8) shows the form of Nocturne no. 8.

Musical figure 5.8: Liebermann's Nocturne no. 8

\begin{tabular}{|c|c|c|}
\hline $\mathbf{A}$ & B & $\mathbf{A}^{\prime}$ \\
\hline $\begin{array}{l}\text { Intro }(1-2)[b] \\
\text { - } \quad \text { m.i. } 1(3-7 ; 8-10)[b] \\
\text { - motives a, b, c, } c^{1}, d, d^{1} \text {, } \\
\text { e, } \mathrm{e}^{1}, b^{1}(11-25)[b] \\
\text { - m.i. } 1(26-37)[b]\end{array}$ & $\begin{array}{l}\text { Meno Mosso } \\
\text { - m.i. } 2(38-41 ; 42-45 ; 46- \\
\text { 50; 51-53; 54-56; 57-60; } \\
\text { 61-64; 65-66; 67-71) } \\
\quad \text { [eb] }\end{array}$ & $\begin{array}{l}\text { transition }(72-87)[b] \\
\text { - } \quad \text { m.i. } 1(88-124)[b] \\
\text { - } \quad \text { cadenza, extension } \\
\quad(124-127) \\
\text { - } \text { m.i. } 1(128-134)[b] \\
\text { - } \operatorname{transition~(135-139)~} \\
\text { - } \quad \text { Coda (140-159) [B] }\end{array}$ \\
\hline
\end{tabular}

152 Mrs. Joan Landry and her husband, Dr. Alphonse Landry, commissioned a musical work in memory of their son, John Rochel Landry, who died of a heart attack at the age of 33, in 1994. [email exchanges with Mrs. Landry, August 2011]

153 Marc-André Hamelin is a Canadian pianist based in Boston. See Appendix B for more information, or consult the artist's personal website at: http://www.marcandrehamelin.com/

154 The score calls for a timing of eight minutes, while Marc-André Hamelin takes ten minutes and nine seconds to play the piece and Sandro Russo performs it in eight minutes and nine seconds.

155 Donald Rosenberg, Cleveland Plain Dealer; Michael Huebner, Birmingham News; John Sutherland, Seattle Times; taken from: http://www.presser.com/composers/info.cfm?Name=LOWELLLIEBERMANN\#Reviews 
The Nocturne opens lento movendo con molto rubato, with a quiet accompanying pattern that permeates the complete first section. This figure alternates between the hands and provides the harmonic fabric. In themselves the harmonic elements are simple, but many dissonances and tonal "blind-spots" are created when the melody unfolds. Two measures of $b$ are played before the first main melodic idea enters. Melodic idea 1 is built according to antecedent (measures 3-10) and consequent (measures 11-24) pattern. Contrary to his habitual practice, in this Nocturne Liebermann seems to utilize conventional harmonic progressions. From measures 1 to 10 , the harmonies accompanying the presentation of the antecedent of the theme can be analyzed as iVI-V-IV-III-I-III-iii-V. This reading is obtained by giving priority to the left-hand main harmonic support, but obviously a different understanding could also be possible. Of course there are close modal interchanges (i-I, iii-III and iv-IV). The harmonies accompanying the consequent of the theme are similar, but venture into further-removed harmonic territories. Thus, measures 11 to 24 can be understood as: i-iv-IV in b, followed by a shift to the key of $\mathrm{f}$ (a tritone relationship) for one measure, $\mathrm{i}$; measures $14-15$ return to the key of $\mathrm{b}$ with a ii-bVII motion; $f$ again at measure 16 for iv; back to $\mathrm{b}$ at 17 for $\mathrm{i}$-which can be understood as iv in F\#-f\#; a final visit in the key of f for a $\mathrm{V}-\mathrm{i}$ gesture at $18-19$; and finally a return to the key of $\mathrm{b}$ for $\mathrm{i}$ which serves to modulate temporarily to the dominant (F\#), i becoming iv, afterwards followed by IV-bii (Neapolitan)-V-i. Moreover, from measure 11 until measure 22, the bass line moves upward chromatically (B-CC\#-D-D\#-E-F-F\#-G-G\#). When the accompanying pattern comes again at measure 25, the last $\mathrm{i}$ in the key of $f \#$ is comprehended as a $v$ in the returning key of $b$. The following musical example (5.8.1) displays the antecedent of melodic idea 1 and the beginning of its consequent. 
Musical example 5.8.1: Liebermann's Nocturne no. 8, measures 1-12

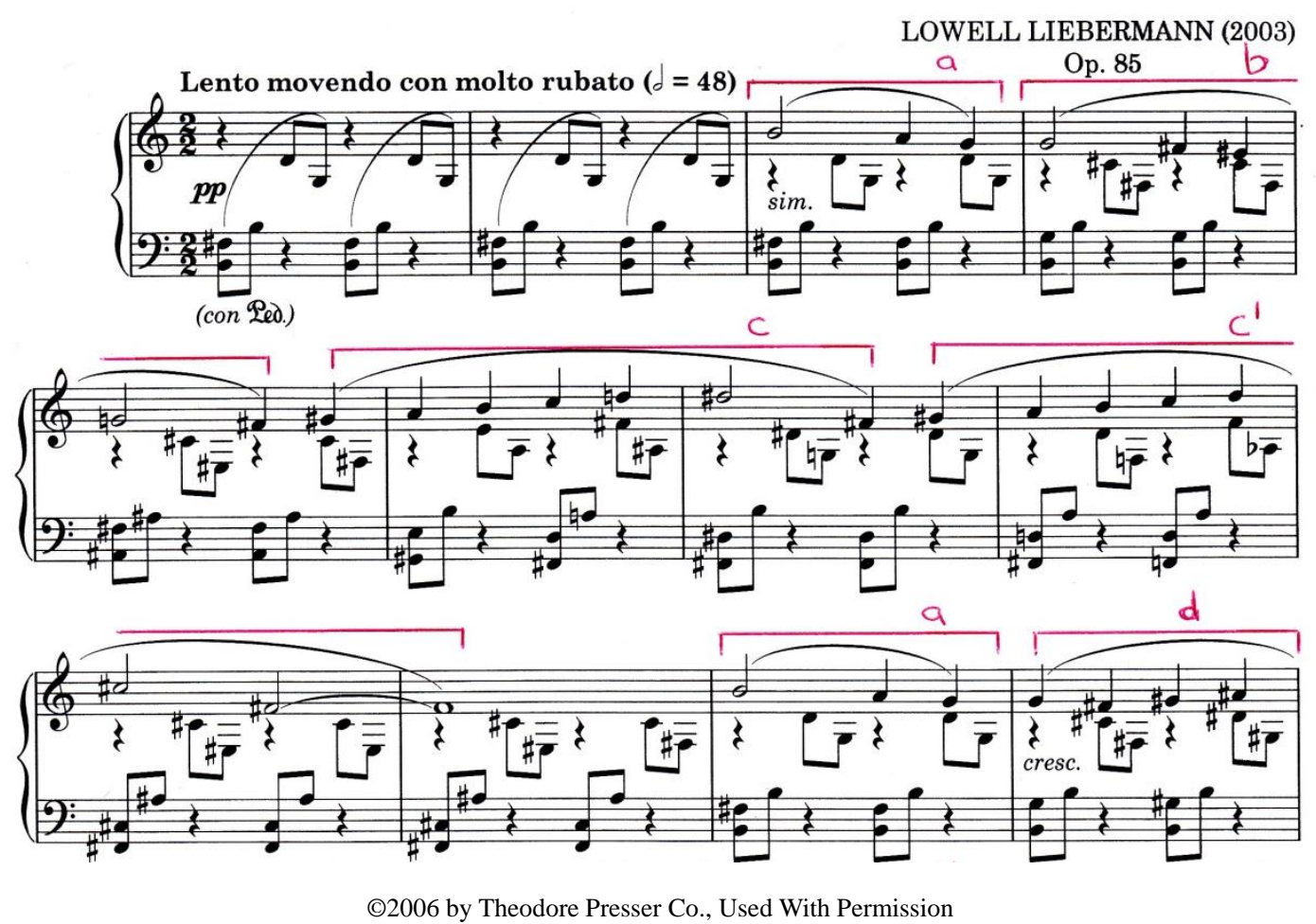

The melody itself unfolds according to the familiar scheme of antecedent-consequent.

The phrasing given by Liebermann sheds light upon his conception of the material in regard to his technique of motivic transformations: in this very instance, the musical phrase is expanded by repetitions. The antecedent can be divided into three important motives: the opening gesture of three steps going down with its characteristic half-quarter-quarter rhythm B-A-G (motive a), followed by a similar motion — rhythm and melody — which emphasizes the first two pitches by repetition G-F\#-E\#-G-F\# (motive b), ${ }^{156}$ followed by a scalar passage resolving with a semitone and a jump down of a sixth G\#-A-B-C-D-D\#-F\# (motive c), and concluded by its twin brother which ends with the jump down of a fifth G\#-A-B-C-D-C\#-F\# (motive $\mathrm{c}^{1}$ ). With this motivic

156 The repetition is based on the first tail of this musical idea; the head of motive b could also be regarded as a motivic transformation of the intervals of motive a: whole step-whole step going down which become half stephalf step going down. 
dissection, it becomes easier to understand the manipulations (melodic and harmonic) exerted by Liebermann on his theme. Thus the consequent begins with motive a. Afterwards, a little transformation occurs on the expected following motive $b^{1}$. Specifically, Liebermann changes the direction and the rhythm and adds one pitch; therefore the motive becomes G-F\#-G\#-A\# (motive d). The theme is expanded by the addition of another motive $\mathrm{d}$ which prolongs the line. It is followed immediately by motive a and $\mathrm{d}^{1}$ (slightly changed rhythmically). At this point a new motive enters, one that resembles earlier fragments but that, through the inclusion of a skip of a third, has its own personality: G-F-D-E-F-E (motive e). ${ }^{157}$ The continuation of the consequent (measures 17-24) reads as follows: motives e, e, $\mathrm{b}^{1}$, e. When broken down into its smallest components, the whole outline of antecedent-consequent would read as follows: a,b,c, $\mathrm{c}^{1}$ —a,d,d,a,d ${ }^{1}, e, e, b^{1}, e$. Even though many other inter-motivic resemblances could be discussed, this example gives enough insight into Liebermann's motivic transformation technique to help us understand how this piece is put together. Musical example 5.8.2 shows the consequent of melodic idea 1.

157 It should be noted that the last two pitches of the motive fill in the gap of the characteristic skip of a third. 
Musical example 5.8.2: Liebermann's Nocturne no. 8, measures 13-24

The motives are indicated above (see also Musical example 5.8.1)

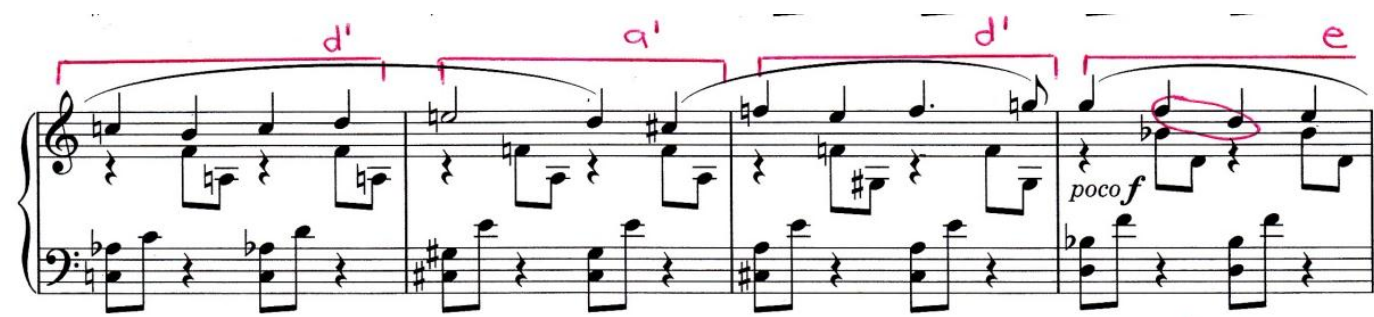

$b^{\prime}$

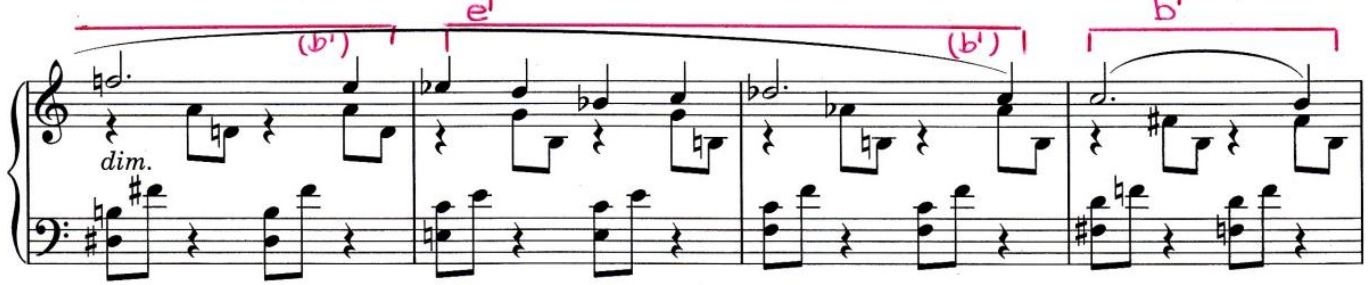

$e^{1}$

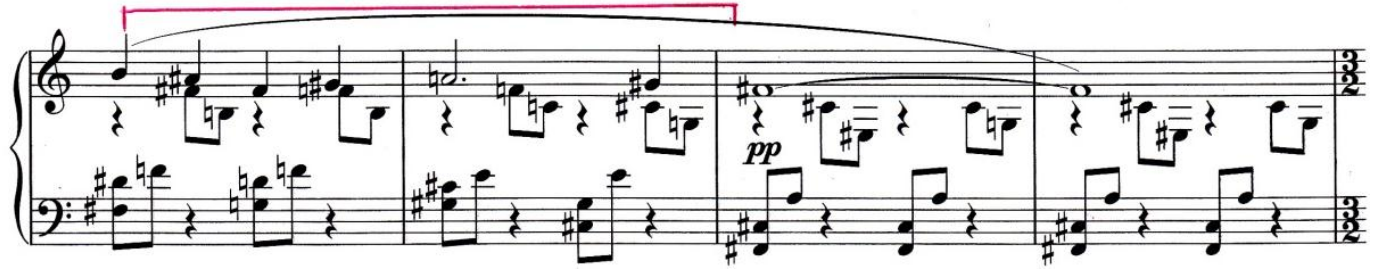

C2006 by Theodore Presser Co., Used With Permission

After the first presentation of the melodic material, one measure of $b$ is heard at measure 25 (parallel to measures 1-2) and melodic idea 1 comes again (measure 26). This next section is built mainly on transformation of motive a (the intervals often recalling the head of motive b) from the principal melodic idea. It is a long sequence in which the melody (upper line of the left hand) slides by semitones: D-C\#-C-B (downbeats of measures 30, 32, 34, 36) and reaches B b for the new section. Harmonically, the areas move from B b (measure 30-31) to F\# (measure 32-33) to $\mathrm{F}$ (measure 34-35) to $\mathrm{E}$ (measure 36-37) and to $\mathrm{Eb}$ (measure 38). Those harmonic elements encompass both their major and minor mediants and the presence of the raised fourth can be easily observed in the melodic material (measures 32, 34 and 36). On top of all that activity, Liebermann adds another layer. The line which was first an echo of the melodic cells, often at the 
fifth (measures $27-28$ and 31), turns into scalar decorative material at measure 32 , and is a mixture of portions of major and octatonic scales. The following musical example (5.8.3) displays material from the second presentation of melodic idea 1, leading to section B.

Musical example 5.8.3: Liebermann's Nocturne no. 8, measures 29-36
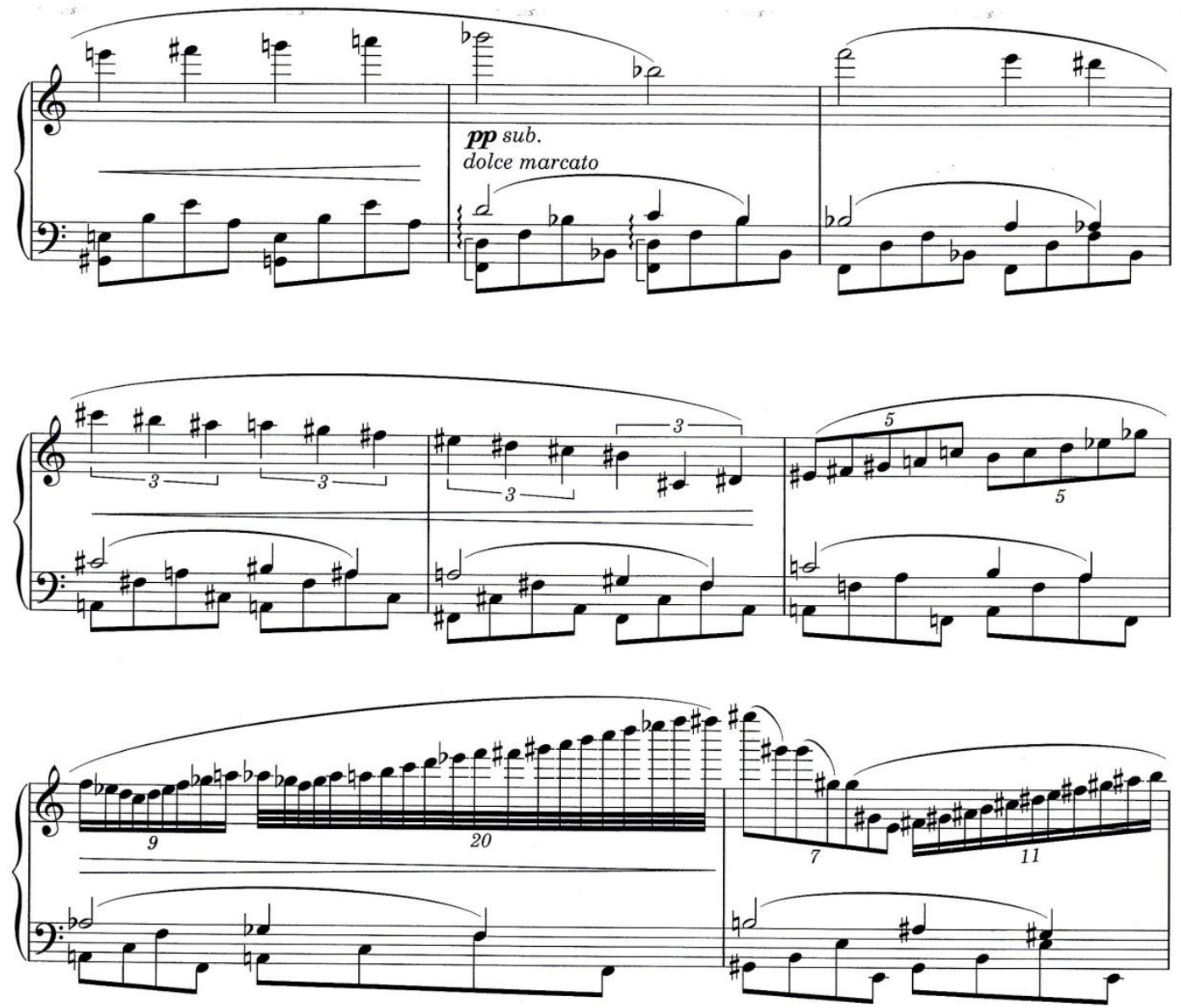

C2006 by Theodore Presser Co., Used With Permission

At measure 38, Liebermann clearly establish the harmony of eb, indicates a new tempo (meno mosso), and presents new material. Even though the opening material also contained plenty of non-harmonic tones, this new material is more dissonant: the harmony does not always 
coincide with the melody. Moreover, when taken separately, the harmonic elements of each hand can be understood - most of the time — quite tonally, but when they are combined, they display some rather clashing dissonances.

The texture is chordal, and soprano and bass play in contrary motion. The main melodic material resembles motive e (stepwise motion and skip of a third) and also recalls the junction of motives a and b (repeated pitch). The first presentation occurs at measures 38-40 and is followed by a one-measure rest. Those three measures are rooted in eb; the following presentations are centered - in the left hand - in e (42-45), eb (46-48), c [which slides to b] (49-53) and a (54-56). Even though, in this very passage, it is quite difficult to decide what is a nonharmonic tone, the melodic and rhythmic motion of the left hand - very characteristic at measure 42 to 44 - helps delineate those "key-centered" zones. The shape of the melodic line remains similar each time it is played. Rhythmically, it is also very characteristic, with one bar in 4/4 followed by three bars in 3/4. After one measure of rest, big portions of this material are reworked in the left hand, più lento, molto libero quasi improvvisando, while the right hand introduces new decorative melodic material made of repeated notes and the octatonic scale. Melodically, the first phrase is a literal repetition and the second is slightly varied; the third is substantially varied, and ends in measures $38-40$, in the key of the first presentation. The music outlines similar harmonic centers than the ones encountered in the previous section: e, eb, c (was previously b), and back to eb. Measures 67 to 69 recall the material presented at 38 to 40 , in the same key (eb), and is prolonged by a harmonic gesture of $\mathrm{i}-\mathrm{vii}^{6}$ (due to the incomplete triad, this could also be analyzed as i-N or as a half cadence in Phrygian mode). The following musical example (5.8.4) shows material from melodic idea 2. 
Musical example 5.8.4: Liebermann's Nocturne no. 8, measures 57-62

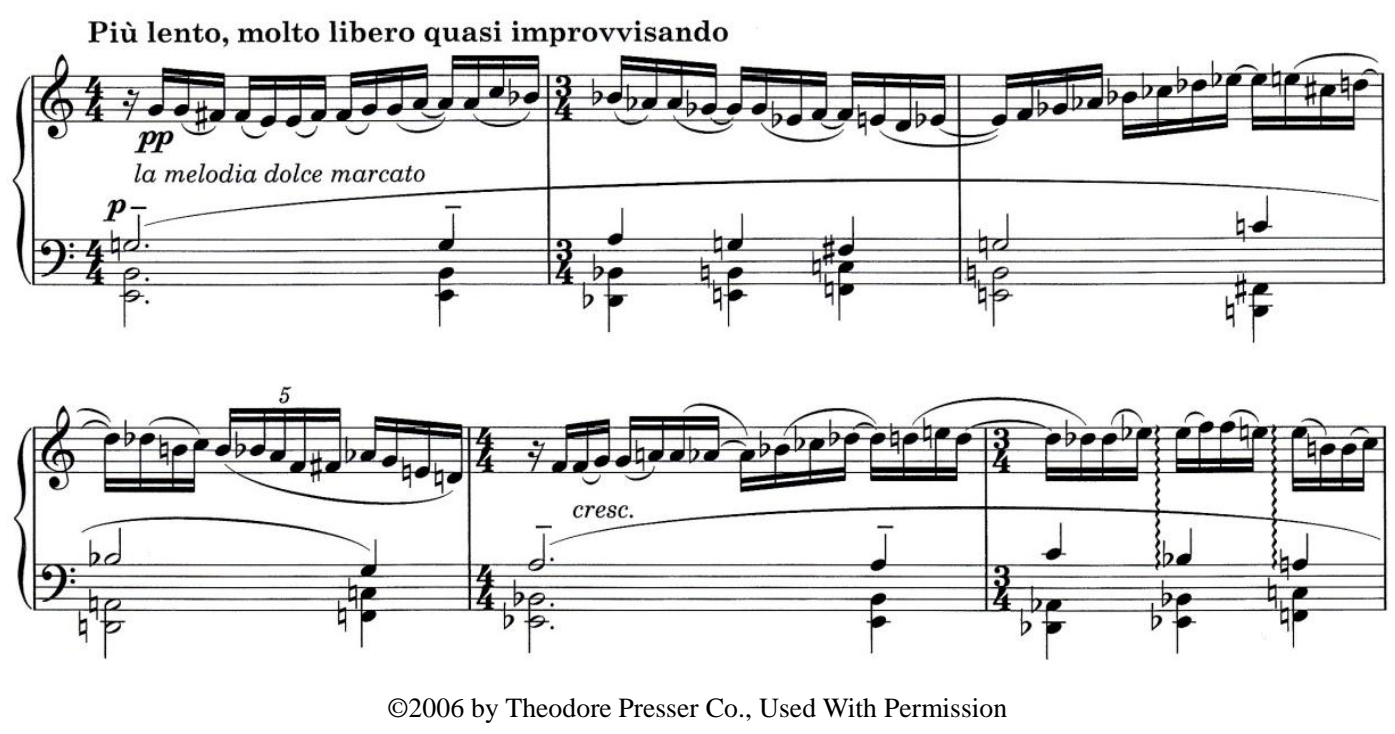

After a measure of rest, tempo I resumes when a figure similar to the opening accompanimental gesture is heard, in the key of B. The atmosphere (the harmony, melody and even the pianistic writing) emerging from this section is reminiscent of Fauré. The material heard from measures 72 until 87 seems transitional. It does not appear to be based on any specific motives, it uses a simpler version of the opening figure (triadic, and without the previous nonharmonic tones), it recalls the accompanimental obligato of measures 57-66, it serves to establish the atmosphere and it introduces a new accompanying pattern on which the following section will be built on (section A', measure 88).

At measure 88, the opening first two measures are played anew; thereafter a new layer of accompanying material is heard in cross-rhythm-triplets in the middle register, to which, one bar later, the melody played in octaves is added. The melody is constructed with transformations of motive a (in this case, the previous stepwise descending motion is changed to half step-whole 
step, labelled $\left.\mathrm{a}^{2}\right),{ }^{158}$ motive $\mathrm{c}$ and motive e. The accompanying ostinati are quite static despite a few melodic adjustments in the middle register and a slow-moving chromatic bass line (B-B bA\#-A-A b-G-F\#). This three-layer texture proceeds uninterrupted until measure 106, where a slight change occurs in the lower accompanying figure. At this point, the left hand plays a counter-line, similar in melodic shape and exact in rhythm to the main melodic material, while also adding an accompanying figure in sixteenths. If the downbeat of measure 108 had a sharp in the bass, the two outer lines would be in parallel thirds throughout, then in parallel seconds beginning the last beat of measure 118 through measure 122. The following musical example (5.8.5) displays the texture, the use of motives $a^{1}, b^{2}$ and e, and the parallelism of the outer lines, soprano and bass.

Musical example 5.8.5: Liebermann's Nocturne no. 8, measures 107-109

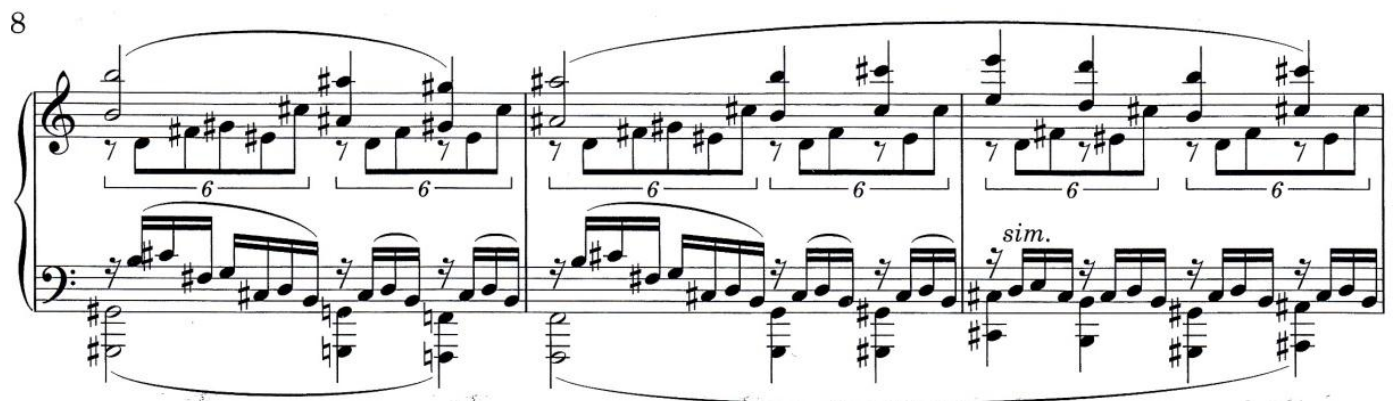

C2006 by Theodore Presser Co., Used With Permission

The whole section is based on previously heard motives $\left(\mathrm{a}, \mathrm{b}^{2}, \mathrm{e}\right.$, and occasional $\mathrm{c}$ —often merged into e). This kind of writing remains the same for a while and serves to pursue the dramatic construction started at measure 91 (cresc. poco a poco). There is a change in texture at

158 Originally, motive a encompasses two consecutives whole steps going down (B-A-G at measure 3 ); motive $\mathrm{a}^{1}$ is made of a whole step down followed by a half-step also going down (E-D-C\# at measure 14); and motive $\mathrm{a}^{2}$ is constructed with a half-step followed by a whole step, both going downward (D-C\#-B at measure 91). In all cases the rhythm remains the same, that is a half note followed by two consecutive quarter notes. 
measure 114 - fuller chordal presentation of the melody in both hands simultaneously, combined with an accompanying ostinato pattern in the left hand in eight notes and an accompanying figure in fifths in the right hand, while the dramatic build up continues. At measure 123, the tension grows to an extreme degree while the hands are moving further apart and play superimposed harmonies that conflict more and more with each other. The big climax is reached at measures 124-125: a B chord in the very low register is sounded simultaneously with a very high e b chord $f f f$. In the reverberations of this sonorous complex, a cadenza appears—chordal at first and followed by a finger-work passage afterwards. ${ }^{159}$ This section ends on another chordal entity of conflicting harmonies made of low B chord and a G chord, sffffz, out of which emerges the familiar opening accompanying motion. Both chords include the pitches of the ensuing ostinato, divided between the hands. Musical example 5.8.6 shows the material used for the build up, leading to the cadenza-like passage right before the return of melodic idea 1.

159 I believe that the final chord of the right hand in the third system (measure 124) is missing a natural sign for the D. 
Musical example 5.8.6: Liebermann’s Nocturne no. 8, measures 121-125
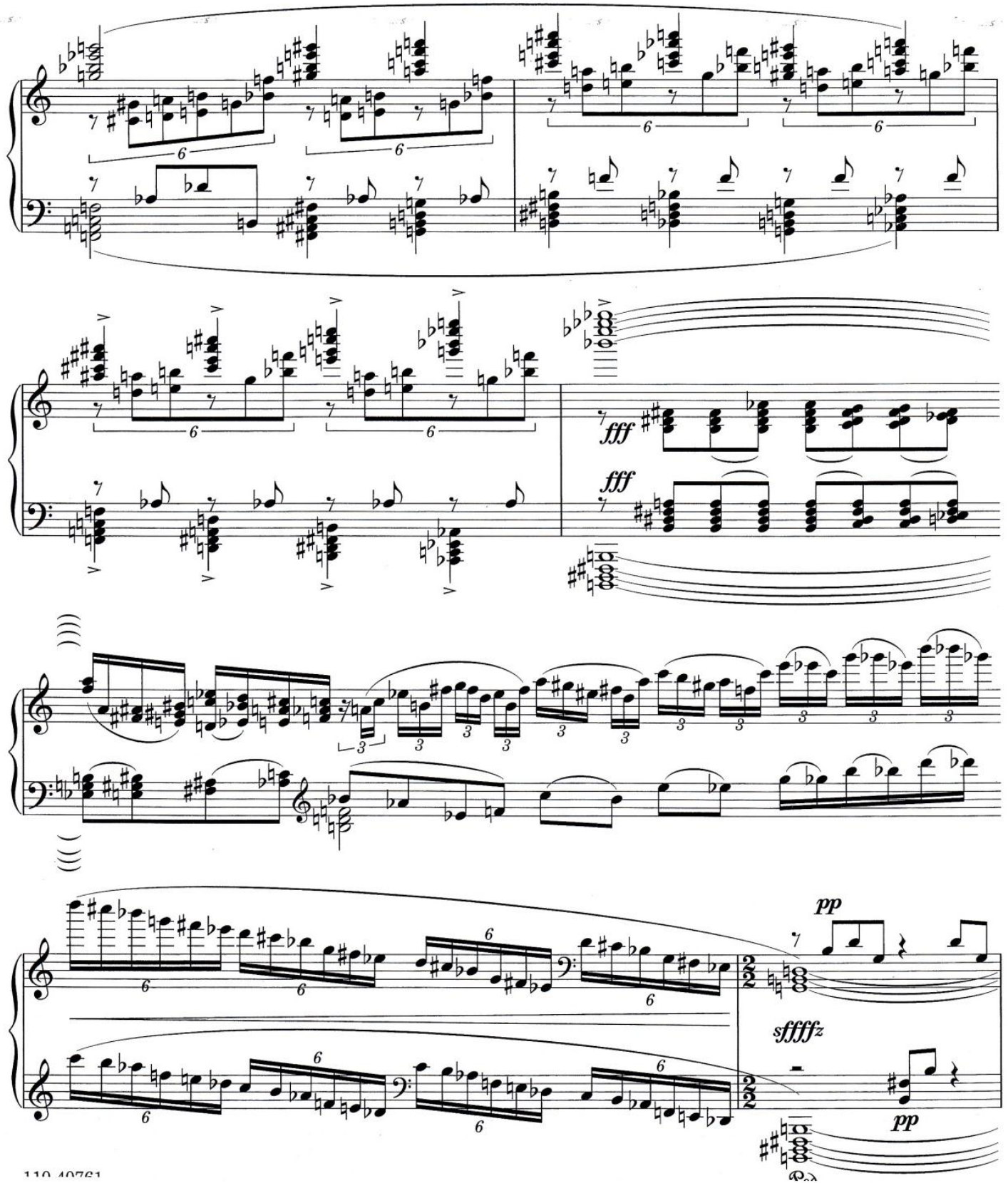

C2006 by Theodore Presser Co., Used With Permission

The excitement generated over the last 34 bars recedes when the dynamic marking calls for $\boldsymbol{p p}$. The familiar head of melodic idea 1 then returns, only to take an unexpected inversional 
turn at measure 129, after which it disappears, to be succeeded by the haze and uncertainty created by the harmony (rapid alternations of $A b-A$ and $A-B b$ ) and by the fluidity of rhythm affecting the decorative octatonic scale fragments (in subdivisions of 5, 6, 7, 8 and 11). There is one measure rest and the Fauré-like transitional material of measures 72-83 is proposed for five bars, before it settles in the key of F\#, pppp and within a 4+5/8 meter. The coda, beginning at measure 140, is based on the downward stepwise motion of the opening melodic idea. Every two bars this motion goes up the diatonic scale of $\mathrm{F}$, until it reaches the tonic chord at measure 150 . The melodic gesture can be reduced as follow: A\#-G\#; B-A\#; D\#-C\#; E\#-D\#; F\#-E\#; F\#. ${ }^{160}$ The remainder of the piece very quietly recalls vestiges of important motives (a and e) over an ostinato F\# accompaniment; it then ventures briefly into Neapolitan harmony with an inversion of motive e, followed by a measure of whole steps alternating with a measure of half steps and another measure of whole steps - the melodic direction and rhythm hinting at motive c. The Nocturne ends with the ostinato on F\# sounded with the high pitch B before it resolves to A\#. The final significant harmonic shift from b to F\# at measures 135 to 140 never gets a reply. The listener is left wondering if the home key of the Nocturne is in fact b or F\#.

Just like its fellow-companion Nocturne no.6, this Nocturne seems to be more motivic in its organization than were the other Nocturnes. Although the melodic material itself is less linearly dissonant than what was seen in no. 6 , dissonances are achieved here as well by superimposing this material over conflicting harmonies. A trend also seems to be developing in regard to pedal markings which appear to be written less explicitly and less precisely than with earlier Nocturnes. Besides the characteristic con Ped. associated with the opening section and its similar returns, only five other pedal indications are given in the score, a striking difference with

160 Or, if we read it as an appoggiatura to a main note, as G\#-A\#-C\#-D\#-E\#-F\#. It should be noted that there is a gap: B. Is Liebermann avoiding the home-key of the Nocturne? 
respect to Nocturnes nos. 2 to 5. Finally in this work, Liebermann reaffirms his dramatic conception of the nocturne-which was not found in Nocturne no. 7.

\subsection{Nocturne no. 9, op. 97}

Nocturne no. 9 was composed in 2006. It was commissioned by Louis Meisel for Nadejda Vlaeva who first performed it on August 9, 2006, at the Husum Music Festival in Germany. ${ }^{161}$ According to the indications included in the published score, this work of 173 measures takes about seven minutes to be performed. ${ }^{162}$

A quick glance at the opening section of Nocturne no. 9 seems to reveal a dramatic simplification in Liebermann's style of piano writing, something similar to what happened with later Nocturnes by Fauré. (Compare with Fauré's Nocturne no. 13, musical example 4.7.) However, this assumption is quickly obliterated when the opening material is revisited at measures 43 and following. This sort of affirmed right-hand virtuoso writing has never been encountered before in any Nocturnes by Liebermann—or in any of his predecessors for that matter. Liebermann's compositional style has often encompassed a virtuoso quality but it was always in regard to the handling of polyrhythms caused by several distinctive musical lines being superimposed at once. This "newer" kind of virtuosity might be here used in a coloristic manner, but it remains virtuosity nevertheless. Musical figure 5.9 shows the formal organization of Nocturne no. 9.

161 Nadejda Vlaeva is a Bulgarian pianist, based in New York City. See Appendix B for more information, or consult the artist's personal website at: http://www.nadejdavlaeva.com/

162 As of now, public recordings of Nocturnes no. 1 to 8 are available. For the approximate durations in regard to following Nocturnes, I used the indications provided in the published scores. Moreover, in the case of Nocturne no. 9 , if one calculates beats divided by tempi, it yields to six minutes and sixty-three seconds, plus ritardandi and fermati. However, there is a recorded version online by pianist Alice Tsui which takes eight minutes and thirty-three seconds. http://www.youtube.com/watch?v=62pYFOBMc0 
Musical figure 5.9: Liebermann's Nocturne no. 9

\begin{tabular}{|c|c|c|}
\hline $\mathbf{A} \mathbf{A}^{\prime}$ & B & A" A" \\
\hline $\begin{array}{ll}\text { - } & \text { Intro }(1-4)[\mathrm{F}] \\
\text { - } & \mathbf{A} \\
& \text { m.i. } 1(5-11 ; 12-14)[\mathrm{F}] \\
& (19-22 ; 23-28) \\
& \text { [D b Lyd. }]^{*} \\
& (29-34 ; 35-38) \\
& \text { [D extended harmonies] } \\
& (39-42)\{\text { intro }\} \\
\text { - } & \\
\text { virtuoso writing } \\
\text { m.i. 1 (43-47; 48-52) [F] } \\
\text { (53-56; 57-60) [a] } \\
\text { Transition (61-64) [a] }\end{array}$ & $\begin{array}{l}\text { m.i. } 2 \text { \{repeated notes + } \\
\text { pedal point ostinato\} } \\
\text { (69-71; 72-78; 79-81; } \\
\text { 82-88; 89-94; 95-96) } \\
\text { [c\#] } \\
\text { Extension }(97-116)\end{array}$ & 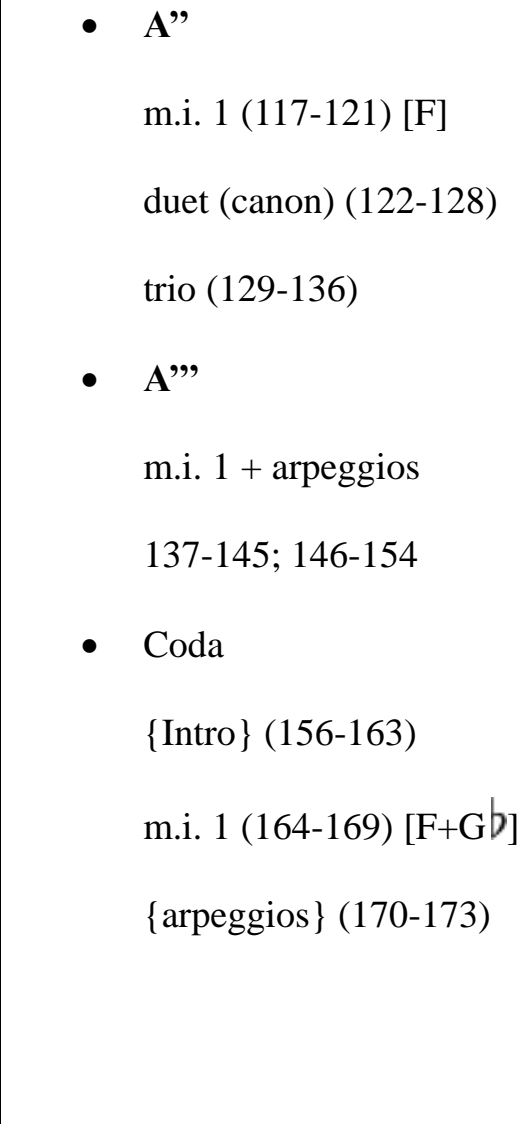 \\
\hline
\end{tabular}

*Lyd. stands for Lydian.

The Nocturne begins with a four-measure accompanying idea (2+2). It is centered in the tonic of $\mathrm{F}$ (both mediants, and lowered second and seventh). At measure 5, the first member of the accompanying idea is repeated, varied and played in other keys (e, eb, ending in $B b$ ), while the left hand crosses over the right hand to play a cantabile melody in the upper register. Melodic idea 1 starts in the key of F. In its entirety, the melodic material of this section is three-fold. The first member (measures 5 to 14 ) is simply accompanied by chromatically-descending harmonies (F-f-e-Eb). The second member is similar: although the melody begins in Db Lydian, the 
harmonic accompanying material displays major followed by minor intervals which slide chromatically from $\mathrm{D} b$ to $\mathrm{B} b$ (measures 19 to 28 ). Finally, we see the third member, in which the texture is fuller and more complex. The third melodic idea (measures 29 to 38) begins in the tonic of $\mathrm{D}$ while the accompanying counterpart displays extended harmonies - chords with added second, at times on the top, and in other instances at the bottom-which represent a very rare manifestation in Liebermann's Nocturnes so far. The accompanying harmonies also differ in their progression from the previously seen material in this Nocturne because they display tertian relationships or are located a step aside (moving from $\mathrm{D}$ to $\mathrm{B} b, \mathrm{~A} b, \mathrm{G} b$ and back to $\mathrm{B} b$ ). Those harmonies could also bear relation to a (partial) whole-tone scale. The following musical example (5.9.1) highlights the opening material—accompanying intervals and melodic idea 1.

Musical example 5.9.1: Liebermann's Nocturne no. 9, measures 1-18
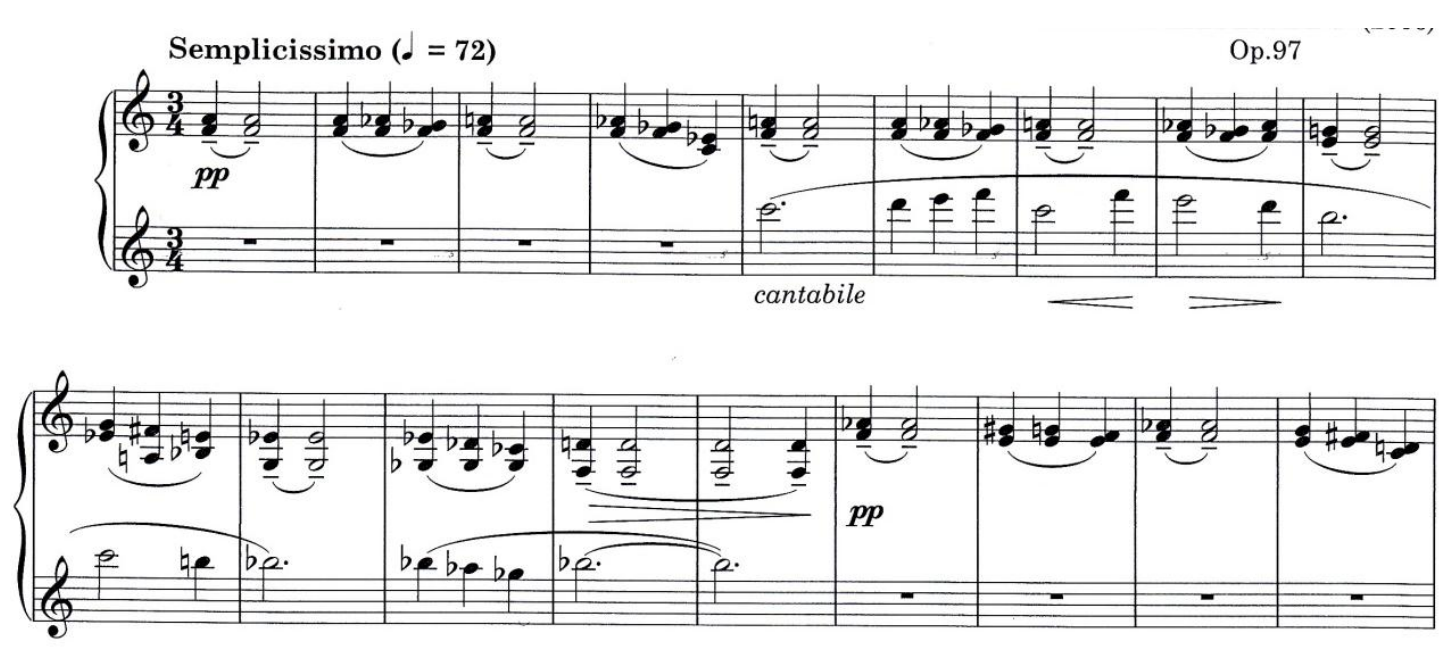

C2009 by Theodore Presser Co., Used With Permission

At measure 39, the opening material comes back, one octave lower, in the left hand (section A'). Melodic idea 1 is played over this figure (at measure 43), also in the left hand, while 
new, decorative, quite virtuosic material is added to it, played by the right hand. This new layer was discussed earlier as being made from portions of major and octatonic scales. The treatment of the rhythm is also very free in this passage: groups of eight, nine, ten, eleven, twelve and thirteen thirty-second notes alternate rapidly. The whole melodic idea is revisited displaying only a few departures from the original: at measures 53 to 56 (which correspond to measures 15 to 18), the material is played a half step higher; at measure 57 and following (cf. measure 19), it is presented a half step lower, suggesting A minor. Within this section (measures 39 to 64), Liebermann uses the highest pitch of the instrument (C) four times (measure 47, 51, 55 and 57) and the lowest pitch (A) once (measure 61), which is a distinctive feature of this passage both within this Nocturne and compared to the previous Nocturnes. The virtuoso figuration stops at measure 61, replaced by four measures of transition where the left-hand bass line moves up from A to $\mathrm{B}$ to $\mathrm{C}$ before finally reaching $\mathrm{C} \#$ for the following section, and the right hand plays simple accompanying rhythms. Musical example 5.9.2 shows melodic idea 1 along with a portion of the virtuoso pianistic material. 
Musical example 5.9.2: Liebermann’s Nocturne no. 9, measures 43-46
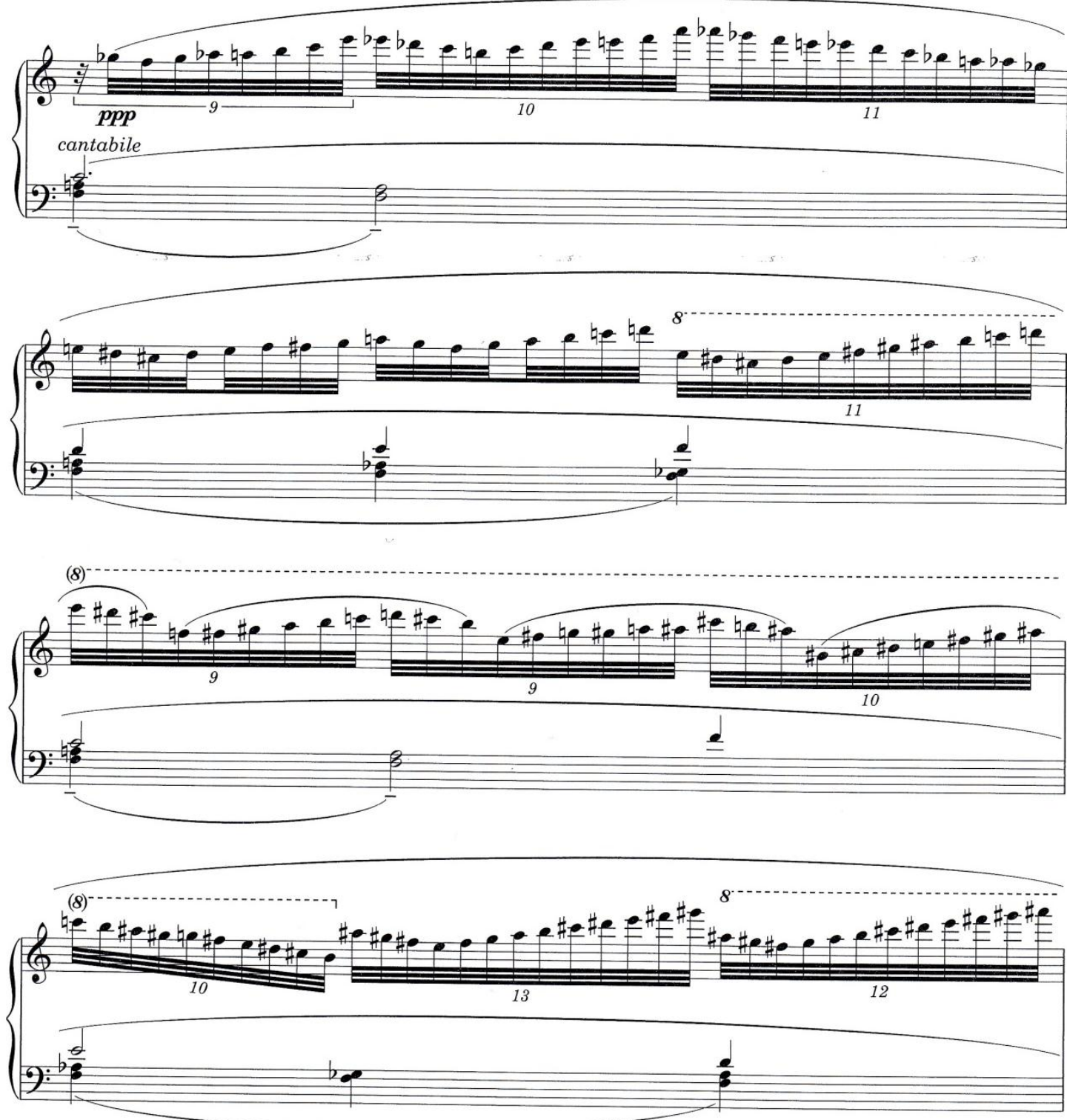

C2009 by Theodore Presser Co., Used With Permission

The following section, più mosso (section B), which spreads from measures 65 to 116, is mainly based on a pedal point (repeated notes: E for 43 measures), an ostinato figure and a new melodic idea. Measures 65 to 68 present the accompanying material for the whole section: repeated notes in the right hand; harmony on the first beat of every two measures, played in the 
low register of the instrument - most often a triad in open or closed spacing; and an ostinato of expanding and contracting intervals - third, fifth, seventh, fifth, third — each about a fixed center, which also recalls a familiar cell taken from melodic idea 1 (three pitches in stepwise motion going upward). On top of this material, a new melody enters at measure 69 (melodic idea 2). The following musical example (5.9.3) displays the material seen in section B: repeated notes, ostinato, harmony and melodic idea 2 . 
Musical example 5.9.3: Liebermann's Nocturne no. 9, measures 67-82
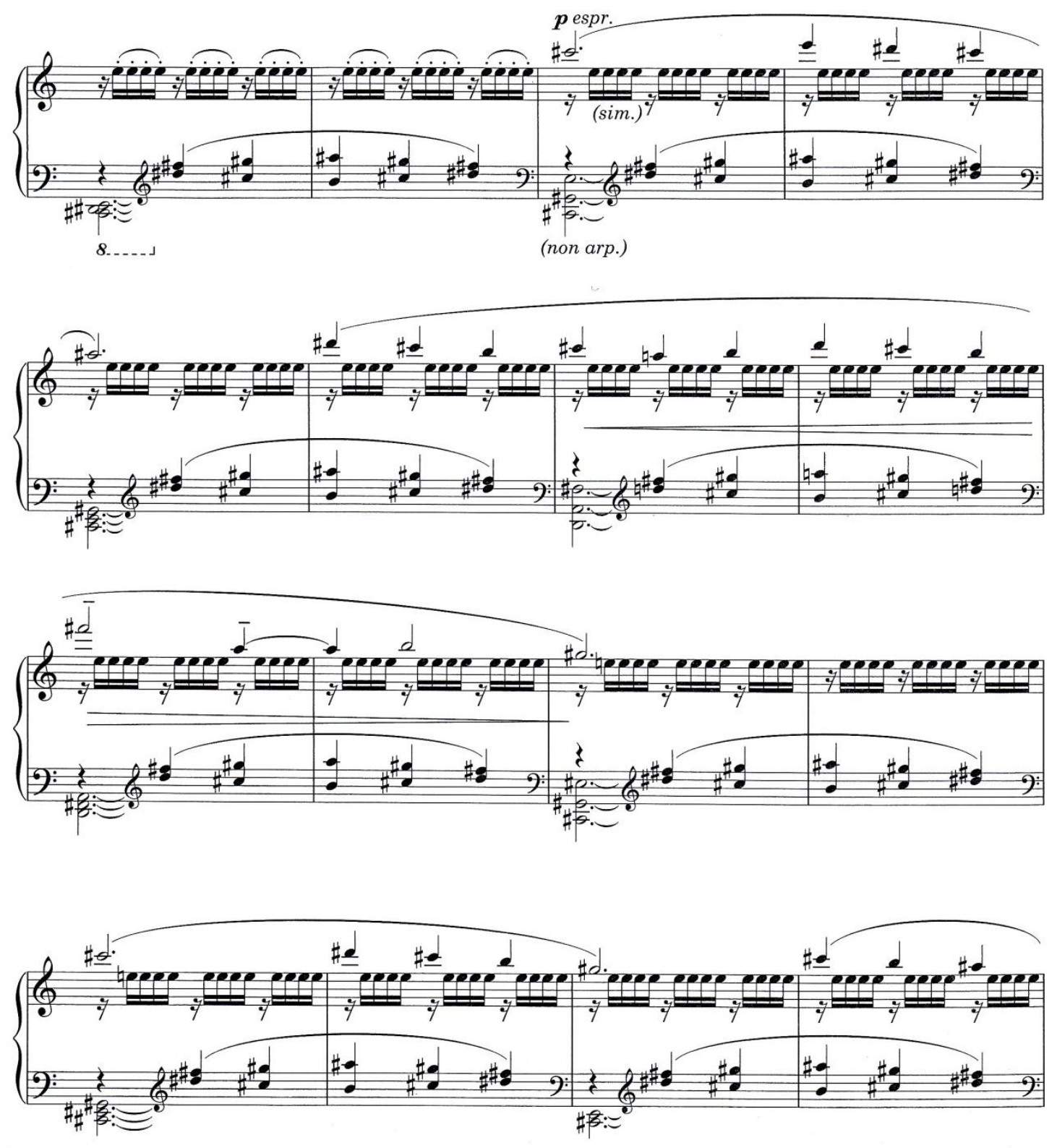

C2009 by Theodore Presser Co., Used With Permission

The structure of melodic idea 2 is very similar to the one encountered in the first section of the work. It is three-fold again: the first member occupies measures 69 to 78 and is supported by harmonic shifts from $\mathrm{C \#}$ to $\mathrm{D}$ and back to $\mathrm{C \#}$; the second member is located at measures 79 to 88, and the harmonies travel from $\mathrm{C} \#$ to $\mathrm{F}$ (including one raised fourth) and $\mathrm{B}$; and finally, the 
ultimate member, from 89 to 109 , which similarly to its counterpart from the first section shows faster harmonic activity — either chromatically related or of tertian nature — displaying harmonies of d, d\#, e, C\#, A, F, D and landing ultimately on a low D D (C\#). It should be noted that toward the end of the first two melodic members, there is the presence of hemiolas (measures 75-76 and 85-86). This new rhythmic feature is thereafter used to open the final member (measure 89-90). The last portion of the melodic material is also expanded through motivic transformation. At measure 100-101, the upper line plays a motive of downward half-step motion which is completed by the repetition of the final pitch (D-C\#-C\#). ${ }^{163}$ This motive becomes the basis of the following section: measures 100-101 and 102-103 display just the half-step motion, while measures 106-107 and 108-109 display the complete motive. This new material is distinguished by a minimal change in texture, in that the melody is doubled in octaves. The following musical example (5.9.4) displays the motive used for the extension of section B (doubled at the octave and with repeated chords).

163 This motive of half-step going down, which was clearly heard at measure 98 (E-D\#), also comes from the head of melodic idea 2 . 
Musical example 5.9.4: Liebermann's Nocturne no. 9, measures 103-109
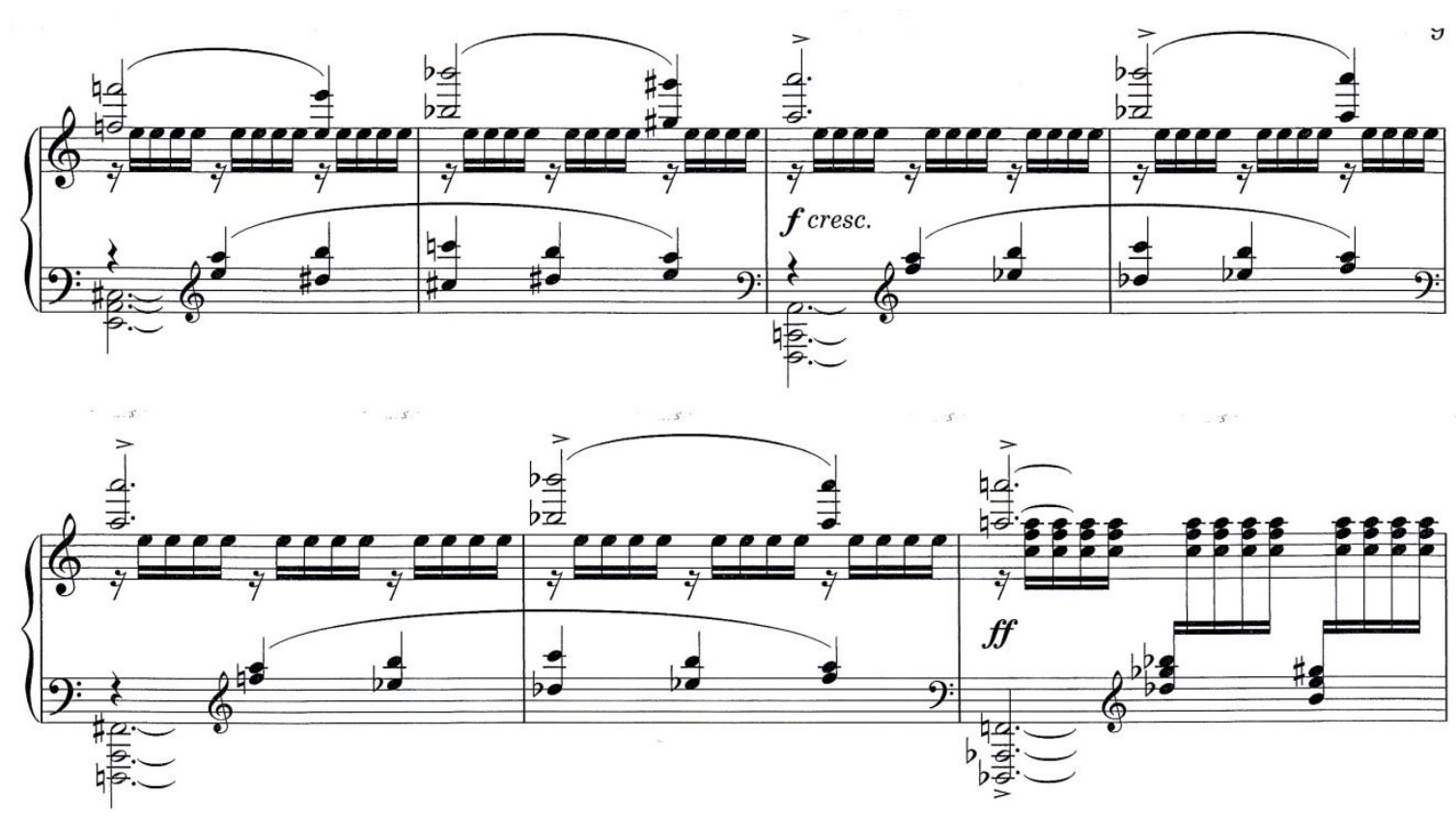

C2009 by Theodore Presser Co., Used With Permission

This section goes through further expansion when the idea of a repeated pitch is

transferred to a whole series of chords. At the same time, two different harmonic worlds seem to be superimposed: the right hand plays harmonies rooted in the key of $\mathrm{F}[\mathrm{F}-\mathrm{D} b-\mathrm{C} ; \mathrm{D} b$ being the lowered sixth] and the left hand plays harmonies which seem rooted in $\mathrm{G}^{b}[\mathrm{G} b-\mathrm{E}-\mathrm{D}-$

$\mathrm{B} b$-A and $\mathrm{D} b ; \mathrm{E}(\mathrm{Fb})$ represents the lowered seventh, $\mathrm{D}(\mathrm{E} b \mathrm{~b})$ the lowered sixth, and $\mathrm{A}(\mathrm{B} b \mathrm{~b})$ the lowered third]. Arguably, this interplay between the hands can also be perceived as the left hand playing neighbor tones for the right. The final measures of this section play a low chord of Db-Ab-Eb with a conflicting F harmony. It seems that Liebermann is trying to unite the important key-centers of the previous sections: $\mathrm{C} \#$ (respelled here as $\mathrm{D} b$ ) from section $\mathrm{B}$ and $\mathrm{F}$ from section A. 
The idea of reconciliation is taken further when a melody recalling melodic idea 1 appears at measure 117 (section A") while the " $\mathrm{D} \mathrm{b}^{9 "}$ chord still sounds in the low register of the piano (Ped. sempre tenuto). At first, we have the impression of the return of the A section; but at measure 119 the melody takes a new turn. The melody modulates and metamorphoses into a duet, and into a trio. The melodic material inspired from the original melodic idea 1 is easily recognizable and includes what could be seen as a 12-tone row (C-D-E-F-B-Eb-Db-B b-Ab-A-GF\#). The second accompanying part, which enters in measure 123 - considering that the texture recalls fugal technique, this could be called the countersubject—is perhaps taken from melodic idea 2, but it is far from representing an exact restatement, and important transformations make it difficult to associate the two ideas. Even though the section is played $\boldsymbol{p p}$, crude dissonances are heard. The principal melody, played in the soprano, ventures into the harmonies of C-Ab, D-B b, $\mathrm{B}-\mathrm{G}$ and a short $\mathrm{f}$ before settling in $\mathrm{D}$ for the più mosso. The accompanying parts do not follow the same key-scheme progression and are more vaguely key-grounded. The following section is transitional, based rhythmically and melodically on the very distinctive melodic opening gesture, accompanied by an aerial texture of superimposed arpeggios of white notes (right hand) and black notes (left hand), which will return at the end the Nocturne. The range of this figure is quite narrow and lies within the octave. The right hand highlights the pitches of a $\mathrm{G}$ chord going up, then of an F chord going down; finally, it plays the three pitches D-F-G, which are members of those previously heard chords. The right hand plays a figure made of a perfect fourth followed by a major second (C\#-F\#-G\#), played again a whole step up (D\#-G\#-A\#), and finally the pitches F\#-G\# are repeated again. Of the 12-tone series, the pitch $E$ is the only one left out of this figure; could it be because it is the leading tone of the home-key? Musical example 5.9.5 
displays the beginning of section A" with its melodic material and the white-notes-black-notes accompanying arpeggio figure.

Musical example 5.9.5: Liebermann's Nocturne no. 9, measures 137-144

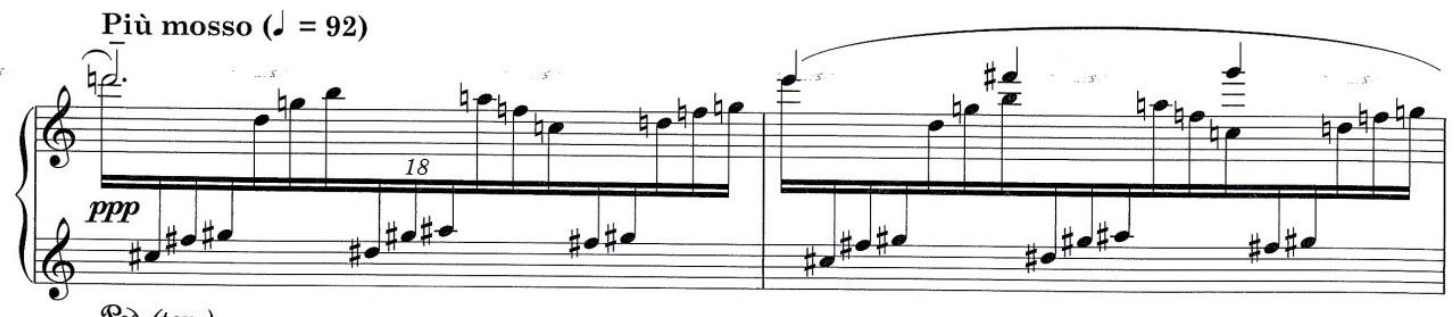

2ed. (ten.)
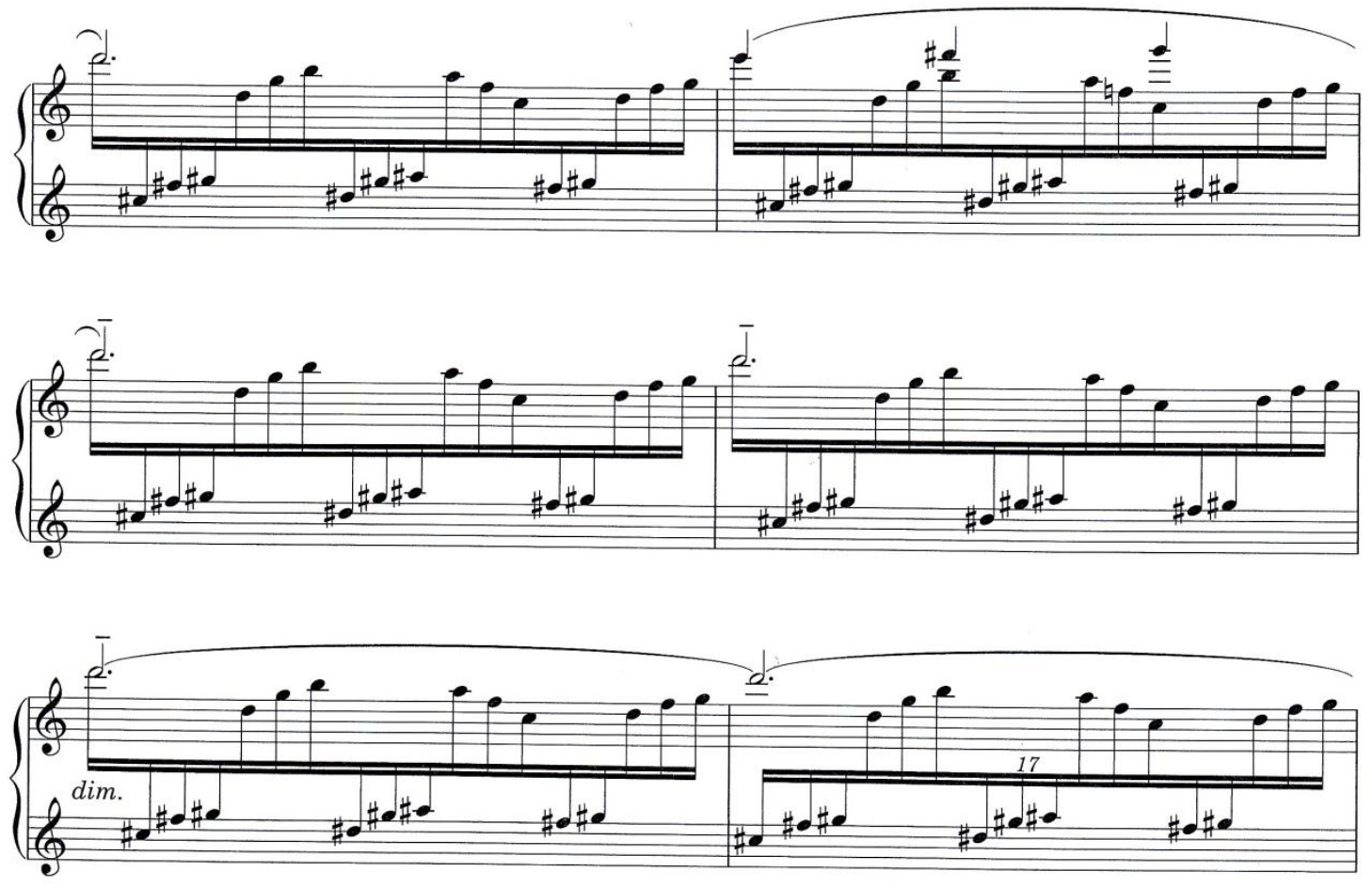

C2009 by Theodore Presser Co., Used With Permission

The principal melody consists of two repetitions of the head of melodic idea 1, in the key of G; underneath that, shimmering harmonies merge together (ped. tenuto) the aforementioned pentatonic figure in $\mathrm{C \#}$ and the six melodic members of C. At measure 146, tempo primo resumes $f f$. The familiar melodic idea 1 is presented in harmonies which tonicize each of its 
respective pitches in full four-voiced major chords. Harmonies of D, D b, Ab, G, eb, B b, G, C, A and $\mathrm{D} b$ are heard next to one another (in the right hand). At the same time, the left hand seems to establish a key, but negates it right after by playing a neighboring but conflicting harmony (for example: $\mathrm{D}$ followed by $\mathrm{D} b$ at measure 146; $\mathrm{D}$ followed by $\mathrm{E}$ at measure 147; and $\mathrm{D}$ followed by $\mathrm{C}$ at measure 148). Harmonies of d, D b, d, E, d, C, Eb, e, A b, F\#, A b, B b and G follow one another in rapid succession. Once again, the relationship between the hands, in regard to harmony, often reflects semitonal parentage. Musical example 5.9.6 illustrates those semitonal superimposed harmonies. In this passage, one can observe $\mathrm{D}$ followed by $\mathrm{C}$ against $\mathrm{D} b$ (measure 148); e against Eb (measure 149); F\# against $\mathrm{G}$ (measure 150); B b against A (measure 151).

Musical example 5.9.6: Liebermann's Nocturne no. 9, measures 145-155

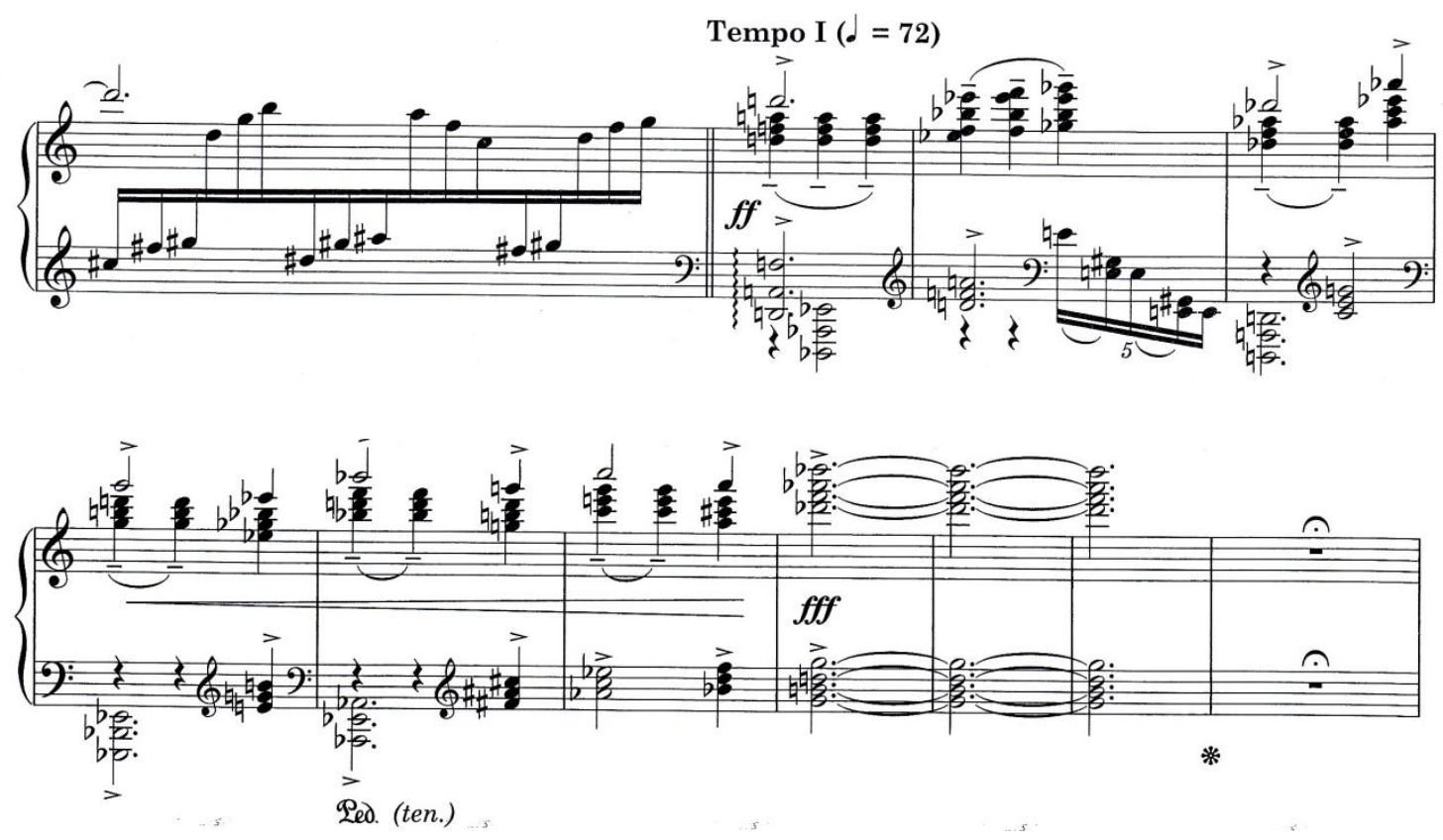

(C2009 by Theodore Presser Co., Used With Permission 
Pedal is taken off for releasing that immense tension. It is followed by a complete silence — the only one in this entire Nocturne —at measure $155 .{ }^{164}$ The opening accompanying gesture comes back again, firstly in F, and thereafter sliding chromatically to E, e, d\# and D. The home-key of $\mathrm{F}$ is restated again with the low chord in the left hand and the accompanying figure in the middle register, while the left hand plays also the familiar head of melodic idea 1 (in the key of $G$ b). Once again, we see another instance of Liebermann's using a multi-layering approach; but this time, this texture of "planing" recalls Debussy's writing, for example in $L a$ cathédrale engloutie (measures 1, 3, 5, 14 and similar). This material is played twice, all wrapped in a pedal tenuto. And, in the final reverberations of this material, the aerial accompanying figure (white-keys-black-keys) from the previous transitional section (measures 137-145) is played again, disappearing into a pppp and a barely audible partial F chord.

Nocturne no. 9 by Liebermann displays familiar features, such as long melodies and multi-layered textures; but at the same time, it seems to venture into a territory which Liebermann has not previously exploited in this genre, with the exploitation of virtuosity in itself. Also beginning with Nocturne no. 6, the dissonances are displayed in a much more pungent manner, along with experimentation in bitonality or more complex harmonies (extended chords of sevenths and ninths). However, Liebermann continues to rely on the pedal generously to combine conflicting harmonies. Finally, in this Nocturne, canons and imitations play a less significant structural role, appearing only in the transition (measures 117-136).

164 Up to this point, only Nocturnes nos. 8 and 9 have used such silences. 


\subsection{Nocturne no. 10, op. 85}

Nocturne no. 10 was composed in 2007 and is dedicated to the memory of composer Gian Carlo Menotti. ${ }^{165}$ It was premiered by Liebermann himself at the memorial concert for Menotti, held on February 10, 2007, at the Salle Garnier in Monte-Carlo. ${ }^{166}$ Even though the Nocturne has only 74 measures, it takes about eight minutes and thirty seconds to be performed. ${ }^{167}$

Nocturne no. 10 also seems quite different from its predecessors. Although some of the familiar features such as ostinato, pedal points and imitations are present, this musical work does not contain complex stratified textures, or virtuoso passages of any kind. It only superimposes simple rhythms grouped by two or three. Moreover, the dramatic construction also is quite contained. The dynamics lie more into the softer side of the spectrum: the softest element is pppp, the loudest is $f$. Moreover, in this Nocturne, Liebermann indicates the use of the una corda pedal. This for the first time he does so in a Nocturne. Musical figure 5.10 displays the formal aspect of Nocturne no. 10.

165 Gian Carlo Menotti was born on July 7, 1911 and died on February 1, 2007. He was an Italian-American composer and a librettist. He wrote about two dozen operas intended to appeal to popular taste. He won the Pulitzer Prize for two of them: The Consul (1950) and The Saint of Bleecker Street (1955). He founded the noted Festival dei Due Mondi (Festival of the Two Worlds) in 1958 and its American counterpart, Spoleto Festival, in 1977.

166 For Liebermann's biography, the reader is referred to Chapter One, Life. See Appendix B (note 16) for more information, or consult the artist's personal website at: http://lowellliebermann.com/

167 While only Nocturnes no. 2 and no. 4 contain a lesser amount of measures, respectively 44 and 67, Nocturne no. 10 is longer in duration. 
Musical figure 5.10: Liebermann's Nocturne no. 10

\begin{tabular}{|c|c|c|}
\hline A & B & $\mathrm{C}$ \\
\hline $\begin{array}{ll}\text { - } & \text { m.i. } 1(1-4 ; 5-8)[\mathrm{G}] \\
\text { - } & \text { m.i. } 2(9-13 ; 14-17) \text { [Ab] } \\
& \text { extension 18-20 } \\
& \text { [D-E-F\#] }\end{array}$ & $\begin{array}{ll}- & \text { m.i. } 3(21-28)[\mathrm{D}] \\
& \text { transition (29-36) [G] } \\
& \{\text { familiar chord }\} \\
- & \text { m.i. } 3(37-46)[\mathrm{E}]\end{array}$ & $\begin{array}{ll} & \text { Fugato 47-58 [C-Eb] } \\
& \{\text { false return of } \mathbf{A}\} \\
& (59-62)[\mathrm{G}] \\
- & \text { Coda }(63-74) \\
& \text { m.i. } 1 \text { (63-67) }[\mathrm{G}] \\
& \{\text { familiar chord }\}\end{array}$ \\
\hline
\end{tabular}

The opening section (A) displays material of a thin texture, in which the melody and the accompanying parts are rather difficult to untangle from each other. Interestingly, when this material comes back at measures 59, 64 and following, Liebermann writes it differently, using the bass clef. The first melodic idea (melodic idea 1) unfolds under antecedent-consequent pattern. The antecedent member, (measures 1 to 5), rooted in the key of $\mathrm{G}$ and played over a tonic pedal point, is accompanied by a more dissonant harmony than its consequent counterpart (measures 5 to 9). The accompanying part could be understood as being in $\mathrm{F \#} \mathrm{(} \mathrm{E} b$ and $\mathrm{A} b$ can be respelled as D\# and G\#). The tension associated with the first phrase recedes rapidly, for the consequent unfolds accompanied in the "right key" of $\mathrm{G}$ with the tonic pedal point. This continues until measure 9 , where the harmony moves to the chromatic upper neighbor $A b$ for a new melodic material. The following musical example (5.10.1) shows musical idea 1. 
Musical example 5.10.1: Liebermann's Nocturne no. 10, measures 1-9
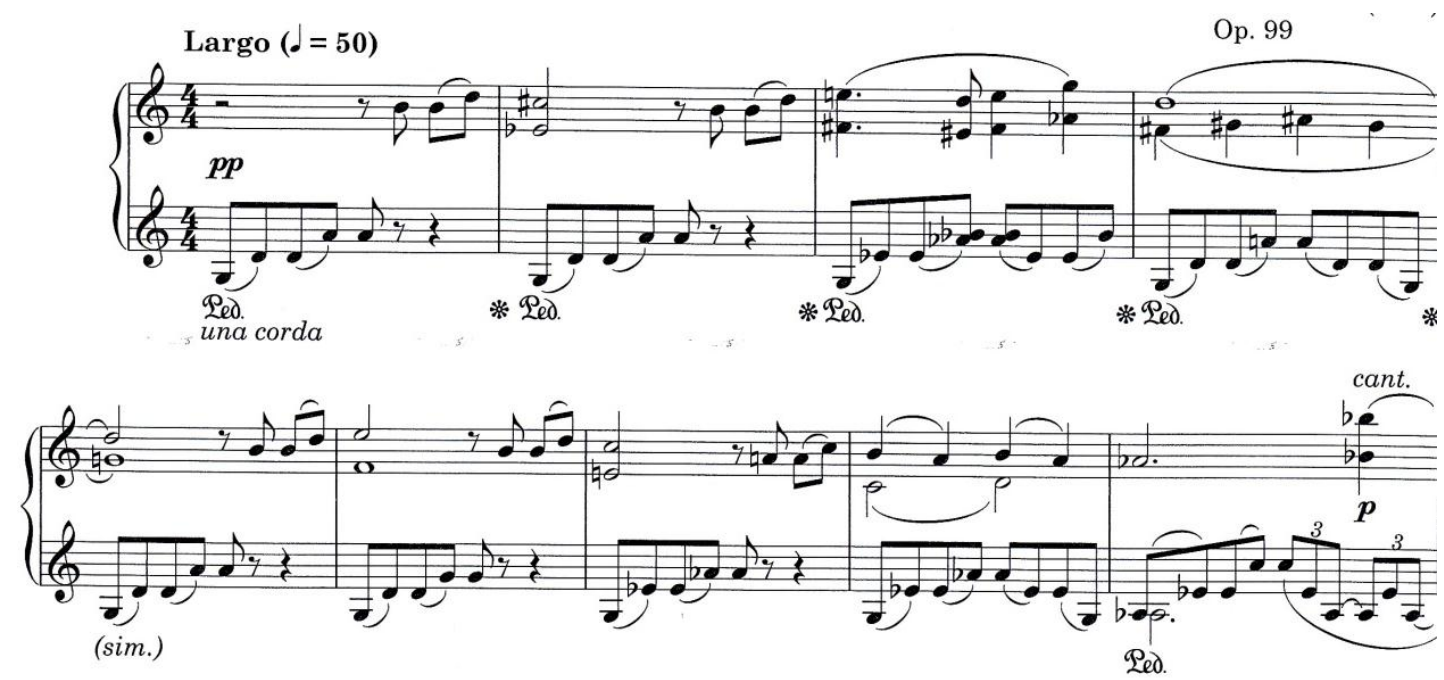

(C2009 by Lowell Liebermann; Published by Theodore Presser Co., Used With Permission

The texture changes when melodic idea 2 enters at measure 9 . The melody is mainly played by octaves in the right hand while the accompaniment is presented in triplets in the left hand. The harmony is at times established clearly, and in the other instances is either only partially suggested or is very complex and conflicting with the melody. The melodic material of this section is also two-fold and appears to be written according to an antecedent-consequent model. The consequent, measures $14-20$, is significantly affected by numerous transformations in rhythms and in melodic intervals. It is expanded through a process of motivic transformations to the extent that only the general direction and shape of the melodic line are preserved. In regard to harmony, the antecedent begins on the $A b$ triad at measures 9 and 10 and follows a progression of $\mathrm{D}$ (measure 11), F\# (measure 12), G (measure 13) and $\mathrm{Eb}$ (measure 14). The consequent begins in the key of $\mathrm{E}^{b}$ (relationship of a fourth with the corresponding material, measures 14 and 15), and continues with a progression to $\mathrm{F \#} \mathrm{(measure} \mathrm{16),} \mathrm{and} \mathrm{C}$ to $\mathrm{Ab}$ (measure 17). It is thereafter (measures 18 to 20) expanded through the harmonies of D, E, and F\#. Structurally 
speaking, the beginning of the Nocturne also rests on a very long and slow-moving chromatic line: $\mathrm{G}$ at measures 1 to $8, \mathrm{~A} b$ at measures $9-10, \mathrm{~A}$ at $11, \mathrm{A \#}$ at 12 and $\mathrm{B}$ at 13 ; however, on account of the very slow tempo, this is probably imperceptible. The following musical example (5.10.2) shows melodic idea 2 (antecedent and consequent).

Musical example 5.10.2: Liebermann's Nocturne no. 10, measures 10-18

The motive used for the expansion is indicated
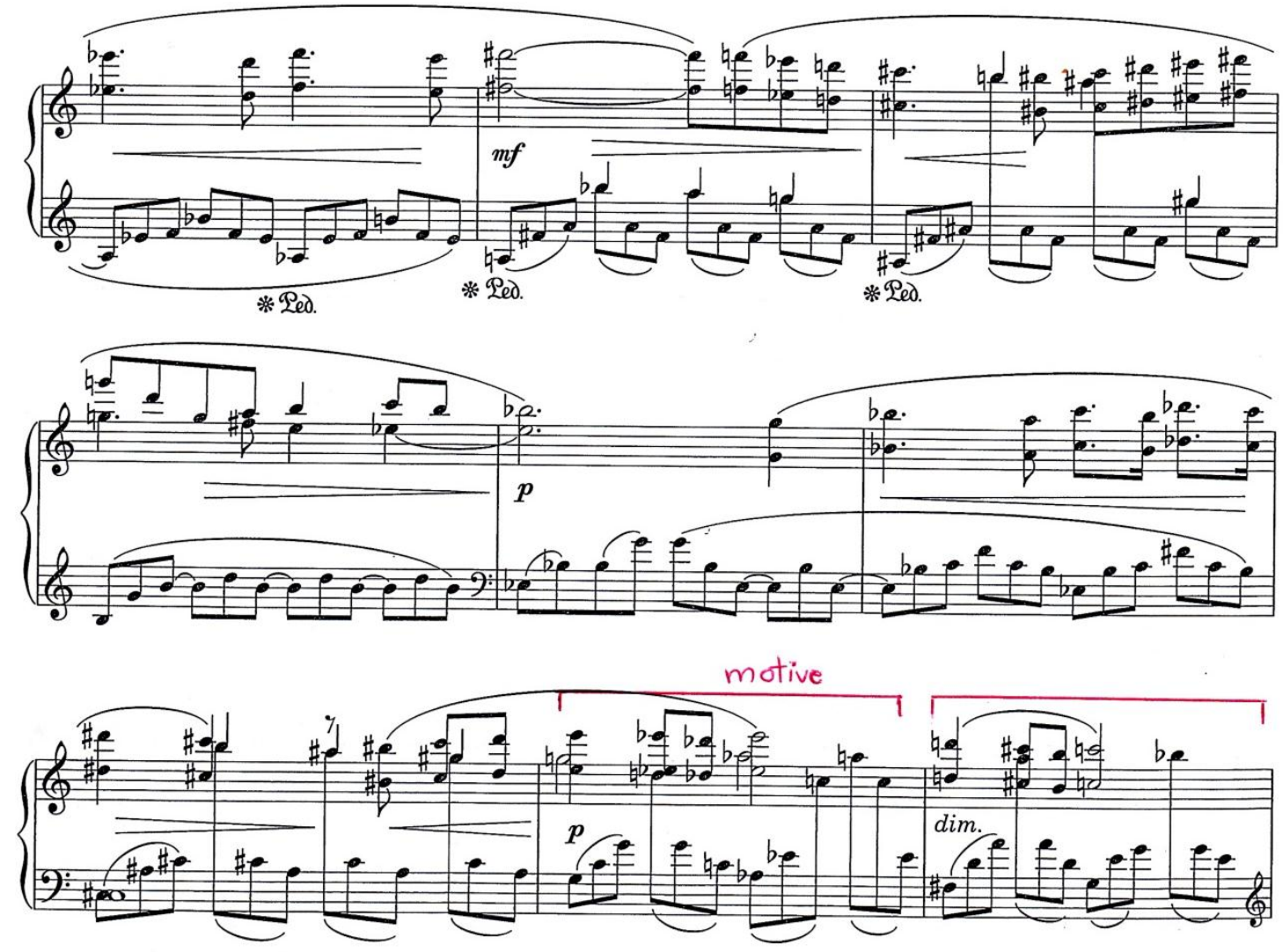

C2009 by Lowell Liebermann; Published by Theodore Presser Co., Used With Permission

At measure 17, we hear a motive based rhythmically on a quarter note followed by two eighth notes and a half note, and melodically on a downward half-step, whole step, and upward whole step, (E-D\#-C\#-Eb). References (rhythmic and intervallic) to this motive will occur again 
in the next two measures (at measure 18: D-C\#-B-C and at measure 19: B-A\#-G\#-A). This process of motivic transformation serves to expand melodic idea 2 and brings the piece to the next section (section B).

At measure 21, the texture changes again and a new melodic idea appears (melodic idea 3). The left hand plays a low bass. The harmony is stated by an ostinato figure played in the middle register of the instrument. This ostinato includes double-notes, made of chromatic elements (the two mediants, lowered sixth and lowered seventh) and a few modal borrowings (lowered second and raised fourth). ${ }^{168}$ On top of this ostinato- - which also bears a connection with the important motive from measure 17 used for the expansion at measures $18-20$ - the right hand plays a single-line melody, which displays a few tonal digressions and undergoes similar motivic expansion. This passage is made of elements of D Lydian (with the odd D\# in measures 23 and 24) giving rise, in connection with the "Lydian" raised fourth degree (G\#), to a fragment on a G\# Ionian scale (measure 26), before returning by way of G\# (functioning as a sort of pivot tone) to D Lydian (measure 27); it then continues to what could be called G\# minor (measure 28). Musical example (5.10.3) displays melodic idea 3.

168 It is also possible to see this ostinato through the whole-tone relationship between the main pitches (A\#-G\#-F\#E-D), the E\# being considered a chromatic passing tone. 
Musical example 5.10.3 Liebermann's Nocturne no. 10, measures 19-24 Melodic idea 3
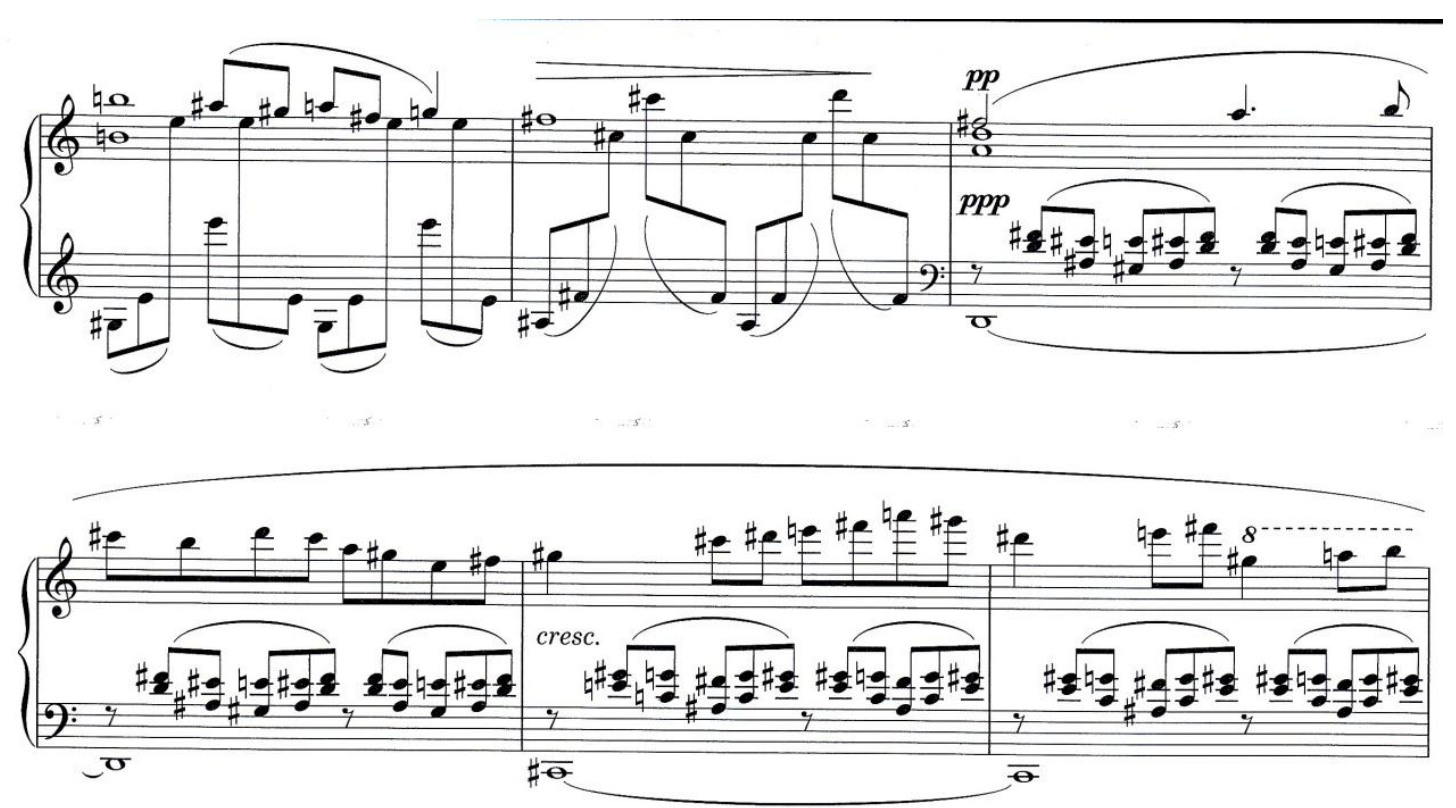

C2009 by Lowell Liebermann; Published by Theodore Presser Co., Used With Permission

As part of this expansion process, at measure 29, the texture in the accompaniment changes to an oscillation between intervals; shortly after that, the melody also changes from being single-line to two voices (with intervals of fourths and octaves), and to occasional chords. A highly chromatic figure of four notes, in measures 35-36, played in four different disguises (that is C-B-B b-G, transposed through a fully-diminished seventh chord-C-A-G $b$ and $E$ b being the first pitch of each respective segments), leads to the next section with the return of melodic idea 3, slightly ornamented. As discussed previously, the ornamentation of a semitone followed by a jump down is typical of Liebermann's style and was seen on numerous occasions in other Nocturnes, especially in Nocturne no. 4, where a striking example is provided at measures 41-45. The familiar low bass and middle register ostinato are re-established while the recognizable melody is revisited with a few rapid written-out mordents, decorative appoggiaturas, and leap-of- 
an-octave figure. The harmony moves from $\mathrm{E}^{\mathrm{b}}$ to $\mathrm{D}$, before settling in $\mathrm{B}$ at measure 41 . However, this appearance of stability is somehow disturbed with the inclusion of major-sevenths and minor-ninths elements into the accompanying ostinato pattern, which continues until measure 45 , where the left hand plays a succession of minor ninths. This section ends on a descending succession of chords built on fourths (perfect-perfect or augmented-perfect; measures 43 to 46). ${ }^{169}$ This "familiar" chord is also coupled with its "familiar" downward, almost tonal resolution; but the tonal feeling is diluted by the clashing accompaniment of ninths in the left hand. At measure 46, the music reaches the triad of $\mathrm{C \#}$ minor in the right hand and of $\mathrm{C}$ in the left hand. Reverberations of that chordal entity $(\mathrm{c \# /C})$ ring in the pedal while a new section begins at measure 47 (section C). This section is imitative, quasi fugal. The interval of the fourth is clearly the basis of the theme of the fugue, for the head of the "subject" encompasses two such fourths, played successively.

The direction of the melodic line makes it also possible to perceive the theme of the fugal section as being closely related to melodic idea 2 . The first entry of the subject is heard at measures 47 to 50 . It is answered by an almost exact reply, one octave higher at measure 49-50, varied mainly by a few rhythmic alterations ( $C$ one beat instead of three, $E b$ two beats instead of three, D two beats instead of one). The third entry occurs in the soprano, a seventh higher than the second entry (therefore, accordingly, beginning on F rather than G). Other appearances of the theme occur, but only partially or with some intervallic adjustments. This is particularly clear in the stretto-like passage in measures 55-56, where a certain feeling of anguish arises from the very close entries, before the music plays three times the characteristic chord with the suspended fourth resolving downward, in c\#, over an incomplete harmony of C—although the E, resolution

169 This type of chord has already been used by Liebermann on numerous occasions, in other Nocturnes, and in this Nocturne at measure 32. 
of the fourth, is heard in the soprano. The following musical example (5.10.4) displays the familiar suspended-fourth chord and the fugal section.

Musical example 5.10.4: Liebermann's Nocturne no. 10, measures 44-60
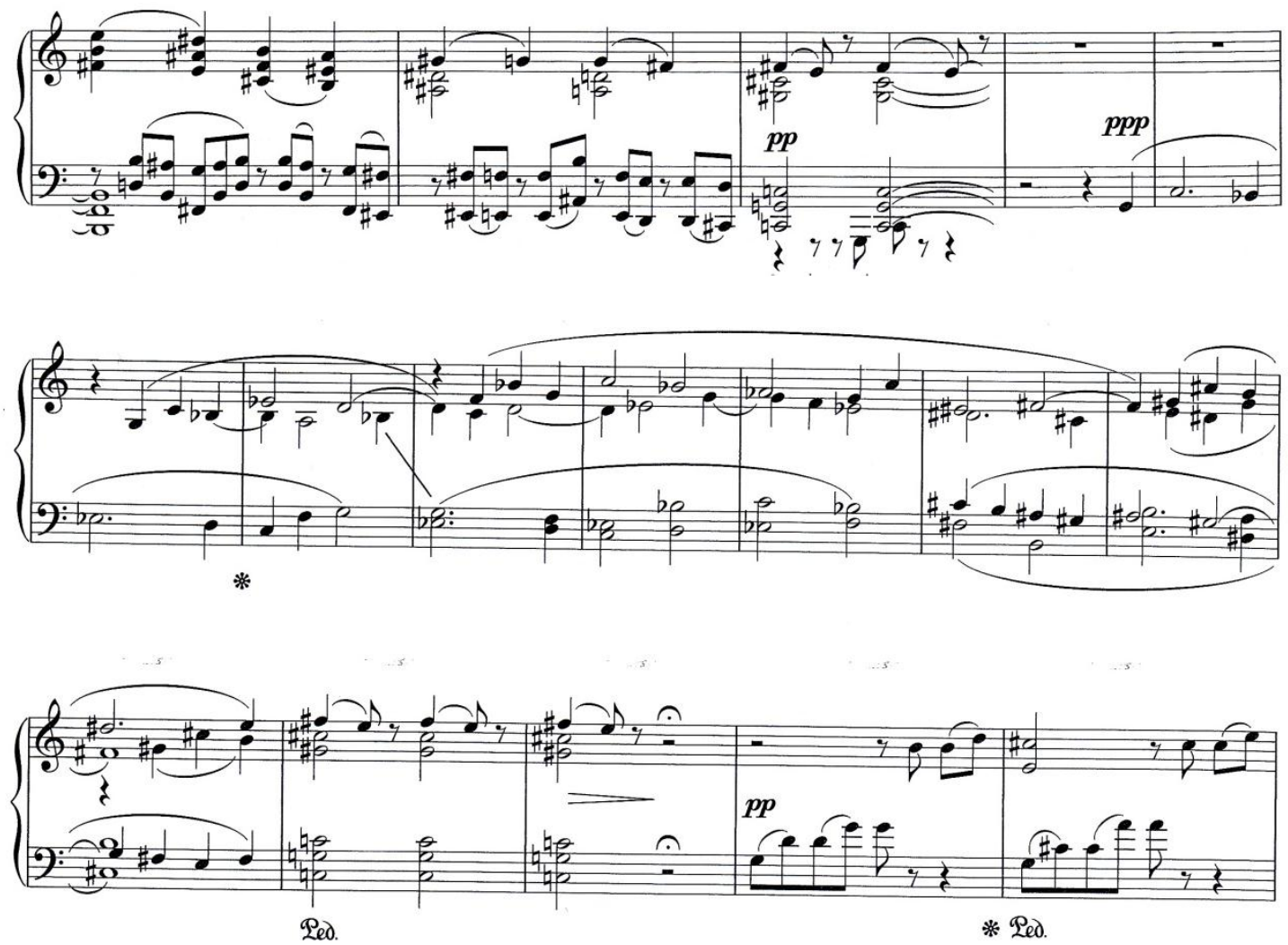

(C2009 by Lowell Liebermann; Published by Theodore Presser Co., Used With Permission

The closing section is based on melodic idea 1. After a fermata over the $\mathrm{c \# -C}$ chordal complex, the Nocturne's familiar opening idea is suggested. Numerous variants in the harmony can be observed and give a new impulse to the material. The tonic pedal point has disappeared and is replaced by harmonic progressions, almost traditional. After the $\mathrm{G}$ chord is played at measure 59, dominant-tonic motions are heard in two different keys: A7-d (V7-i); G-C (V-I); 
and evaded in the last one, F7- while one would predict this to go to B b, instead the G chord is heard, although sounding the B b pitch (its minor third) in the soprano. ${ }^{170}$

At this point, the entire melodic idea 1 is played again, almost untouched. The pedal point is reinstated for five measures. The following bass line reaffirms the key of $\mathrm{G}$ with a downward motion F-E, and back to G. A little departure into thirdless harmonies (C\#, A and F) - in the left hand - follows at measure 71, but the Nocturne ends quietly and expectedly in G. As mentioned earlier, the melodic material is mainly left untouched except for the inclusion of a few pitches at measure 70. This addition of one pitch to the two-voice texture allows Liebermann to bring back the quartal chord and also to generate a superimposed different harmony to the already existent one in the left hand. This could be perceived as a $\mathrm{V}^{7}$ with an appoggiatura (the $\mathrm{B}$ ) over a pedal point: a tonal cliché. To make sure the chordal entity will be aurally recognizable, Liebermann writes it with its downward resolution. Therefore, at measure 71, harmonies of $\mathrm{F}, \mathrm{g \#}$ and $\mathrm{b}$ are heard against the thirdless harmonies of C\#, A and F. Once again, semitone relationships between the hands can be observed, along with contrary motion of the melodic direction (right hand goes up while the left hand goes down). Moreover, there is a contrast between the major-third relationship of the progression in the left hand $(\mathrm{C \#}, \mathrm{A}$ and $\mathrm{F})$ and the minor-third relationship in the right hand (F, G\# and $\mathrm{B}$, to be understood as $\mathrm{F}, \mathrm{A} D$ and $\mathrm{Cb})$.

Nocturne no. 10 is a smaller-scale piece which does not carry any of the grandiloquentand at times "romantic" — pianistic gestures of the previous Nocturnes. It is nevertheless a fine addition to the genre, for in it Liebermann expresses a more ethereal conception through a simpler style that relies on color and delicacy of touch. In that regard, as mentioned previously, Liebermann specifies the use of the una corda at measure 1 of this Nocturne. Is it to be used

170 It is possible to understand this progression of these elements as a single circle progression and would read as such: in G major: starting at measure 59, I-V/V-v-V/IV-IV-V/iii-I(i). Special note should be made of the stepwise voice leading in those final eights in each harmony (fermata). 
throughout the piece? Does one have to resume the use of the una corda at measure 59? Or at 63 ? After the numerous experimentations with canons and with the idea of imitation, the inclusion of a fugal passage in a Nocturne becomes a very "normal" and interesting feature. Moreover, as one works through Liebermann's Nocturnes, it appears that he has adopted as a usual practice the appearance of an imitative transition.

\subsection{Nocturne no. 11, op. 112}

Nocturne no. 11 was composed in 2010 and was commissioned by Mark Wölffer in memory of his father, Christian. ${ }^{171}$ This Nocturne was premiered by William Hobbs on July 16, 2010, at the Wölffer Estate Vineyard in Sagaponack, New York, as part of the Music Festival of the Hamptons. ${ }^{172}$ This work of 121 measures takes some six minutes and thirty seconds to be performed. Reviewing the work at the premiere, F. Cord Wolkmer of the Southampton Press called it "a gorgeous piece of music...the Nocturne featured broken clusters of notes like stars spanning the night sky, a tumultuous center section leading to a tender, slightly bluesy finale...it was refreshingly tonal, melodically beautiful." 173

With his most recent Nocturne, Liebermann returns to a grander conception of the genre. This Nocturne displays some of his favorite "romantic" pianistic gestures, virtuoso passages and multi-layered textures, while also revealing experiments with new features, such as more

171 Christian Wölffer was born in Hamburg, Germany, on March 15, 1938. He founded the Wölffer Estate Vineyard, a highly regarded boutique winery on Long Island. He died in a swimming accident off the Brazilian coast. He was 70 and lived in Sagaponack, N.Y., on an estate that included the vineyard, spanning 55 acres. Among Wölffer's best-known wines are its Cabernet Sauvignon, Cabernet Franc, Pinot Gris, Merlot and Cuvée Sparkling Brut.

172 William Hobbs is a pianist/vocal coach, based in New Jersey. See Appendix B for more information, or consult the artist's website at: http://www.operaslavica.com/

173 F. Cord Wolkmer of the Southampton Press; the citation is taken from: http://www.lowellliebermann.com/works/opus112.html and http://www.presser.com/composers/info.cfm?Name=LOWELLLIEBERMANN\#Reviews 
generous use of bitonality and an exploitation of a faster tempo (including accelerando) to generate drama. Musical figure 5.11 shows the formal structure of Nocturne no. 11.

Musical Figure 5.11: Liebermann's Nocturne no. 11

\begin{tabular}{|c|c|c|}
\hline $\mathbf{A A}^{\prime}$ & BA" & CA'" $^{\prime \prime}$ \\
\hline $\begin{array}{l}\text { - m.i. } 1 \text { \{intro\} (3-5; 6-8; } \\
\text { 9-13; ext. 14-18) } \\
\text { [C-Gb Lyd.*] } \\
\text { - m.i. 1(21-23; 24-26; } \\
\text { 27-33) [C-Gb Lyd.] }\end{array}$ & $\begin{array}{l}\text { - } \text { Più mosso: } \\
\text { m.i. } 2(34-37 ; 38-42 ; \\
\text { m.i.3 43-48; 49-56) [Eb] } \\
\text { Presto: } \\
\quad(57-61 ; 62-66 ; 67-74)[\mathrm{F}] \\
\text { extension (75-82) } \\
\text { - }\{\text { intro\} }(83-86)[\mathrm{D} \text { b] } \\
\text { m.i. } 1(87-90 ; 91-98)[\mathrm{C}]\end{array}$ & $\begin{array}{ll}\cdot & \text { Molto semplice } \\
& (99-102 ; 103-106 ; \\
& \text { 107-110; 111-114) [a] } \\
-\quad & \text { recapitulating Coda }\} \\
& (115-121) \\
\text { m.i. } 1 \text { (117-121) } \\
\text { [C-Gb Lyd.*] }\end{array}$ \\
\hline
\end{tabular}

*The $\mathrm{G} b$ Lydian could also be perceived as $\mathrm{D} b$.

The Nocturne begins with two measures of simple and pure $\mathrm{C}$ arpeggio in first inversion, enveloped in the una corda pedal. ${ }^{174}$ After the accompanying ostinato has established the tonality, the main melodic idea enters at measure 3. When the first pitch of the melody, $G b(F \#)$, is played, one has the impression of being in the presence of the familiar raised fourth. Soon after, Liebermann repeats that same pitch two more times and thereafter continues with the melodic line, quite diatonically, but in what seems to be rooted in the key of Gb Lydian (preserving the familiar raised fourth, and thereby emphasizing the tritone relationship between the two tonics). 
In earlier pieces, Liebermann has also used bitonality, but it was usually for shorter moments, and often was generated by superimposing two different chords. In this specific instance, a triad of $\mathrm{C}$ is established (suggesting tonality) and on top of it, a melody rooted in a totally different key (Gb Lydian) unfolds; bitonality is created and expressed in a larger, more melodic way. Melodic idea 1 unfolds according to an antecedent-consequent ${ }^{1}$-consequent ${ }^{2}$ scheme. $^{-}$ Because of the way it is written, the melody has to be played through sharing the line between the hands, as the composer kindly suggests in the score. Although it would be possible to play this material without the sharing, splitting the task between the hands allows a smoother legato. The underlying harmony is based on chords presented in first inversion; the antecedent appears over a triad of $\mathrm{C}$, and consequent ${ }^{1}$ occurs over triads of $\mathrm{A}$ and $\mathrm{D}$. The consequent travels through $\mathrm{d}, \mathrm{A} b, \mathrm{a}, \mathrm{D}, \mathrm{d}$ and $\mathrm{C}$, all in first inversion. The second consequent (consequent ${ }^{2}$ ) begins with a similar melodic motion than its predecessors, but soon after, is expanded with the idea of imitation (in the triplets at measures 10-11), still relying on superimposed bitonality. Often the upper part is set in a key a semitone lower than its lower counterpart. ${ }^{175}$ The important components of that melodic cell are the six notes (two groups of triplets) going down (diatonically) and the repeated pitch at the junction of these two groups of triplets. This melodic cell will be used extensively in the following sections of this Nocturne. The following musical example (5.11.1) shows the opening material, antecedent and beginning of consequent ${ }^{1}$.

175 Of course alternate readings are also possible. In that passage, the right hand of the second consequent can be viewed as being almost entirely diatonic, in the same mode as the left hand, with standard nonharmonic tones: $\mathrm{G \#}$ in measure 8 as a neighbor tone; $\mathrm{B}$ and $\mathrm{C}$ in measure 9 as passing tones; measure 10 is in $\mathrm{Ab}$ Lydian; $\mathrm{Gb}$ in measure 11 is a chromatic passing tone and so are the next $\mathrm{E}$ and $\mathrm{E} b$. The only bitonality could then be detected in the complexities of measure 13 , and even there one can see the $\mathrm{Db}$ as a passing tone between $\mathrm{D}$ and $\mathrm{C}$, displaced by an octave (admittedly blurred by the sustaining D). However the reading in the main body of the text highlights the idea of bitonality — or superimposed tonalities — which perseveres through the whole work. 
Musical example 5.11.1: Liebermann's Nocturne no. 11, measures 1-6
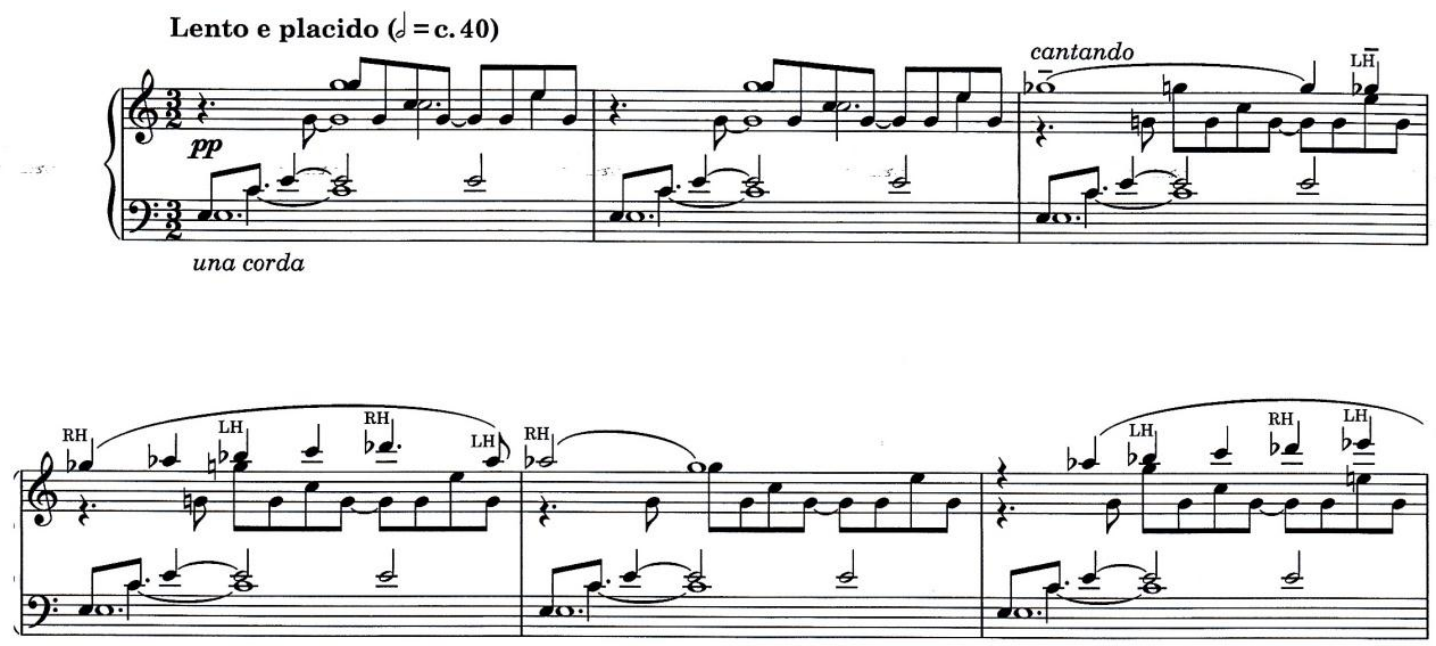

C2010 by Lowell Liebermann; Published by Theodore Presser Co., Used With Permission

Measures 14 to 18 represent more an extension of the material than a new melodic idea, for three reasons. Firstly, this new material is not reused thereafter in the Nocturne. Secondly, the main melodic material is again presented over the same simple accompanying patterns. And thirdly, it still highlights familiar melodic cells of repeated pitches and downward resolution (recalling for example: Ab-A b-G, the end of antecedent at measures 4-5; and B-B-A, end of consequent ${ }^{1}$ at measures $7-8$ ). This can be seen in the important melodic notes E-Eb-Eb-Db-C from measures 17 onwards. At measure 18-19, a brief motion D b-C (Neapolitan-I) brings back the opening material. The following section (measures 19-33) is a restatement of the material of the first section, but revisited through changes of texture: the melody is played in octaves while the accompaniment turns to arpeggios in root position covering the span of three octaves. The harmony is also enriched occasionally through the inclusion of a few nonharmonic tones: $\mathrm{E} b$ and A $b$ at measure 21 for instance. And the first note of the melody is shortened by two quarters. Midway through consequent ${ }^{2}$, there is an enharmonic respelling at measure 28 , which 
corresponds to measure 10: $\mathrm{E} b$ is respelled D\#. Accordingly, the harmonic motion is affected by this small change (now $\mathrm{B}, \mathrm{A}$ b, $\mathrm{A}, \mathrm{G}, \mathrm{F}$ and $\mathrm{B}$ ); consequent $^{2}$ is shortened from eleven to seven measures (measures 27-33). Musical example 5.11.2 displays Melodic idea 1 in its enriched presentation.

Musical example 5.11.2: Liebermann's Nocturne no. 11, measures 21-28
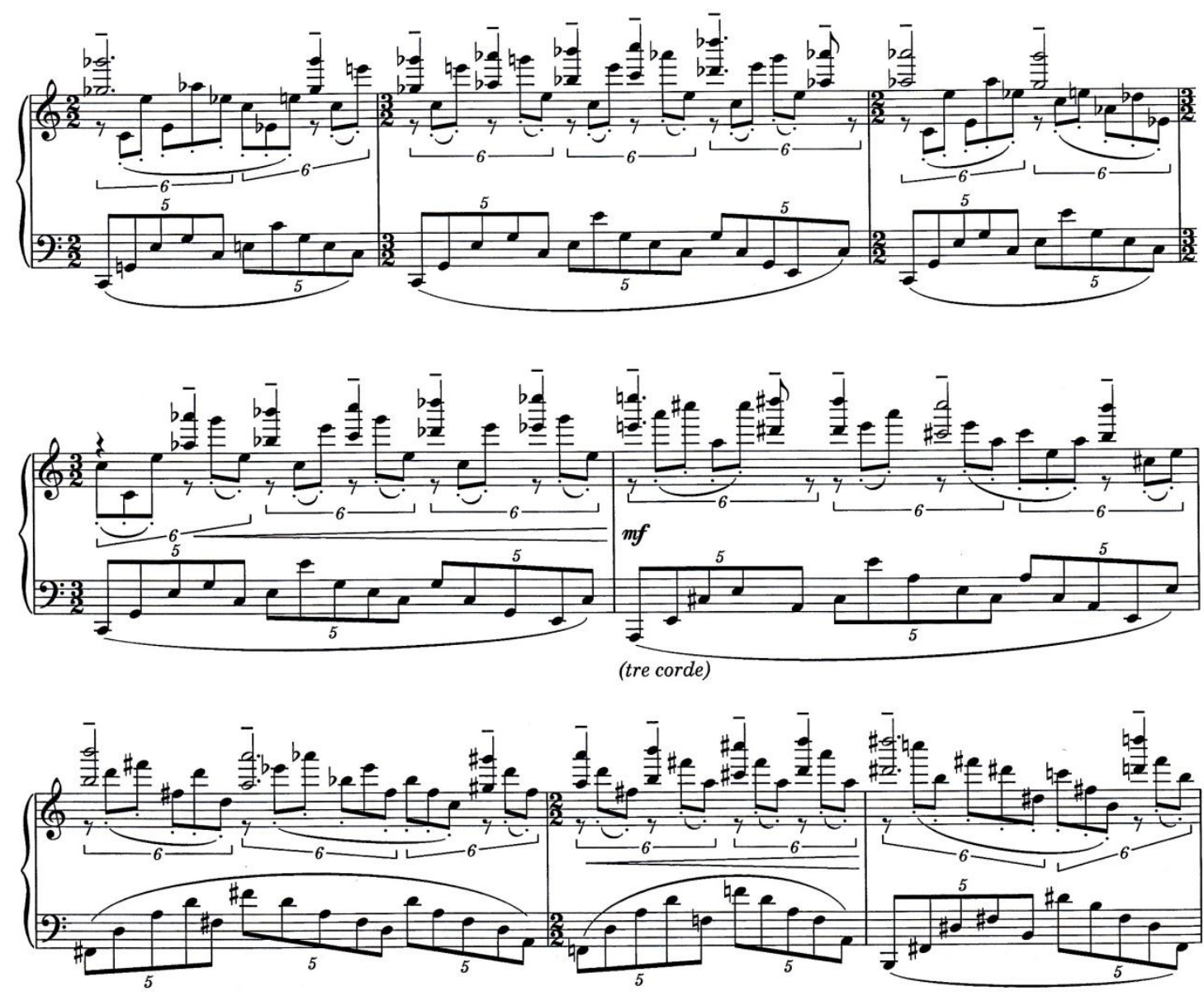

(C2010 by Lowell Liebermann; Published by Theodore Presser Co., Used With Permission

Changes in tempo (più mosso) and in texture (downward triplet scales in the left hand), and a new melodic idea mark clearly the arrival of a new section (section B). Melodic idea 2 is based on two important elements: a diatonic scale going upwards, followed by an arpeggio 
which also rises. The first two measures of the idea agree with the left-hand harmonic background of Eb Lydian, while the remaining extension of two measures retains the idea of bitonality, an important structural feature of the first section. From measures 34 to 37 , taking in consideration both voices in the right hand, the theme is heard in Eb Lydian with its bitonal counter-part in $\mathrm{f \# .} \mathrm{This} \mathrm{is} \mathrm{followed} \mathrm{by} \mathrm{a} \mathrm{repetition} \mathrm{in} \mathrm{G}$ at measure 38 , for which the counterpart is more tonally ambiguous (based on the whole-tone scale). ${ }^{176}$ Throughout this section, the left hand provides the harmonic support (including the raised fourth) and also acts as an ostinato (lasting two beats). As mentioned earlier, this cell is taken from material that was previously heard at measures 10-11, the downward groups of triplets connected by a repeated pitch. Musical example 5.11.3 shows the beginning of section B, melodic idea 2, the use of the new accompanying ostinato and the presence of bitonality: Eb Lydian and f\#.

Musical example 5.11.3: Liebermann's Nocturne no. 11, measures 33-40
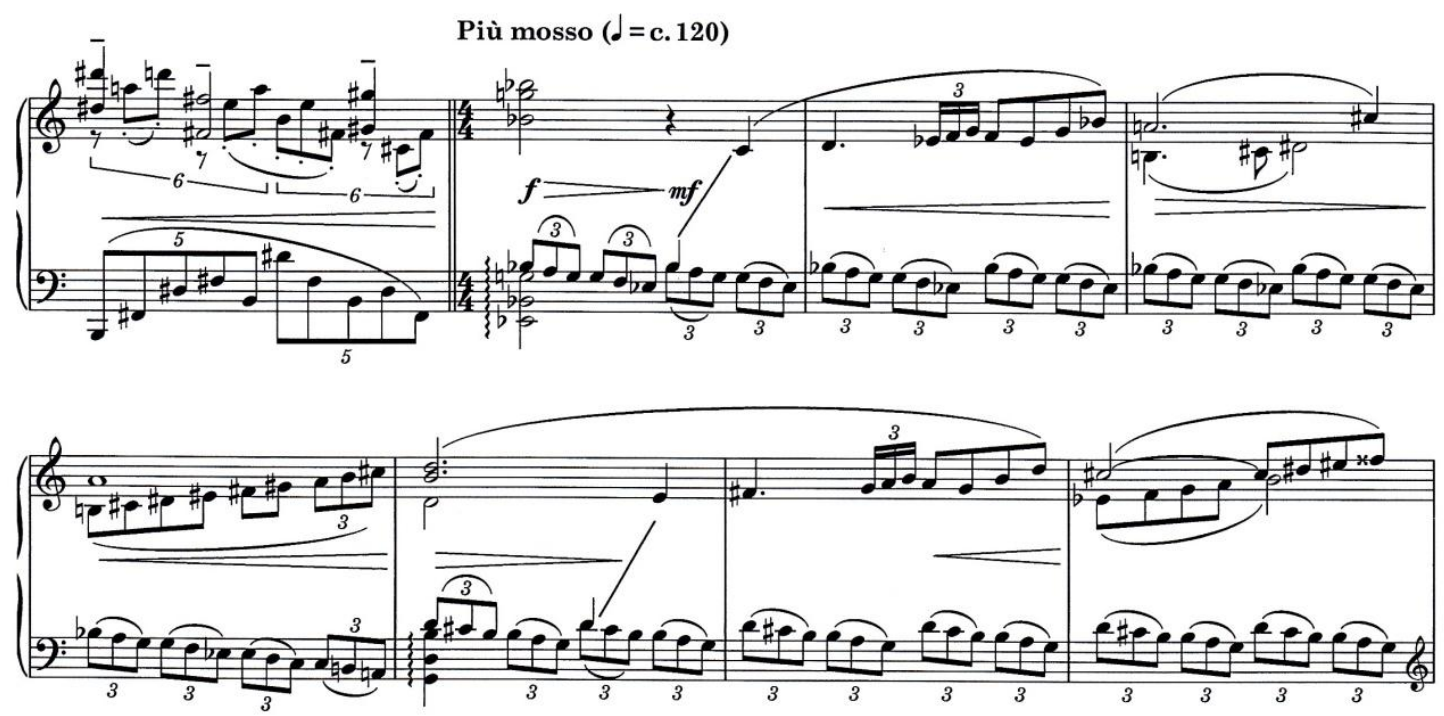

C2010 by Lowell Liebermann; Published by Theodore Presser Co., Used With Permission

176 A special note should be made for the use of A as a link between the Eb Lydian scale and f\# minor, along with the use of the longest whole-tone segment available in the f\# minor scale, A-B-C\#-D\#-E\#, in measures 36-37. 
Measure 43 marks the beginning of a substantial section, developmental in nature, based on previously heard motives. At first, a clear sway between third-related harmonies is heard in the left hand, while the right hand plays rhythmic transformations of a few elements of melodic idea 2 (which is also related to melodic idea 1). A new melodic idea, melodic idea 3 characterized rhythmically by a quarter note tied to another quarter note, eighth note (member of a triplet figure) and two quarter notes - is played in thirds over rapid shifts in the left hand between harmonies of $\mathrm{E}^{\mathrm{D}}$ and $\mathrm{C}$ (measures 43-44), and A and F\# (measures 45-46). At the same time, another layer of musical material is added, played in the lower part of the right hand. This material is yet another transformation of the triplet motive and the repeated note, this time inverted and affected by octatonicism. Both hands agree on the background harmony, with the addition of the raised fourth and lowered seventh. The new melodic material is played four times (measures 43 which is repeated at 44 , and then 45 which is also restated at 46 ) before it is expanded (tail of 46) and continues through further transformations (in 47 and following, the characteristic rhythm of the upper line now becomes even quarter notes). At measure 49 , the figure which has been used as a left-hand ostinato since the beginning of this section is now transferred to the right hand and becomes an important melodic element. Since the material is more chromatic, the sizes of the intervals change; but the use of triplets, the melodic direction, the spanning of the interval of a fifth and the presence of the repeated pitch at the junction of each group of triplets make it quite recognizable. At the same time, the texture also changes. Now we see octaves in the left hand, playing third-related perfect fifths (F/C-A b/Eb, A/E-C\#/G\# and $\mathrm{C} / \mathrm{F}-\mathrm{A} / \mathrm{b} / \mathrm{D} b)$; at the same time we find octaves with upper thirds in the right hand. This material is presented in staccato eighths, a new texture. ${ }^{177}$ More changes occur over the next

177 Of course one other possible analysis would be to perceive those as seventh chords: F minor, A Major and Db major. 
measures. An accelerando begins in measure 51, gradually leading the music to a new tempo (Presto). At the same time, the left hand moves to triplets, encompassing harmonies less stable (d-Ab-b-f\#, e-b-f\#-c\#), while the right hand continues to elaborate the material related to the sixnote accompanying figure of descending triplets, now shortened to four-note cells. One might argue that this analysis of triads rather than fifths or sevenths chords makes sense in measure 53 but is not so obvious in measures 51 and 52; however, this ambiguity can be partially explained by the presence of semitonal pitch relationships between some members of the adjacent harmonies in measure 51-52 (A vs. Ab, and D vs. C\#), while measures 53 does not encompass such friction.

At measure 54, a cluster made of B-C\#-A-B is heard $s f z$ in the low register; thereafter, for the next three measures, the hands play in mirror image with respect to each other based on the accompanying figure, initially retaining the ideas of the thirds, Lydian mode, and the repeated pitch from the previous texture, but eventually discarding the latter two features. The following musical example (5.11.4) shows a few of the numerous transformations and expansions affecting melodic idea 3 and its characteristic accompanying motive (triplet and repeated note). 
Musical example 5.11.4: Liebermann's Nocturne no. 11, measures 48-54
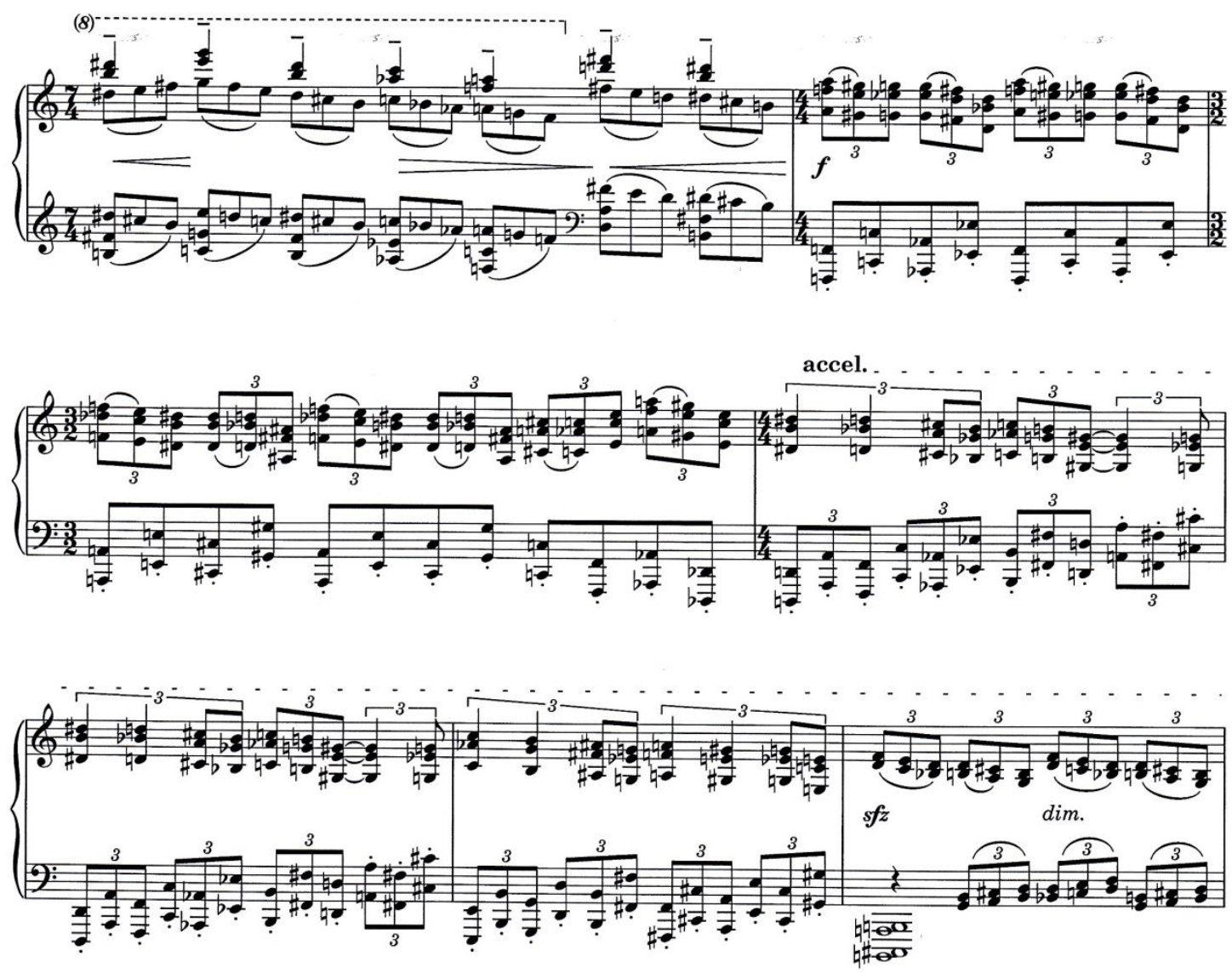

C2010 by Lowell Liebermann; Published by Theodore Presser Co., Used With Permission

At measure 57, the tempo reaches presto. As mentioned earlier, this is an unusual occurrence in a nocturne. Other composers studied also attempted to convey excitement and drama with fast tempi and even with accelerandos, but none of them used any presto marking in their Nocturnes. ${ }^{178}$ The texture thins out to a single line in the right hand, in triplets, recalling the familiar accompanying cell—which now seems to act as a theme-over the left hand which plays mainly intervals of melodic thirds. The material used in the left hand is related to that

178 Wallach discussed Field's experimentations with faster starting tempi and stated that this feature was not continued or developed by later composers. However, the fastest tempo used by Field was allegro. (Wallach, 125-126.) Tempo changes in the middle sections of Chopin's Nocturnes were usually for a faster tempo, but only con fuoco and doppio movimento can be found; nothing approaching presto. Finally, the fastest tempo encountered in Fauré's Nocturnes was also allegro. 
encountered at measure 49: the jumps of fifths are now shortened to jumps of thirds. At the same time, the material used in the right hand also recalls that seen at measure 49, keeping the triplet figure, the repeated note and the main direction of the melodic line. The first five measures of the left hand (measures 57 to 61) highlight a chromatic line which ascends from $\mathrm{F}$ to A. At measure 62, the principal melodic idea (melodic idea 2 from the B section) is played again. The harmonic setting is less stable than what was experienced during the previous hearing but can be understood as an instance of an octatonic scale. Melodic idea 2 returns once more at measure 67 , again less stable; the key of f\# is subtly suggested. It is followed by a short extension of a few measures, based on the melodic direction of the theme; both hands are treated very chromatically, passing through the keys of $\mathrm{c}$ and e, and through less-defined harmonic zones. Another texture establishes itself at measure 75: the familiar accompanying cell is played in the right hand (octave for the first member of the triplet); at the same time, the left hand plays in duplets, sounding intervals of thirds in octaves in the lower part of the instrument and in single notes in the middle register. Once again, this material (melody and accompaniment) is closely related to what we saw at measures 49 and 57: jumps of thirds (and occasional augmented fourths — turning into fifths and sixths at 79 and following) in the left-hand accompaniment, and the triplet figure, repeated note and melodic direction in the right hand. Because of the numerous jumps in the left hand, a three-layer texture is created.

The material from measure 75 is repeated at 76 , and measure 77 is repeated at 78 . One bar of extension is added before both hands finally come to an agreement at measure 80 when descending triplet figures resume in both hands, playing the familiar cell (with its characteristic repeated pitch). A crescendo concludes this section. 
At measure 83, the low chord $\mathrm{D}^{b}-\mathrm{G}^{\mathrm{b}-\mathrm{D} b} \mathrm{~b}$, played $s f f z$, becomes the release point for all the tension that from measure 34 onwards was generated by means of crescendi, accelerandi (both through tempo changes and as specified continuous changes), changes of textures, clashing dissonances and virtuoso jumps. A decorative, rapidly-moving motive, made of octatonic scalar elements is added on top of that $\mathrm{D} b$ chord. It serves to reduce the tension, for Liebermann asks that it be performed dim.e calmato. This new layer initially goes downward both within and between four-note cells, and then moves up the instrument until it settles in the high register. At measure 86, a $\mathrm{C}$ chord is struck, followed by its arpeggio. Unmistakably, this brings back the opening material of the Nocturne, although dressed up differently: the left hand solely provides the whole simple harmonic background while the right hand is given the task of playing the melody (melodic idea 1) and at the same time managing the filigree of octatonic scalar elements. The following musical example (5.11.5) displays the return of melodic idea 1, along with its new accompanying filigree motive. 
Musical example 5.11.5: Liebermann's Nocturne no. 11, measures 87-91
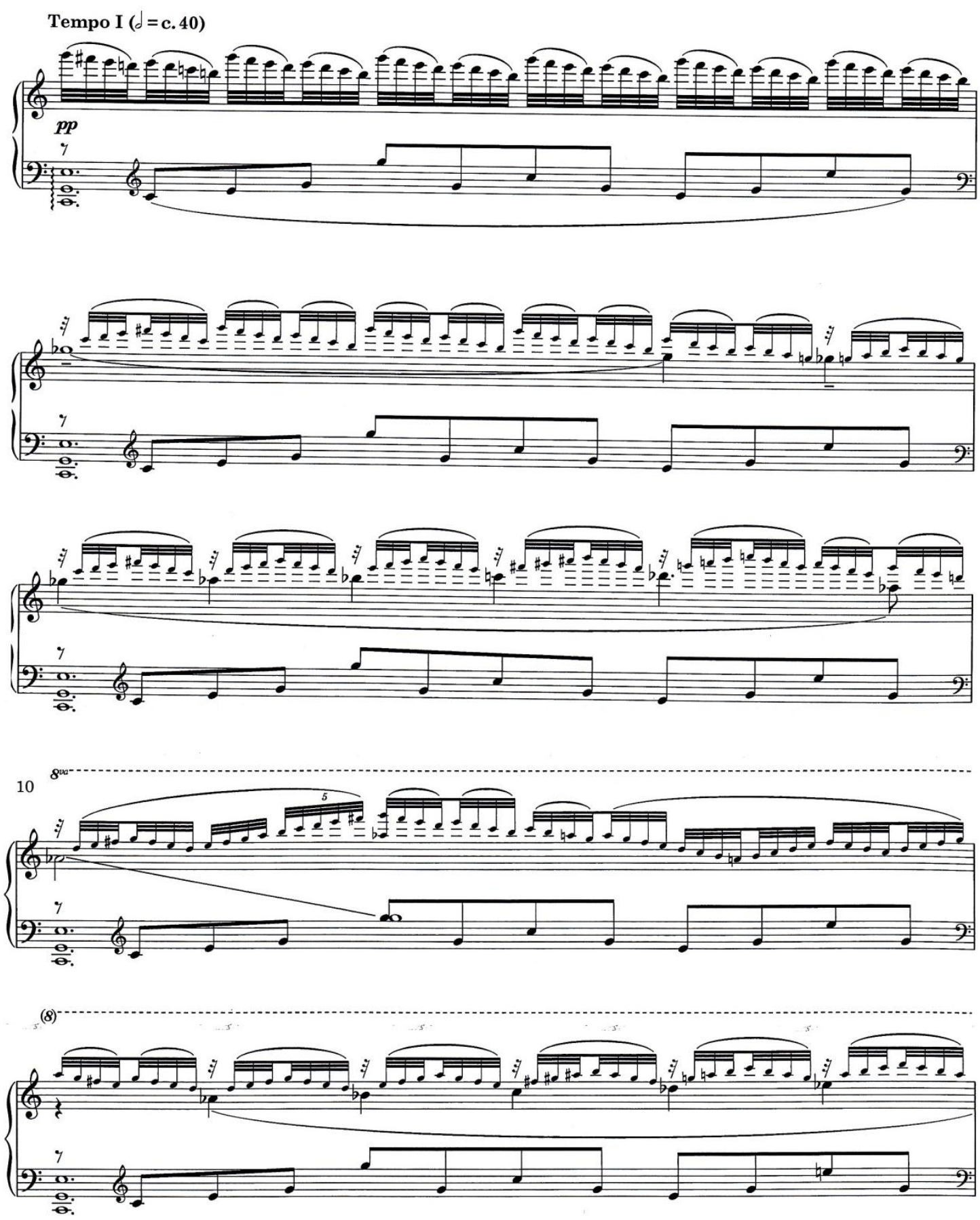

C2010 by Lowell Liebermann; Published by Theodore Presser Co., Used With Permission 
Amazingly, the material is presented unaltered melodically except for one enharmonic respelling. ${ }^{179}$ The harmony displays chords in root position and also digresses slightly from the original by replacing the major chords with their corresponding third-related minor counterparts: c\# at measure 92, instead of A (measure 7); f\# at measure 93, instead of D (measure 8); and c at measure 95, instead of $A b$ (measure 10). One bar of extension is inserted at measure 96. It is based on the familiar accompanying cell of the B section. Two more bars of simple D harmony (including the counterpart layer made of octatonic elements) are played ritardando and lead to the penultimate section, molto semplice.

A tremendous change of atmosphere and of texture from what was previously heard occurs within this section (section C). This "Molto semplice" section displays new material which is quite homophonic, and relies strongly on pedal points. The first phrase of four measures (99-102) is heard three times. This is repeated without any changes at measures 103 to 106 , and later transposed a semitone lower at measures 111 to 114 . The inserted phrase, measures 107 to 110 , seems to be inspired by similar material but played in mirror image. The harmonic background of measures 107 to 110 also seems more dissonant, for it relies more on interval of minor ninths and major sevenths, while the three other phrases encompass interval of minor sevenths and major ninths. Moreover, harmonically speaking, there is a connection between what could be called A Aeolian (measures 99-100) and Eb Lydian (measure 101) — with B b as a linkwhich recalls the opening $\mathrm{C}$ and $\mathrm{G} b$ Lydian. Musical example 5.11.6 displays the beginning of section C.

$179 \mathrm{~Gb}$ from measure 11 is respelled $\mathrm{F} \#$ at measure 96. 
Musical example 5.11.6: Liebermann's Nocturne no. 11, measures 103-112

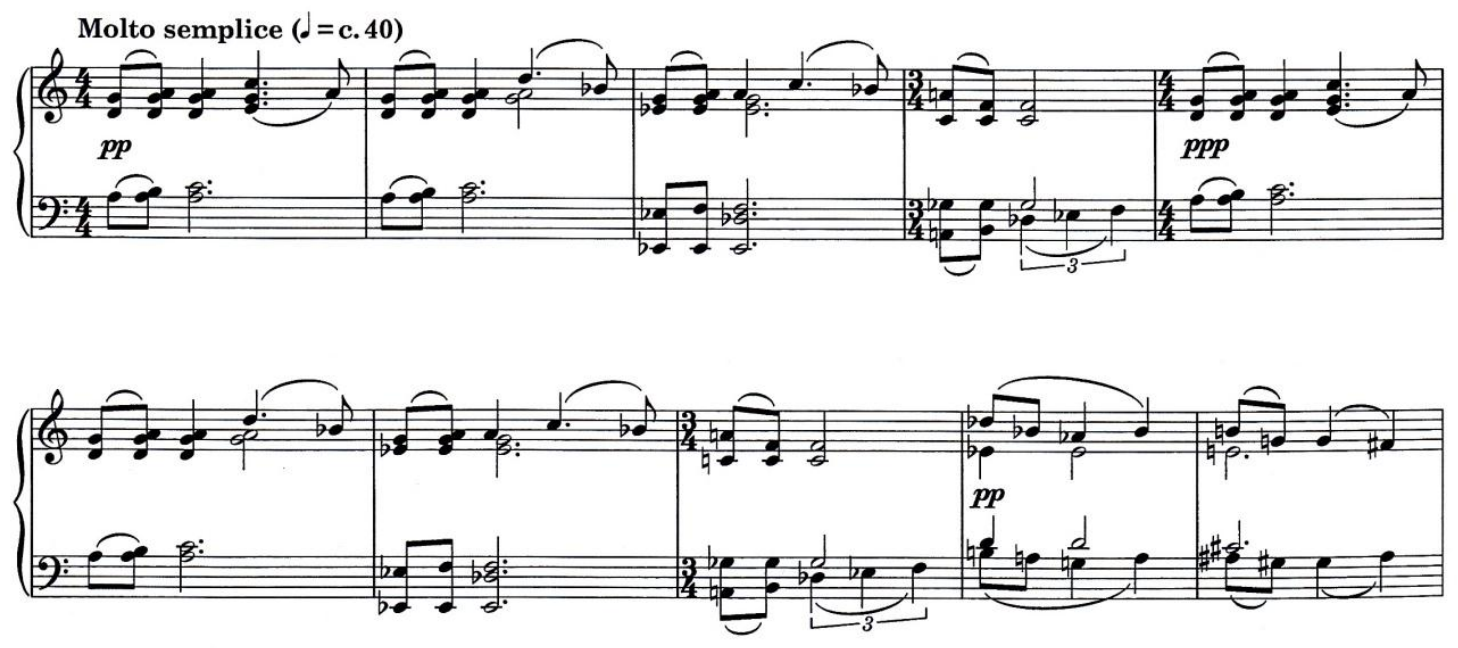

C2010 by Lowell Liebermann; Published by Theodore Presser Co., Used With Permission

At measure 115, Tempo I resumes with the final return of the opening material. The material is unchanged except for a few additions: a very low $\mathrm{C}$, and a few filigree figures of quintuplets going down diatonically with the inclusion of a raised fourth — that is Liebermann's well-loved Lydian spice. As he did for the corresponding section that opens the piece, Liebermann asks for the use of the una corda pedal. At measures 117-118, the main melodic idea is heard one last time, in the expected Gb Lydian, before it is prolonged for a few pitches and merges through an octatonic scale (B b-C-D b-Eb-E-F\#-G) at last into the key of C.

Harmonies of $\mathrm{C}$ in first inversion are played consistently throughout this section, except for the arrival at measure 115 which establishes the key and where the tonic is heard in the low register, and at the rolled chord in measure 119, when melody and harmony blend into the longinglyexpected pure C. The final gesture is a chord of C, played $\boldsymbol{p p}$ to which a barely audible pppp 
Db chord (its bi-tonal counterpart) is added. ${ }^{180}$

In his last Nocturne for solo piano, Liebermann has visited old familiar paths, but he also ventured into new, uncharted territories. Nocturne no. 11 speaks the familiar language of thirdrelated harmonies, modal borrowings, multi-layered writing, and constant, clever renewal of accompanimental figures. It also explores virtuosity expressed frankly—not for coloristic purpose but as a finality - and fast tempo combined with accelerando to generate drama and excitement.

Through his eleven Nocturnes, Liebermann confirms the established features of the genre, including singable melody, simple accompaniment and the importance of pedal. At the same time, he also offers new tools to enrich the medium, including canon, virtuosity and speed. The combination offers music of great beauty to performers and listeners alike.

180 If this last $\mathrm{D} b$ chord is a hint at interpreting earlier similar passages containing melodic idea 1 (cf. measures 3-6, 21-24, 88-91 and 117-119), then one could see this previous material as being presented in C and in Db instead of reading it as a combination of $\mathrm{C}$ and $\mathrm{Gb}$ Lydian. 


\section{SUMMARY AND CONCLUSIONS}

As a summary, it is time now to review the features encountered in Liebermann's Nocturnes and see if they relate to the style, specific trademarks and traditions associated with the genre established by Field, developed by Chopin and further expanded by Fauré.

Liebermann's melodies retain the singing nature inherent to the genre. Similarly to his predecessors, Liebermann writes diatonic lines most of the time. These melodies can also include a few chromatic inflections and modal borrowings; this kind of writing emulates closely Fauré's. Melodic material more dissonant in nature has been observed on a few occasions, particularly when the treatment of the Nocturne was motivic, but eventually the smaller cells are assembled together to create a theme, which in itself proves to be quite melodic and rooted in a key. (See Liebermann's Nocturne no. 6.)

Ornamentation, strongly associated with the genre even from its early days, had already been affected by significant changes under the hands of Fauré. Fauré's ornamentation is more pianistic than vocal in its treatment. Liebermann maintains a similar approach; the idea of embellishing a melody usually materializes through multi-layer writing. The texture can become quite complex in fact. Sometimes, very simple material becomes the basis of a complex two or three-voice canon or of a passage containing imitation—almost fugal. (See Liebermann's Nocturnes no. 3, no. 4, no. 5 and no. 10.) Occasionally, Liebermann adds a small pianistic gesture to a familiar theme, especially rapid displacements of an octave, which is treated either like a melodic line or like a resolving appoggiatura. (See Liebermann's Nocturnes no. 2 and no. 4.)

On account of the very nature of his writing, the idea of imitation is present in numerous Nocturnes by Fauré. Liebermann exploits imitation as well but in a much more extensive manner, 
making the canon an ornamented rendition of the thematic material and a crucial structural part of the work. (See particularly Nocturne no. 3, no. 5 and no. 9 for uses of canon, and Nocturne no. 10 for the use of a fugue-like passage.)

Among the favorite modal borrowings used by Liebermann, one should mention the raised fourth (Lydian mode), the lowered third, sixth and seventh (Aeolian mode), and less frequently encountered, the lowered second (Phrygian). It has been observed on numerous occasions how these melodic borrowings are similar to the ones found in Fauré's compositions.

In regard to rhythm, a great flexibility has always characterized the genre of the nocturne. It was expressed mainly in two different manners: the rubato element which, often indicated by the composer, could mean a fluidity of the pulsation or a slight desynchronisation between the hands, or a complex subdivision of the beat, which can encompass groups of less frequently seen numbers of pitches_encountered in cadenza-like passages or in heavily ornamented phrases. Numerous examples of these can be seen in Field's Nocturnes and to a greater extend in Chopin's. However, the more complex divisions of the basic beat were not exploited as much by Fauré. Fauré's rhythmic approach seems less diversified and simpler. Nevertheless, he generated complexity by layering numerous simple rhythms on top of each other. This also seems to reflect the approach taken by Liebermann. Most of the rhythms are simple in themselves, but great complexity —often creating tremendous challenge for the performer - is caused by the layering of several different simple rhythmic elements. In Fauré's as well as in Liebermann's Nocturnes, polyrhythm appears to be used as a substitute for rhythmic freedom. (See Liebermann's Nocturnes no. 5 and no. 8.) However, it should be mentioned that use of more diversified and complex rhythmic figures is also observed in later Nocturnes by Liebermann. (See Liebermann's Nocturnes no. 8 and no. 9.) 
Ostinati are also a favorite device amply used by Liebermann. Very often he relies on them to establish tonality (tonal center) or to create an atmosphere. They also are a recognizable element, closely linked to the thematic material they accompany, and used as part of the multilayer texture. (See Liebermann’s Nocturne no. 4.)

From its origins, the nocturne was based on a lyrical, singable melody and an unobtrusive simple accompaniment. Chopin varied the accompaniments and departed from the simple arpeggio, the Alberti-type figurations or the “oompah” found in Field's Nocturnes. Chopin's accompaniments exploit a wider range of the piano, generating suaver and more sensuous atmospheres. Fauré elaborated on these and made the accompanimental part almost impossible to separate from the melody. Often the hands share the accompanying lines while the melody emerges subtly from that fabric. This is again closer in spirit to the path taken by Liebermann. Numerous examples of hands sharing the material — accompaniment and melody — were encountered in his Nocturnes. (See Liebermann's Nocturnes no. 3, no. 4 and no. 7.) As mentioned earlier, Liebermann frequently relies on ostinati for his accompaniment, or on simple arpeggio (Nocturnes no. 3, no. 5, no. 8, and no. 11), and melodico-rhythmic figure (Nocturne no. 4). Occasionally, long passages based on pedal points are seen; those are often transitional in nature. (See Liebermann's Nocturnes no. 1, no. 6 and no. 9.) The use of pedal point was suggested by Wallach as representing a possible characteristic stylistic feature of the genre, encountered in opening and closing sections of Nocturnes by Field and Chopin, but neglected, or not used systematically by other composers. ${ }^{181}$ It is interesting to see Liebermann reusing that device occasionally, but not systematically, and certainly not limiting himself to the opening or closing sections of his musical works. Perhaps, for Liebermann, the ostinato represents a fuller and more promising device than the pedal point, yet similar in nature and function.

181 Wallach, 125-126. 
Liebermann searches for ingenuity in the presentation of the accompanying material. The accompaniment always remains very pianistic and quite playable even in very thick multilayered sections. (See Liebermann's Nocturnes no. 3, no. 4, no. 7 and no. 8.)

The harmonic approach has always been very important with the nocturne, although there was no one distinctive harmonic palette associated with the genre. Each composer brought his own harmonic personality to the nocturne, and so has Liebermann. Moreover, from a harmonic viewpoint, his musical personality expresses itself through the genre in a very articulate and clear manner. Third-related harmonies which are connected through common tones are abundant in those Nocturnes. A favorite device used by Liebermann is a chord—or an accompanimentwhich includes its major and minor mediants (split-third chord). This typical chord is particularly abundant in the early Nocturnes. (See Liebermann's Nocturnes no. 2, no. 3, and no. 4.) Adjacent harmonies, often conflicting, displaying relationships of tritone or a semitone, can be blurred in the same pedal to create a special effect. (See Liebermann's Nocturne no. 2.) In the early Nocturnes, Liebermann seems to take a more conservative approach in regard to single harmonic entities, the chords being mostly purely major or minor, or including both mediants. With Nocturne no. 6, Liebermann goes into more venturesome territories probably on account of the more dissonant nature of the material; clusters encompassing seconds, sevenths and ninths are to be found. Liebermann experiments further with extended harmonies in Nocturne no. 9, and bitonality is suggested in Nocturne no. 6 and no. 10, while it is expressed frankly in Nocturne no. 11. There were also a few instances of chords, built upon fourths, used generously and taking an important harmonic, melodic (suspension resolving down) and structural role within the piece. (See Nocturnes no. 4 and no. 10.)

In regard to form, although most Nocturnes of Field and Chopin fit nicely into an ABA' 
formal structure, they were not restricted solely to that specific scheme. We also saw that Fauré rendered the form quite complex, utilizing recurrences of patterns, citations from previous material, changes of key signatures and tempi, and enlarged codas. Among Liebermann's Nocturnes, one can find representatives of the simple ABA' form: Nocturnes no. 1, no. 2, no. 7 and no. 8, while others display forms more complex just like Fauré's Nocturnes did. Additionally, form is problematized by a number of features: through canon and imitation (Nocturnes no. 3, no. 4, no. 5 and no. 10), through long episodes using pedal point (Nocturne no. 6 , and no. 8), through emphasis on other considerations, especially virtuosity (Nocturnes no. 9 and no. 11), and through motivic connections that undermine strong sectional divisions (Nocturnes no. 5, no. 6, no. 8). Among the other forms encountered one should mention: ABCDA'B' (Nocturne no. 3); ABA'B'A'B" (Nocturne no. 4); AA' [ABA'-A"B'A"'] (Nocturne no. 5), ABCA' (Nocturne no. 6), AA'BA"A", (Nocturne no. 9), ABC (Nocturne no. 10), AA'B'A"CA"” [Rondo-like] (Nocturne no. 11).

Although Liebermann most often prefers the dramatic conception of the nocturne (especially of the middle section) pioneered by Chopin, striking exceptions to this generality are Nocturnes no. 1, no. 7 and no. 10, which all seem to unfold in a homogeneous mood and are more restricted in their dynamic range - closer to the Field's model. To convey drama, Liebermann uses either extreme dynamics within a single piece (See Nocturnes no. 3 and no. 4), or an extremely long crescendo which leads to a climactic point (See Nocturnes no. 3, no. 8, no. 9 and no. 11).

As with his predecessors, Liebermann relies generously on the damper pedal to create the desired "nightly" atmosphere. In the early Nocturnes, the pedal is marked precisely, and specific effects like the blurring of different harmonies is explicitly required. (See Liebermann's 
Nocturnes no. 2, no. 3 and no. 4.) With later Nocturnes, Liebermann does not give pedal indications as frequently or precisely. Is he assuming that by now pianists are well-acquainted with his language and therefore there is no need to be as precise any longer? Or is he simply not interested in sonic experimentations with the pedal? The latter hypothesis shall be rejected for, in the last two Nocturnes, Liebermann specifies the utilization of the una corda, thus showing that the pedal and the atmospheric qualities it provides are still of interest to him. We must therefore conclude that a generous use of the pedal is expected while playing a Nocturne by Liebermann, for it is intrinsic to the composer's sonorous conception of lyricism especially associated to the genre of the nocturne.

Close study of Liebermann's Nocturnes proves that there is a definite continuation of the tradition of nocturne-writing. The conception of the nocturne with a clear singable melody presented with a "simple" accompaniment, and (closely or not) suggesting the atmosphere of the night still applies. Obviously the language has changed; Liebermann cannot conceal that he is a composer writing in the twenty-first century. While remaining faithful to his own personal style - that is to say, elements of the past are mixed with elements of the present — he has kept the spirit of the nocturne alive. He has further experimented with the aspects of ornamentation, multi-layering and form. Moreover, he brought new features to the genre, and exploited them in a very convincing manner, namely the canon and virtuosity (either used as an end in itself or for coloristic effects).

The history of the evolution of the nocturne as a genre has been established though Field, Chopin and Fauré. Although there have been numerous composers who wrote nocturnes since Fauré's opus 119 in 1921, no one did so with an interest as marked as Liebermann's. Moreover, as demonstrated on countless occasions in this research paper, Liebermann shares with Fauré 
many stylistic features, including: harmonic procedures, modal borrowings, procedures of expansion of the material, codas quoting previously heard material, symbiosis of melody and accompaniment in their pianistic presentation and presence of imitation. All of these elements combined with a keen understanding of the genre and of the writing for the instrument make Liebermann the true and sole successor to this great dynasty of nocturne-composers thus far.

Generalizations are always tricky and often fall short of covering all the aspects and idiosyncrasies of a specific work of art. That being said, considering the previously mentioned general characteristics of the respective models of the nocturne by Field, Chopin and Fauré, it becomes very revealing to draw some connections between these aforementioned models and each Nocturne by Liebermann. If one considers the homogeneity of the material and character, and the "simple" formal aspect, Liebermann's Nocturnes no. 1 and no. 10 appear to be following the spirit of the Field model; in regard to ornamentation of the melody and contrasting middle section, Nocturne no. 2 seems to emulate the Chopin model; in light of the preponderance of imitation (canon, fugato, etc.), the significant structural importance conferred to the coda which recapitulates the important material, the symbiosis between the lines, or the leaner texture, Nocturnes no. 3 , no. 4 , no. 5 , no. 7 and no. 8 belong to the Fauré model; finally, on account of their striking new features (motivic development, virtuosity, and tremendous speed)—which give the respective Nocturnes a recognizable and a undeniable personal signature-Nocturnes no. 6, no. 9 and no. 11 would belong to the Liebermann's model of the nocturne, thus completing the established nocturne lineage: Field-Chopin-Fauré-Liebermann. Although significantly important, the extreme dynamic range and the very personal use of the pedal seen on numerous instances in Liebermann's Nocturnes cannot be considered an attempt to bring the nocturne to uncharted territories: since these features give a personal flavor to much of Liebermann's writing for the 
piano, they cannot be called a characteristic of his Nocturnes in particular. Furthermore, these specific features are scattered throughout the entire corpus of Liebermann's Nocturnes and their use is not solely restricted to Nocturnes nos. 6, 9 and 11 .

Liebermann himself is a skilled pianist. He follows in the tradition of pianist-composers who write idiomatically for the instrument and sympathetically for the listener; not only that, but his Nocturnes are a gift to audiences and to performers. They are a pleasure to listen to and pianists greatly enjoy playing them. Those beautiful musical works undoubtedly deserve their place side-by-side with the gems of Field, Chopin, and Fauré, on recordings, in recital, and even in salons. 


\section{BIBLIOGRAPHY}

\section{DISSERTATIONS, ETC.:}

Chang, Hsiao-Ling. Lowell Liebermann's Concerto No. 1 for Piano and Orchestra, op. 12: A Historical and Analytical Study. DMA dissertation, University of North Texas, 2010.

Clark, Adam. Modern Marvels: A Pedagogical Guide to Lowell Liebermann's Album for the Young, op. 43. DMA graduate thesis, University of Cincinnati, 2008.

Crouch, Richard Henry. The Nocturnes and Barcarolles of Gabriel Fauré. PhD dissertation, The Catholic University of America, Washington, DC, 1980.

Dennis, Jeannine Marie. The Life and Music of Lowell Liebermann with an Emphasis on His Music for the Flute and the Piccolo. DMA thesis, University of Cincinnati, 1999.

Garner, Lisa M. Lowell Liebermann: A Stylistic Analysis and Discussion of the Sonata For Flute and Piano, op. 23, Sonata for Flute and Guitar, op. 25, and Soliloquy for Flute Solo, op. 44. DMA thesis, Rice University, 1997.

Kenaston, Karen S. An Approach to the Critical Evaluation of Settings of the Poetry of Walt Whitman: Lowell Liebermann's Symphony No. 2. DMA dissertation, University of North Texas, 2003.

Kikuchi, Mayumi. The Piano Works of Lowell Liebermann: Compositional Aspects in Selected Works. DMA research paper, University of Illinois at Urbana-Champaign, 1999.

Lim, Chan Kiat. Twentieth-Century Piano Nocturnes by American Composers: Echoes of Romanticism. DMA thesis, University of Cincinnati, 2004.

MacArthur, Lisa R. Lowell Liebermann: His Compositional Style as Derived from Three Flute Works and Applied to Other Selected Instrumental Works. PhD dissertation, University of Kentucky, 1999.

Nichols, Dean Alan. A Survey of the Piano Works of Lowell Liebermann. DMA research project, Lexington, University of Kentucky, 2000.

Uchino, Tomoko. An Analysis of Three Impromptus, op. 68 by Lowell Liebermann. DMA document, Arizona University, 2007.

Valicenti, Joseph Anthony. The Thirteen Nocturnes of Gabriel Fauré. DMA essay, University of Miami, 1980. 
Wallach, Deborah Lynn. The Development of the Nocturne for Solo Piano from 1800 to 1850. MM thesis research, University of Illinois at Urbana-Champaign, 1995.

Wicaksono, Aryo. Liebermann's Gargoyles, op. 29 for Solo Piano. BM thesis, University of Arizona, 2005.

Winegardner, Brian James. A Performer's Guide to Concertos for Trumpet and Orchestra by Lowell Liebermann and John Williams. DMA essay, University of Miami, 2011.

Yu, Wei-Hui. A Stylistic Analysis of Piano Concerto No. 2, op. 36 by Lowell Liebermann. DMA dissertation, University of Northern Colorado, 2003.

\section{BOOKS (general):}

Antokoletz, Elliott. Twentieth-Century Music. Upper Saddle River: Prentice-Hall, 1998.

Brown, Maurice J. E. and Kenneth L. Hamilton. "Nocturne.” In The New Grove Dictionary of Music and Musicians, ed. Stanley Sadie, $2^{\text {nd }}$ ed., vol. 18:11-12. London: Macmillan, 2001.

Crawford, Richard. America’s Musical Life. New York: Norton, 2000.

Crocker, Richard. A History of Musical Style. New York: Dover, 1986.

Dubal, David. The Art of the Piano: Its Performers, Literature and Recordings-Revised and Expanded Edition. Amadeus, $3^{\text {rd }}$ ed., 2005.

Gann, Kyle. American Music in the Twentieth Century. New York: Schirmer, 1997.

Gordon, Stewart. A History of Keyboard Literature. New York: Schirmer, 1996.

Griffiths, Paul. Modern Music and After. New York: Oxford University Press, 1995.

Hinson, Maurice. Guide to the Pianist's Repertoire, $3^{\text {rd }}$ ed. Bloomington: Indiana University Press, 2000. [2nd edition, Bloomington: Indiana University Press, 1987.]

Kennedy, Michael ed. The Concise Oxford Dictionary of Music, $4^{\text {th }}$ ed. Oxford and New York: Oxford University Press, 1996.

Kostka, Stefan. Materials and Techniques of Twentieth-Century Music, $2^{\text {nd }}$ ed. Upper Saddle River: Prentice-Hall, 1999.

Kirby, F. E. Music for Piano: A Short History, Portland, OR: Amadeus, 1995. 
LaRue, Jan. Guidelines for Style Analysis. $2^{\text {nd }}$ ed. Warren, MI: Harmonie Park, 1992.

Mach, Elyse. Great Pianists Speak for Themselves. Vol. 2. New York: Dodd, Mead and Company, 1988.

Marks, Fred. Who's Who in America 2002, 56th ed. Berkeley Heights, NJ: Marquis Who's Who Publishing, 2001.

Morgan, Robert. 20th-Century Music. New York: Norton, 1991.

Nectoux, Jean-Michel. Gabriel Fauré: Les Voix du Clair-obscur. Paris: Harmoniques, Flammarion, 1990.

Randel, Don Michael ed. The New Harvard Dictionary of Music. Cambridge, MA: Harvard University Press, 1986.

Slonimsky, Nicolas. Baker's Biographical of 20th Century Classical Musicians, edited by Laura Kuhn. New York, NY: Schirmer, 1997.

Strickland, Edward. American Composers. Bloomington, IN: Indiana University Press, 1991.

Tawa, Nicholas E. A Most Wondrous Babble: American Art Composers, their Music, and the American Scene, 1950-1985. New York: Greenwood, 1987.

—. American Composers and their Public: A Critical Look. Metuchen, NJ: Scarecrow, 1995.

Todd, R. Larry, ed. Nineteenth-Century Piano Music. New York: Schirmer, 1990.

Wolff, Konrad. Master of the Keyboard. Bloomington, IN: Indiana University Press, 1990.

\section{ARTICLES (liner notes, magazines, newspapers):}

Agay, Denis. “Commissioned by Clavier.” Clavier 33 (December 1994), 26-27.

Amacher, Brett. "Symphony Tackles Though Works with Flair.” The Repository, Canton, OH, May 19, 1997.

Anderson, Claudia. Liner notes for American Flute. Compact Disc CRC 2203. Centaur. 1994.

Anthony, Michael. “Galway's Flute Leads New Concerto with Harp.” Minneapolis Star Tribune, November 3, 1995, 12E. 
Ardoin, John. "Dederich-Pejovich and Flutist Galway are DSO Guests.” Dallas Morning News, October 11, 1996, 39A.

—. "DSO Rises to a New Level: Local Debut of Liebermann, Corigliano Pieces Thrilling." Dallas Morning News, June 27, 1998, 33A.

Barcellona, John. “A Performance Guide to Liebermann’s Flute Sonata.” Flute Talk, April 1997, 12-15.

Basrak, Cathy. Notes for American Viola Works. Cedille Records CDR 90000 053, 2000. Compact Disc.

Bicknell, Nixon. “Eroica Trio Elicits An Appreciated Nod.” The Montclair Times, April 22, 1993.

Brixey, Elizabeth. “Galway Inspires Orchestra, Crowd.” Wisconsin State Journal, October 1, 1993, 3E.

Buell, Richard. “Viable Alternatives to Silence.” The Boston Globe, September 24, 1991.

Byrwasser, Peter. Review of Virtuoso American Flute Music. Katherine Kemler, flute; Jan Grimes and Kathleen Rountree, piano. Centaur CRC 2146 (DDD); 70:48.

Cantrell, Scott. “So-So Symphony: Predictability Stifles Joy in New Liebermann Work.” Dallas Morning News, February 11, 2000, 43A.

—_. "Nothing Wilde in 'Dorian Gray'.” Dallas Morning News, November 17, 2000, 45A.

—. "DSO Puts on Energetic Show at Carnegie Hall." Dallas Morning News, February 10, 2001, 39A.

Carrington, Mark. “Viola Virtuosity.” The Washington Post, March 17, 1992, 7B.

Chism, Olin. "DSO Concert Goes Down Easily: Audience is Treated to Likable 'Sampler'.” Dallas Morning News, June 26, 1999, 39A.

—_. “Composers Sound Off.” Dallas Morning News, March 4, 2000, 35A.

—. “Pegasus Takes Flight.” Dallas Morning News, January 11, 2001, 33A.

—. "DSO Plays to Strength: Liebermann, Sibelius and Brahms a Bold Program.” Dallas Morning News, April 27, 2001, 41A.

—. "Liebermann Didn’t Want to Put in Any Wrong Notes.” Dallas Morning News, June 15, 2000, 10C. 
_ . "Old-fashioned Modernist: New DSO Composer Liebermann Writes Unbashedly Accessible Music.” Dallas Morning News, February 21, 1999, 1C.

Clements, Andrew. “Paula Robison: Wigmore Hall.” Financial Times, January 30, 1990, 21 (section I: The Arts).

Crebo, Anna. “Classical Composer Wins Early Success.” Sunday Cape Cod Times, August 5, 1990.

Davidson, Justin. “Dorian Mode.” Opera News 60, No. 16, May 1996: 57, 69.

Fanning, David. "Look North and Listen: David Fanning on New Music in Manchester and American Premiere in Liverpool.” The Independent, February 24, 1994. 24 (Arts Page).

__. "Piano Wizardry.” Gramophone, September 1997: 15-16.

Fleming, Michael. "Flutist Galway Continues to Delight Audiences.” Saint Paul Pioneer Press, November 2, 1995. 11D.

Freed, Richard. "Classical Music_Liebermann: Piano Concertos nos 1 and 2: Album for the Young (Stephen Hough).” Stereo Review 62 (1997): 142.

_ . "Liebermann, Lowell (Seth)." In The New Grove Dictionary of Music and Musicians, Stanley Sadie ed., 2nd edition, vol. 14: 659-660. London: Macmillan, 2001.

—_. "Music for an Audience.” Stereo Review 62, November 1997): 142.

Gay, Wayne Lee. "U.S. Composers to Share Spotlight at Cliburn Event.” Pittsburgh PostGazette, April 6, 2001.

Ginell, Richard S. "Music Reviews: Flutist Robison at Bing Theater.” Los Angeles Times, March 30, 1991, 4F.

Gippo, Jan. “Liebermann’s Piccolo Concerto.” Flute Talk, February 1997, 31-32.

__. "Performing Liebermann’s Piccolo Concerto.” Flute Talk, March 1997, 31-32.

_. "Liebermann's Piccolo Concerto: An Analysis of the Third movement." Flute Talk, April, 1997, 30-32.

Glackin, William. “Wind Quintet Lets 4 Composers Sing Out Their Own Voices.” Sacramento Bee, November 11, 1990.

Gowen, Bradford. "New Music for Performance.” Piano Quarterly 40, no.158, summer 1992: 28-29. 
Greenberg, Mike. “New Stars Shines for Music Club.” San Antonio Express-News, October 18, 1990.

—. “Dowling Blooms Late, Lovely.” San Antonio Express-News, October 21, 1991, $16 \mathrm{~A}$.

Gudger, William D. “Pianist, Violinist Perform Premieres Impressively.” Spoleto, News and Courier, June 4, 1987, 5A.

Harbach, Barbara. "Margaret Mills Plays Piano Works by Lowell Liebermann and Ruth Schöntal.” Women of Note Quarterly 4, 1996: 12-13.

Holland, Bernard. “Steinway Foundation.” New York Times, June 16, 1992, 15C.

Hough, Stephen. Notes for Lowell Liebermann Piano Concertos, Stephen Hough/BBC Scottish Symphony Orchestra/Lowell Liebermann, conductor. Hyperion Records Ltd. CDA 66966, 1997. Compact Disc.

Jack, Adrian, “Quietly Does It: Stephen Hough-Wigmore Hall.” The Independent, April 27, 1990, 14 (Arts page).

Jolly, James. “Opinion: Lowell Liebermann—From Where I Sit.” Gramophone, February 2001, 23.

Jones, Robert. “Overview”. Spoleto, News and Courier, June 5, 1987.

_- "Chamber Concerts Offer Best Music-Making." Spoleto, News and Courier, May 30, 1989, 1 A.

—. "Gifted Composer Shines in Music of Spoleto.” Spoleto, News and Courier, May 23, 1989, 5A.

Kandell, Leslie. “Robert White, Tenor.” American Record Guide, May/June 1993, 42.

Kasow, J. “Monaco.” Opera News 61, November 1996, 52-53.

—. "Monaco: On the Wilde Side.” Opera 47, October 1996, 12-23.

Kennicott, Philip. "Review of Concertos for Piano and Orchestra, by Lowell Liebermann.” Gramophone vol. 75, no. 892, September 1997: 64.

—_. "Eclectic Ingredients for a Triple Whammy.” New York Newsday, January 14, 1991. 55 (II).

Kemler, Katherine. Liner notes for Virtuoso American Flute Works, Compact Disc CRC 2146, Centaur. 1992. 
Keuffel Jr., Ken. “Galway Plays With the N.J. Symphony.” Philadelphia Inquirer, April 5, 1993, 3D.

Kevles, Barbara. “Lowell Liebermann: A New 'Tonalist' Thrives on Old Harmonies.” American Record Guide, March/April 2003, 26-27, 33.

- Review of Lowell Liebermann: Piano Music, Vol. 1 KOCH International Classics 7548 performed by David Korevaar. Fanfare 27, Jan-Feb 2004: 143-5.

Korevaar, David. “Liebermann, Lowell. Piano Music, Vol. I.” Performed and Liner notes written by David Korevaar. KOCH International Classics 3-7548-2 HI, 2003. Compact Disc.

_. "Lowell Liebermann, Piano Music, Vol. II.” Performed and Liner notes written by David Korevaar, KOCH International Classics 3-7552-2 HI, 2004. Compact Disc.

Larner, Gerald. “Northern Lights Shines in Darkness.” The Times, February 18, 1994, (Features).

Lehman, Mark. "Liebermann: Piano Concertos nos. 1 and 2, Album for the Young.” American Record Guide 60, No. 5, September/October 1997: 161.

Leonard, Stephen F. “SPAC Commissions Concertos.” Post-Star, August 19, 2000.

Liebermann, Lowell. Liner notes for Moore/ Weber / Liebermann / Van Appledorn / Barber / Johnson. CD 169, Opus One, 1994. Compact Disc.

. “Concerto for Flute, Harp and Orchestra Op.48.” Notes to Publisher, September 25, 1996.

—_ “Concerto for Piccolo and Orchetra Op. 50.” Notes to Publisher, July 10, 1997.

. World Premiere Recording Symphony No. 2; Concerto for Flute and Orchestra, Eugenia Zuckerman/Dallas Symphony Orchestra and Chorus/Andrew Litton. Delos International 3256, 2000. Compact disc.

Lim, Karen. "Weiss Performance of Concerto a Bid to Raise its Status.” Denver Post, July 4, 2002, 6F.

Marcusson, Goran. Liner notes for American Sonatas. Compact Disc IMCD 034, Intim Musik, 1994.

Matheu, Colleen. “Performance Analysis: Lowell Liebermann’s Piccolo Concerto.” Flute Talk, January 2007, 13-17.

McLellan, Joseph. “NSO’s Piano Premieres.” Washington Post, June 12, 1992, 2C. 
McPhail, Claire. “Liebermann’s New Flute Sonata a Tour De Force for Musicians.” News and Courier, May 23, 1988, 5A.

Midgette, Anne. "Classical Music Review: Inwardness and Showmanship in the Quirky and Familiar.” New York Times, July 21, 2003, Late Edition, 4E.

Modi, Sorab. "National Symphony/ Rostropovich-Schifrin, Schedrin, Liebermann:

Piano Concertos (Premieres).” American Record Guide 55, September/October 1992: 5455.

Morrison, Bryce, “After the Best.” Gramophone 75, September 1997: 25-26.

“Natural Born Composer: Lowell Liebermann.” Accent 47, fall 2002: 9, 12.

Naughtin, Matthew. Review of "Concerto No. 2 for Piano and Orchestra, Op.36 (1992) by Lowell Liebermann.” In Summer at Chautauqua 2002 Program Guide, 46-47.

Oestreich, James R. “Old Forms in New Composition.” New York Times, January 17, 1991, 13 C.

—_. "Wilde with Shades of Mahler and Strauss.” New York Times, February 8, 1999, 5E.

Pompa-Baldi, Antonio. “Three Impromptus by Liebermann: Music Performed in the 2001 Cliburn Competition.” Clavier, September 2002, 26-29.

Pixley, Zaide. “Liebermann’s Concerto a Work Meant to Last.” Kalamazoo Gazette, January 15, 1994.

Reel, James. “A Conversation with Lowell Liebermann.” Fanfare, January-February 2004, 31-32, 34, 36, 38.

Rice, Bill. “Liebermann Takes Music Personally.” Dallas Morning News, February 21, 1999, 6D.

—. “Chamber Pieces Reveal Range of Liebermann’s Work.” Dallas Morning News, February 21, 1999. 6D.

Riding, Alan. "Making New Opera Unstylishly Melodic (Lowell Liebermann's Picture of Dorian Gray Performed by the Opéra de Monte Carlo).” New York Times, May 22, 1996, 13C.

Rivers, Kate. “Three by Three: Making Room for New Piano Concertos.” Piano Quarterly 40, fall 1992: 44-47.

Robison, Paula. Liner notes for Carmen Fantasy. Compact Disc OVC 4058. Vanguard Classics. 1982.

Robison, Paula and Eliot Fisk. Liner notes for Mountain Songs. Compact Disc 7038-2-C. Music Masters. 1986. 
Rockwell, John.”Sextet Mixes the Unknown and Known.” New York Times, March 24, 1989, 29C.

Rodgers, Jonathan. “Flutist’s Unmistakable Enthusiasm for Music Becomes Infectious.” Florida Times, May 29, 1988, IE, 6E.

Scherer, Barrymore Laurence. “A Composer Balances Tradition, Invention.” Wall Street Journal, June 15, 2002, 2.

Schwarz, K. Robert. “Bringing Tonality, and Fans, to Contemporary Music.” New York Times, January 31, 1999, Sec. II, p. 28-29.

Shen, Ted. “Vermeer Quartet Helps Evoke Soul of Whitman.” Chicago Tribune, February 22, $1994,18 \mathrm{~N}$.

Simmons, Walter. Review of Lowell Liebermann: Piano Music, Vol. 1 KOCH International Classics 7548 performed by David Korevaar., Fanfare 27 (2004): 145.

Somers, Paul. “Chamber Group Shines in Liebermann Concerto.” The Star-Ledger, October 13, 1992.

Spiller, William T. "Review of Lowell Liebermann: Keyboard Music”, Notes 60 June 2004: 1034-1039.

Spurrell, Maria. “Music for the Next Century.” The Review, July 1992.

Staff, Charles. “He Writes Sort of Music He’d Like to Hear.” Indianapolis Star: Arts and Entertainment, February 14, 1999, 1-2.

Starr, William W. “N.C. Composer’s Work May Become Staple of Chamber Music Repertory.” The State, May 30, 1989.

—. "Spoleto Chamber Musicians Offer Beguiling Sonata.” The State, May 23, 1988, 2 (Living Section).

“Steinway Concertos Premier at Kennedy Center.” The Music Trades 140, August 1992: 150.

Teachout, Terry. “Back to the Future,” Time, March 6, 2000, 75.

_ . "Short Takes: James Galway Plays Lowell Liebermann.” Time Magazine, November 30, 1998, The Arts/Short Takes, 1.

—_. “The New Tonalists,” Commentary 104, no.6, December 1997: 53-57.

Tommasini, Anthony. “A Trumpet Has its Moment Onstage.” New York Times, May 30, 2000, 5E (L). 
Weiss, Suzanne. “Let’s Hear it for a New Symphony.” Pioneer Press, November 3, 1988.

Wigler, Stephen. “Liebermann Crafts Powerful Concerto.” Baltimore Sun, June 13, 1992, 2D.

Windeler, Diane. “Artists Combine Solo Talents for Inspired Performance. “ San Antonio Light, October 17, 1990.

__ .Pianists with Contrasting Styles Top Finals.” San Antonio Light, October 22, 1991.

\section{CORRESPONDENCE:}

Dowling, Richard. E-mail to author, August 13, 2011.

Giles, James. E-mail to author, August 28, 2011.

Gurwitz, (Mrs.) Arthur. E-mail to author, July 20, 2011.

Hough, Stephen. E-mail to author, September 16, 2011.

Krieger, Norman. E-mail to author, July 6, 2011.

Korevaar, David. E-mail to author, July 6, 2011.

Landry, Joan. E-mail to author, August 19, 2011.

Liebermann, Lowell. E-mail to author, July 02, 2010.

Russo, Sandro. E-mail to author, Sept. 22, 2010.

Syme, David. E-mail to author, July 7, 2011.

Vlaeva, Nadejda. E-mail to author, July 13, 2011.

Wicaksono, Aryo. E-mail to author, September 29, 2009.

\section{WEBSITES:}

Lowell Liebermann: http://www.lowellliebermann.com. Accessed on July 14, 2012. Theodore Presser Company: http://presser.com/liebermann.html. Accessed on July 14, 2012. 


\section{MUSICAL SCORES:}

Chopin, Fryderyck:

Nocturnes and Polonaises, (Paderewski Edition), New York: Dover, 1983.

Fauré, Gabriel:

Nocturnes and Barcarolles, (Durand and Hamelle Editions), New York: Dover, 1994.

Oeuvres completes pour piano, Edited by Yoshio Miyama and Kazuoki Fujii, Tokyo: Shunjùsha Edition, 1986.

Field, John:

Eighteen Nocturnes for the Piano, Revised and essay by Fr. Liszt, biographical sketch by Th. Baker, New York: Schirmer, 1908, renewed 1967.

Liebermann, Lowell:

SOLO PIANO

Piano Sonata No. 1, op. 1 (1977)

Published by Theodore Presser Co. 410-4130

Piano Sonata No. 2, Sonata-Notturna, op. 10 (1983)

Published by Theodore Presser Co. 410-41293

Four Apparitions, op. 17 (1985)

Published by Theodore Presser Co. 410-41289

Variations on a Theme by Anton Bruckner, op. 19 (1986)

Published by Theodore Presser Co. 410-41275

Nocturne No. 1, op. 20 (1986)

Published by Theodore Presser Co. 110-40679

Gargoyles. op. 29 (1989)

Published by Theodore Presser Co. 410-41289

Nocturne No. 2, op. 31 (1990)

Published by Theodore Presser Co. 110-40715

Nocturne No. 3, op. 35 (1991)

Published by Theodore Presser Co. 110-40700

Evening Prayer and Dream from 'Hansel und Gretel', op. 37 (1992)

Published by Theodore Presser Co. 110-40702 
Nocturne No. 4, op. 38 (1992)

Published by Theodore Presser Co. 110-40703

Album for the Young, op. 43 (1993)

Published by Theodore Presser Co. 410-41300

Nocturne No. 5, op. 55 (1996)

Published by Theodore Presser Co. 110-10724

Nocturne No. 6, op. 62 (1998)

Published by Theodore Presser Co. 110-40736

Nocturne No. 7, op. 65 (1999)

Published by Theodore Presser Co. 110-40738

Three Impromptus, op. 68 (2000)

Published by Theodore Presser Co. 110-40740

Piano Sonata No. 3, op. 82 (2002)

Published by Theodore Presser Co. 410-41337

Nocturne No. 8, op. 85 (2003)

Published by Theodore Presser Co. 110-40761

Variations on America by Charles Ives, transcription for piano solo, op. 96 (2006)

Published by Theodore Presser Co.110-41768

Nocturne No. 9, op. 97 (2006)

Published by Theodore Presser Co. 110-41774

Nocturne No. 10, op. 99 (2007)

Published by Theodore Presser Co. 110-41775

Nocturne No. 11, op. 112 (2010)

Published by Theodore Presser Co. 110-41787

TWO PIANOS

Variations on a Theme by Mozart, op. 42 (1993)

Published by Theodore Presser Co. 410-41322

\section{PIANO AND ORCHESTRA}

Concerto No. 1 for Piano and Orchestra, op. 12 (1983)

Published by Theodore Presser Co. Piano Reduction 410-4128 
Concerto for Piano and Orchestra No. 2, op. 36 (1992)

Published by Theodore Presser Co. Piano Reduction 410-41294

Rhapsody on a Theme of Paganini, op. 72 (2000)

Published by Theodore Presser Co. Piano Reduction 410-41335 


\section{APPENDIX A: LIEBERMANN'S PIANO WORKS}

\section{NOCTURNES:}

Nocturne no. 1, op. 20 (1986)

ca.6'09"

Commissioned by the La Gesse Foundation;

First performance: November 21, 1986, Terreace Theatre, Kennedy Center, Washington, DC, David Syme;

Dedicated to David Syme;

Published by Theodore Presser Co. 110-40679

Recordings: A B D E

Nocturne no. 2, op. 31 (1990)

ca.6'39"

Commissioned by the Alumni Young Artists, Inc.;

First performance: March 28, 1990, Alice Tully Hall,

New York, NY, Hung-Kuan Chen;

Dedicated: "In memory of Steven De Groote;"

Published by Theodore Presser Co. 110-40715

Recordings: D

Nocturne no. 3, op. 35 (1991)

ca.6'14"

Commissioned for the San Antonio International Keyboard Competition

by Mr. And Mrs. Arthur Gurwitz in loving memory of their son, Andrew Russel Gurwitz;

First performance: October 19, 1991, Ruth Taylor Concert Hall, Trinity University,

San Antonio, TX, Richard Dowling;

Published by Theodore Presser Co. 110-40700

Recordings: D

Nocturne no. 4, op. 38 (1992)

ca.5'33"

Commissioned by the North West Arts Board, Great Britain;

First performance: November 22, 1992, Queen Elizabeth Hall,

London, UK, Andrew Wilde;

Dedicated to Andrew Wilde;

Published by Theodore Presser Co. 110-40703

Recordings: A D

Nocturne no. 5, op. 55 (1996)

ca.6'33"

Commissioned by Adele Marcus Foundation;

First performance: February 22, 1997, Carnegie Hall,

New York, NY, Norman Krieger;

Dedicated: "In memory of Adele Marcus;"

Published by Theodore Presser Co. 110-40715

Recordings: C D 
Nocturne no. 6, op. 62 (1998)

ca.8'26"

Commissioned by Richard Goula in memory of Lynn Hantel;

First performance: November 15, 1998, Alice Tully Hall,

New York, NY, James Giles;

Dedicated to James Giles;

Published by Theodore Presser Co. 110-40736

Recordings: D

Nocturne no. 7, op. 65 (1999)

ca.7'01"

Commissioned by the Welsh Arts Council;

First performance: September 29, 1999, North Wales Festival,

St. Asaph, Wales, Iwan Llewelyn-Jones

Dedicated to Iwan Llewelyn-Jones

Published by Theodore Presser Co. 110-40738

Recordings: D

Nocturne no. 8, op. 85 (2003)

ca.8'09"

Commissioned in memory of John Rochel Landry by his parents;

First performance: July 18, 2003, Mannes Festival of Piano Music,

NYC, NY, Marc-André Hamelin;

Dedicated to Marc-André Hamelin;

Published by Theodore Presser Co. 110-40761

Recordings: F

Nocturne no. 9, op. 97 (2006)

ca.7'00"

Commissioned by Louis Meisel;

First performance: August 9, 2006, Husum Music Festival,

Husum, Germany, Nadejda Vlaeva;

Dedicated to Nadejda Vlaeva;

Published by Theodore Presser Co. 110-41774

Nocturne no. 10, op. 99 (2007)

ca.8'30"

In memory of Gian Carlo Menotti;

First performance: February 10, 2007, Memorial concert for Gian Carlo Menotti,

Salle Garnier, Monte-Carlo, Lowell Liebermann;

Published by Theodore Presser Co. 110-41775

Nocturne no. 11, op. 112 (2010)

ca.6'30"

Commissioned by Mark Wolffer in memory of Christian Wolffer;

First performance: July 16, 2010, Music Festival of the Hamptons,

Wolffer Estate Vineyard, Sagaponack, NY, William Hobbs;

Published by Theodore Presser Co. 110-41787

Approximate durations are taken from recording $\mathrm{D}$ for no. 1 to no. 7 , and from recording $\mathrm{F}$ for no. 8. Durations for nos. 9, 10 and 11 are based on the indications included in the music scores. 
At this moment, no public recordings exist for nocturnes 9, 10 and 11, although there are audioclips available on the internet of:

Nocturne no. 9 by Alice Tsui, at: http:/www.youtube.com/watch?v=sPqlS7H1OJc; ca. 8'45" Nocturne no. 10 at: http://www.youtube.com/watch?v=7MQS8TptKR4\&noredirect=1; ca. 8'07" and none of Nocturne no. 11.

\section{RECORDINGS:}

Listed alphabetically by artist's family name
A Azica ACD-71213. Lara Downes piano
B Carolyn Enger, In the Evening Air, Carolyn Enger piano
C Robert Henry, Twelve Nocturnes and a Waltz, Robert Henry piano
D Koch International Classics 3-7548-2 HI, David Korevaar piano
E Musical Heritage Society MHS512647Y, David Korevaar piano
F Sandro Russo Recital (private recording copyright 2006), Sandro Russo piano

\section{OTHER WORKS FOR SOLO PIANO}

Sonata no. 1, op. 1 (1977)

Published by Theodore Presser Co. 410-41305

Sonata no. 2, “Sonata Notturna”, op. 10 (1983)

Published by Theodore Presser Co. 410-41293

Four Apparitions op. 17 (1985)

Published by Theodore Presser Co. 410-41292

Variations on a Theme by Anton Bruckner op. 19 (1986)

Published by Theodore Presser Co. 410-41275

Gargoyles op. 29 (1989)

Published by Theodore Presser Co. 410-41289 
Evening Prayer and Dream from "Hansel und Gretel” op. 37 (1992)

(Concert transcription by Lowell Liebermann)

Published by Theodore Presser Co. 110-40702

Album for the Young op. 43 (1993)

Published by Theodore Presser Co. 410-41300

Three Impromptus op. 68 (2000)

Published by Theodore Presser Co. 110-40740

Sonata no. 3, op. 82 (2002)

Published by Theodore Presser Co. 410-41337

Four Etudes on Brahms Songs op. 88 (2004)

Published by Theodore Presser Co. 110-41786

Three Songs of Robert Franz op. 91 (2005)

Published by Theodore Presser Co. 110-41788

Variations on America by Charles Ives op. 96 (2006)

(Arranged by Lowell Liebermann)

Published by Theodore Presser Co. 110-41768

Variations on a Theme of Schubert op. 100 (2007)

Published by Theodore Presser Co. 110-41789

\section{WORKS FOR PIANO (more than one performer)}

Variations on a Theme by Mozart for Two Pianos op. 42 (1993)

Published by Theodore Presser Co. 410-41335

Three Lullabies for Two Pianos op. 76 (2001)

Published by Theodore Presser Co. 110-40759

Daydream and Nightmare for two Pianos, Eight Hands op. 94 (2005)

Published by Theodore Presser Co. 410-41339 


\section{WORKS FOR PIANO AND ORCHESTRA}

Concerto no. 1, op. 12 (1983)

Published by Theodore Presser Co. 410-41286

Concerto no. 2, op. 36 (1992)

Published by Theodore Presser Co. 410-41294

Rhapsody on a Theme by Paganini op. 72 (2001)

Published by Theodore Presser Co. 410-41335

Concerto no. 3, op. 95 (2006)

Published by Theodore Presser Co. 410-41338 


\section{APPENDIX B: IMPORTANT CONTRIBUTORS}

From Chapter Two: (Number in parenthesis refers to the footnote number in the research paper)

Stephen Hough ${ }_{(14)}$ is widely regarded as one of the most important and distinctive pianists of his generation. In recognition of his achievements, he was awarded a prestigious MacArthur Fellowship in 2001 for having made unique contributions to contemporary life. Hough has appeared with most of the major European and American orchestras and plays recitals regularly in the major halls and concert series around the world. An exclusive Hyperion recording artist, his catalogue contains more than $50 \mathrm{CDs}$, many of which have garnered international prizes. As a writer, Hough has published scholarly and critically-acclaimed CD liner notes and articles. $\mathrm{He}$ is also a composer and among his works one can find numerous piano compositions, virtuoso piano transcriptions of vocal works, a cello concerto, a trio, a string sextet and two masses. A resident of London, Stephen Hough is a visiting professor at the Royal Academy of Music in London and holds the International Chair of Piano Studies at his alma mater, the Royal Northern College in Manchester.

Hough is connected to Liebermann's music for premiering the Piano Concerti 1 and 2, the Paganini Rhapsody for Piano and Orchestra, the Piano Sonata no. 2, the Three Impromptus op. 68, and the Cello Sonata no. 2.

Two of his recordings are devoted to Liebermann's music:

- Gargoyles, op. 29, Virgin Classics, VC 759304 2;

- Concertos for Piano, no. 1 and no. 2, and 6 pieces from Album for the Young, op. 43, Hyperion, CD A66966;

More information can be obtained from the artist's personal website at http://stephenhough.com/

David Korevaar ${ }_{(15)}$ is a pianist who has performed across the United States with orchestras, in chamber ensembles and in solo recitals. International performances have included appearances in Australia, Japan, Korea, Abu Dhabi and Europe. He also holds a teaching position at the University of Colorado at Boulder, where he has been Associate Professor of Piano since 2000. Korevaar began his piano studies at age six and at age thirteen he became a student of the great American virtuoso Earl Wild. He holds a Bachelor's, Master's, and Doctor of Musical Arts degrees from the Juilliard School where he studied piano with Earl Wild and Abbey Simon and composition with David Diamond. He also studied under the guidance of French pianist Paul Doguereau. Korevaar has been the recipient of many honors which include top prizes from the University of Maryland William Kapell International Piano Competition (1988), the Peabody-Mason Music Foundation (1985), the Robert Casadesus Competition (1989), and the Richard French award from the Juilliard School for his doctoral document on Ravel's 
Miroirs. In addition to his continuing association with the music of Lowell Liebermann, Korevaar has performed and recorded music by composers including Paul Schoenfield, Mike Barnett, Aaron Jay Kernis, George Rochberg, Aaron Copland, Ned Rorem, Stephen Jaffe, Scott Eyerly and Libby Larson.

He is responsible for the creation of Four Apparitions op. 17, for which he is also the dedicatee. He also holds many recordings devoted to Liebermann's music:

- Piano Sonatas Nos. 1 and 2, Nocturne No. 1, Four Apparitions, Variations on a Theme by Anton Bruckner, Musical Heritage Society MHS 512647Y;

- Gargoyles, op. 29, Variations on a Theme of Anton Bruckner, Piano Sonata No. 1, op. 1, Piano Sonata No. 2, op. 10 ("Sonata Notturna"), Album for the Young, op. 43, Koch \# 37552-2 HI;

- $\quad$ Three Impromptus, op. 68, Nocturnes 1-7, Four Apparitions, op. 17, Koch \# 3-7548-2 HI;

- Quintet for Piano and Strings, op. 34, Quintet for Piano, Clarinet, and String Trio, op. 26, Six Songs on Poems by Raymond Carver, op. 80, Koch KIC CD 7743;

- Sonata for Flute and Piano, op. 23, (Alexa Still, flute), Koch \# 3-7549-2 HI;

He now lives in Boulder, CO, with his family. Mr. Korevaar is a Kawai artist. More information can be obtained from the artist's personal website at http://www.davidkorevaar.com/

Lowell Liebermann (16) participated in the premiere of many of his works, mainly songs: opp. 11, 18. 21, 22, 51, 53 and 57, a few chamber music pieces: Cello Sonata 1 and 3, and only three piano solo works: Piano Sonata no. 1, the transcription to Evening Prayer and Dream from "Hansel und Gretel" op. 37, and the Nocturne no. 10, op. 99. Among his contributions to the recording of his own works, one can find:

- $\quad$ Out of the Cradle, Endlessly Rocking, op. 41, Six Songs on Poems of Henry W. Longfellow, op. 57, Final Songs, op. 21, Three Dream Songs, op. 53, A Poet To His Beloved, op. 40, and Night Songs, op. 22, (with Robert White, tenor), Arabesque \# Z6770;

- Piano Concerto No. 1, op. 12, Piano Concerto No. 2, op. 36 (Stephen Hough, piano, BBC Scottish Symphony Orchestra, Lowell Liebermann, conductor), Hyperion CDA66966;

- Concerto for Piccolo and Orchestra, op. 50, Concerto for Flute, Harp and Orchestra op. 48, Concerto for Flute and Orchestra op. 39, (James Galway, flute and piccolo, HyunSun Na, harp, London Mozart Players, Lowell Liebermann, conductor), RCA Victor Red Seal 09026-63235-2; RCA Victor Red Seal 09026-63432-2; RCA Victor Red Seal 09026-63431-2;

A short biographical sketch can be found in Chapter One (Life) of this research paper.

More information can be obtained from the artist's personal website at: http://www.lowellliebermann.com/ 
James Galway (17) was born in Belfast, and studied in London and Paris before embarking on his orchestral career for the Royal Covent Garden Operas, the BBC, the Royal Philharmonic and the London Symphony Orchestra, before taking up the coveted position of solo flautist with the Berlin Philharmonic under Herbert von Karajan. He launched his career as a soloist in1975, and has been busy touring worldwide since, performing with the world's leading orchestras and most prestigious conductors. His repertoire includes masterworks by Bach, Vivaldi and Mozart as well as contemporary music. Regularly, new flute works are commissioned by him and for him. Recently, Galway has premiered works by composers such as Adamo, Amram, Bolcom, Corigliano, Hammond, Heath, Lieberman, Maazel, and Whelan. Sir James has also created a platform to help launch and promote young flutists through a competition: The James Galway International Flute Competition which will be held in Belfast, in June 2012, in collaboration with the Ulster Orchestra, BBC Northern Ireland, Northern Ireland Tourist Board and the Northern Ireland Arts Council.

Alongside his busy performing schedule he makes time to share his wisdom and experience, conducting annual master classes and publishing articles, flute studies and books. His website is devoted to students and educators. In his remaining free time, he gives support to charitable organizations such as SOS, FARA, Future Talent, Youth Music (UK), the Caron Keating Foundation and UNICEF. Among the many honors and awards for his musical achievements are: the Recording Academy's President's Merit Award; Classic Brits Lifetime Achievement Award; and numerous gold and platinum CDs. He has been honored twice by Her Majesty Queen Elizabeth II, with the OBE in 1979 and again in 2001 with a Knighthood for his services to music. Galway holds an impressive discography of over 65 CDs with BMG Sony Classics and Deutsche Gramophone. Galway lives with his wife and family in Switzerland and currently plays on the $20 \mathrm{~K}$ "Galway" Nagahara Flute-especially commissioned for him.

James Galway is associated with Liebermann's music in many aspects: the commission of the Concerto for Flute op. 39 and the Trio op. 83, the premieres of opp. 39, 40 and 48 (Concerto for Flute and Harp), and many recordings:

- Concerto for Piccolo and Orchestra, op. 50, Concerto for Flute, Harp and Orchestra op. 48, Concerto for Flute and Orchestra op. 39, (James Galway, flute and piccolo, HyunSun Na, harp, London Mozart Players, Lowell Liebermann, conductor), RCA Victor Red Seal 09026-63235-2; RCA Victor Red Seal 09026-63432-2; RCA Victor Red Seal 09026-63431-2;

More information can be obtained from the artist's personal website at http://www.thegalwaynetwork.com/ 
Robert White ${ }_{(18)}$ was born into a New York family that enjoys a strong tradition of song. He studied at the Juilliard School, earning a Master's Degree in voice. European studies included work with the legendary Nadia Boulanger at Fountainebleau. He went on to sing with Leonard Bernstein and the New York Philharmonic, as well as with the Monte Carlo Opera and many other orchestras. He has recorded with colleagues Yo-Yo Ma, Samuel Sanders, Placido Domingo, William Bolcom, and Graham Johnson in music ranging from Beethoven to Richard Rodgers. Mr. White has premiered works by composers John Corigliano, Gian Carlo Menotti, Sheldon Harnik, Paul Hindemith, Milton Babbitt, and Lowell Liebermann. He has appeared in England with flutist James Galway and hosted his own BBC series with orchestra. He has had the unique distinction of having sung for six U.S. Presidents and he also sang for Britain's Queen Mother and Prince Charles, Monaco's Royal Family, and Pope John Paul II. White has been a distinguished member of Juilliard's faculty in the Vocal Arts Department since 1992.

He recently received the September 2007 Award for Artistic Excellence by the Lincoln Center Chamber Music Society, and was awarded Juilliard's 2008 William Schuman Scholars Chair, which is presented annually to an artist and educator who has made significant contributions both to the intellectual and artistic life of the Juilliard community. He is a member of the Directors Council on the New York City Opera.

Tenor Robert White has collaborated with Lowell Liebermann on numerous occasions for the creation or the recording of some of the vocal works. He participated into the first performances of opp. 40,53, 57 and 78 . He also made several recordings with the composer at the piano and he is the dedicatee of op. 57. With the composer at the piano, he recorded:

- Out of the Cradle, Endlessly Rocking, op. 41, Six Songs on Poems of Henry W. Longfellow, op. 57, Final Songs, op. 21, Three Dream Songs, op. 53, A Poet To His Beloved, op. 40, and Night Songs, op. 22, Arabesque \# Z6770;

More information can be obtained at: http://www.juilliard.edu/

From Chapter Five: (Pianists who premiered a nocturne, listed in chronological order. The number in parenthesis refers to the footnote number in the research paper.)

David Syme ${ }_{(94)}$ is an American pianist based in Houston, TX, and in Ireland. A protégé of the legendary Jorge Bolet, he was schooled in the grand tradition of the great masters, and also studied with Ozan Marsh, Sascha Gorodnitzki, Ania Dorfmann, Louis Kentner and Constance Keene. Syme has appeared at Lincoln Center, Carnegie Hall, Kennedy Center, The Dorothy Chandler Pavilion, and in major venues in seventeen European countries, Canada and Mexico. He has recorded twenty-five concertos on nineteen CDs with such orchestras as the Royal Philharmonic, London Philharmonia, the Vienna Symphony and Czech National Symphony. 
Recent and forthcoming concerto engagements have featured the Tchaikovsky, Grieg, Schumann, Liszt E-Flat, Gershwin and Rachmaninoff 2nd and 3rd with orchestras throughout the U.S.A. and Europe. In recent years, he has emerged as pre-eminent and definitive interpreter of the works of Gershwin for piano and orchestra. He premiered Nocturne no. 1, op. 20 by Liebermann.

More information can be obtained from the artist's personal website: www.symepiano.com/

Hung-Kuan Chen (101) was born in Taipei but grew up in Germany. His early studies fostered strong roots in Germanic Classicism which he tempered with the sensibility of Chinese philosophy, this resulting in a dynamic and imaginative artistry. Furthermore, he is regarded as an extraordinary interpreter of Beethoven's music. He has been called enigmatic, brilliant and versatile. He is a pianist of uncompromising individuality and a remarkably inspiring pedagogue. Chen won the Gold Medal in the Arthur Rubinstein competition, and also won top prizes in the Busoni and the Geza Anda International Piano Competitions, along with prizes in the Queen Elisabeth, Montreal, Van Cliburn, and Chopin International Competitions.

Chen has appeared in the music capitals of Asia, Europe and the Americas and collaborated with many major orchestras and with highly esteemed conductors and colleagues such as Yo-Yo Ma, Cho-Liang Lin, Roman Totenberg, Denes Zsigmondy, Bion Tsang, Anthony Gigliotti, David Shifrin, and Laurence Lesser.

He is Chair of the Piano Department of the Shanghai Conservatory and is the Director of the International Piano Academy in Shanghai. Prior to this he taught at Boston University, New England Conservatory Preparatory and was a Distinguished Artist in Residence at Mount Royal Conservatory in Canada. Chen has also adjudicated international piano competitions. Hung-Kuan Chen is represented by Blackstone Artists Management Inc. He premiered Nocturne no. 2, op. 31 by Liebermann.

More information can be obtained from the website of the manager's artist: http://www.blackstoneartistsmanagement.com/hkchen/index.html

Richard Dowling (111) is an American pianist who won numerous national competitions among which are the San Antonio International Keyboard Competition and the New Orleans International Piano Competition. He was also declared National Winner of the prestigious Music Teachers National Association College Artist Competition. Dowling holds a DMA in piano performance from the University of Texas. His principal teacher was Abbey Simon. Dowling keeps a busy concertizing schedule nationwide as well as internationally. He resides in New York City and in Houston. He is a Parker Artist. As a businessman, he works for his own music publishing company: www.dowlingmusic/. He premiered Nocturne no. 3, op. 35 by Liebermann.

More information can be obtained from the artist's personal website: http://www.richarddowling.com/ 
Andrew Wilde ${ }_{(117)}$ was born in 1965. He is an English pianist. Wilde studied at Chetham's School of Music and the Royal Northern College of Music in Manchester, the city where he is still based. Wilde plays often as a recitalist, and has a particular affinity for the music of Chopin. $\mathrm{He}$ also has a wide concerto repertoire. Wilde has performed with numerous English orchestras such as the Bournemouth Symphony, Halle Orchestra, London Mozart Players, London Philharmonic, Royal Liverpool Philharmonic, and Royal Philharmonic. In the Americas he has performed with the National Symphony (Washington) and Dallas Symphony. His discography includes Haydn sonatas.

$\mathrm{He}$ is listed as a freelance performer and teacher at the University of Manchester. He premiered Nocturne no. 4, op. 38 by Liebermann.

The artist does not seem to possess a website.

Norman Krieger ${ }_{(125)}$ is a native of Los Angeles, where he studied piano with Esther Lipton. Subsequently, he became a full scholarship student of Adele Marcus at the famed Juilliard School, from which he received both Bachelor's and Master's degrees. He also studied with Alfred Brendel and Maria Curcio in London, and was awarded an Artists Diploma from the New England Conservatory, where he worked with Russell Sherman. Krieger is the founding Artistic Director of The Prince Albert Music Festival in Hawaii. Since 1997, he has been an Associate Professor at the University of Southern California.

Gold Medal Winner of the first Palm Beach Invitational Piano Competition, Krieger is also the recipient of the Paderewski Foundation Award, the Bruce Hungerford Memorial Prize, the Victor Herbert Memorial Prize, the Buffalo Philharmonic Young Artists Competition Prize and the Saint Louis Symphony Prize.

He regularly appears with the major orchestras of North America. He has also been heard as guest soloist in Asia and in Europe. He has played throughout the United States, Europe, Mexico and Asia, in recital as well as in chamber music concerts

Krieger's recordings include some nine albums. A champion of contemporary music, he features the music of John Adams, Leonard Bernstein, John Corigliano, Daniel Brewbaker, Judith St. Croix, Lukas Foss and Lowell Liebermann among his active repertoire. He premiered Nocturne no. 5 , op. 55 by Liebermann.

More information can be obtained from the artist's personal website: http://www.normankrieger.com/ 
James Giles ${ }_{(132)}$ regularly performs in important musical centers in America, Europe, and Asia, as a soloist with renowned orchestras, in chamber music settings and in recital.

With an eclectic repertoire encompassing the solo and chamber music literature, Giles is equally at home in the standard repertoire as in the music of our time. He has commissioned and premiered works by William Bolcom, Curtis Curtis-Smith, Stephen Hough, Lowell Liebermann, Ned Rorem, Augusta Read Thomas, Earl Wild, and James Wintle.

A native of North Carolina, Giles studied with Byron Janis at the Manhattan School of Music, Jerome Lowenthal at the Juilliard School, Nelita True at the Eastman School of Music, and Robert Shannon at Oberlin College. He also received early career assistance from the Clarisse B. Kampel Foundation and was awarded a Fulbright Scholarship to study in Florence with the legendary pianist Lazar Berman.

He was the recipient of a fellowship grant and the Christel Award from the American Pianists Association. He won first prizes at the New Orleans International Piano Competition, the Joanna Hodges International Piano Competition, and the Music Teachers National Association Competition. He has written for Piano and Keyboard magazine and has presented lecture-recitals at the national conventions of the Music Teachers National Association, the College Music Society, and Pi Kappa Lambda. He has served on the juries of several international piano competitions.

Giles is on the piano faculty at Northwestern University. He has also served as conference artist for the music teachers associations of Oklahoma, Arizona, and Nevada and frequently gives master classes at colleges and universities nationwide. He formerly served on the faculties of the University of North Texas and the Interlochen Arts Academy. Dr. Giles is married to pianist Sevgi Kurtoglu and they are the parents of two children, Patrick and Henry. He premiered Nocturne no. 6, op. 62 by Liebermann.

More information can be obtained from the artist's personal website: http://www.jamesgiles.net/

Iwan Llewelyn-Jones ${ }_{(135)}$ is one of Britain's most imaginative and successful pianists. He has performed to audiences worldwide. Llewelyn-Jones studied at Oxford University and the Royal College of Music where he won several awards and competitions for both academic and pianistic excellence. Further prizes followed in international piano competitions in Spain, France, Italy and Great Britain. His repertoire is wide-ranging, incorporating keyboard music from the Baroque era to the present day, with a special affinity with $19^{\text {th }}$-century and $20^{\text {th }}$-century French music. He is also actively involved in promoting new music. Composers who have written works especially for him include Alun Hoddinott, John Metcalf, John Pickard, Pwyll ap Siôn, Karl Jenkins and Lowell Liebermann. In 2005, Llewelyn-Jones was awarded the Sir Geraint Evans Award by the Welsh Music Guild in recognition of his support for and promotion of Welsh music. At present, he has made three CDs. He premiered Nocturne no. 7, op. 65 by Liebermann.

More information can be obtained from the artist's personal website: http://www.iwanpiano.com/ 
Marc-André Hamelin ${ }_{(138)}$ was born in Canada. This pianist has built his reputation on account of his unique blend of musicianship and virtuosity which brings forth interpretations remarkable for their freedom and originality. Of him, Alex Ross of The New Yorker wrote: "Hamelin's legend will grow_right now there is no one like him."

Long known for his bold exploration of unfamiliar pianistic terrain, Hamelin has increasingly turned his attention to the established masterworks of the piano literature, in performances and recordings of the piano sonatas of Haydn, major works by Mozart, Schumann, Brahms, Chopin and others. He is quite versatile, being as comfortable in a solo recital, as a vocal accompanist, as a chamber collaborator or as a guest soloist with an orchestra. He has performed in all those venues around the world: throughout America and Europe, in Australia, and in the Far East.

Under exclusive contract with Hyperion Records, Hamelin has received 8 Grammy nominations. In the fall of 2010 Hyperion releases a disc of Hamelin's own compositions, Etudes and other works. His complete Hyperion discography numbers more than forty albums, and includes concertos and works for solo piano by composers such as Alkan, Busoni, Godowsky, and Medtner, as well as brilliantly received performances of Brahms, Chopin, Haydn, Liszt and Schumann.

Hamelin was recently presented with a lifetime achievement prize by the German Record Critic's Award. He was made an Officer of the Order of Canada in 2003 and a Chevalier de l'Ordre du Québec in 2004; he is also a member of the Royal Society of Canada. He makes his home in Boston. He premiered Nocturne no. 8, op. 85 by Liebermann.

More information can be obtained from the artist's personal website: http://www.marcandrehamelin.com/

Nadejda Vlaeva ${ }_{(140)}$ was born in Sofia, Bulgaria and began playing the piano at the age of five. She studied piano at the Sofia Music School, Sofia Music Academy, Sweelinck Conservatorium in Amsterdam, and the Manhattan School of Music, with Antoanetta Arsova, Anton Dikov, Jan Wijn, and Ruth Laredo. She also worked closely with Lazar Berman.

She has won First Prize at the Liszt competition in Lucca, Italy, Third Prize at the International Liszt Competition in Budapest, and the Yamaha Award for the best interpretation of Brahms, in Weimar. Vlaeva has performed internationally, giving solo recitals in Bulgaria, Russia, Slovakia, Hungary, The Netherlands, Germany, England, Spain, Barbados, Canada and the United States. She has played as a soloist with the Budapest Symphony Orchestra, the Calgary Philharmonic Orchestra, the Capella Istropolitana in Slovakia, the Edinburgh Symphony Orchestra, the Wroclaw Philharmonic, and with various other orchestras throughout the world.

She has made four CDs: piano music of Dimiter Christov, Liszt, Chopin Works for Piano and Orchestra, and Russian Romantic Piano music. Her second CD, Piano Music of Liszt, was released on the MSR Classics label and won the International Grand Prix "Liszt" du Disque. Nocturne No. 9 (2006) and Variations on a Theme of Schubert (2007) by Liebermann were composed for her. In 2009, she premiered the Variations at Merkin Concert Hall, in New York 
City. She also gave the North American Premiere of Piano Sonata No. 2 by Sergey Bortkiewicz. Vlaeva currently resides in New York. She premiered Nocturne no. 9, op. 97 by Liebermann.

More information can be obtained from the artist's personal website: http://www.nadejdavlaeva.com/

Lowell Liebermann ${ }_{(144) \text {. See also previous note }(16) .}$

He premiered Nocturne no. 10, op. 99 by Liebermann.

More information can be obtained from the artist's personal website: http://www.lowellliebermann.com/

William Hobbs ${ }_{(150)}$ was born in Austin, Texas. He received a Bachelor of Music in Piano Performance, summa cum laude, from the University of Colorado at Boulder, and a Master of Music in Piano Performance, Research and Literature from the Eastman School of Music in Rochester, N.Y. His teachers have included Thomas Schumacher, Paul Parmelee, Doris Pridinoff Lehnert and Larry Graham for piano and Neil Varon, Brad Lubman and Allan MacMurray for conducting.

Mr. Hobbs works at many of the world's major opera houses including the Opéra National de Paris, the Salzburg Festival, San Francisco Opera, Chicago Lyric Opera, Seattle Opera, Washington Opera and the Opéra de Monte-Carlo as répétiteur and conductor. His repertoire ranges from Handel to the European avant-garde, as well as works by Slavic composers and a number of premieres by American composers such as Lowell Liebermann and John Musto. He has assisted conductors such as Abbado, Mackerras, Davis, Conlon, Bonynge, and many others. He has worked closely with singers Renee Fleming, Susan Graham, Frederica von Stade, Roberto Alagna, Placido Domingo, Dmitri Hvorostovsky, Samuel Ramey and Kurt Moll.

Hobbs has served on the faculty of the Aspen Opera Theater Center of the Aspen Music Festival, and CoOperative at Westminster Choir College, and on the coaching staff of the Juilliard School of Music. He was invited twice by the National Theater of Tokyo as visiting Master Coach.

$\mathrm{He}$ is the founder and artistic director of Opera Slavica, which is devoted to presenting forgotten masterworks from Russian, Czech and Polish composers, and to providing singers with no background in these languages the knowledge and training to sing, read and translate them. Hobbs resides in New Jersey, with his partner, Lowell Liebermann. He premiered Nocturne no. 11, op. 112 by Liebermann.

More information can be obtained at: www.operaslavica.com/ 
Special collaboration (recording of Nocturne no. 8, op. 85)

Sandro Russo has performed for audiences around the world and has unanimously received accolades for his sparkling virtuosity, his profound sense of poetry and distinctive style; and his playing has often been referred to as a throwback to the grand tradition of elegant pianism and beautiful sound.

Russo was born in San Giovanni Gemini, in Sicily. Russo displayed exceptional musical talent from an early age. In 1995, he graduated summa cum laude from the Bellini Conservatory and earned the Pianoforte Performing Diploma from the Royal College of Music in London "with honors." He won top prize awards in numerous national and international competitions, including Senigallia, and the Ibla Grand Prize, the Bergen Philharmonic Orchestra Concerto Competition.

He has appeared as a soloist with numerous orchestras around the world. Russo's extensive repertoire comprises well-known masterpieces of all periods as well as more obscure and challenging works of the piano literature by such composer-pianists as Medtner, Sorabji and others. He has also been given the honor of premiering compositions by Lowell Liebermann, Paul Moravec, and Marc-André Hamelin. Lowell Liebermann wrote of him: "Sandro Russo is a musician's musician, and a pianist's pianist. There is no technical challenge too great for him, but it is his musicianship that ultimately makes the greatest impression. His interpretations reveal a unique and profound artist at work." 182 His discography includes four CDs. He premiered Liebermann's Four Etudes on Brahms songs op. 88, and he recorded Nocturne no. 8, op. 85 by Liebermann, providing the first public recording of that work.

More information can be obtained from the artist's personal website: http://www.sandrorussopianist.com/ 


\section{APPENDIX C1: FIELD'S NOCTURNES}

\begin{tabular}{|c|c|c|c|c|c|c|c|}
\hline Nocturne \# & $\begin{array}{l}\text { Opening } \\
\text { markings } \\
\text { meter key }\end{array}$ & $\begin{array}{l}\text { Middle } \\
\text { section's } \\
\text { markings }\end{array}$ & $\begin{array}{l}\text { Other } \\
\text { expressive } \\
\text { markings }\end{array}$ & $\begin{array}{l}\text { Opening } \\
\text { dynamic }\end{array}$ & $\begin{array}{l}\text { Closing } \\
\text { dynamic }\end{array}$ & $\begin{array}{l}\text { Dynamic } \\
\text { range }\end{array}$ & Form \\
\hline 1 & $\begin{array}{l}\text { Molto } \\
\text { moderato } \\
12 / 8 \quad \mathrm{~Eb}\end{array}$ & scherzando & un poco $f$ & mezza voce & ppp & $p p p-f$ & ABA' \\
\hline 2 & $\begin{array}{l}\text { Moderato e } \\
\text { molto } \\
\text { espressivo } \\
3 / 8 \quad \text { c }\end{array}$ & & $\begin{array}{l}\text { con dolore } \\
\text { sospirando }\end{array}$ & $p$ & $p p$ & $\begin{array}{l}p p-p \\
\text { cresc. }\end{array}$ & $\mathrm{ABA}^{\prime}$ \\
\hline 3 & $\begin{array}{l}\text { Un poco } \\
\text { allegretto } \\
6 / 8 \quad \mathrm{Ab}\end{array}$ & più moderato & espressivo & $\begin{array}{l}p \\
\text { sempre e legato }\end{array}$ & $p p p$ & $\begin{array}{l}\text { ppp-p } \\
\text { cresc. } \\
s f\end{array}$ & ABA' \\
\hline 4 & $\begin{array}{l}\text { Poco adagio } \\
\text { C } \quad \text { A }\end{array}$ & $\begin{array}{l}\text { piangendo } \\
\text { poco } f\end{array}$ & $\begin{array}{l}\text { marcato } \\
\text { delicatissimo } \\
\text { morendo }\end{array}$ & $p$ & ppp & $\begin{array}{l}\text { ppp-f } \\
s f, \text { cresc }\end{array}$ & ABCA'B' \\
\hline 5 & $\begin{array}{l}\text { Cantabile, } \\
\text { assai Lento } \\
12 / 8 \quad \text { B b }\end{array}$ & & & $p$ & $p p$ & $p p-m f$ & AA' \\
\hline $\begin{array}{l}6 \\
\text { Cradle-Song }\end{array}$ & $\begin{array}{l}\text { Andante } \\
\text { tranquillo } \\
6 / 8 \quad \mathrm{~F}\end{array}$ & & \begin{tabular}{|l|} 
eguale e \\
sempre pp \\
poco agitato \\
con delicatezza
\end{tabular} & $\begin{array}{l}p \\
\text { dolce }\end{array}$ & $\begin{array}{l}\text { calando } \\
\text { dolcissimo } \\
\text { ppp }\end{array}$ & $p p p-p$ & Rondo \\
\hline 7 & $\begin{array}{l}\text { Andante } \\
6 / 8 \quad \mathrm{~A}\end{array}$ & & $\begin{array}{l}\text { con tenerrezza } \\
\text { delicatissimo } \\
\text { leggiero }\end{array}$ & $p$ & $\begin{array}{l}\text { sotto voce } \\
p p\end{array}$ & $p p-m f$ & $\begin{array}{l}\text { ABA'B'A', } \\
\text { (rondo) }\end{array}$ \\
\hline 8 & $\begin{array}{l}\text { Andante } \\
\text { spianato } \\
6 / 8 \quad \mathrm{~Eb}\end{array}$ & & \begin{tabular}{|l} 
grazioso \\
dolente \\
dolcissimo
\end{tabular} & $p$ & ppp & $p p p-f$ & $\begin{array}{l}\text { Through- } \\
\text { composed, } \\
\text { Repetitive but } \\
\text { many contrasts }\end{array}$ \\
\hline 9 & $\begin{array}{l}\text { Adagio } \\
12 / 8(4 / 4) \mathrm{e} \\
\text { dolente }\end{array}$ & & $\begin{array}{l}\text { sospirando } \\
\text { dolcissimo }\end{array}$ & $\begin{array}{l}\text { mf pp } \\
\text { dolente }\end{array}$ & ppp & $p p p-f z$ & ABA' \\
\hline $\begin{array}{l}10 \\
\text { Nocture- } \\
\text { Pastorale }\end{array}$ & $\begin{array}{l}\text { Andante con } \\
\text { moto } \\
6 / 8 \quad \text { E }\end{array}$ & & $\begin{array}{l}\text { il canto ben } \\
\text { marcato } \\
\text { con forza }\end{array}$ & $m f$ & ppp & $\begin{array}{l}\text { ppp-mf } \\
\text { con forza }\end{array}$ & $\mathrm{ABA}^{\prime}$ \\
\hline 11 & $\begin{array}{l}\text { Moderato } \\
12 / 8 \quad \mathrm{~Eb}\end{array}$ & & $\begin{array}{l}\text { sempre legato } \\
\text { il basso } \\
\text { molto } \\
\text { espressivo e } \\
\text { languido }\end{array}$ & $p$ & $\begin{array}{l}\text { perdendo e } \\
\text { sostenuto }\end{array}$ & $p p-f$ & ABB' \\
\hline $\begin{array}{l}12 \\
\text { Noontide }\end{array}$ & $\begin{array}{l}\text { Allegro } \\
2 / 4 \quad \mathrm{E} \\
\text { sognante }\end{array}$ & & \begin{tabular}{|l} 
rinf. \\
leggiero \\
brillante \\
dim. senza rall.
\end{tabular} & $p>$ leggiero & $f z$ & $p p-f$ & $\begin{array}{l}\text { ABA'CA'”B' } \\
\text { A'”D }\end{array}$ \\
\hline 13 & $\begin{array}{l}\text { Dreamily } \\
3 / 4 \quad C\end{array}$ & più agitato & $\begin{array}{l}\text { Ssringendo } \\
\text { smorzando }\end{array}$ & $f \operatorname{dim} p$ & pp estinto & $p p p-f$ & $\mathrm{AB}$ \\
\hline
\end{tabular}




\begin{tabular}{|c|c|c|c|c|c|c|c|}
\hline Nocturne \# & $\begin{array}{l}\text { Opening } \\
\text { markings } \\
\text { meter key }\end{array}$ & $\begin{array}{l}\text { Middle } \\
\text { section's } \\
\text { markings }\end{array}$ & $\begin{array}{l}\text { Other } \\
\text { expressive } \\
\text { markings }\end{array}$ & $\begin{array}{l}\text { Opening } \\
\text { dynamic }\end{array}$ & $\begin{array}{l}\text { Closing } \\
\text { dynamic }\end{array}$ & $\begin{array}{l}\text { Dynamic } \\
\text { range }\end{array}$ & Form \\
\hline 14 & \begin{tabular}{|ll} 
Lento & \\
$6 / 8$ & G
\end{tabular} & & $\begin{array}{l}\text { teneramente } \\
\text { delicatissimo }\end{array}$ & $m f$ & pp dolcissimo & $p p-m f$ & $\begin{array}{l}\text { Through- } \\
\text { composed }\end{array}$ \\
\hline \begin{tabular}{|l}
15 \\
Song without \\
Words
\end{tabular} & $\begin{array}{ll}\text { Lento } & \\
3 / 4 & \mathrm{~d} \\
\text { dolente }\end{array}$ & $\begin{array}{l}\text { più moto } \\
\text { dolce } \\
\text { più agitato }\end{array}$ & & $p$ & $p p$ & $p p-f$ & ABA' \\
\hline 16 & $\begin{array}{l}\text { Molto } \\
\text { moderato } \\
\text { C C }\end{array}$ & & $\begin{array}{l}\text { a capriccio } \\
\text { smorzando }\end{array}$ & $p$ & ppp & $\begin{array}{l}\text { ppp-mf } \\
s f z\end{array}$ & ABCA' \\
\hline 17 & $\begin{array}{l}\text { Molto } \\
\text { moderato } \\
\text { C C }\end{array}$ & $\begin{array}{l}\text { dolce } \\
\text { A }\end{array}$ & $\begin{array}{l}\text { calando } \\
\text { mancando }\end{array}$ & $p$ & $p p$ & $p p-f$ & ABA' $^{\prime}$ \\
\hline 18 & $\begin{array}{l}\text { Molto } \\
\text { moderato } \\
3 / 4 \quad F\end{array}$ & & $\begin{array}{l}\text { cantando } \\
\text { scherzando } \\
\text { più agitato }\end{array}$ & $p<s f>p$ & $\begin{array}{l}\text { pp } \\
\text { smorz }\end{array}$ & $p p-f$ & $\begin{array}{l}\text { Through- } \\
\text { composed }\end{array}$ \\
\hline
\end{tabular}




\section{APPENDIX C1-2: FIELD'S NOCTURNES}

\begin{tabular}{|c|c|c|}
\hline $\begin{array}{l}\text { Nocturne \# } \\
\text { Hopkinson } \\
\text { catalog } \\
\text { (year of } \\
\text { publication) }\end{array}$ & $\begin{array}{l}\text { Number of } \\
\text { measures } \\
\text { app. duration }\end{array}$ & $\begin{array}{l}\text { Special features } \\
\text { Observations } \\
\text { Comments }\end{array}$ \\
\hline $\begin{array}{r}\mathrm{H} 24 \\
(1812)\end{array}$ & $\begin{array}{l}66 \text { measures } \\
\text { ca } 3^{\prime} 34^{\prime \prime}\end{array}$ & $\begin{array}{l}\text { Triple division of beat; Alberti-type accompaniment; Lightly ornamented return of material; } \\
\text { Pedal indications. }\end{array}$ \\
\hline $\begin{array}{r}2 \mathrm{H} 25 \\
(1812)\end{array}$ & $\begin{array}{l}92 \text { measures } \\
\text { ca } 3^{\prime} 23^{\prime \prime}\end{array}$ & $\begin{array}{l}\text { Triple division of beat; Alberti-type accompaniment; Lightly ornamented return of material; } \\
\text { Pedal indications; single mood; Expressive operatic gesture (sospirando); chromaticism. }\end{array}$ \\
\hline $\begin{array}{r}3 \mathrm{H} 26 \\
(1812)\end{array}$ & $\begin{array}{l}73 \text { measures } \\
\text { ca } 5{ }^{\prime} 28^{\prime \prime}\end{array}$ & $\begin{array}{l}\text { Triple division of beat; Passages with active left-hand figuration; Changes of key signatures } \\
\text { with double bars; Pedal indications; in general 3-voice texture. }\end{array}$ \\
\hline $\begin{array}{r}4 \mathrm{H} 36 \\
(1817) \\
\end{array}$ & $\begin{array}{l}72 \text { measures } \\
\text { ca } 5^{\prime} 21^{\prime \prime}\end{array}$ & $\begin{array}{l}\text { Active right hand; Generous use of chromaticism; Numerous scalar passages, at times played } \\
\text { by both hands; Pedal indications. }\end{array}$ \\
\hline $\begin{array}{r}5 \mathrm{H} 37 \\
(1817) \\
\end{array}$ & $\begin{array}{l}43 \text { measures } \\
\text { ca } 33^{\prime} 01^{\prime \prime}\end{array}$ & $\begin{array}{l}\text { Triple division of beat; Arpeggio accompaniment; Section based on pedal point with repeated } \\
\text { chords and staccato upper line; Pedal indications; Called "Serenade". }\end{array}$ \\
\hline $\begin{array}{r}6 \mathrm{H} 40 \\
(1817) \\
\end{array}$ & $\begin{array}{l}71 \text { measures } \\
\text { ca } 4 ' 50 "\end{array}$ & $\begin{array}{l}\text { Arpeggio accompaniment; Generous ornamentation, fermatas, cadenza-like passages; } \\
\text { Pedal indications; Originally, was the slow movement of Piano Concerto no. } 6 .\end{array}$ \\
\hline \begin{tabular}{|l}
$7 \mathrm{H} 14$ \\
$(1815-16)$ \\
\end{tabular} & $\begin{array}{l}61 \text { measures } \\
\text { ca } 62^{\prime \prime}\end{array}$ & $\begin{array}{l}\text { Rondo-type, the main material is constantly varied and ornamented; Pedal indications; } \\
\text { passages including diversified rhythms. }\end{array}$ \\
\hline $\begin{array}{r}8 \mathrm{H} 30 \\
(1815-16)\end{array}$ & $\begin{array}{l}61 \text { measures } \\
\text { ca } 3 ' 54 "\end{array}$ & $\begin{array}{l}\text { Bass+chords accompaniment; Light texture; Very little ornamented passages; Pedal } \\
\text { indications at the beginning, simile. }\end{array}$ \\
\hline \begin{tabular}{|l}
$9 \mathrm{H} 46$ \\
$(1821-22)$
\end{tabular} & $\begin{array}{l}37 \text { measures } \\
\text { ca } 3 ' 25^{\prime \prime}\end{array}$ & $\begin{array}{l}\text { Triple division of beat; Arpeggio accompaniment; Light texture, cadenza-like passage at the } \\
\text { end, chromatic; Pedal indications; written-in grupettos. }\end{array}$ \\
\hline $\begin{array}{r}10 \mathrm{H} 54 \\
(1830)\end{array}$ & $\begin{array}{l}90 \text { measures } \\
\text { ca } 3^{\prime} 06^{\prime \prime}\end{array}$ & $\begin{array}{l}\text { Accompaniment is more chordal; Active right hand; Changes of key signatures with double } \\
\text { bars; Pedal indications; Pedal indications; called "Nocturne-Pastorale"; theme in the left } \\
\text { hand. }\end{array}$ \\
\hline $\begin{array}{r}11 \mathrm{H} 56 \\
(1830) \\
\end{array}$ & $\begin{array}{l}118 \text { measures } \\
\text { ca } 5^{\prime} 30^{\prime \prime}\end{array}$ & $\begin{array}{l}\text { Triple division of beat; Arpeggio figuration accompaniment, highlighting chromatic } \\
\text { decorations; Light texture; No pedal indications; }\end{array}$ \\
\hline $\begin{array}{l}12 \mathrm{H} 13 \\
(1815-16)\end{array}$ & $\begin{array}{l}256 \text { measures } \\
\text { ca } 2^{\prime} 10^{\prime \prime}\end{array}$ & $\begin{array}{l}\text { Numerous changes of keys with double bars; Relies on pedal points; Descriptive effect - } \\
\text { bell strokes; No pedal indications; called "Noontide" (in rondo form); Found as "interlude" } \\
\text { in the } 1^{\text {st }} \text { movement of Piano Concerto no. 7; }\end{array}$ \\
\hline $\begin{array}{r}13 \mathrm{H} 45 \\
(1830)\end{array}$ & $\begin{array}{l}99 \text { measures } \\
\text { ca } 34^{\prime} 34^{\prime \prime}\end{array}$ & $\begin{array}{l}\text { Chordal left hand accompaniment; Active right hand; Interval of octave is quite important; } \\
\text { Pedal indications, turn to simile; called "Rêverie-nocturne". }\end{array}$ \\
\hline $\begin{array}{r}14 \mathrm{H} 58 \\
(1830) \\
\end{array}$ & $\begin{array}{l}24 \text { measures } \\
\text { ca 9'37" }\end{array}$ & $\begin{array}{l}\text { Triple division of beat; Accompaniment based on large arpeggios in the left hand; Single } \\
\text { mood; Active texture throughout; Pedal indications. }\end{array}$ \\
\hline $\begin{array}{r}15 \text { H59 } \\
(1830) \\
\end{array}$ & $\begin{array}{l}69 \text { measures } \\
\text { ca } 33^{\prime} 40^{\prime \prime}\end{array}$ & $\begin{array}{l}\text { Light texture; Changes of key, with double bars; No Pedal indication; Called "Song without } \\
\text { Words". }\end{array}$ \\
\hline $\begin{array}{r}16 \mathrm{H} 60 \\
(1830)\end{array}$ & $\begin{array}{l}171 \text { measures } \\
\text { ca } 5^{\prime} 04^{\prime \prime}\end{array}$ & $\begin{array}{l}\text { Accompaniment based mainly on repeated chords and pedal points; Chromaticism very } \\
\text { present in the melody; Active passages in the right hand; Written-out trills; Partial pedal } \\
\text { indications. }\end{array}$ \\
\hline $\begin{array}{r}17 \text { H61 } \\
(1830) \\
\end{array}$ & $\begin{array}{l}78 \text { measures } \\
\text { ca } 10^{\prime} 52^{\prime \prime}\end{array}$ & $\begin{array}{l}\text { Texture with double-notes in both hands (mainly thirds); Changes of keys with double bars; } \\
\text { Partial pedal indications; Passages in sixths. }\end{array}$ \\
\hline $\begin{array}{r}18 \mathrm{H} 62 \\
(1830)\end{array}$ & $\begin{array}{l}97 \text { measures } \\
\text { ca } 4^{\prime} 10^{\prime \prime}\end{array}$ & Triple division of beat; Light texture; Lightly ornamented; Partial pedal indications. \\
\hline
\end{tabular}


Approximate durations are taken from:

John Field 15 Nocturnes, John O'Conor piano, Telarc CD-80199

John Field Sonatas and Nocturnes, John O'Conor piano, Telarc CD-80290

The musical scores consulted were:

John Field, Eighteen Nocturnes for Piano, revised by Franz Liszt, essay by Franz Liszt, biographical sketch by Dr. Theodore Baker: Schirmer's Library, 1893.

In his catalogue of 1961, Cecil Hopkinson also lists: H55 Nocturne in C Major; H63 Nocturne in Bb Major; and H66 Nocturne "Dernières Pensées" (lost). These are not included in the common compilations. The Nocturnes may have been composed many years before publication (Steven Ledbetter, liner notes taken from TELARC CD 80290. 


\section{APPENDIX C2: CHOPIN'S NOCTURNES}

\begin{tabular}{|c|c|c|c|c|c|c|c|}
\hline $\begin{array}{l}\text { Nocturne \# } \\
\text { Opus \# }\end{array}$ & $\begin{array}{l}\text { Opening } \\
\text { markings } \\
\text { meter key }\end{array}$ & $\begin{array}{l}\text { Middle } \\
\text { section's } \\
\text { markings }\end{array}$ & $\begin{array}{l}\text { Other } \\
\text { expressive } \\
\text { markings }\end{array}$ & $\begin{array}{l}\text { Opening } \\
\text { dynamic }\end{array}$ & $\begin{array}{l}\text { Closing } \\
\text { dynamic }\end{array}$ & $\begin{array}{l}\text { Dynamic } \\
\text { range }\end{array}$ & Form \\
\hline $\begin{array}{l}1 \\
\text { op. } 9 \text { no. } 1\end{array}$ & $\begin{array}{l}\text { Larghetto } \\
6 / 4 \quad \mathrm{~b} b\end{array}$ & $\begin{array}{l}\text { sotto voce } \\
p p \quad \mathrm{Db}\end{array}$ & $\begin{array}{l}\text { smorzando } \\
\text { poco stretto } \\
\text { legatissimo }\end{array}$ & $\begin{array}{l}p \\
\text { espressivo }\end{array}$ & $p p p$ & $p p p-f f$ & $\mathrm{ABA}^{\prime}$ \\
\hline $\begin{array}{l}2 \\
\text { op. } 9 \text { no. } 2\end{array}$ & $\begin{array}{l}\text { Andante } \\
12 / 8 \quad \mathrm{~Eb}\end{array}$ & & $\begin{array}{l}\text { poco rubato } \\
\text { stretto, } \\
\text { senza tempo(st) }\end{array}$ & $\begin{array}{l}P \\
\text { espressivo } \\
\text { dolce }\end{array}$ & $p p p$ & $p p p-f f$ & $\begin{array}{l}\text { AA'A'” } \\
(\mathrm{W}: \mathrm{A})\end{array}$ \\
\hline $\begin{array}{l}3 \\
\text { op. } 9 \text { no. } 3\end{array}$ & $\begin{array}{l}\text { Allegretto } \\
6 / 8 \quad \mathrm{~B}\end{array}$ & \begin{tabular}{ll}
\multicolumn{2}{l}{ agitato } \\
$\mathrm{f} \quad \mathrm{b}$
\end{tabular} & $\begin{array}{l}\text { leggierissimo } \\
\text { scherzando } \\
\text { stretto, }(\text { st })\end{array}$ & $\begin{array}{l}p \\
\text { scherzando }\end{array}$ & $p p p$ & $\begin{array}{l}p p p-f f \\
\text { con forza }\end{array}$ & $\begin{array}{l}\text { AABA' } \\
\text { coda } \\
(\mathrm{W}: \text { ABCA })\end{array}$ \\
\hline $\begin{array}{l}4 \\
\text { op. } 15 \text { no. } 1\end{array}$ & $\begin{array}{l}\text { Andante cantabile } \\
3 / 4 \quad \text { F }\end{array}$ & \begin{tabular}{lr}
\multicolumn{2}{l}{ con fuoco } \\
$\mathrm{f}$
\end{tabular} & $\begin{array}{l}\text { sotto voce } \\
\text { sempre legato }\end{array}$ & $\begin{array}{l}\text { P semplice } \\
\text { e tranquillo }\end{array}$ & $\begin{array}{l}p p \\
\text { smorzando }\end{array}$ & $p p-f f$ & $\mathrm{ABA}^{\prime}$ \\
\hline $\begin{array}{l}5 \\
\text { op. } 15 \text { no. } 2\end{array}$ & $\begin{array}{l}\text { Larghetto } \\
2 / 4\end{array}$ & $\begin{array}{l}\text { doppio } \\
\text { movimento } \\
\text { sotto voce }\end{array}$ & $\begin{array}{l}\text { leggiero } \\
\text { molto rall. }\end{array}$ & $\begin{array}{l}p \\
\text { sostenuto }\end{array}$ & $\begin{array}{l}\text { pp } \\
\text { smorzando }\end{array}$ & $p p$-con forza & $\mathrm{ABA}^{\prime}$ \\
\hline $\begin{array}{l}\mathbf{6} \\
\text { op. } 15 \text { no. } 3\end{array}$ & \begin{tabular}{|l} 
Lento \\
$3 / 4 \quad \mathrm{~g}$
\end{tabular} & $\begin{array}{l}\text { a tempo } \\
\text { religioso } \\
\mathrm{p}\end{array}$ & $\begin{array}{l}\text { sotto voce } \\
\text { sempre legato }\end{array}$ & $\begin{array}{l}\text { p languido } \\
\text { e rubato }\end{array}$ & $p p$ & $p p-f$ & $\mathrm{ABC}$ \\
\hline $\begin{array}{l}7 \\
\text { op. } 27 \text { no. } 1\end{array}$ & $\begin{array}{l}\text { Larghetto } \\
\text { C c\# }\end{array}$ & $\begin{array}{lc}\text { piu } & \text { mosso } \\
p & 3 / 4 \\
& \mathrm{c \#}+\mathrm{Db}\end{array}$ & $\begin{array}{l}\text { poco a poco } \\
\text { cresc., calando } \\
\text { appassionato } \\
\text { accelerando } \\
\text { stretto, con duolo }\end{array}$ & $\begin{array}{l}p p<> \\
\text { sotto voce }\end{array}$ & $p p$ & $p p-f f f$ & $\begin{array}{l}\text { ABCA' } \\
\left(\mathrm{W}: \mathrm{ABA}^{\prime}\right)\end{array}$ \\
\hline $\begin{array}{l}8 \\
\text { op. } 27 \text { no. } 2\end{array}$ & $\begin{array}{l}\text { Lento sostenuto } \\
6 / 8 \quad \mathrm{Db}\end{array}$ & & appasionato & $\begin{array}{l}p \text { dolce } \\
\text { sempre legato }\end{array}$ & $\begin{array}{l}\text { calando } \\
\text { smorzando } \\
\text { dolcissimo } \\
\text { e dim. }\end{array}$ & $p p$-fff & $\begin{array}{l}\text { AA'A" } \\
\text { coda }\end{array}$ \\
\hline $\begin{array}{l}\mathbf{9} \\
\text { op. } 32 \text { no. } 1\end{array}$ & $\begin{array}{l}\text { Andante sostenuto } \\
\text { C B B }\end{array}$ & $\begin{array}{l}\text { a tempo } \\
\text { tranquillo }\end{array}$ & stretto & dolce & $\begin{array}{l}\text { adagio } \\
f\end{array}$ & $p p-f$ & $\begin{array}{l}\text { ABB' } \\
\text { coda }\end{array}$ \\
\hline $\begin{array}{l}\mathbf{1 0} \\
\text { op. } 32 \text { no. } 2\end{array}$ & $\begin{array}{l}\text { Lento } \\
\text { Appasionato } \\
12 / 8 \quad \text { Ab }\end{array}$ & $\begin{array}{ll}12 / 8 & \\
p & \mathrm{f}+\mathrm{f} \#\end{array}$ & $\begin{array}{l}\text { delicatissimo } \\
\text { appasionato }\end{array}$ & $\begin{array}{l}p \\
\text { sempre piano } \\
\text { e legato }\end{array}$ & $\begin{array}{l}\text { delicatissimo } \\
\text { Lento }\end{array}$ & $p-f f$ & $\begin{array}{l}\text { ABA' } \\
\text { intro } \\
\text { coda }\end{array}$ \\
\hline $\begin{array}{l}11 \\
\text { op. } 37 \text { no. } 1\end{array}$ & \begin{tabular}{|l|} 
Lento \\
$\mathrm{C} \quad \mathrm{g}$
\end{tabular} & $p \quad \mathrm{~Eb}$ & & $p$ & $p p$ & $p p-f f$ & $\mathrm{ABA}^{\prime}$ \\
\hline $\begin{array}{l}12 \\
\text { op. } 37 \text { no. } 2\end{array}$ & $\begin{array}{l}\text { Andante } \\
6 / 8 \quad \mathrm{G}\end{array}$ & $\begin{array}{l}p \\
\text { sostenuto }\end{array}$ & & $\begin{array}{l}\text { dolce } \\
\text { legato }\end{array}$ & $p p p$ & $p p p-f$ & $\begin{array}{l}\text { ABA'B'A" } \\
\text { coda (B") }\end{array}$ \\
\hline $\begin{array}{l}\mathbf{1 3} \\
\text { op. } 48 \text { no. } 1\end{array}$ & $\begin{array}{ll}\text { Lento } \\
\mathrm{C} \quad \mathrm{c}\end{array}$ & $\begin{array}{c}\text { poco piu lento } \\
\text { sotto voce } \\
\mathrm{C}\end{array}$ & $\begin{array}{l}\text { accelerando } \\
\text { dim. e rall. }\end{array}$ & mezza voce & $p p$ & $p p-f f$ & $\mathrm{ABA}^{\prime}$ \\
\hline $\begin{array}{l}\mathbf{1 4} \\
\text { op. } 48 \text { no. } 2\end{array}$ & $\begin{array}{l}\text { Andantino } \\
\mathrm{C} \quad \mathrm{f} \#\end{array}$ & $\begin{array}{l}\text { piu lento } \\
3 / 4 \quad \mathrm{D} b\end{array}$ & ritenuto & $p<>$ & $\begin{array}{l}p \\
\text { smorzando }\end{array}$ & $p p-f f$ & $\begin{array}{l}\text { ABA' } \\
\text { intro } \\
\text { coda } \\
\text { (W: AA'B A') }\end{array}$ \\
\hline
\end{tabular}




\begin{tabular}{|c|c|c|c|c|c|c|c|}
\hline $\begin{array}{l}\text { Nocturne \# } \\
\text { Opus \# }\end{array}$ & $\begin{array}{l}\text { Opening } \\
\text { markings } \\
\text { meter key }\end{array}$ & $\begin{array}{l}\text { Middle } \\
\text { section's } \\
\text { markings }\end{array}$ & $\begin{array}{l}\text { Other } \\
\text { expressive } \\
\text { markings }\end{array}$ & $\begin{array}{l}\text { Opening } \\
\text { dynamic }\end{array}$ & $\begin{array}{l}\text { Closing } \\
\text { dynamic }\end{array}$ & $\begin{array}{l}\text { Dynamic } \\
\text { range }\end{array}$ & Form \\
\hline $\begin{array}{l}\mathbf{1 5} \\
\text { op. } 55 \text { no. } 1\end{array}$ & $\begin{array}{l}\text { Andante } \\
\mathrm{C} \quad \mathrm{f}\end{array}$ & $\begin{array}{lc}\text { piu } & \text { Mosso } \\
\mathrm{f} & \mathrm{f}\end{array}$ & $\begin{array}{l}\text { molto legato e } \\
\text { stretto }\end{array}$ & $p$ & $\operatorname{dim}$ & $p-f$ & $\begin{array}{l}\text { ABA' } \\
\text { coda }\end{array}$ \\
\hline $\begin{array}{l}\text { 16 } \\
\text { op. } 55 \text { no. } 2\end{array}$ & $\begin{array}{ll}\text { Lento } & \\
12 / 8 \quad \mathrm{~Eb}\end{array}$ & & $\begin{array}{l}\text { cresc. } \\
\text { dim. }\end{array}$ & $\begin{array}{l}f \\
\text { sempre legato }\end{array}$ & $f$ & $p$-ff & ABA' \\
\hline $\begin{array}{l}17 \\
\text { op. } 62 \text { no. } 1\end{array}$ & $\begin{array}{l}\text { Andante } \\
\mathrm{C} \quad \mathrm{B}\end{array}$ & $\begin{array}{l}\text { sostento } \\
\mathrm{Ab}\end{array}$ & $\begin{array}{l}\text { sempre legato } \\
\text { poco più lento } \\
\text { dolce }\end{array}$ & $\begin{array}{l}f \\
\text { dolce, legato }\end{array}$ & p calando & $p p-f$ & $\begin{array}{l}\text { ABA' } \\
\text { coda }\end{array}$ \\
\hline \begin{tabular}{|l|}
18 \\
op. 62 no. 2
\end{tabular} & \begin{tabular}{|l} 
Lento \\
sostenuto \\
$\mathrm{C} \quad \mathrm{E}$
\end{tabular} & $\begin{array}{ll}\text { agitato }^{2} & \\
\mathrm{c \#} & \mathrm{f}\end{array}$ & $\begin{array}{l}\text { cresc. } \\
\text { dim. }\end{array}$ & $(p)$ & $p$ & $p-f f$ & ABA' \\
\hline \begin{tabular}{|l|}
19 \\
op. 72 no. 1 \\
op. posth.
\end{tabular} & $\begin{array}{l}\text { Andante } \\
\mathrm{C} \quad \mathrm{e}\end{array}$ & & $\begin{array}{l}\text { poco a poco } \\
\text { cresc. }\end{array}$ & $\begin{array}{l}p \\
\text { molto legato }\end{array}$ & $p p$ & $p p-f$ & $\begin{array}{l}\mathrm{AB}^{\prime} \mathrm{B}^{\prime \prime} \\
\text { or AA' }\end{array}$ \\
\hline \begin{tabular}{|l|}
$\mathbf{2 0}$ \\
op. posth.
\end{tabular} & $\begin{array}{l}\text { Lento con } \\
\text { gran espressione } \\
\text { C c\# }\end{array}$ & $\begin{array}{ll}\text { A } \quad p p p \\
3 / 4 \quad p \\
\text { adagio }\end{array}$ & $\begin{array}{l}\text { con forza } \\
\text { sotto voce } \\
\text { sempre dim. } \\
\text { morendo } \\
\text { appasionato }\end{array}$ & $p p$ & $p p p$ & $p p-f f$ & ABCA' \\
\hline \begin{tabular}{|l|}
21 \\
op. posth.
\end{tabular} & $\begin{array}{l}\text { Andante } \\
\text { sostenuto } \\
\mathrm{C} \quad \mathrm{c}\end{array}$ & & $\begin{array}{l}\text { animato } \\
\text { poco più forte }\end{array}$ & $p$ & $f>$ & $p-f$ & $\begin{array}{l}\text { ABB' } \\
\text { c } f^{\prime} c\end{array}$ \\
\hline
\end{tabular}

W: refers to Wallach's chart at page 79. (indicated when different from my opinion on the formal scheme) 


\section{APPENDIX C2-2: CHOPIN'S NOCTURNES}

\begin{tabular}{|c|c|c|}
\hline $\begin{array}{l}\text { Nocturne \# } \\
\text { Brown } \\
\text { Catalog of } 1972 \\
\text { (year of } \\
\text { composition) }\end{array}$ & $\begin{array}{l}\text { Number of measures } \\
\text { app. duration }\end{array}$ & $\begin{array}{l}\text { Special features } \\
\text { Comments } \\
\text { Other markings }\end{array}$ \\
\hline $\begin{array}{l}1 \mathrm{~B} 54 \\
(1830-31)\end{array}$ & $\begin{array}{l}85 \text { measures } \\
\text { ca } 55^{\prime \prime}\end{array}$ & $\begin{array}{l}\text { Triple division of beat; Accompaniment in arpeggios throughout in LH; Lightly } \\
\text { ornamented return of material; Pedal indications (sempre, simile); B section: Octaves } \\
\text { and double-notes in RH. }\end{array}$ \\
\hline $2 \mathrm{~B} 54$ & $\begin{array}{l}34 \text { measures } \\
\text { ca } 3 ' 58 "\end{array}$ & $\begin{array}{l}\text { Triple division of beat; Bass+chords accompaniment; Highly ornamented return of } \\
\text { material, mordents, grupettos; Cadenza-like passage, senza tempo; Pedal indications; } \\
\text { Single mood (Field-like in spirit and texture). }\end{array}$ \\
\hline $\begin{array}{l}\mathrm{B} \text { B54 } \\
(1830-31)\end{array}$ & $\begin{array}{l}156 \text { measures } \\
\text { ca 6'11" }\end{array}$ & $\begin{array}{l}\text { Triple division of beat; Accompaniment in broke arpeggios; Highly embellished, } \\
\text { rhythmic diversity and freedom in RH; towards the end, cadenza-like passage, senza } \\
\text { tempo; Pedal indications. }\end{array}$ \\
\hline $\begin{array}{l}4 \mathrm{~B} 55 \\
(1830-31)\end{array}$ & $\begin{array}{l}74 \text { measures } \\
\text { ca } 5{ }^{\prime} 01 "\end{array}$ & $\begin{array}{l}\text { Triple division of beat; Accompaniment displaying repeated notes; More active left } \\
\text { hand in the B section; Dramatic middle section, based on melody in LH and double- } \\
\text { note accompaniment in RH; Partial pedal indications. }\end{array}$ \\
\hline $\begin{array}{l}5 \text { B55 } \\
(1830-31) \\
\end{array}$ & $\begin{array}{l}63 \text { measures } \\
\text { ca } 37^{\prime} 27^{\prime \prime}\end{array}$ & $\begin{array}{l}\text { Active RH with rhythmic freedom; Highly embellished; Contrasting middle section; } \\
\text { Multi-layer writing in B section; Pedal indications. }\end{array}$ \\
\hline $\begin{array}{r}6 \text { B } 79 \\
(1833)\end{array}$ & $\begin{array}{l}152 \text { measures } \\
\text { ca } 5^{\prime} 00^{\prime \prime}\end{array}$ & $\begin{array}{l}\text { Triple division of the measure: LH rhythm of two beats and rest; Chordal texture; } \\
\text { Religioso section; Partial pedal indications. }\end{array}$ \\
\hline $\begin{array}{c}7 \text { B91 } \\
(1835)\end{array}$ & $\begin{array}{l}101 \text { measures } \\
\text { ca 5'35" }\end{array}$ & $\begin{array}{l}\text { Triple division of beat; Accompaniment in wide-spaced arpeggios in LH; Chromatic } \\
\text { and modal qualities of the melody; Middle section contains a mazurka-like moment, } \\
\text { cadenza for the left hand in octaves; Pedal indications. }\end{array}$ \\
\hline 8 B96 & $\begin{array}{l}77 \text { measures } \\
\text { ca } 4 \text { '22" }\end{array}$ & $\begin{array}{l}\text { Triple division of beat; Melody in Thirds, sixths and octaves in RH; Highly } \\
\text { embellished; Constant arpeggios figuration LH; } 7 \text { against } 6 \text { at the end, mordents; } \\
\text { Pedal indications. }\end{array}$ \\
\hline $\begin{array}{l}9 \text { B } 106 \\
(1836-37)\end{array}$ & $\begin{array}{l}65 \text { measures } \\
\text { ca } 4 \text { ' } 15 "\end{array}$ & $\begin{array}{l}\text { Accompaniment in broken arpeggios; No dramatic middle section but Dramatic } \\
\text { recitative-like section at the end; Hands doublings; Trills; Stretto; Pedal indications. }\end{array}$ \\
\hline $\begin{array}{r}10 \mathrm{~B} 106 \\
(1836-37)\end{array}$ & $\begin{array}{l}76 \text { measures } \\
\text { ca } 5^{\prime} 40^{\prime \prime}\end{array}$ & $\begin{array}{l}\text { Triple division of beat; Accompaniment in broken chords; Very chromatic B section } \\
\text { over pedal point accompaniment, repeated chords; Return of material embellished; } \\
\text { Rhythmic flexibility; } 5 \text { against 3; Pedal indications. }\end{array}$ \\
\hline $\begin{array}{c}11 \text { B } 119 \\
(1838)\end{array}$ & $\begin{array}{l}91 \text { measures } \\
\text { ca 5'31" }\end{array}$ & $\begin{array}{l}\text { Rhythmic flexibility RH; LH chords; B section chordal texture; Partial pedal } \\
\text { indications (no indication for B section). }\end{array}$ \\
\hline $\begin{array}{c}12 \mathrm{~B} 127 \\
(1839)\end{array}$ & $\begin{array}{l}139 \text { measures } \\
\text { ca 5'30" }\end{array}$ & $\begin{array}{l}\text { Triple division of beat; Accompaniment in arpeggios; Double-notes etude-like in RH; } \\
\text { Partial pedal indications, no pedal markings for B section. }\end{array}$ \\
\hline $\begin{array}{l}13 \mathrm{~B} 142 \\
(1841)\end{array}$ & $\begin{array}{l}77 \text { measures } \\
\text { ca } 4{ }^{\prime} 42^{\prime \prime}\end{array}$ & $\begin{array}{l}\text { Accompaniment of low bass in octave and chords; Rhythmic flexibility of RH; Very } \\
\text { dramatic B section; Octave doublings; Virtuoso writing; Cadenza; Return of A, } \\
\text { double tempo, multi-layer, thicker texture, polyrhythmic; Pedal indications. }\end{array}$ \\
\hline $\begin{array}{l}14 \mathrm{~B} 142 \\
(1841)\end{array}$ & $\begin{array}{l}137 \text { measures } \\
\text { ca 3'11" }\end{array}$ & $\begin{array}{l}\text { Triple division of beat; Accompaniment in broken arpeggios; Change of key } \\
\text { signatures with double bars (c\#-D b); Exchange of material in between the hands; } \\
\text { Long trill. }\end{array}$ \\
\hline $15 \mathrm{~B} 152$ & $\begin{array}{l}101 \text { measures } \\
3^{\prime} 46^{\prime \prime}\end{array}$ & $\begin{array}{l}\text { Accompaniment of low bass and chord; Rhythm is very 'controlled', not as flexible; } \\
\text { Middle section Più mosso, hands doublings; Chromatically embellished return of } \\
\text { material; Long accelerando in coda; Pedal indications. }\end{array}$ \\
\hline $\begin{array}{c}16 \mathrm{~B} 152 \\
(1843)\end{array}$ & $\begin{array}{l}67 \text { measures } \\
\text { 3'54', }\end{array}$ & $\begin{array}{l}\text { Triple division of beat; Accompaniment in broken arpeggios; Harmony is very rich; } \\
\text { Rhythmic flexibility; Numerous lines superimposed; Poly-rhythms at the end: } 4 \\
\text { against 3, } 5 \text { against 3, } 7 \text { against 3, } 7 \text { against 6; Pedal indications. }\end{array}$ \\
\hline
\end{tabular}




\begin{tabular}{|c|c|c|}
\hline $\begin{array}{l}\text { Nocturne \# } \\
\text { Brown } \\
\text { Catalog of } 1972 \\
\text { (year of } \\
\text { composition) }\end{array}$ & $\begin{array}{l}\text { Number of measures } \\
\text { app. duration }\end{array}$ & $\begin{array}{l}\text { Special features } \\
\text { Comments } \\
\text { Other markings }\end{array}$ \\
\hline $\begin{array}{c}17 \text { B } 161 \\
(1846)\end{array}$ & $\begin{array}{l}94 \text { measures } \\
5^{\prime} 44^{\prime \prime}\end{array}$ & $\begin{array}{l}\text { Accompaniment in broken arpeggios; Double-notes in RH; Greater rhythmic } \\
\text { flexibility closer to the end of A section; Cadenza-like passage; Less active, less } \\
\text { dramatic B section; Long chain of trills; Pedal indications. }\end{array}$ \\
\hline $\begin{array}{c}18 \text { B } 161 \\
(1846)\end{array}$ & $\begin{array}{l}81 \text { measures } \\
5^{\prime} 15^{\prime \prime}\end{array}$ & $\begin{array}{l}\text { Accompaniment made of low bass and chord; Simple melodic line in RH; Lightly } \\
\text { embellished; More activity in LH; Middle section, agitato, activity in both hands; } \\
\text { Multi layers; Pedal indications. }\end{array}$ \\
\hline $\begin{array}{r}19 \text { B } 19 \\
(1827)\end{array}$ & $\begin{array}{l}57 \text { measures } \\
3^{\prime} 12^{\prime \prime}\end{array}$ & $\begin{array}{l}\text { Triple division of beat; Accompaniment in broken arpeggios; Double-notes, Octaves, } \\
\text { Chords in RH; Rhythmic flexibility RH; Dramatic embellishments: octaves; scales; } \\
\text { arpeggios, trills; Pedal indications. }\end{array}$ \\
\hline $\begin{array}{r}20 \text { B49 } \\
(1830)\end{array}$ & $\begin{array}{l}62 \text { measures } \\
4^{\prime} 07^{\prime \prime}\end{array}$ & $\begin{array}{l}\text { Accompaniment of broken arpeggios; Single-line melody; Trills; Greater rhythmic } \\
\text { freedom toward the end of the main idea; Dance-like middle section; Texture is } \\
\text { sparser; Return of material embellished with rapid scales; Partial pedal indications. }\end{array}$ \\
\hline $\begin{array}{c}21 \mathrm{~B} 108 \\
(1838)\end{array}$ & $\begin{array}{l}44 \text { measures } \\
3^{\prime} 43^{\prime \prime}\end{array}$ & $\begin{array}{l}\text { Accompaniment made of a mixture of broken arpeggios and chord; Rhythmic } \\
\text { flexibility RH; Embellished melody; Strong tonic-subdominant relationship; Pedal } \\
\text { indications (simile). }\end{array}$ \\
\hline
\end{tabular}

Approximate durations for numbers 1-15 are taken from:

Tamas Vasary, Chopin Nocturnes, DG 429 154-2

Numbers 16-19 from:

Samson François, Chopin Nocturnes and Preludes, EMI Classics, CMZ 07777-69158-2-1

Number 20:

"Mikhail Vovskresensky plays Chopin Nocturne in c-sharp minor,"

http://www.youtube.com/watch?v=79Wsp9TpIZw

Number 21:

"Claudio Arrau plays Chopin Nocturne in c minor, op. Posthumous,"

http://www.youtube.com/watch?v=X30hh24okf4\&feature=related

The musical scores consulted were:

Frederic Chopin, Nocturnes and Polonaises for Piano, (The Paderewski Edition), Dover Publications Inc., NY, 1983.

Frederic Chopin, Nocturne in c\# minor, op. posth, G.Henle Verlag, Munich, 2003.

Frederic Chopin, Nocturne in c minor, op. posth. B.108.

(Downloaded from the internet: http://www.justsheetmusic.com/sheet-music/frederic-chopin-nocturne-in-c-minor-posthumous/) 
APPENDIX C3: FAURÉ'S NOCTURNES

\begin{tabular}{|c|c|c|c|c|c|c|c|}
\hline Nocturne \# & $\begin{array}{l}\text { Opening } \\
\text { markings } \\
\text { meter key }\end{array}$ & \begin{tabular}{|l|} 
Middle \\
section's \\
markings \\
keys if contrasting
\end{tabular} & $\begin{array}{l}\text { Other } \\
\text { expressive } \\
\text { markings }\end{array}$ & $\begin{array}{l}\text { Opening } \\
\text { dynamic }\end{array}$ & $\begin{array}{l}\text { Closing } \\
\text { dynamic }\end{array}$ & $\begin{array}{l}\text { Dynamic } \\
\text { range }\end{array}$ & Form \\
\hline $\begin{array}{l}\mathbf{1} \\
\text { op. } 33 \text { no. } 1\end{array}$ & $\begin{array}{ll}\text { Lento } & \\
3 / 4 & \text { eb }\end{array}$ & cantando & $\begin{array}{l}\text { crescendo molto } \\
\text { leggierissimo }\end{array}$ & pp sempre & $p p$ & $p p-f f$ & $\mathrm{ABA}^{\prime} \mathrm{c}$ \\
\hline $\begin{array}{l}2 \\
\text { op. } 33 \text { no. } 2\end{array}$ & $\begin{array}{l}\text { Andantino } \\
\text { espressivo } \\
\text { cantando } \\
\mathrm{C} \quad \mathrm{B}\end{array}$ & $\begin{array}{l}\text { Allegro ma non } \\
\text { troppo } \\
\mathrm{p} \quad \mathrm{b}\end{array}$ & $\begin{array}{l}\text { dolce espressivo } \\
\text { perdendosi } \\
\text { ritardando }\end{array}$ & $m p$ & $p p p$ & $p p p-f$ & $\mathrm{ABA}^{\prime} \mathrm{c}$ \\
\hline $\begin{array}{l}3 \\
\text { op. } 33 \text { no. } 3\end{array}$ & $\begin{array}{l}\text { Andante con moto } \\
\text { Molto espressivo } \\
3 / 4 \quad A b\end{array}$ & $\begin{array}{l}\text { Dolcissimo } \\
\text { sempre } \\
\text { senza ped. }\end{array}$ & $\begin{array}{l}\text { dolce subito } \\
\text { senza ped. } \\
\text { molto cresc. }\end{array}$ & $m f$ & $\begin{array}{l}\text { tranquillamente } \\
\text { p sempre } \\
\text { dolce }\end{array}$ & $p p-f$ & $\mathrm{ABA}^{\prime} \mathrm{c}$ \\
\hline $\begin{array}{l}4 \\
\text { op. } 36\end{array}$ & $\begin{array}{l}\text { Andante } \\
\text { molto moderato } \\
\mathrm{C} \quad \mathrm{Eb}\end{array}$ & $\begin{array}{l}\text { Tranquillamente } \\
\mathrm{p} \quad \mathrm{eb}\end{array}$ & $\begin{array}{l}\text { dolce e cantabile } \\
\text { appassionato }\end{array}$ & dolce & $p p$ & $p p-f f$ & ABA'c \\
\hline $\begin{array}{l}5 \\
\text { op. } 37\end{array}$ & $\begin{array}{l}\text { Andante } \\
\text { quasi Allegretto } \\
3 / 4 \quad \mathrm{~B} \mathrm{~b}\end{array}$ & $\begin{array}{l}\text { Allegro } \\
\text { ben marcato il } \\
\text { canto } \\
6 / 8 \quad \mathrm{bb}\end{array}$ & $\begin{array}{l}\text { sostenuto } \\
\text { sans presser } \\
\text { leggeriero }\end{array}$ & $\begin{array}{l}\text { mp } \\
\text { ed espressivo }\end{array}$ & $p p$ & $p p-f f$ & $\mathrm{ABA}^{\prime} \mathrm{c}$ \\
\hline $\begin{array}{l}6 \\
\text { op. } 63\end{array}$ & $\begin{array}{l}\text { Andante } \\
3 / 2 \quad \mathrm{Db}\end{array}$ & $\begin{array}{l}\text { Allegretto molto } \\
\text { moderato } \\
\text { Allegro moderato }\end{array}$ & $\begin{array}{l}\text { leggiero } \\
\text { espressivo } \\
\text { marcato }\end{array}$ & $p$ & $p$ & $p p-f f$ & $\mathrm{ABA}^{\prime} \mathrm{c}$ \\
\hline 7 op. 74 & $\begin{array}{l}\text { Molto lento } \\
18 / 8 \quad \mathrm{c} \# \\
\text { sostenuto }\end{array}$ & $\begin{array}{l}\text { Un poco più } \\
\text { mosso } \\
\text { Allegro }\end{array}$ & $\begin{array}{l}\text { Legato } \\
\text { p subito } \\
\text { marcato }\end{array}$ & $p$ & P sempre & $p p-f f$ & ABA'c \\
\hline $\begin{array}{l}8 \\
\text { op. } 84 \text { no. } 8\end{array}$ & $\begin{array}{l}\text { Adagio non } \\
\text { troppo } \\
12 / 8 \quad \mathrm{Db}\end{array}$ & & espressivo & p e cantabile & sempre $\mathrm{p}$ & $p p-f$ & $\begin{array}{l}\text { Through- } \\
\text { composed }\end{array}$ \\
\hline $\begin{array}{l}9 \\
\text { op.97 }\end{array}$ & $\begin{array}{l}\text { Andante } \\
3 / 2 \quad \mathrm{~b}\end{array}$ & & $\begin{array}{l}\text { Meno } f \\
\text { espressivo } \\
\text { poco a poco } \\
\text { cresc. }\end{array}$ & $p$ & $p$ & $p-f$ & $\begin{array}{l}\text { Through- } \\
\text { composed }\end{array}$ \\
\hline $\begin{array}{l}\text { 10 } \\
\text { op. } 99\end{array}$ & $\begin{array}{l}\text { Quasi adagio } \\
\mathrm{C} \quad \mathrm{e}\end{array}$ & & $\begin{array}{l}\text { poco a poco } \\
\text { cresc. } \\
\text { marcato }\end{array}$ & $p$ & $p p$ & $p p-f f$ & $\begin{array}{l}\text { Through- } \\
\text { composed }\end{array}$ \\
\hline $\begin{array}{l}11 \\
\text { op. } 104 \text { no. } 1\end{array}$ & $\begin{array}{l}\text { Molto moderato } \\
3 / 4 \quad \text { f\# }\end{array}$ & cantando & cresc. molto & dolce & $p$ & $p-f f$ & $\mathrm{AA}^{\prime}$ \\
\hline $\begin{array}{l}\text { 12 } \\
\text { op. } 107\end{array}$ & $\begin{array}{l}\text { Andante moderato } \\
12 / 8 \mathrm{e}\end{array}$ & & $\begin{array}{l}\text { Poco a poco } \\
\text { cresc. e più } \\
\text { animato } \\
\text { Allegro ma non } \\
\text { troppo } \\
\text { Con anima } \\
\text { Più mosso }\end{array}$ & $f>p$ & $p p$ & $p p-f f$ & $\mathrm{ABA}^{\prime}$ \\
\hline $\begin{array}{l}13 \\
\text { op. } 119\end{array}$ & $\begin{array}{l}\text { Andante } \\
3 / 2 \quad \mathrm{~b}\end{array}$ & $\begin{array}{l}\text { Allegro } \\
2 / 2 \quad \text { B }\end{array}$ & $\begin{array}{l}\text { Marcato } \\
\text { poco a poco dim. } \\
\text { cantando }\end{array}$ & $m p$ & $p p$ & $p p-f$ & $\mathrm{ABA}^{\prime}$ \\
\hline
\end{tabular}

$\mathrm{c}=$ coda 


\section{APPENDIX C3-2: FAURÉ'S NOCTURNES}

\begin{tabular}{|c|c|c|}
\hline $\begin{array}{l}\text { Nocturne \# } \\
\text { (year of } \\
\text { composition) }\end{array}$ & $\begin{array}{l}\text { Number of measures } \\
\text { app. duration }\end{array}$ & $\begin{array}{l}\text { Special features } \\
\text { Comments }\end{array}$ \\
\hline $\begin{array}{c}1 \text { op. 33-1 } \\
(1883)\end{array}$ & $\begin{array}{l}124 \text { measures } \\
\text { ca 7'50" }\end{array}$ & $\begin{array}{l}\text { Triple division of measure; Varied accompaniments: repeated chords, motivic } \\
\text { figurations, broken arpeggios; Hand crossings; Ornamented return of material; No } \\
\text { pedal indications; cadenza passage coda eluding to B section. }\end{array}$ \\
\hline $\begin{array}{c}2 \text { op. } 33-2 \\
(1883)\end{array}$ & $\begin{array}{l}91 \text { measures } \\
\text { ca 5'54" }\end{array}$ & $\begin{array}{l}\text { Varied accompaniments: figurations, broken arpeggios; Numerous finger-work } \\
\text { passages and one cadenza-like episode; Hand crossings and material exchanges; } \\
\text { Rhythmic layering; Lightly ornamented return of material; Accompaniment and } \\
\text { melodic material difficult to separate; No pedal indications; Coda alluding to B } \\
\text { section. }\end{array}$ \\
\hline $\begin{array}{c}3 \text { op. } 33-3 \\
(1883)\end{array}$ & $\begin{array}{l}109 \text { measures } \\
\text { ca 5'01" }\end{array}$ & $\begin{array}{l}\text { Single-mood type; Varied accompaniments: bass + chords, arpeggios; Senza ped. } \\
\text { indication in one passage; Hand crossings; Rhythmic layering; Lightly ornamented } \\
\text { return of material. }\end{array}$ \\
\hline 4 op. 36 & $\begin{array}{l}98 \text { measures } \\
\text { ca 7'00" }\end{array}$ & $\begin{array}{l}\text { Varied accompaniments: bass + chords, arpeggios; Hand crossings; Rhythmic } \\
\text { layering; Lightly ornamented return of material; Imitations; Pedal indications for the } \\
\text { sostenuto pedal. }\end{array}$ \\
\hline 5 op. 37 & $\begin{array}{l}208 \text { measures } \\
\text { ca } 8 \text { '26" }\end{array}$ & $\begin{array}{l}\text { Varied accompaniments: bass + chords, arpeggios; Hand crossings and material } \\
\text { exchanges; Lightly ornamented return of material; Rhythmic layering; Big dramatic } \\
\text { construction; Pedal indications for the sostenuto pedal. }\end{array}$ \\
\hline 6 op. 63 & $\begin{array}{l}133 \text { measures } \\
\text { ca 9'11" }\end{array}$ & $\begin{array}{l}\text { Varied accompaniments: chords, arpeggios; Material exchanges in between hands; } \\
\text { Numerous tempo and key signature changes; Accompaniment and melodic material } \\
\text { difficult to separate; Grander and more complex conception of the form-quotations } \\
\text { from previous sections; Pedal indications for the sostenuto pedal. }\end{array}$ \\
\hline $7 \underset{\text { op. } 74}{1898)}$ & $\begin{array}{l}121 \text { measures } \\
\text { ca } 10^{\prime} 02 "\end{array}$ & $\begin{array}{l}\text { Varied accompaniments: chords, arpeggios, single line counterpoint, octave } \\
\text { doublings; Material exchanges in between hands; Numerous tempo and key signature } \\
\text { changes; Accompaniment and melodic material difficult to separate; Grander and } \\
\text { more complex conception of the form; No pedal indications. }\end{array}$ \\
\hline $\begin{array}{c}8 \text { op. } 84-8 \\
(1902)\end{array}$ & $\begin{array}{l}33 \text { measures } \\
\text { ca } 2^{\prime} 27^{\prime \prime}\end{array}$ & $\begin{array}{l}\text { Material is very scalar (etude-like); single mood, tempo, key; Material exchanges in } \\
\text { between hands; Smaller approach to the genre; No pedal indications. }\end{array}$ \\
\hline $\begin{array}{l}9 \text { op. } 97 \\
(1908)\end{array}$ & $\begin{array}{l}61 \text { measures } \\
\text { ca } 4 \text { '50" }\end{array}$ & $\begin{array}{l}\text { Through-composed; Monothematic; Motivic transformations; Accompaniment made } \\
\text { of chord members and small arpeggios; Very thin texture; Homogeneous in mood; } \\
\text { Rhythm functions as an ostinato; No pedal indications. }\end{array}$ \\
\hline $\begin{array}{c}10 \text { op. } 99 \\
(1909)\end{array}$ & $\begin{array}{l}75 \text { measures } \\
\text { ca } 4 \text { '32" }\end{array}$ & $\begin{array}{l}\text { Through-composed; Accompaniment made of chord members and small arpeggios; } \\
\text { Very thin texture; Unexpected modulations and tonal shifts exploited to an } \\
\text { extraordinary degree; Passages with whole-tone connotations; No pedal indications. }\end{array}$ \\
\hline 11 op. 104 & $\begin{array}{l}72 \text { measures } \\
\text { ca } 4 \text { '21" }\end{array}$ & $\begin{array}{l}\text { Monothematic_-almost treated like a theme and variations; Highly chromatic and } \\
\text { contrapuntal throughout; No pedal indications. }\end{array}$ \\
\hline 12 op. 107 & $\begin{array}{l}107 \text { measures } \\
\text { ca } 5^{\prime} 42^{\prime \prime}\end{array}$ & $\begin{array}{l}\text { Return to Bravura Style-grander formal conception and gestures; Motivic themes; } \\
\text { Numerous striking dissonances; Accompaniment made of scalar elements, arpeggios, } \\
\text { broken chords; Coda recapitulates all the themes; No pedal indications. }\end{array}$ \\
\hline 13 op. 119 & $\begin{array}{l}155 \text { measures } \\
\text { ca 7'12" }\end{array}$ & $\begin{array}{l}\text { Exercise in 4-parts harmony, transparent simplicity; Contrapuntal (canon) style; A } \\
\text { definite tonality is difficult to ascertain; Accompaniment is made of short arpeggios; } \\
\text { Numerous exchanges of material in between hands; Passage in parallel scales; No } \\
\text { pedal indications. }\end{array}$ \\
\hline
\end{tabular}

Approximate durations are taken from:

Gabriel Fauré 13 Nocturnes, Jean-Philippe Collard piano, EMI CMS-7691492

The musical scores consulted were:

Gabriel Fauré, Oeuvres Complètes pour Piano, volume 1, "Nocturnes,” Édité et Revisé pas Yoshio Miyama et Kazuko Fujii, Shunjusha Edition, pp 4-110.

Gabriel Fauré, Nocturnes and Barcarolles for Solo Piano, Dover Publications, Inc. NY, 1994. pp 3-99. 


\section{APPENDIX C4: LIEBERMANN'S NOCTURNES}

\begin{tabular}{|c|c|c|c|c|c|c|c|}
\hline Nocturne \# & $\begin{array}{l}\text { Opening } \\
\text { markings } \\
\text { meter key }\end{array}$ & $\begin{array}{l}\text { Middle } \\
\text { section's } \\
\text { markings }\end{array}$ & $\begin{array}{l}\text { Other } \\
\text { expressive } \\
\text { markings }\end{array}$ & $\begin{array}{l}\text { Opening } \\
\text { dynamic }\end{array}$ & $\begin{array}{l}\text { Closing } \\
\text { dynamic }\end{array}$ & $\begin{array}{l}\text { Dynamic } \\
\text { range }\end{array}$ & Form \\
\hline $\begin{array}{l}1 \\
\text { op. } 20\end{array}$ & $\begin{array}{l}\text { Adagio con } \\
\text { molto rubato } \\
6 / 8 \quad G\end{array}$ & $\begin{array}{l}\text { a tempo } \\
m f\end{array}$ & calando & $\begin{array}{l}\text { pp } \\
\text { cantando }\end{array}$ & $p p$ & $p p-f f$ & ABA'c \\
\hline $\begin{array}{l}2 \\
\text { op. } 31\end{array}$ & $\begin{array}{l}\text { Largo con } \\
\text { rubato } \\
4 / 4 \quad \mathrm{~B} \mathrm{~b}\end{array}$ & $f f$ & $\begin{array}{l}\text { pochiss. } \\
\text { movendo } \\
\text { leggerissimo } \\
*\end{array}$ & $p p$ & $\begin{array}{l}\text { pp dim. } \\
\text { niente }\end{array}$ & ppp-fff & ABA'c \\
\hline $\begin{array}{l}3 \\
\text { op. } 35\end{array}$ & $\begin{array}{l}\text { Andante } \\
4 / 4 \quad \text { B }\end{array}$ & $\begin{array}{l}\text { legatissimo } \\
\text { cresc. }\end{array}$ & $\begin{array}{l}\text { cantando } \\
\text { dim. molto }\end{array}$ & $p p$ & pppp & $p p p p-\mathrm{s} f f f \mathrm{z}$ & ABACDA'B' \\
\hline $\begin{array}{l}4 \\
\text { op. } 38\end{array}$ & $\begin{array}{l}\text { Adagio } \\
\mathrm{C} \quad \mathrm{C}\end{array}$ & $\begin{array}{l}\text { ben cantando } \\
\text { pp }\end{array}$ & dim. molto & $\begin{array}{l}p p \\
\text { molto semplice } \\
\text { ma espressivo }\end{array}$ & pppp & $p p p p$-sffffz & $\begin{array}{l}\text { ABA'B'A"B" } \\
\text { (AA'A") }\end{array}$ \\
\hline $\begin{array}{l} \\
\text { op. } 55\end{array}$ & $\begin{array}{l}\text { Semplice, } \\
\text { ** } \\
3 / 4 \quad \text { D }\end{array}$ & & $\begin{array}{l}\text { ppp cristallino } \\
\text { dim. molto }\end{array}$ & $p p$ & pp dim. & $p p p-f$ & $\begin{array}{l}\text { ABA'A"B"A" } \\
\text { c } \\
\quad\left(\text { AA' }^{\prime}\right)\end{array}$ \\
\hline $\begin{array}{l}6 \\
\text { op. } 52\end{array}$ & $\begin{array}{l}\text { Larghissimo } \\
4 / 4 \quad \mathrm{~Eb}\end{array}$ & $\begin{array}{l}\text { movendo } \\
\text { cantando }\end{array}$ & $\begin{array}{l}\text { dim.molto } \\
\text { delicato } \\
\text { dolcissimo }\end{array}$ & $\begin{array}{l}p \\
\text { pocof }\end{array}$ & $p p p>$ & pppp-sffffz & iABCA'c \\
\hline $\begin{array}{l}7 \\
\text { op. } 65\end{array}$ & $\begin{array}{l}\text { Adagio con } \\
\text { rubato } \\
4 / 4 \quad \mathrm{E}\end{array}$ & $\begin{array}{l}\text { più mosso } \\
\text { ppp sempre }\end{array}$ & $\begin{array}{l}\text { sempre legato } \\
\text { calmato poco a } \\
\text { poco }\end{array}$ & $p p$ & ppp & ppp-ff & i ABA'c \\
\hline $\begin{array}{l}8 \\
\text { op. } 85\end{array}$ & $\begin{array}{l}\text { Lento movendo } \\
\text { con molto } \\
\text { rubato } \\
2 / 2 \quad \text { b }\end{array}$ & $\begin{array}{l}\text { meno mosso } \\
\text { molto legato } \\
* * *\end{array}$ & $\begin{array}{l}\text { cantando } \\
\text { dolcissimo }\end{array}$ & $p p$ & pppp & pppp-sffffz & ABA'c \\
\hline $\begin{array}{l}9 \\
\text { op.97 }\end{array}$ & $\begin{array}{l}\text { Semplicissimo } \\
3 / 4 \quad \mathrm{~F}\end{array}$ & $\begin{array}{l}\text { più mosso } \\
\text { pp }\end{array}$ & $\begin{array}{l}\text { Cantábile } \\
\text { ped. tenuto }\end{array}$ & $p p$ & pppp & pppp-fff & $\begin{array}{l}\text { AA'BA"A"'c } \\
\text { (ou ABA'c) }\end{array}$ \\
\hline $\begin{array}{l}\mathbf{1 0} \\
\text { op. } 99\end{array}$ & $\begin{array}{ll}\text { Largo } & \\
4 / 4 & \mathrm{G}\end{array}$ & & $\begin{array}{l}\text { rit. } \\
\text { a tempo }\end{array}$ & $\begin{array}{l}\text { pp } \\
\text { una corda }\end{array}$ & $p p p>$ & pppp- $f$ & ABB' $A^{\prime}$ \\
\hline $\begin{array}{l}\mathbf{1 1} \\
\text { op. } 112\end{array}$ & $\begin{array}{l}\text { Lento e placido } \\
3 / 2 \quad \mathrm{C}\end{array}$ & $\begin{array}{l}\text { più mosso } \\
\text { accel. presto }\end{array}$ & $\begin{array}{l}\text { dim.e calmato } \\
\text { molto semplice }\end{array}$ & $\begin{array}{l}\text { pp } \\
\text { una corda }\end{array}$ & $\begin{array}{l}\text { pp } \\
\text { pppp }\end{array}$ & pppp-ff & $\begin{array}{c}\text { i AA'BA"CA"” } \\
\text { (rondo) }\end{array}$ \\
\hline $\begin{array}{l}\text { la mel } \\
\text { ma cor } \\
\text { più len }\end{array}$ & $\begin{array}{l}\text { lia ben legato e } \\
\text { rubato e con som } \\
\text {, molto libero qu }\end{array}$ & $\begin{array}{l}\text { cantando } \\
\text { uma delicatezza } \\
\text { uasi improvisan }\end{array}$ & empre legatissi & & & & $\begin{array}{l}i=\text { intro } \\
c=\operatorname{cod} a\end{array}$ \\
\hline
\end{tabular}




\section{APPENDIX C4-2: LIEBERMANN'S NOCTURNES}

\begin{tabular}{|c|c|c|}
\hline $\begin{array}{l}\text { Nocturne \# } \\
\text { (year of } \\
\text { composition) }\end{array}$ & $\begin{array}{l}\text { Number of measures } \\
\text { app. duration }\end{array}$ & $\begin{array}{l}\text { Special features } \\
\text { Comments }\end{array}$ \\
\hline 1 op. 20 & $\begin{array}{l}104 \text { measures } \\
\text { ca 6'09" }\end{array}$ & $\begin{array}{l}\text { Accompaniment made mainly of broken arpeggios, ostinati and pedal points; } \\
\text { Barcarolle-like feel; Three melodic ideas; Harmonic progressions non functional, } \\
\text { vagrant, even difficult to identify chords; Pedal indications (tenuto). }\end{array}$ \\
\hline 2 op. 31 & $\begin{array}{l}44 \text { measures } \\
\text { ca 6'39" }\end{array}$ & $\begin{array}{l}\text { Accompaniment made mainly of arpeggios and chords; Clear third-related } \\
\text { progressions; Three main melodic ideas; Typical Liebermann chord (major-minor } \\
\text { mediants); Return presents the material highly embellished; Passage with clashing } \\
\text { dissonances; Dramatic conception with dynamics; Multi-layered writing; Pedal } \\
\text { indications. }\end{array}$ \\
\hline 3 op. 35 & $\begin{array}{l}131 \text { measures } \\
\text { ca 6'14" }\end{array}$ & $\begin{array}{l}\text { Accompaniment made mainly of arpeggios; Clear third-related progressions; Two } \\
\text { main melodic ideas; Presence of the raised } 4^{\text {th; }} \text { Typical Liebermann chord (major- } \\
\text { minor mediants); Return presents the material highly embellished; Canon and } \\
\text { superimposition of material; Redistribution of material in between hands; Dramatic } \\
\text { construction with dynamics, texture and activity; Ostinato; Multi-layered writing; } \\
\text { Pedal indications. }\end{array}$ \\
\hline 4 op. 38 & $\begin{array}{l}67 \text { measures } \\
\text { ca 5'33" }\end{array}$ & $\begin{array}{l}\text { Accompaniment made mainly of arpeggios; Clear third-related progressions; Two } \\
\text { main melodic ideas (diatonic); Presence of the raised } 4^{\text {th }} \text {; Typical Liebermann chord } \\
\text { (major-minor mediants); Return presents the material embellished; Redistribution of } \\
\text { material in between hands; Canon and superimposition of material; Dramatic } \\
\text { construction with dynamics, texture and activity; Multi-layered writing; Rhythmic } \\
\text { layering; Virtuosity created by superimposition of numerous lines; Pedal indications. }\end{array}$ \\
\hline 5 op. 55 & $\begin{array}{l}116 \text { measures } \\
\text { ca 6'33" }\end{array}$ & $\begin{array}{l}\text { Accompaniment made mainly of ostinati; Clear third-related progressions; Two main } \\
\text { melodic ideas (diatonic); Presence of the raised } 4^{\text {th }} \text {; Melodic material constantly } \\
\text { presented with diversified accompaniments: decorative filigree, etude-like in thirds, } \\
\text { harmonized in the parallel minor; canon ( } 2 \text { and } 3 \text { voices), superimposition of } \\
\text { material; Dynamics are much more constricted; Multi-layered writing; Rhythmic } \\
\text { layering; Virtuosity created by superimposition of numerous lines; Pedal indications. }\end{array}$ \\
\hline 6 op. 52 & $\begin{array}{l}109 \text { measures } \\
\text { ca } 8{ }^{\prime} 26^{\prime \prime}\end{array}$ & $\begin{array}{l}\text { Accompaniment made mainly of pedal points and arpeggios; Two main melodic } \\
\text { ideas; Material is more dissonant (raised } 4^{\text {th }} \text {, almost bi-tonal at times); Motivic } \\
\text { transformations to generate theme; Presence of the raised } 4^{\text {th. }} \text {; Finger passage episode; } \\
\text { Dramatic construction with rhythmic layering, long crescendo and dissonances; } \\
\text { Multi-layered writing; No pedal indications. }\end{array}$ \\
\hline 7 op. 65 & $\begin{array}{l}134 \text { measures } \\
\text { ca } 7{ }^{\prime} 01 "\end{array}$ & $\begin{array}{l}\text { Accompaniment made mainly of arpeggios; Two main melodic ideas; Presence of the } \\
\text { raised } 4^{\text {th }} \text {; Third-related harmonies and superimposition of conflicting harmonies; } \\
\text { Transitional passage episode based on pedal point and repeated chords; Numerous } \\
\text { crossings of hands; Multi-layered writing; Dynamics are more constricted; Very little } \\
\text { pedal indications. }\end{array}$ \\
\hline 8 op. 85 & $\begin{array}{l}159 \text { measures } \\
\text { ca } 88^{\prime} 09^{\prime \prime}\end{array}$ & $\begin{array}{l}\text { Accompaniment made mainly of broken arpeggios, intervals and chords; Two main } \\
\text { melodic ideas; Material is very motivic; Motivic transformations to generate theme; } \\
\text { Presence of the raised } 4^{\text {th }} \text {; Finger passage episodes; Chordal passage encompassing } \\
\text { clashing dissonances, verging on bi-tonality; Dramatic construction with rhythmic } \\
\text { layering, long crescendo and dissonances; Multi-layered writing; Virtuosity created } \\
\text { by superimposition of numerous lines; A few pedal indications. }\end{array}$ \\
\hline $\begin{array}{c}9 \text { op. } 97 \\
(2006)\end{array}$ & $\begin{array}{l}173 \text { measures } \\
\text { ca } 8^{\prime} 33^{\prime \prime}\end{array}$ & $\begin{array}{l}\text { Accompaniment made mainly of simple intervals, ostinati, repeated notes, and black- } \\
\text { keys-white keys arpeggios; Two main melodic ideas; Material is very motivic; } \\
\text { Presence of the raised } 4^{\text {th; }} \text { Passage based of virtuoso finger-work; Octatonic scales; } \\
\text { Chordal passage encompassing extended harmonies; Dramatic construction with long } \\
\text { crescendo and dissonances; Multi-layered writing; Virtuosity created by } \\
\text { superimposition of numerous lines; Very little pedal indications. }\end{array}$ \\
\hline
\end{tabular}




\begin{tabular}{|l|l|l|}
\hline $\begin{array}{l}\text { Nocturne \# } \\
\text { (year of } \\
\text { composition) }\end{array}$ & $\begin{array}{l}\text { Number of measures } \\
\text { app. duration }\end{array}$ & $\begin{array}{l}\text { Special features } \\
\text { Comments }\end{array}$ \\
\hline $\begin{array}{c}\mathbf{1 0} \text { op. 99 } \\
\text { (2007) }\end{array}$ & $\begin{array}{l}74 \text { measures } \\
\text { ca 8'06" }\end{array}$ & $\begin{array}{l}\text { Accompaniment made mainly of broken arpeggios, ostinati of 2 bars, and double- } \\
\text { notes intervals; Three main melodic ideas; Suggestions of bi-tonality; Motivic } \\
\text { expansions; Presence of the raised 4th; Finger passage episodes; Section built on long } \\
\text { chromatic bass line Short fugal episode; Quartal chord with downward stepwise } \\
\text { resolution; Dynamics are more constricted; Una corda indication. }\end{array}$ \\
\hline $\begin{array}{c}\text { 11 op. 112 } \\
\text { (2010) }\end{array}$ & $\begin{array}{l}121 \text { measures } \\
\text { ca 6'30" }\end{array}$ & $\begin{array}{l}\text { Accompaniment made mainly of broken arpeggios, scalar passages and jumps; Two } \\
\text { main melodic ideas; Material is intimately (motivic) connected; Presence of the } \\
\text { raised 4th; Frankly exploited bi-tonality; Finger passage episodes; Development } \\
\text { passage displaying great virtuosity; Rhythmic layering; Long crescendo and } \\
\text { accelerando; Dissonances; Multi-layered writing; Virtuosity created by } \\
\text { superimposition of numerous lines and by speed; Filigree decorations; Octatonic } \\
\text { scales; Una corda indication. }\end{array}$ \\
\hline
\end{tabular}

Approximate durations are taken from:

for Nocturnes no. 1 to no. 7 :

Lowell Liebermann —Piano Music, vol. 1, David Korevaar piano, Koch International Classics 3-7548-2 HI;

for Nocturne no. 8:

Sandro Russo Piano Recital (private recording copyright 2006), Sandro Russo piano

for Nocturne no. 9:

"Lowell Liebermann, Nocturne no. 9, Alice Tsui piano," http://www.youtube.com/watch?v=62pYFOBMc0

for Nocturne no. 10:

"Lowell Liebermann, Nocturne no. 10, Alice performer not identified," http://www.youtube.com/watch?v=7MQS8TptKR4

for Nocturne no. 11:

No recording was available at the time; timing is taken from the score itself.

The musical scores consulted were:

all published as individual numbers by Theodore Presser. Information is provided in Appendix A: "Liebermann's Piano Works." 


\title{
CARL FISCHER, LLC.
}

\author{
65 Bleecker Street \\ New York, NY 10012
}

April 2, 2013

Martin Harvey

5

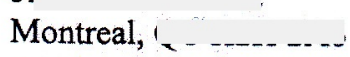

CANADA

Carl Fischer, LLC, on behalf of Theodore Presser Company (the 'Owner'), hereby grants to Martin Harvey (the 'Licensee') non-exclusive permission to include excerpts from copyrighted musical works by Lowell Liebermann as listed in the attached Schedule A ('Musical Works') in a dissertation as per the following:

Title of dissertation: Lowell Liebermann: The Eleven Nocturnes for Solo Piano

School: West Virginia University

Fee: An administrative fee of Twenty-Five Dollars (US\$25.00)

The dissertation may be made available on-line through the West Virginia University Scholar Institutional Repository website provided that no fee or fee-based subscription is required for access.

Dissertation may also be included in University Microfilms Inc.'s ProQuest database with a permanent embargo status (i.e. the title and abstract are the only viewable/accessible portion).

The copyright notice, as it appears in the published works, shall appear in the Dissertation along with an indication that they were used with permission.

Dissertation may not be sold, duplicated or distributed beyond the above without written consent by the Owner. This license is valid solely for the rights described above. Owner reserves all rights not specifically granted herein.

Carl Fischer, LLC

o/b/o Theodore Presser Company

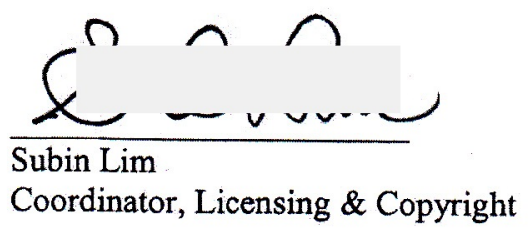

Martin Harvey

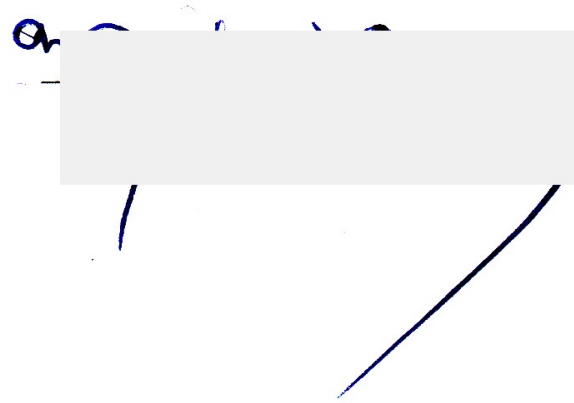




\section{$\underline{\text { Schedule A }}$}

Nocturne no. $1, \mathrm{~mm} .1-8 ; 5-12 ; 21-28$.

Nocturne no. 2 , mm. 1-6; 14-18; 21-23; 24-28.

Nocturne no. 3 , mm. $1-2 ; 1-7 ; 16-23 ; 4-7 ; 16-23 ; 64-71$.

Nocturne no. 4 , mm. $1-8 ; 17-23 ; 24-29 ; 41-46 ; 49-53 ; 63-67$.

Nocturne no. 5 , mm. $6-15 ; 35-40 ; 49-52 ; 68-73 ; 89-98$.

Nocturne no. 6 , mm. 1-10; 7-18; 30-42; 56-63; 74-77; 78-88.

Nocturne no. $7, \mathrm{~mm} .5-14 ; 20-23 ; 79-87 ; 102-108$.

Nocturne no. 8 , mm. 1-12; 13-24; 29-36; 57-62; 107-109; 121-125.

Nocturne no. 9, mm. 1-18; 43-46; 69-82; 103-109; 137-144; 145-155.

Nocturne no. 10, mm. 1-9; 10-18; 19-24; 48-60.

Nocturne no. $11, \mathrm{~mm} .1-6 ; 21-28 ; 33-40 ; 48-54 ; 87-91 ; 103-112$. 